\title{
REVISITING THE HILLSIDE: \\ ORGANIC, AGGREGATIVE MEDIUM DENSITY \\ HOUSING IN A WELLINGTON HILLSIDE \\ ENVIRONMENT
}

MATTHEW BERNARD WENDEN

A 120 - POINT THESIS

SUBMITTED TO THE VICTORIA UNIVERSITY OF WELLINGTON IN PARTIAL FULFILMENT OF THE REQUIREMENTS FOR THE DEGREE OF MASTER OF ARCHITECTURE (PROFESSIONAL)

VICTORIA UNIVERSITY OF WELLINGTON SCHOOL OF ARCHITECTURE 


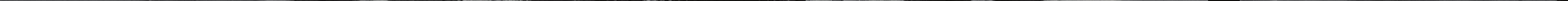


ACKNOWLEDGEMENTS

Thank-you to everyone who has helped me along my way at university. I have been lucky enough to have met some fantastic people, whether they be colleagues studying with me, lecturers and tutors, or people out in the real world who have given me experience in the industry and taught me so much.

I would like to thank in particular my supervisor Chris McDonald who has been fantastic support through this year and without whose knowledge and guidance this thesis would not be the same.

To my parents, thank-you for your support, guidance, editing and advice on putting together his project. Thank-you as well for all of your support through my other years of university and school, I cannot thank, you enough.

Finally, Olivia, Thank-you for being there through all of this, your presence and encouragement have made the last five years a very enjovable time. 


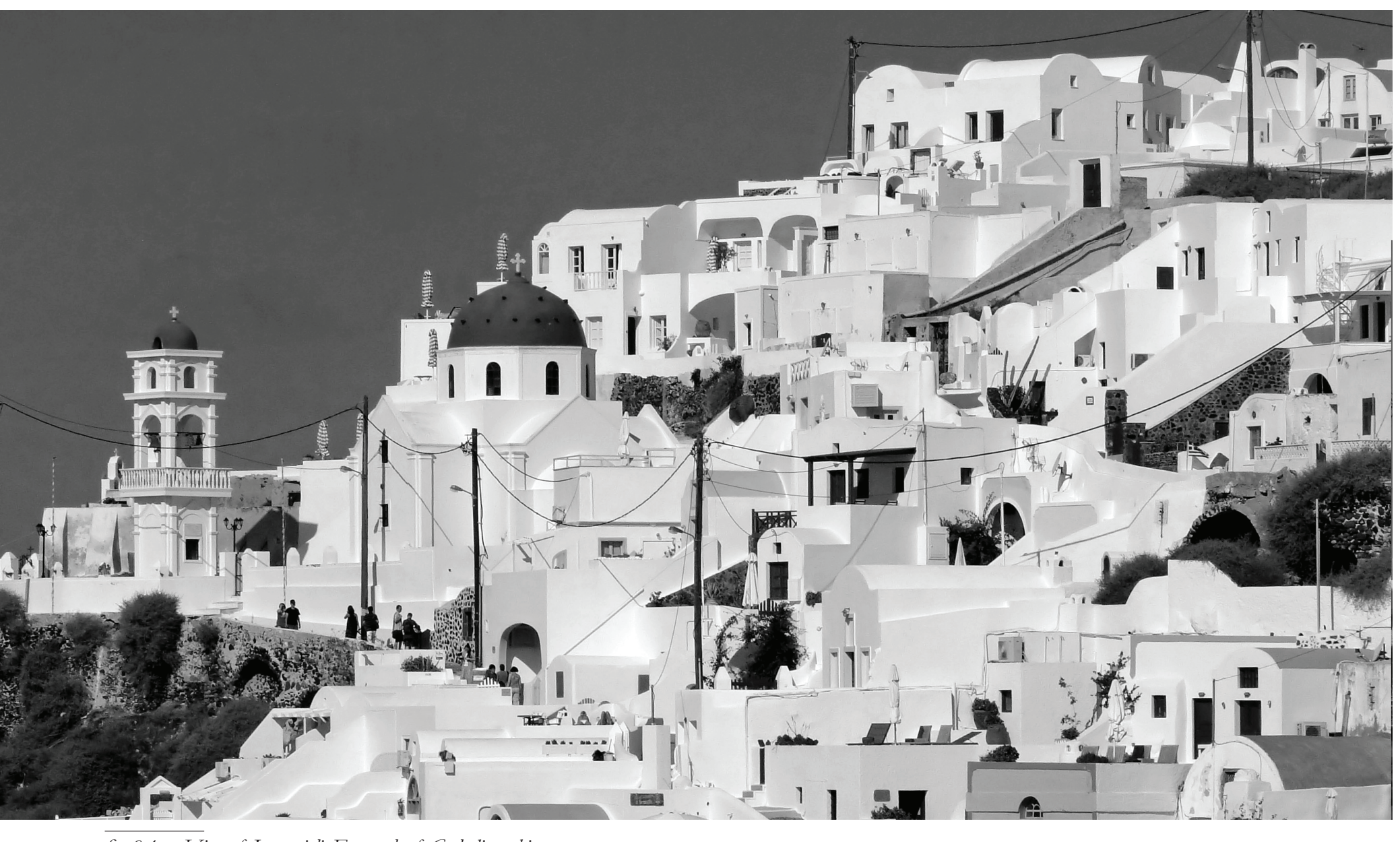
$<$ fig: 0.1 View of Imerovigili: Example of Cycladic arcbitecture

\section{ABSTRACT}

The 'Conzen School' of Urban Morphology identified by Kostof in his book The City Shaped, is a western way of looking at parcels of land, lots, and the street grid from above in a geometric manner imposed on the land, then analysing this in terms of land use pattern, town plan, and building form. This model of analysis and development lends itself to flat sites, and separted, isolated developments, and forms the basis for the existing model of development in western colonial nations. This thesis investigates whether an alternate development approach based on agreerative design can provide a viable alternative to the standard model of Medium Density Housing found in New Zealand. Investigation in the frame of Christopher Alexander's New Theory of Urban Design, Lucien Kroll, and The New Urbanists addresses a new way of approaching these sites through the use of organic geometries and accumulative principals. Accompanying and informing this approach is a case study of vernacular Cycladic Architecture.

In balance with the Cycladic case study the thesis addresses the acceptance of this model of development in a New Zealand context. In particular, with reference to the physical aspects of privacy, view, shared space as well as perceptions of ownership, individuality and identity in a higher density environment. The aggregative approach is similar to that explored through lan

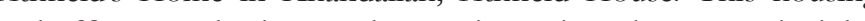
and office complex is an early experiment into the same principles that this thesis addresses. The thesis develops a methodological approach to testing the aggregative nature of development and simulates this through the use of an studio design excersises. These exercises will be a combination of external input from other designers and internal, single author thput. The fnal design outcome will be addressing the resuls of this simulation, the design principals, guidelines and rules, rather than producing 


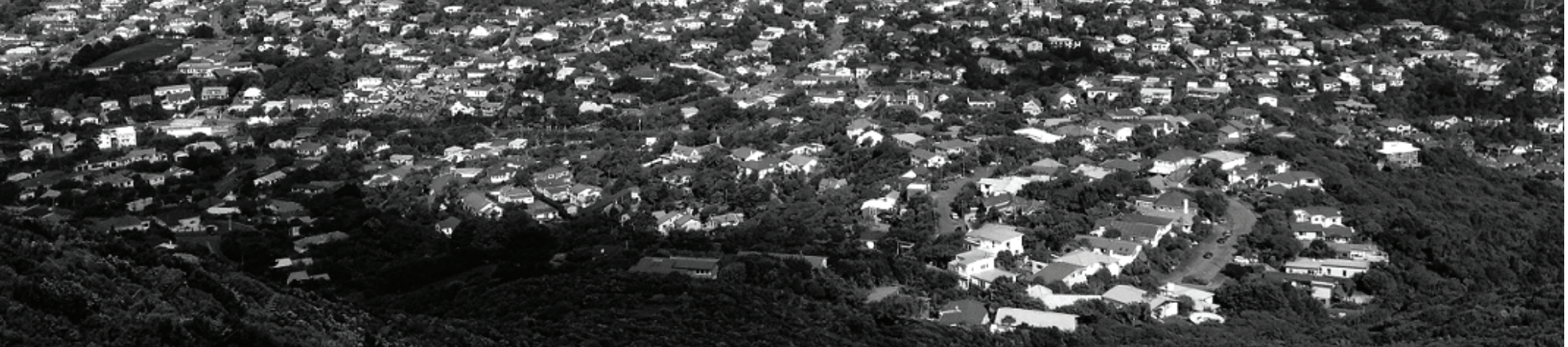

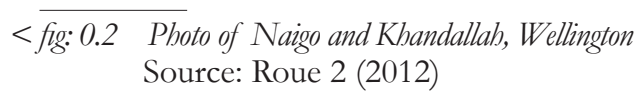




\section{TABLE OF CONTENTS}

Cover Page
Acknowledgements
Abstract
Table of Contents

\section{PART 1: INTRODUCTION}

\section{Introduction}

The Problems

The Approach

3 The Scope

(.4 Thesis Structure

Chapter One: Process

Conceptual Framewor

Case/Field Based Literature

1.2 Process

PART 2: PRE-DESIGN

Chapter Two: Cycladic Vernacular

Cycladic Vernacular Architecture

Sifnos: Apollonia, Hatavate \& Xampela

Hydra: Chora and Kastro

Santorini: Oia

2.4 Street Study

Hillside Impact Study

Chapter Three: Pilot Study

Pilot Study: Test Framework

Aggregative Simulation Study

2 Comprehensive Control Study

Design Exercise: Parametric Modelling
PART 3: DEVELOPED DESIGN

Chapter Four: Simulation Stage 1

- Developed Design

Development Framework

2 Simulation Methodology

Access Infrastructure

Development Seeds

3 Results/Challenges

\section{Chapter Five: Simulation Stage 2}

50 Stage 2

Narrative

\section{PART 4: EXEGESIS}

\section{Chapter Six: Conclusion}

60 Design Exegesis

61 Development Framework

62 Project Conclusion

\section{PART 5: APPENDIX}

Bibliography

Image Sources

Development Framework 


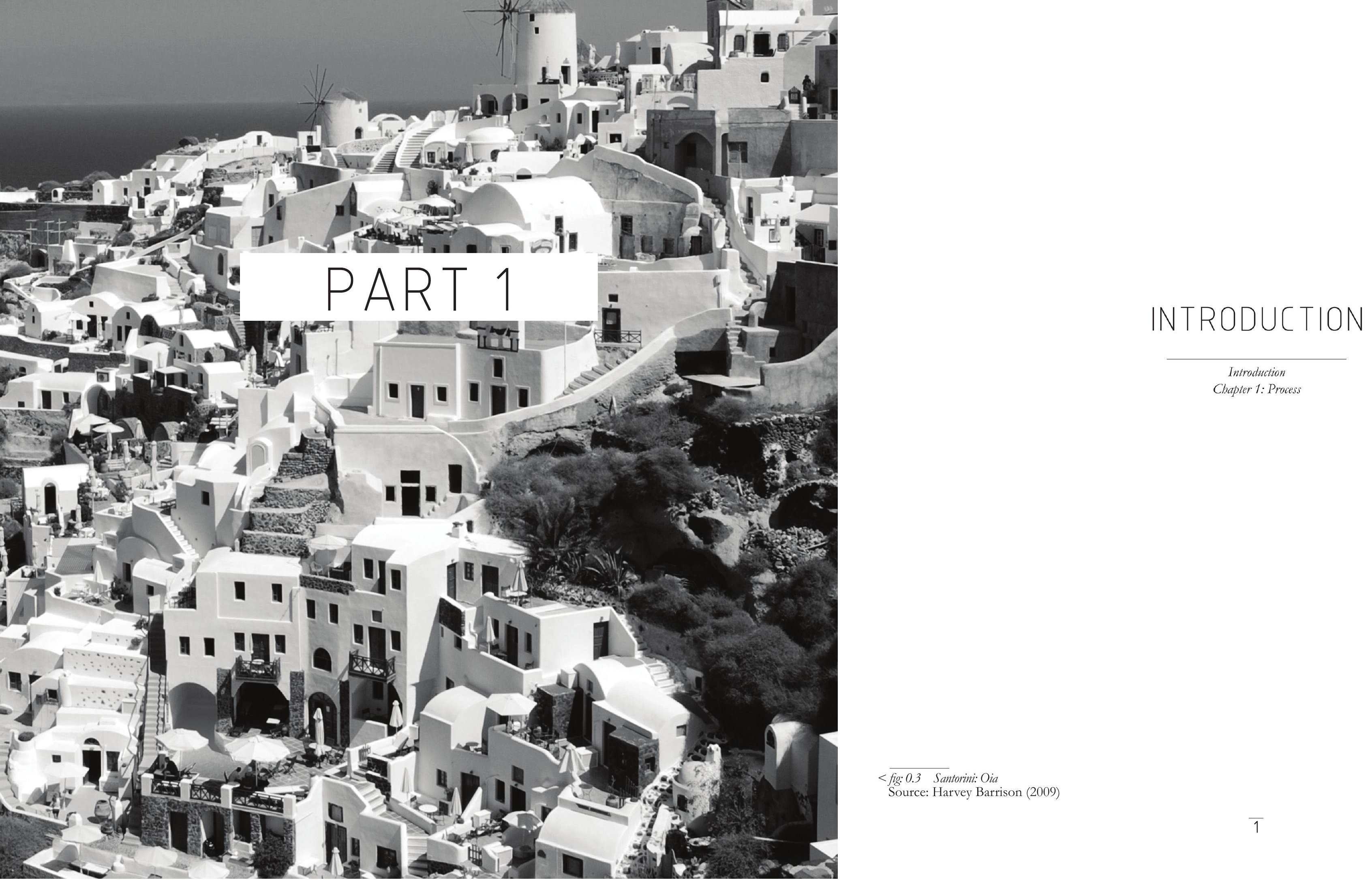


Wellington as a city and New Zealand as a whole continue to grow $^{1}$ with the number of dwellings in Wellington forecast to grow from 77,940 in 2015 to 88,305 by $2028^{2}$. With amongst the general population about the need for amongst the general population about the need for
intensification within our cities the need for higher density housing models that can make use of existing urban space becomes more and more important.

Urban Sprawl as a concept is well documented within the academic community ${ }^{3}$, and as such the argument for increased density within our cities and suburbs has been robustly debated. However despite this increasingly growing body of literature and a growing built stock of medium density developments, they have been focused primarily around flat sites. Wellington is a city with a majority of its land area located in hilly environments, this thesis seeks to fill a gap by combining the site and topological conditions as
1 .id the population experts, "Population Forecasts | Wellington City | Forecast.Id."

2 "Population, Households \& Dwellings | Wellington City | Forecast. d."

3 Robert Breuegman, Sprawl: A Compact History (Chicago: University of Chicago Press, 2005); Richard Harris and P. J. Larkham, "Changing http:// public.eblib.com/choice/publicfulltrecord.aspx?p=181091; Garry Cross, "The Suburban Weekend: Perspectives on a Vanishing TwentiethCentury Dream," in Visions of Suburbia, ed. Roger Silverstone London; New York: Routledge, 1997); Peter Hall, Urban and Regional Planning Fourth Edition, Fourth ed.(London: Routledge, 2002).
The main intention of the thesis is to investigate and propose a new model for medium density housing developments in a hillside environment. The thesis questions how aggregative and organic approaches to design, could provide a new way of developing hillside sites using organic geometries and accumulative principals. The thesis analyses vernacular Cycladic Architecture of the Greek Aegean Islands focusing on their spatial structure, particularly their treatment of public/private space and their development structure through time. Through a series of designs of a medium density housing development sited in wellington, this thesis seeks to establish a set of design principals/guidelines for new way of looking at medium density housing in a hillside environment with particular reference to a New Zealand context.

Framing the paradigm of inquiry for the thesis are authors such as Christopher Alexander ${ }^{4}$, Lucien Kroll ${ }^{5}$ and poststructuralist theorist Jean Baudrillard ${ }^{6}$. I am particularly interested in Alexander's work from A New Theory of Urban Design, where he advocates for a collective whole, embracing the complexity that results from an unplanned development pattern resonant with the 'old city'. In this book he runs a design experiment, focusing on a consciously not master planned process. Alexander argues for a set of development principals, and the freedom to allow the city to grow outside of a

Christopher Alexander, $A$ New Theory of Urban Designn(New York

Observations on a City of Ideas New Yo, Viens of Seaside: Commentaries and Distributed to the U.S. trade by Random House ; Seaside Institute, 2008. 6 C McDonald, "City of Melbourne," Lighting Strategy, (Melburne, 2003). 7 Daniel Maudlin, "Crossing Boundaries: Revisiting the Thresholds of Vernacular Architecture," Vernacular Arcbitecture 41, no. 1 (2010). 
with a major aspect of his argument calling for increased participation from the inhabitants in order to create obscurity, irrationality and therefore complexity within the architecture. Baudrillard's arguments on simulacra support the arouments of Alexander and Kroll in creating, at a more abstract level a distinction between an (t) rationalise and simplify - and the real; the physical substance of a place.

A key outcome for this thesis is to develop a design process

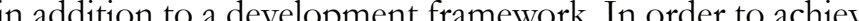
the aggregive gow I I am looking for, I am seting up a process to simulate this mode of production and design through a series of design exercises. As such the final buil form is not set entirely by me as the designer but is strongly influenced by input from outside sources. However my role as the researcher and designer in this process revolves around process - analysis of precedent and setting up the guidelines and framework from which the designers will work. This process is informed by the case study of the Zealand context.

The design simulations take part in three stages; (i) the pilot study, an initial test for the process and as an early analysis too to critique the desion outputs and evaluate where addition control the desired. (ii) The first design stage where the developed biter the ceve several designs. And the fina stage (ii) will ther develop some of the spaces and dwellings from the design stage in order to test the resulting outcome of the design simulation and the viability of this mode of production. Through this whole process the final design guidelines and process are intended to be the final thesis outcome.
[CASERESEARCH]

CASE STUDY "CYCLADIC VERNACULAR ARCHITECTURE"

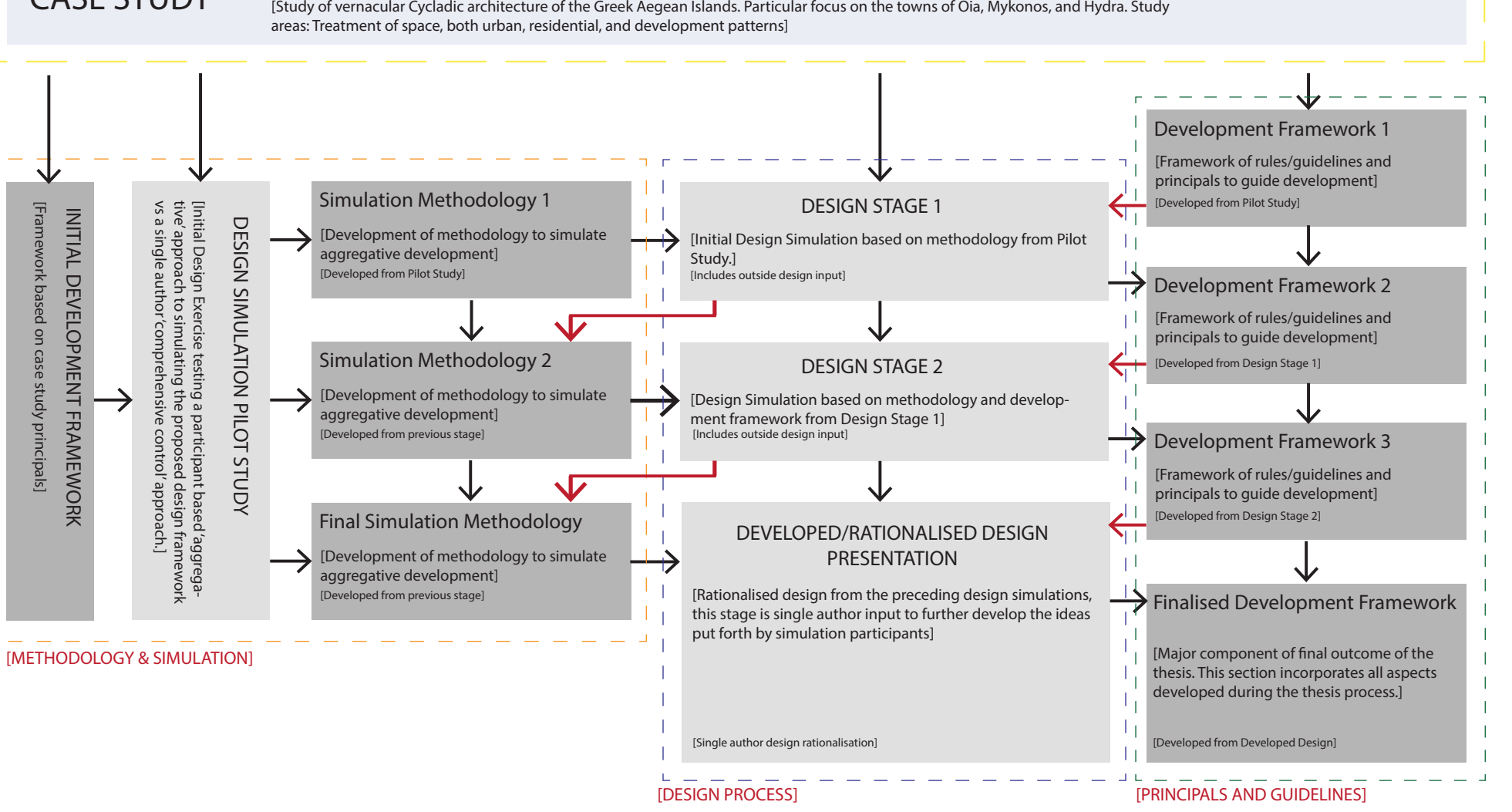

<fig: 0.4 Researcb Process Diagram

Source: Author 
[CASERESEARCH

CASE STUDY

IStudy of vermactur "CYCLADIC VERNACULAR ARCHITECTUR

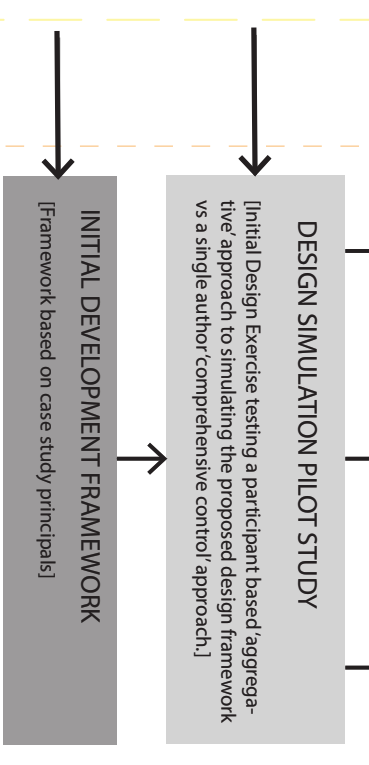

terent of space, both urban, residential, and development patterns

METHODOLOGGY \& SIMULATTON]

< fig: 0.5 Researrb Process Diagram: Initial Pilot Study Source: Autho
[CASERESEARCH]

CASE STUDY

"CYCLADIC VERNACULAR ARCHITECTUR

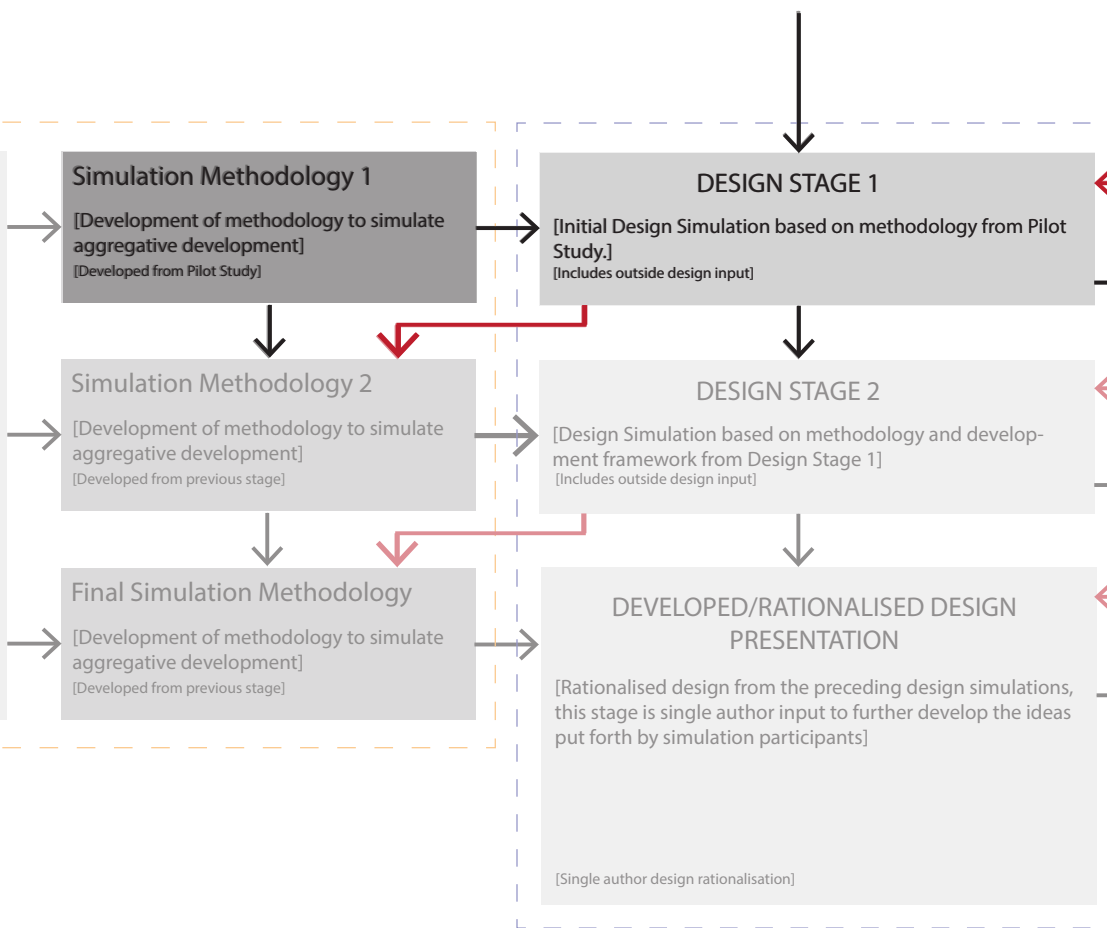

DESIGN PROACËST

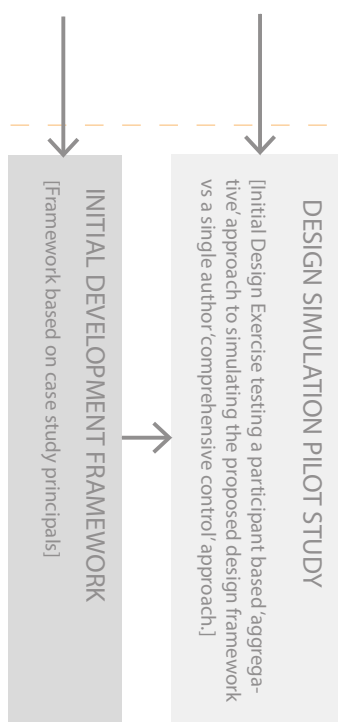

METTODOLOGGY \& SIMULLATION]

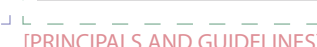

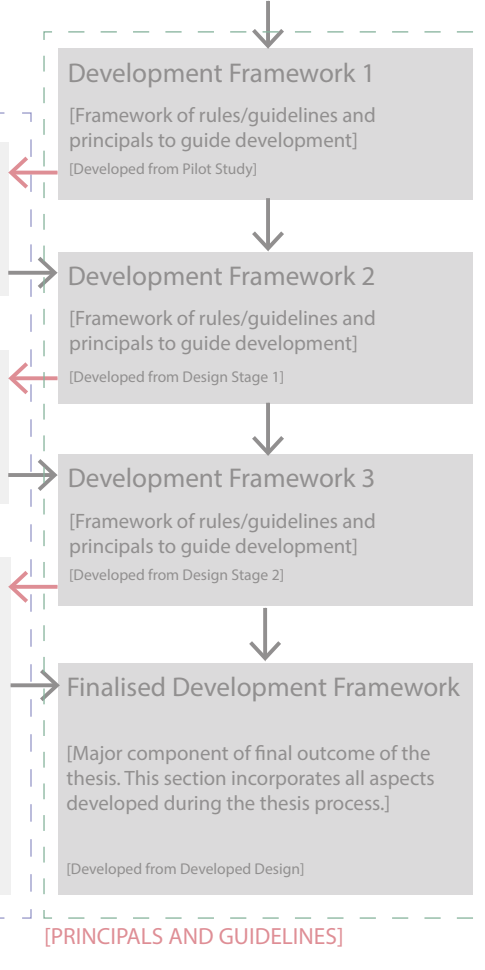
$\overline{<\text { fig: } 0.6 \text { Research Process Diagram: Main Design Stages }}$
The study on Cycladic vernacular architecture informs each stage through the research process and is ongoing for the entirety of the project. The initial framework and pilot study is run as a test case for the main design stages going forward and mainly influence the simulation methodology.
This section of the process diagram reads downwards, with each stage being fed by a new iteration of both the simulation methodology and development framework. At each stage the design will then inform the next iteration of these inputs. 
THE SCOPE

The nature of this research means that there are inherent limitations that are not practicable to overcome within the time frame of a master's thesis. Firstly In the setup and framing of the research I have made a series of epistemological assumptions. These are mainly focused around the weight of academic literature surrounding the concept of urban sprawl and the inherent assumption that a higher density, infill residential model is a desirable condition.

The analysis of material for my case study of Cycladic Vernacular Architecture is relatively novel in that the majority of the material and academic publication on architecture in that area is either focused on a more social, historical, of anthropological aspect of the islands. Alternatively studies apply an environmental perspective to the development of these areas. As such there is little dimensionally accurat material available on the areas so any analysis undertaken in the thesis is not to scale and is therefore indicative only.

The process, simulation methodology and framework for the proposed housing model makes up the main focu for the research. As a result, many of the more pragmatic considerations around building will fall outside of the scope of the research. Factors such as costing, engineering, ground condition, materiality and structural considerations would be dealt with on a case by case basis and will not be dealt with in the main thesis.

Finally, there are several limitations to the design simulation process I am undertaking due to the time limits for the thesis project and time demands on the participants themselves. As such the buy-in from any designers used in the design exercises will be less than that of a designer/architect involved in a real world process. This takes into account that the participants are only spending, on average, an hour to do a design that would otherwise take weeks or months of planning to put together. Also the motivation and pressure is not there with no financial or reputational impetus.
THESIS STRUCTURE

'Part 1: Introduction'

Background, Process and Methodological Framework

This chapter frames the paradigm of inquiry for the research by giving a brief background literature review as well as contextualising the arguments presented throughout the research.

$$
\text { 'Part 2: Pre Design' }
$$

Initial case study, setup, and process testing - First site iteration (Pilot Study)

This chapter explores the basic fundamentals of the simulation methodology in its first form as well as the main guiding principles of the development framework. It also gives an overview of findings from the Cycladic Vernacular study that informs much of the design decisions for the rest of the thesis This section of the research sets the platform from which subsequent iterations ca build from

'Part 3: Developed Design'

Refined process and derlhoment guidelins (Design Stages 1 + 2)

This more evolved version of the simulation methodology and development framework that was developed through work in the previous chapter is tested over two stages, with discussion around the successfulness of some of the rules/guidelines and limitation to the research methodology

$$
\begin{gathered}
\text { 'Part 4: Exegesis' } \\
\text { Design Exegesis, } \\
\text { project conclusion and critical reffection }
\end{gathered}
$$

Following the design work, this chapter discusses the successes and limitations of both the simulated process for this research and developed and surgests areas of weaknesses and areas for possib further research. 


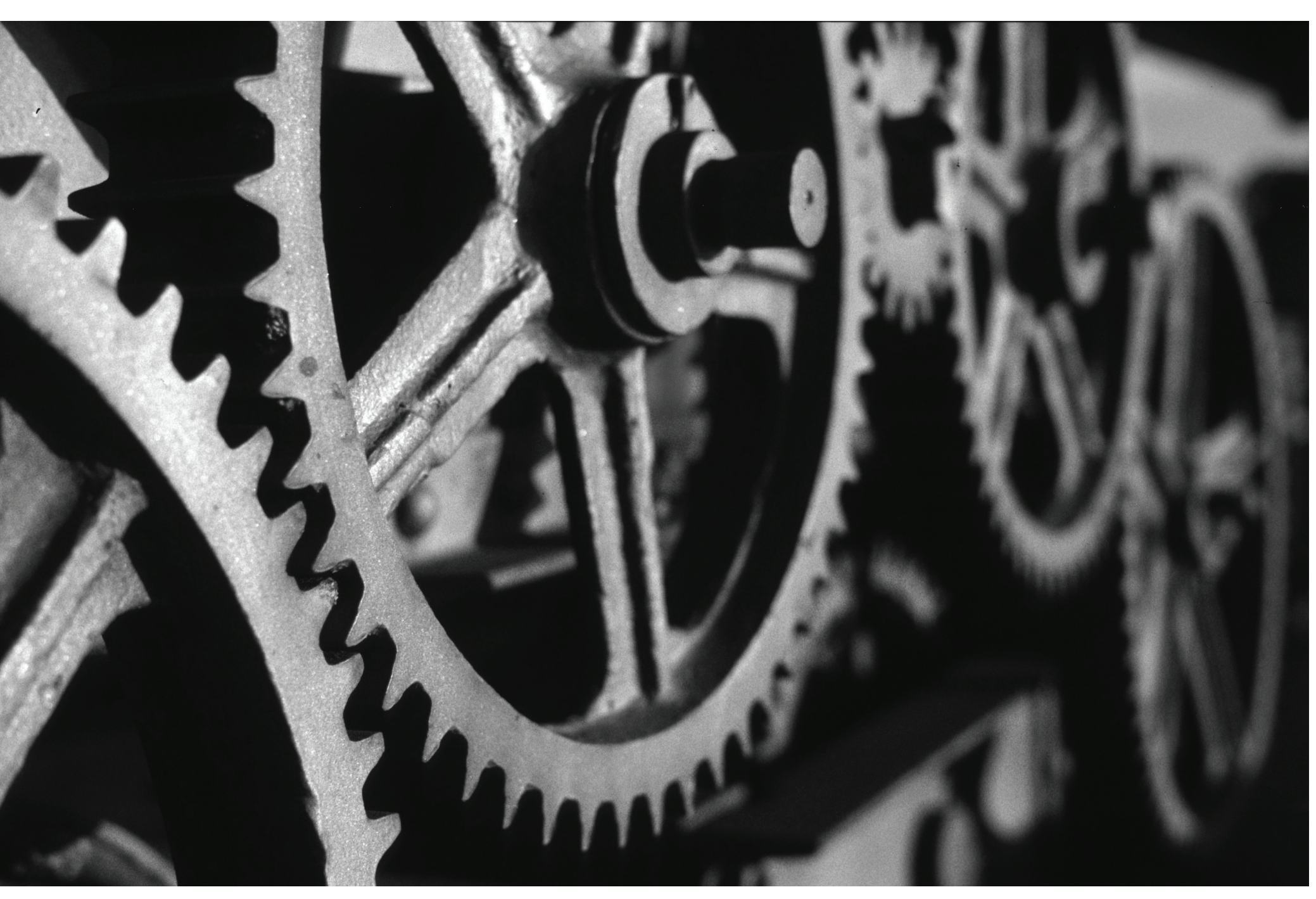

CHAPTER 1: PROCESS

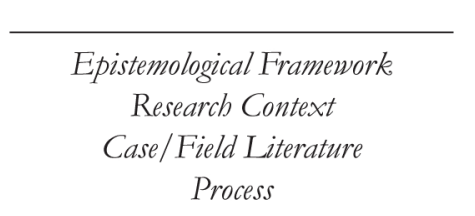

<fig: 1.0 Crane Gears

Source: Kevin Utting (2006) 
CONCEPTUAL FRAMEWORK

"The tendency all too often is to see urban form as a finite thing, a closed thing, a complicated object. I want to stress what we know instead to be the case-that a city, however perfect its initial shape, is never complete, never at rest. Thousands of witting and unwitting acts every day alter its lines in ways that are perceptible only over a certain stretch of time. ,

$<$ Spiro Kostof
Spiro Kostof argues that there is a disconnect in urbanism between the fast rate of socio-economic change and the persistence of urban artefact ${ }^{1}$ he cites Aston and Bond in stating that towns are built by and for people, not of some inevitable physical control ${ }^{2}$ This view contrasts with that of most of the phanned cites of the new world, and particut of most of phe plat per cor progress evidenced in the colonial city planning contradict these ideas of the individual and complexity in favour of the grid. Kostof points to the treatment of cities after the breakdown of the Roman Empire and their development towards an organic structure as movement patterns soon cut swathes through the rigid and inflexible grid ${ }^{3}$ as an example of the prevalence of organic patterns of growth and change. This development strategy is seen by some as a positive that is not present in the new world, as the colonial power tended to wipe away previous land tenure systems and cultures making way for an oultures making way for an organised version of western forma 
Framing the main paradigm of enquiry for the thesis is Christopher Alexander's ANew Theory of Urban Desion. In this text Alexander posits the theory of an aggregative approach to urban desion, by which the aggregaivc approach goes towards creating a "whole" reminiscent of thexander follows this theory and proposes methodology for design hat is ani-maser phapr instead reling on a set of gidelines and wiles that he tests in an actenic envion gent hough a studio execise. Alexacer arese that the act of poducing 'wholeness' in Ale

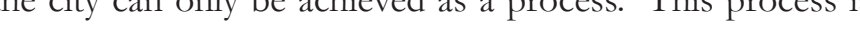
in direct conflict with the modern ideas surrounding urban design and planning, where private ownership and property setbacks etc. produce largely unrelated acts of built form. Alexander's studio exercise, run in 1978 at UC Berkeley saw post-graduate students 'representing' developers in order to simulate the propagation of an area of downtown San rules. In this sense the concepion of my project follows Alexanders work, fitting it instead to a more residential and hillside based context.

Lucien Kroll, another major author informing the direction of my work, follows a similar approach as Alexander. Kroll seeks to achieve this through the input of the individual occupant into the design process, embracing the mistake and irrationality created as a result?. Kroll argues that by creating architecture or urban design as a process, not

5 Christopher Alexander, A New Theory of Urban Design(New York: Oxford University Press, 1987).

6 Ibid.

7 Ibid., 3

8 Ibid., 10-16.

Nan Ellin, "Participatory Architecture on the Parisian Periphery: Lucien Kroll's Vignes Blanches," Journal of Architectural Education 53, no. $3(2000)$.
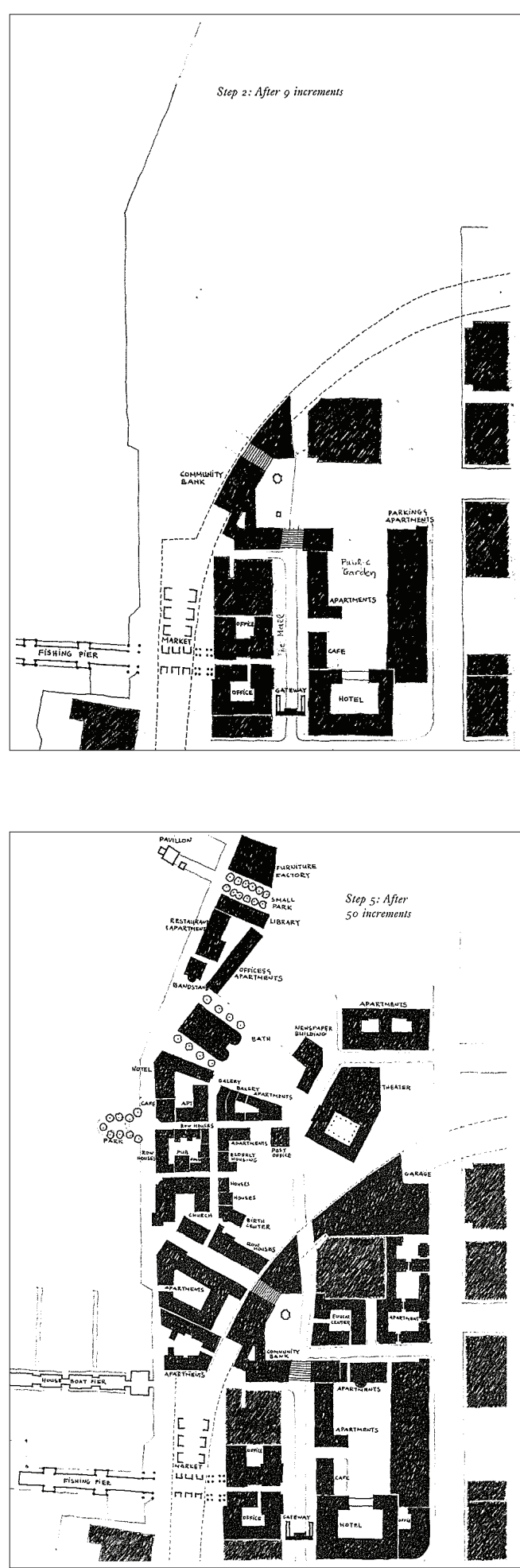

Alexander's studio project at Berkeley aster

2 and 50 increments respectively. pg $45-49$

< fig: 1.1 Christopher Alexander New Theory of Urban Design
Source: Christoper Alexander (1987) pg 46,49 


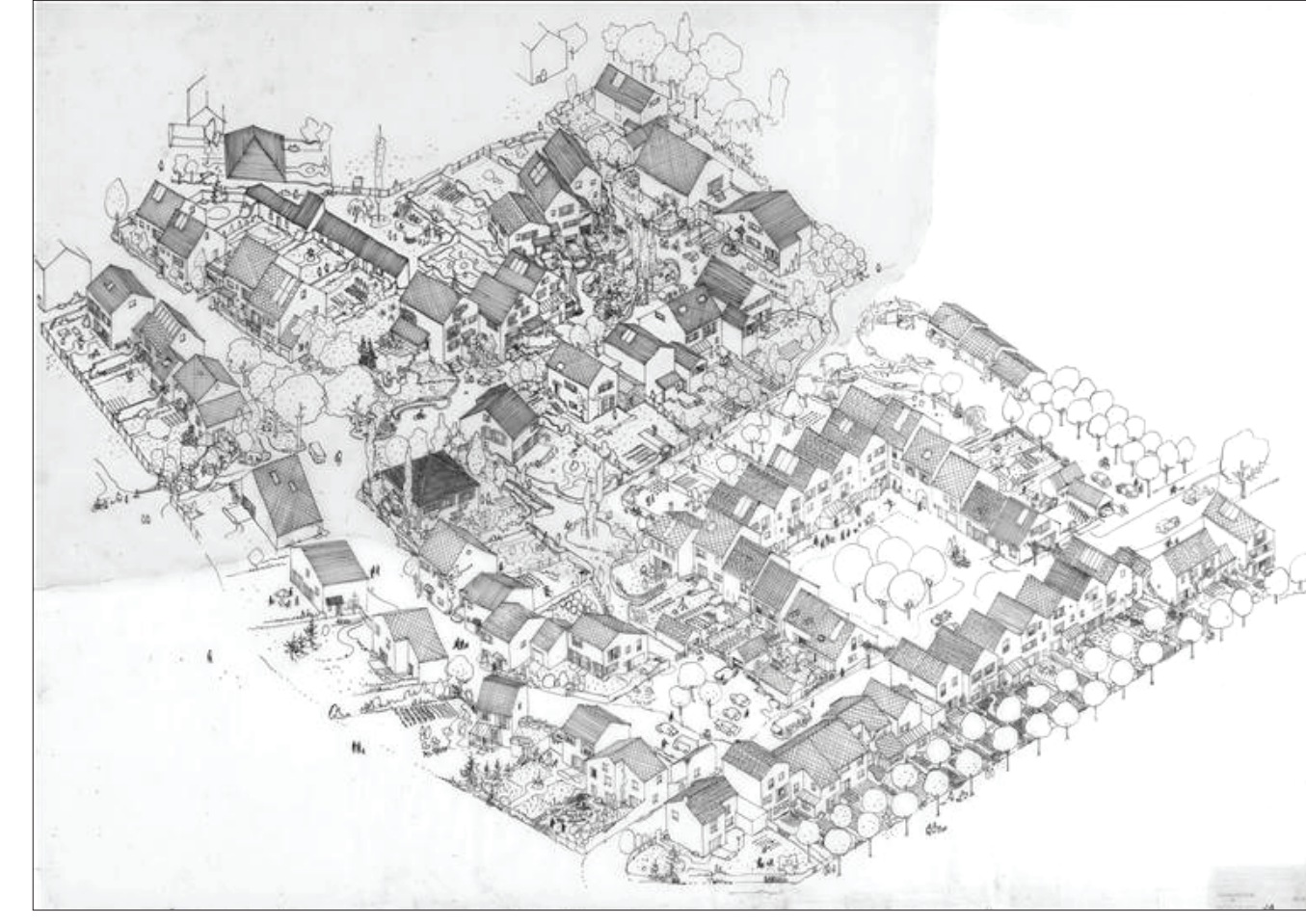

Kroll's Participatory project, Paris 1976

< fig: 1.2 Luicen Kroll: Vignes Blanches

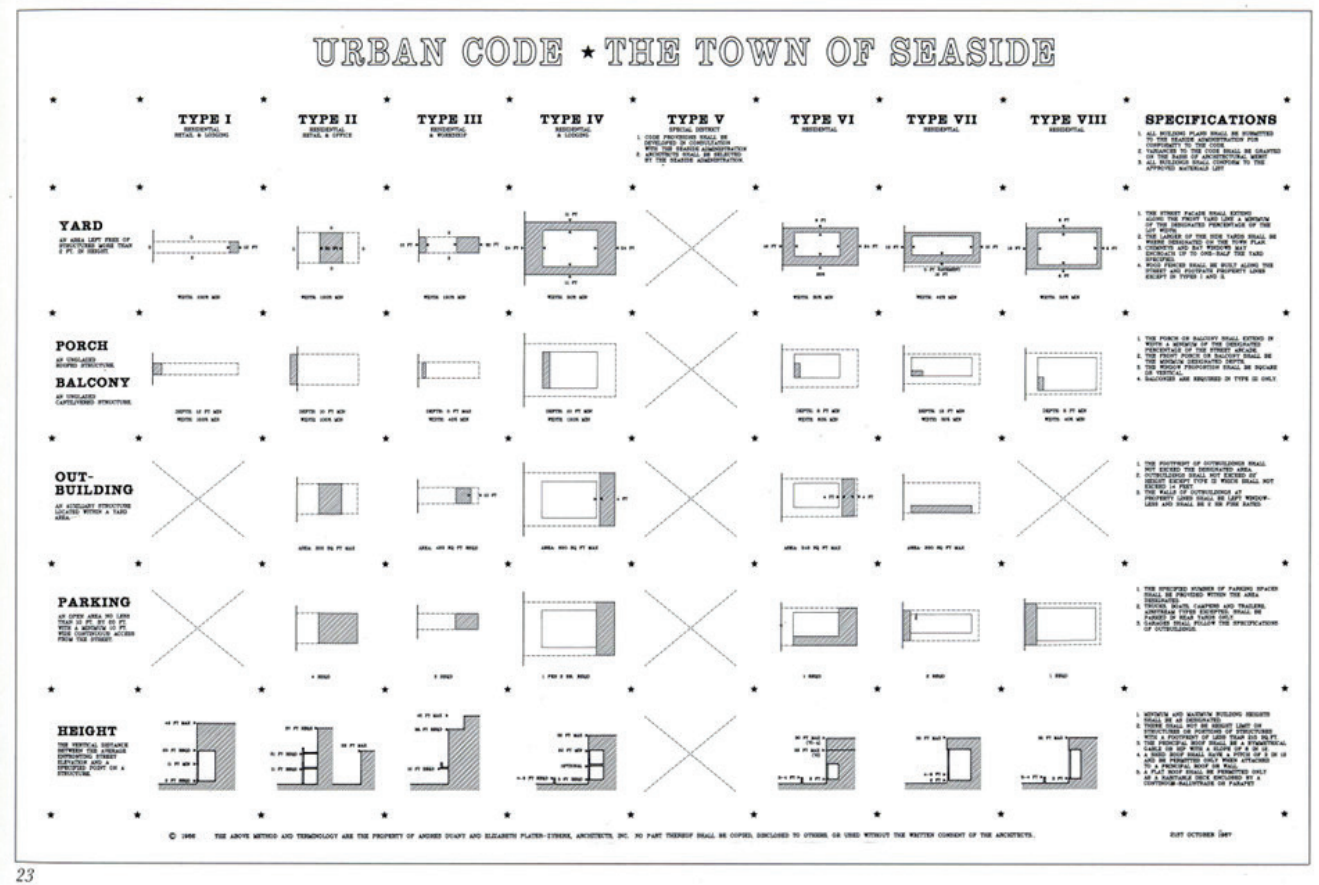
< fig: 1.3 Andres Duany \& Elizabett Plater-Zyberkes Urban Codefor the town of Seaside
Source: Mahney, D. Easterling, K. (1991) pg 99 controlling or predetermining the outcome, it promotes a better understanding of a fluid reality as well as producing a more efficacious result. The resulting outcome is not necessarily rational, but is instead reasonable ${ }^{10}$ Kroll's work here cuts away at the hermetically sealed ide of urban desig that perist in Alexanders work. White Alexander used outsile developers, the in

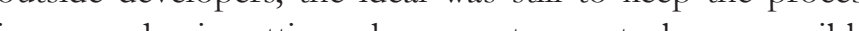
in an academic setting where greater control was possible. Kroll instead opens the door to diverse/external ideals and priorities, even if his Vignes Blanches project did struggle to implement these ideas into the built form. ${ }^{1}$

New Urbanism as a movement has grown primarily in the United States over the past three decades as an alternative to prevailing low-density development patterns ${ }^{12}$. One stream of New Urbanism ${ }^{13}$ culture tends towards re-introducing the idea of incrementalism and complexity back into urban design. Emily Talen identifies this culture and suggests that the incremental build-up of the "old city" can be seen as a positive move in city building ${ }^{14}$. However there remain scepticism amonost parts of the academic community ${ }^{15}$. Many of these criticisms, although rebutted by the New Urbu Cach pon for New Urbanism is the of nostgia, a dese

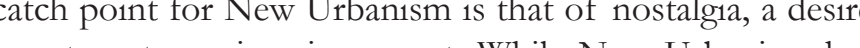
to return to an inaginary past. While New Urbanism has countered this, their main arguments treat nostalgia as a legitimate tool for combatting a sense of severance from 10 Ibid.

11 Ibid.

12 Cliff Ellis, "The New Urbanism: Critiques and Rebuttals," Journal of

Urban Design 7, no. 3 (2002).

13 New Urbanism: Peter Culthorte Vs L ars Lerut, vol. II, Michigan Debates on Urbanism (University of Michigan, 2005).

14 Emily Talen, New Urbanism es American Planning: The Confict of $\mathrm{Cu}$ tures, ed. Dennis Hardy, Planning, History and the Environment Series (New York: Routledge, 2005), 69.

15 Ellis, "The New Urbanism: Critiques and Rebuttals," 261-63. 
政 cartographers of the Empire draw up a map so detailed that it ends up covering the territory exactly (the decline of the Empire witnesses the fraying of this map, little by little, and its fall into ruins, though some shreds are still discernible in the deserts - the metaphysical beauty of this ruined abstraction testifying to a pride equal to the Empire and rotting like a carcass, returning to the substance of the soil, bit as the double ends by being confused with the real through aging) - as the most beautiful allegory of simulation, this fable has now come full circle for us, and possesses nothing but the discrete charm of second-order simulacra.

Today abstraction is no longer that of the map, the double, the mirror, or the concept. Simulation is no longer that of a territory, a referential being, or a substance. It is the generation by models of a real without origin or reality: a byperreal. The territory no longer precedes the map, nor does it survive it. It is nevertheless the map that precedes the territory - precession of simulacra - that engenders the territory, and if one must return to the fable, today it is the territory whose shreds slowly rot across the extent of the map. It is the real, and not the map, whose vestiges persist here and there in the deserts that are no longer those of the Empire, but ours..

...The desert of the real itself." valued places ${ }^{16}$. As the forms and styles that are often superficially affected - when talking about nostaloia - are either illusory, or from different cultural backgrounds, this argument becomes insincere. Many of the New Urbanist approaches towards incremental development, avoidance of sprawl through uban infll, and transport focused cites re

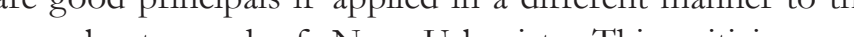
incumbent guard of New Urbanists. This criticism can again be levelled at Alexander, however the New Urbanis approach adds a tradition of visual, diagrammatic Urban Codes such as the ones seen in the Seaside development of the early 1980's. This approach again cuts away at the esoteric, all-encompassing vision of Alexanders work.

Baudrillard's writings about simulacra deal with the idea of simulation and the simulacrum, representations where ther is no original, where the representation or copy can either exist independently or precede the reality of the original.

Baudrillard quotes Émile Littré in describing the idea of simulation; "Whoever fakes an illness can simply stay in bed and make everyone believe he is ill. "Whoever simulates an illness produces in himself some of the symptoms (Littré)"18. Therefore pretending or dissimulating leaves the "principal of reality"19 intact whereas simulation blurs the line between the real and imaginary. The lot patterns that direct Westem development and ownerhip modes ar direct Westere an

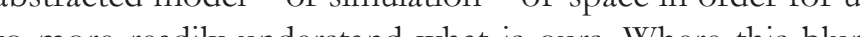

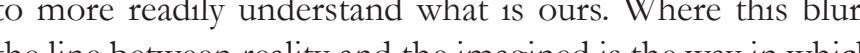
the line between reality and the imagined is the way in which these abstract lines define the site.

16 Ibid., 266.

17 Jean Baudrillard, Simulacra and Simulation, trans. Sheila Faria

Glaser(Michigan: The University of Michigan Press, 1994).

18 Ibid., 3-4 
The ridge-line, or dip in the site that may otherwise be a useful rise to make the most of the sun, when transected by the lot boundary becomes in and of itself a barrier. In this way by the application of the abstracted simulation the site, and its use, changes without any change in the physical site, antance of place. Our conception of the ste physical subs un of place Our con a the our understanding of it as a physical object, in this way it becomes a simulacrum. By changing the way we look at the site and land division for ownership patterns I am intending to minimise (by the nature of ownership this cannot be completely negated) the limitations for building that arise out of this disparate view of the reality of the site.

This widespread critique of New Urbanist nostalgia is consistent with Baudrillard's arguments about the generation by models of a real without origin or reality. In a way the idealised versions of the "old city ${ }^{20}$ upon which much of their arguments are built are themselves a representation, simulation of the real, in reproducing these the outcomes are considered simulacra; a hyperreal generated without origin or reality In trying to reproduce this condition one leaves reality behind
Instead of re-representing this imagined past we can instead analyse and learn from the processes rather than the simulated representation. This approach is not without its own problems, however it seeks to avoid [at the most superficial level the trap of the simulacrum into which many of the built examples of New Urbanism fall.

Urban design and planning theorists have long warned that normative theories are only statements of belief in "goodness" on the part of professional elites. These theories demand that followers make a leap of faith and simpty trust in the beneficil out that they claim will occur. ${ }^{21}$ - Anne Moudon (2000)

With all of these theories, and in particular the organicist principals from the preceding authors, there is a tendency This This tre generalisations of the way in which "mechanical' market society forms cities and space. ${ }^{22}$ By using legal concepts that relate directly back to existing New Zealand Legislation this project addresses these concerns and justifies the nonconformity of the approach. 
CASE/FIELD BASED LITERATURE

New Zealand as a society comes from a postcolonial background, however Campbell Gibson Argues that as a 'viroin nation' we had a comparatively hioh level of urbanization fro to the nature of of f of New Zealand culture'. The Quater Acre Dream and the imitation of an English country lifestyle that was present in the early colony ${ }^{25}$ has evolved, however this still leaves New Zealand with a different social and cultural attitude toward higher density housing. Any move towards the proposed aggregative method of design would require a change in either the views of the public towards higher density developments, or careful design to bring the expectations of the matket into the design considerations. The quality of increased density housing has a bad reputation, however Walton, Murray and Thompson argue that there is not necessarily a negative perception of medium density housing in New Zealand ${ }^{26}$. However Citiscope Consultants contradict this with their finding that the state house has tainted the reputation of increased density ${ }^{27}$.

3 Campbell Gibson, "Urbanization in New Zealand: A Comparative Analysis," Demography 10, no. 1 (1973).

24 Chelen aroa," Pacific Coast Pbilology 49, no. 2 (2014).

26 D. Walton, S. J. Murray, and J. A. Thomas, "Relationships between Popula Quality of Neighbourbood", Social Indicator Research 89, no. 3 (2008): 41 .

27 CitySCope Consultants, "Improving the Design, Quality and Affordability of Residential Intensification in New Zealand," (Centre for Housing Ressarch, Aot aroa New Zealand, 2011), 8-11.

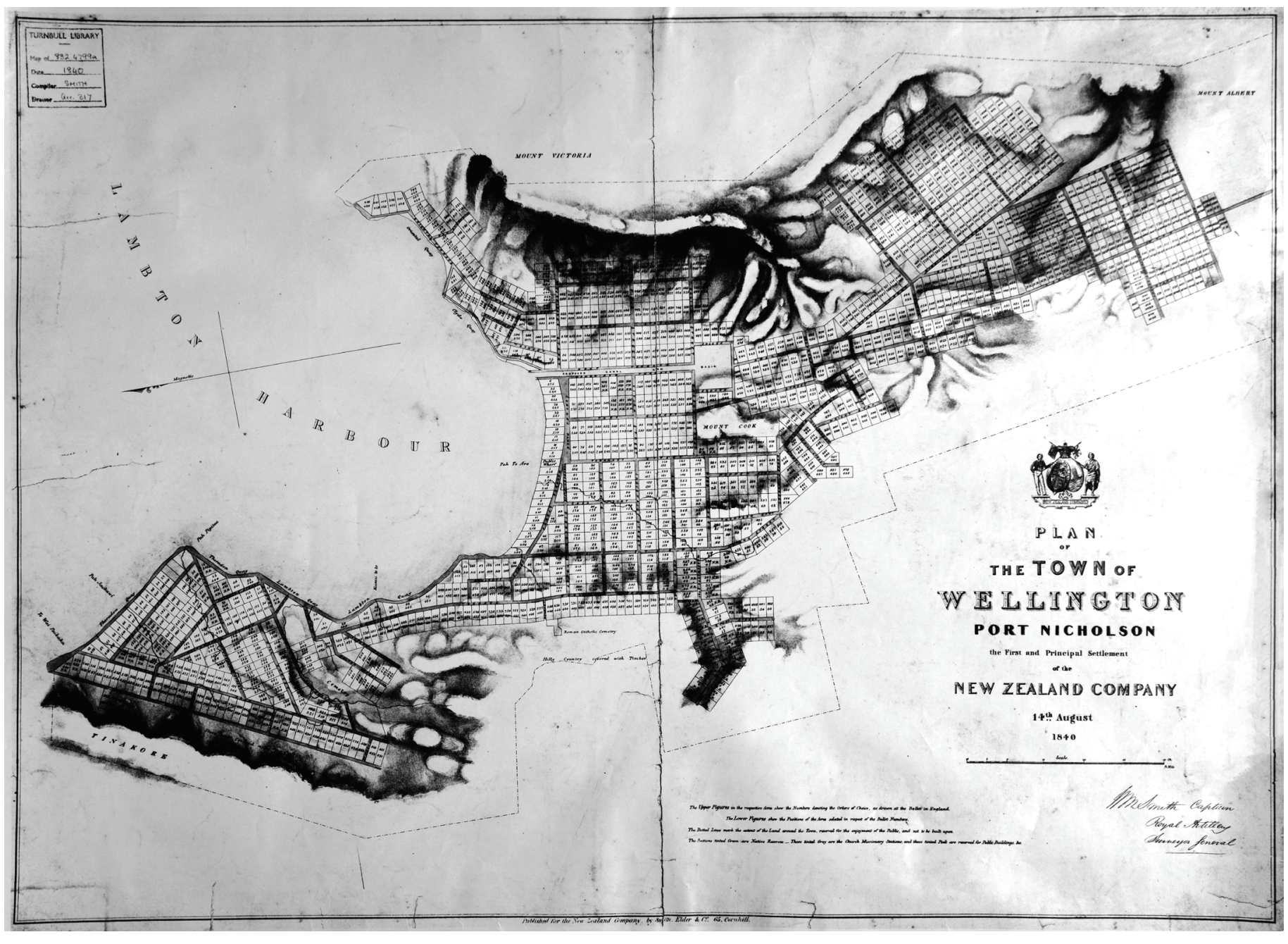

< fig: 1.4 Wellington Map 1840 ource: Archives New Zealand 


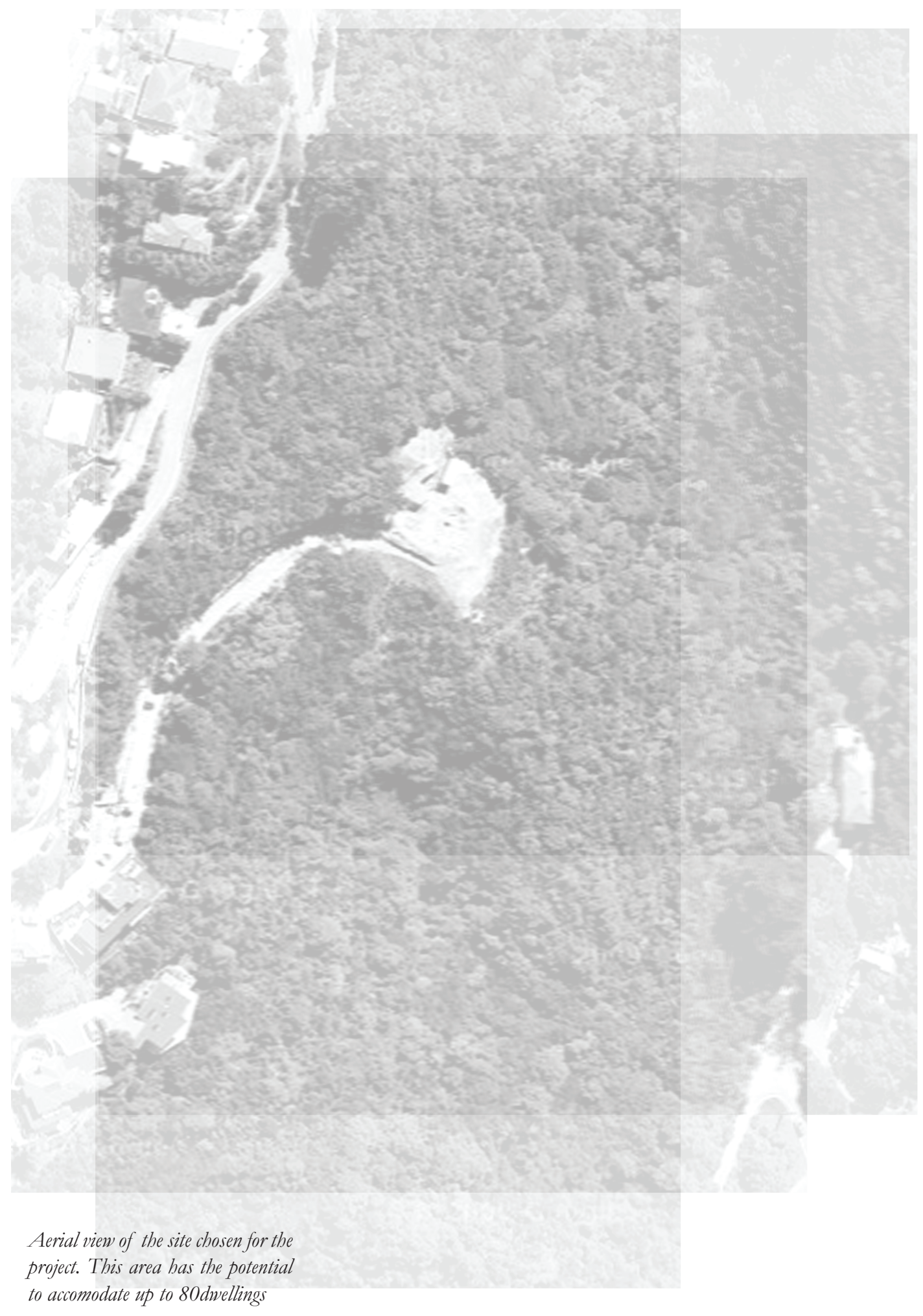

The process for the research (as described briefly in the introduction) is formed around the idea of aggregative, incremental growth. It adopts a housing model that will both support, and be formed by this process. Alexander's work on a New Theory of Urban Design will form the basis for the studio experiment and simulation. The experiment for the studio experiment and simulation. The experiment
consists of a simulated process of urban growth, using input from both myself as the researcher and outside participants who include final year post-graduate students and practicing professionals. All participants have architectural training or experience as the process does not seek to imitate some imagined idea of a new vernacular or of non-selfconscious design. Instead, the process introduces a new protoco produce a contemporary hillside settlement.

For the Simulation I have chosen a site (fig 1.5) in Wellington's northern suburb of Khandallah. The site is roughly $39,500 \mathrm{~m}^{2}$ of the hillside with about $23,000 \mathrm{~m}^{2}$ of land within my build imits. The averge slope of the ste is $26^{\circ}$ or a gadient 1:2. This site looks out over Wellingto $26^{\circ}$ or a is lis Thed in one of the more gentifed sububs. Each is located in one of the more gentrified suburbs. Each participant designer is asked to site and design - at a basic evel - a new dwelling for the simulation adding each time to the whole. Unlike the physical model created for Alexander's work, modern BIM technology allows for a digital mode that can be transcribed into different software and forms. It is this form where the projects exists, a simulation of an imagined reality. In addition to this main digital model, physical models will represent different stages and forms of the experiment.

< fig: 1.5 Site: Khandallah Nicholson Rd)

Source: Image based on original content from Google Earth (2009) 
This experiment is intended as a testing ground for the research and is not the outcome. The intended outcome of the research is not the final design as an object, but of the development guidelines and protocols of a delivery proces which could be replicated in a modified form in the real

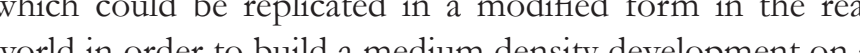
worl cour be replich a

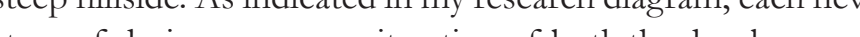
stage of design sees a new iteration of both the development framework and simulation methodology, working towards final outcome.

Initially the pilot study takes place with two parallel processes, each based on a single turning/parking area. A draft development framework is produced and dwellings are designed using its guidelines. In the first 'comprehensive control' process the four dwellings are designed, in successive stages, by myself as a single designer. The second 'aggregative experiment' process uses purely outside design input but applies the same Framework. Comparison of the two processes leads to refinement of the framework and the manner of its application.

Following the pilot study process (chapter 3) Design Stage One begins again on the same site. As an initial setup for the development, I have - in my role as curator and project architect - set up the main infrastructure for the project. This includes parking structures, road access to the top and Thettom of the site, cable car access between these pop and he locrion of key series, As well as this infastucture he location of key sevics. As well as this infapre have also designed three 'seed" developments with two to three dwellings to be built before the start of the project to both allow for other designs to propagate out from and to set a precedent for the application of the development frameworks
In order to keep the time taken by the outside designers to a minimum, I will assist by driving the software and filling in some of the smaller scale architectural detailing (the form and structure of the spaces being the focus of the research). This mixing of inputs from outside focus of the reserch). This mixing of inpus fos besigners and a single curator will

This process has been finding a balance between the comprehensive control of exhaustive rules/guidelines and the desired flexibility and unpredictability of an infor an che des ge creating an outcome that is of sufficient quality and amenity to fit in with, or improve, the current New Zealand market. At the same time, the design must allow for differences in interpretation and approach that comes from many different designers collaborating on an aggregative whole. 


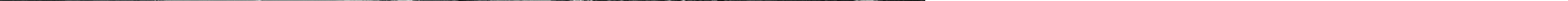




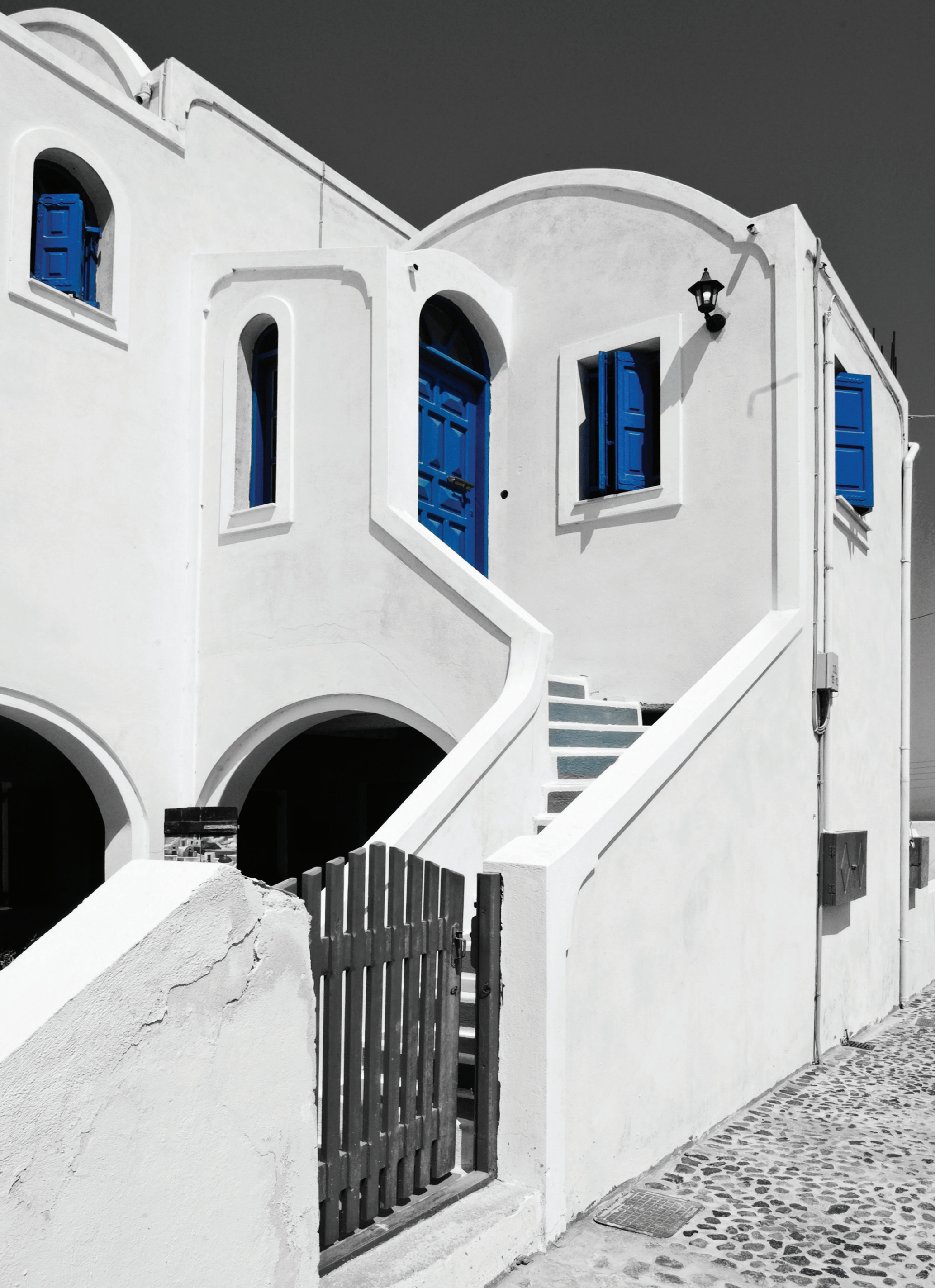

CHAPTER 2: CYCLADIC VERNACULAR

Theoretical Background
Town Development Studies
Street Studies




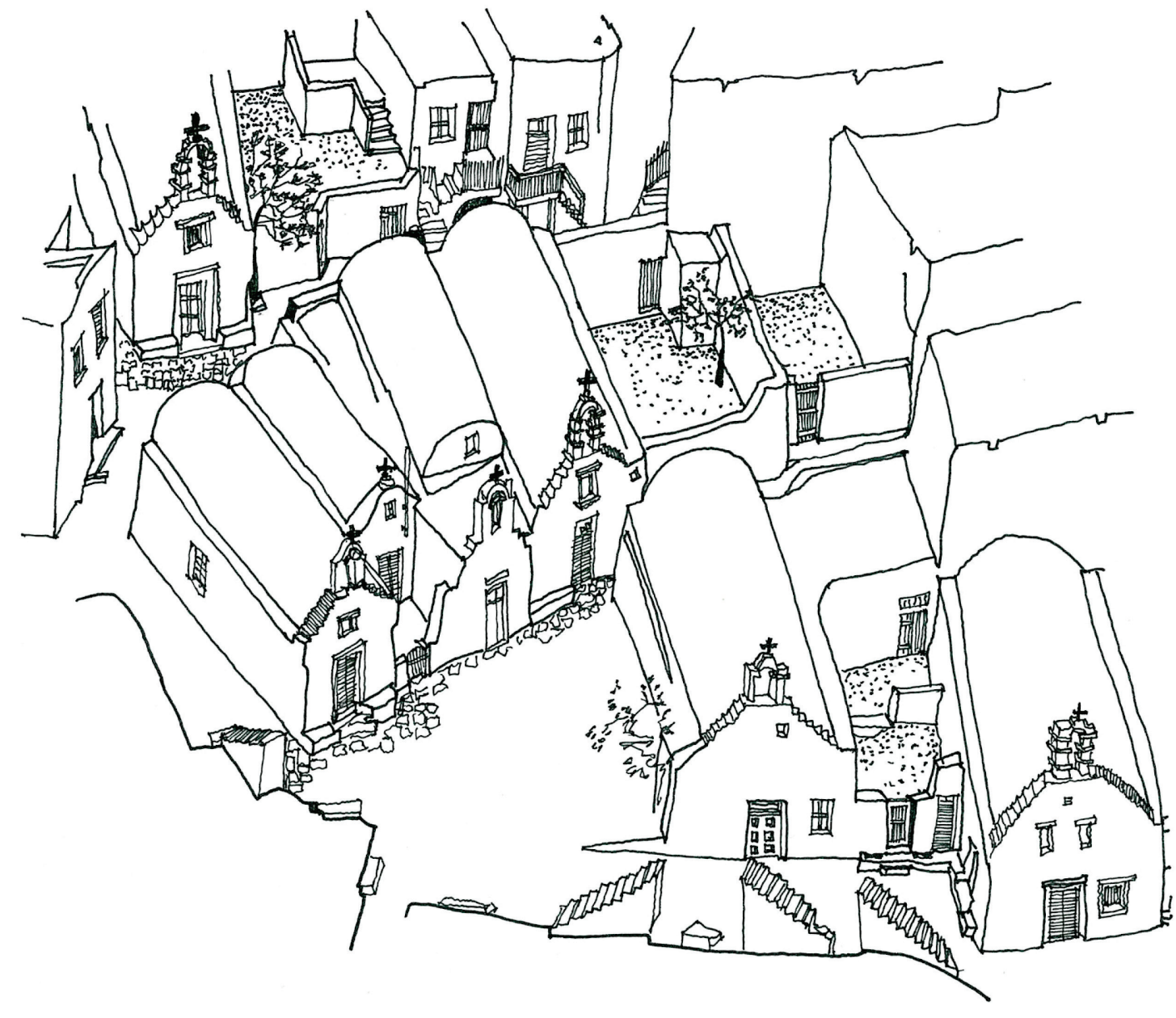

<fig: 2.1 Myconos Precinct of Seven Churches

Source: Image based on original by Kovatsi (1979) pg 74-75
2.0

CYCLADIC VERNACULAR ARCHITECTURE

Bernard Rudofsky, speaking about his work on native and vernacular architecture, Arcbitecture without Architects ${ }^{1}$, points out that the architectural field's preoccupation with formal and noble architecture has led to the exclusion of the common dwelling ${ }^{2}$ in discourse. As such the vernacular is often relegated to the area of anthropology and geography. Since Rudofsky wrote this, there has been a resurgence in interest with the vernacular and the supposed 'purity' of this type of dwelling. However authors such as Dimitri Philippedes argue that most often architects resort to an aesthetic evaluation of such architecture that is by its nature unsystematic and often leaning towards lyricism. However analysing the spatial structure of such a dwelling system could help to inform a response to a condition that has been largely overlooked in this country. Authors such as Philippedes, Michaelides, and Vionis advance the study of these towns and their vernacular architecture, with in depth analysis of not only the typology (n a context less situation) but of the urban framework, history and residential scale a well.

This chapter analyses the development and patterns of these towns and streetsin order to identify how they have overcome the challenge of building not only on a steep hillside, but also of developing through time in a non-planned fashion.

1 Bernard Rudofsky, Architecture witbout Architects: A Short Introduction to Non-Pedigreed Architecture(London: Academy Editions, 1964).

2 Ibid.

3 Dimitri Philippides, ed. Greek Traditional Architecture: Eastern Aegean, Sporades, Ionian Islands, 1st ed., vol. 1 (Athens: "Melissa”" Publishing House,

4 Ibid.

5 Constantine E. Michaelides, Hydra: A Greek Island Town Its Growth and Form(Chicago: The University of Chicago Press, 1967)

6 Athanasios K. Vionis, A Crusader, Ottoman, and Early Modern Aegean $A_{t}$ cbaeology, ed. CC. Kamermans Bakels, H., Archaeological Studies Leiden University (Leiden: Leiden University Press, 2012). 
Exhaustive histories of the Cyclades have been covered by several authors such as Aalen, Arnaoutoglou, Bouras, Kovats history of the Cyclades is and Vionis. A comprehensive however some aspects of the history do oreatly influcch, their development.

The area of the Cyclades, around the Aegean Ocean has been recorded as an area of maritime and agriculture since the late roman times of around the $4^{\text {th }}$ century ${ }^{8}$. The area was hotly contested and control of the area changed hands many times throughout this period and as such has been subject to many rebuilds. The modern physical evidence, and hence the focus of my case study begins around the $13^{\text {th }}-16^{\text {th }}$ century with the Latin establishment in the Aegean, followed by the Ottoman dominance of the Cyclades. This time period is transitional time for the area with many pirate attacks - such as the Ottoman corsair Heyreddin Barbarossa - causing devastation and instability in the region ${ }^{10}$. This influenced the development of the towns, with new settlements built on steep hillsides as a defensive measure against the maritime attacks. Towards the end of the $16^{\text {th }}$ century as Ottoman power in the Cyclades solidified the area went through a period of economic growth and stability. Under the protection or the Ortom their main living.

7. H. A. Aalen, "The Cycladic House in South Evvoia, Greece,"

Vernacular Arcbitecture 13, no. 1 (1982); Dimitri Philippides, ed. Greek. Traditional Architecture Eastern Aegean, Sporades, Ionian Islands, vol. 1 (Athens: Melissa Publishing House, 1999); Athena Kovatsi, "The Church and the Urban Structure of the Aegean Island Towns," (Pro Publishing, 1979); Michaelides, Hyara, Athanasios K. Vionis, A Crusader,

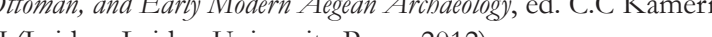
(1)

Archaeology.

Structure of the Aegean Island Towns

A Crusader Ottoman, and Early Modern Aegean Archaeeloges.

11 Ibid.
Many aspects of the vernacular building tradition were dependent on the local conditions, as well as the limited comselves ${ }^{12}$. Typical construction type was heavy stone plasterand cement based due to the arid environment and lack of usable timber for construction. Constantine Michaelides argues that these towns are 'crown' towns, and that the form that is created is something recognisable to its inhabitants, something that could be seen and understood by everyone ${ }^{13}$ This idea is in line with the way in which accretion worked in these areas, where the logistics and details of building in these areas, where the logistics and details of building were not set by law, but instead by an unwritten tradition addition to this locally informed knowledge and tradition, here was some cultural cross pollination through both the Venetian (Latin) and Ottoman periods of rule in the form of traveling craftsmen. As such aspects of the building tradition found throughout the Cyclades can be seen in various forms throughout the Balkans and 'Asia Minor ${ }^{13}$.

2 C. Bouras, "General Introduction," in Greek Traditional Archi(1) 1999).

3 Michaelides, Hydra.

14 Ibid.; C. Arnaoutoglou, "Sporades: Skyros," in Greek Tradition al Arcbitecture, ed. Dimitri Philippides(Athens: Melissa Publishing House, 1999).

15 C. Bouras, "General Introduction," ibid. 

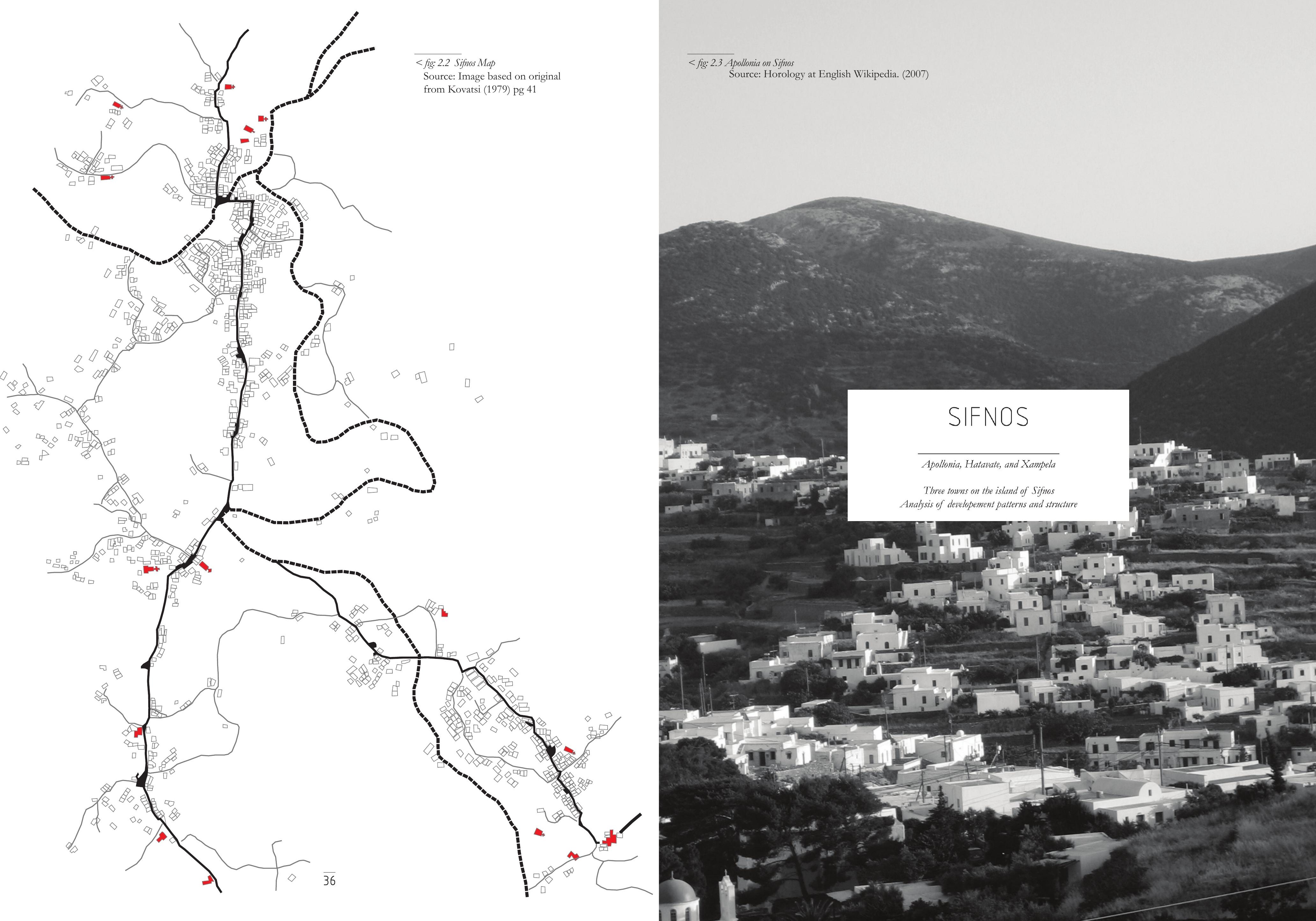

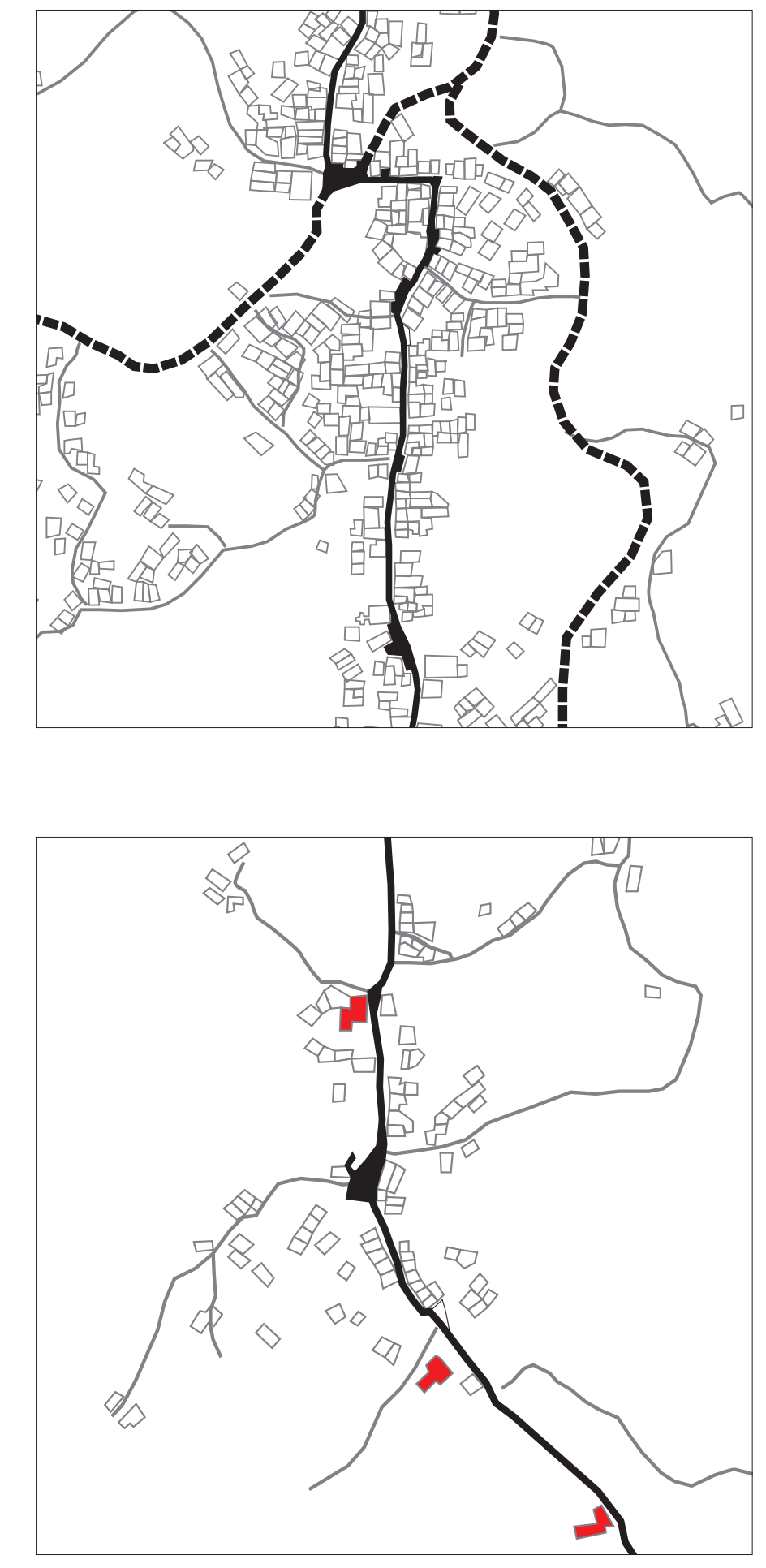

The main town in the area, Apollonia has developed further from the road the contours) and denser than the surrounding villages

fig: 2.4 Sifnos: Apollonia map Source: Base map after

original from Kovatsi (1979)

An offshoot village, this developed from rural gricultural spread that wo close to small pastures

<ig: 2.5 Sifnos: Hatavate map Source: Base map after
SIFNOS: APOLLONIA, HATAVATE \& XAMPELA

These three towns on the island of Sifnos were primarily agricultural towns built away from the sea to avoid pirate attacks. The three towns began separately and have grown together (fig 2.8) over time due to the linear nature of their surrounding topology. The primary access around the town runs along the ridge lines or parallel to the contours of the and (fig 2.10). This has caused the majority of growt and accretion of housing to build up in a linear fashion following these access routes (fig 2.11). Further growth in the area happens along secondary routes perpendicular to the topography allowing for growth down the hills. 


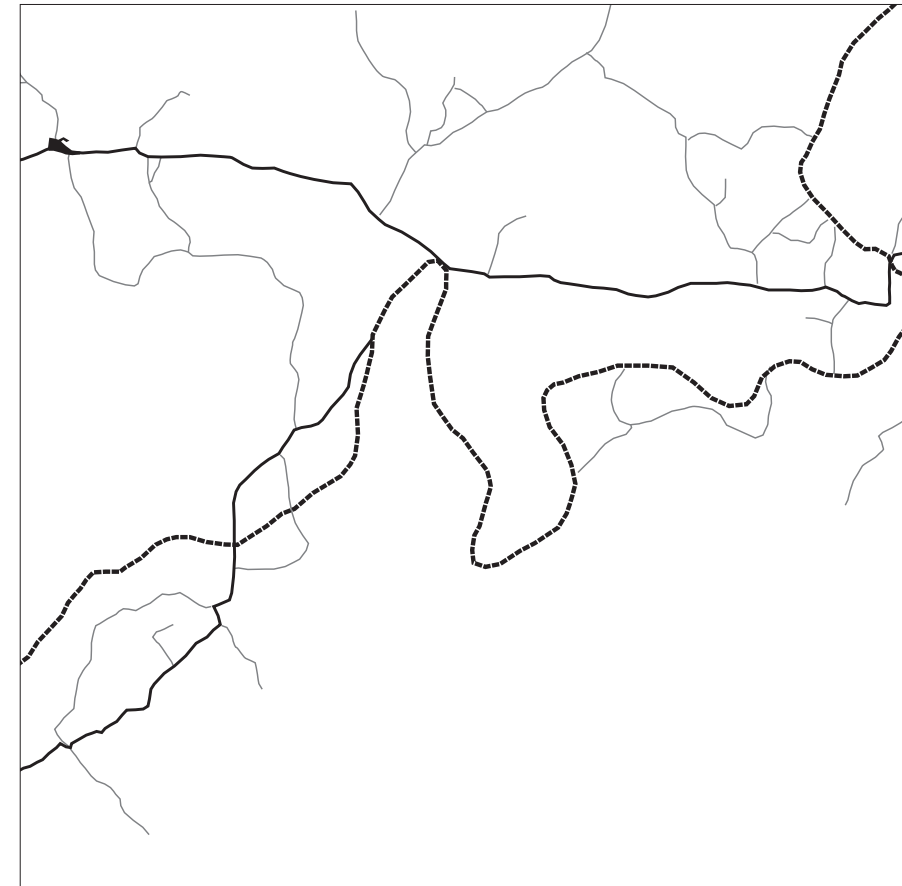

Road pattern: primary and secondary pedestrian route. through the towns running parallel and perpendicular access noted in dotted line)

<fig: 2.6 Sifnos Road Pattern Source: Base map after original from Kovatsi (1979)

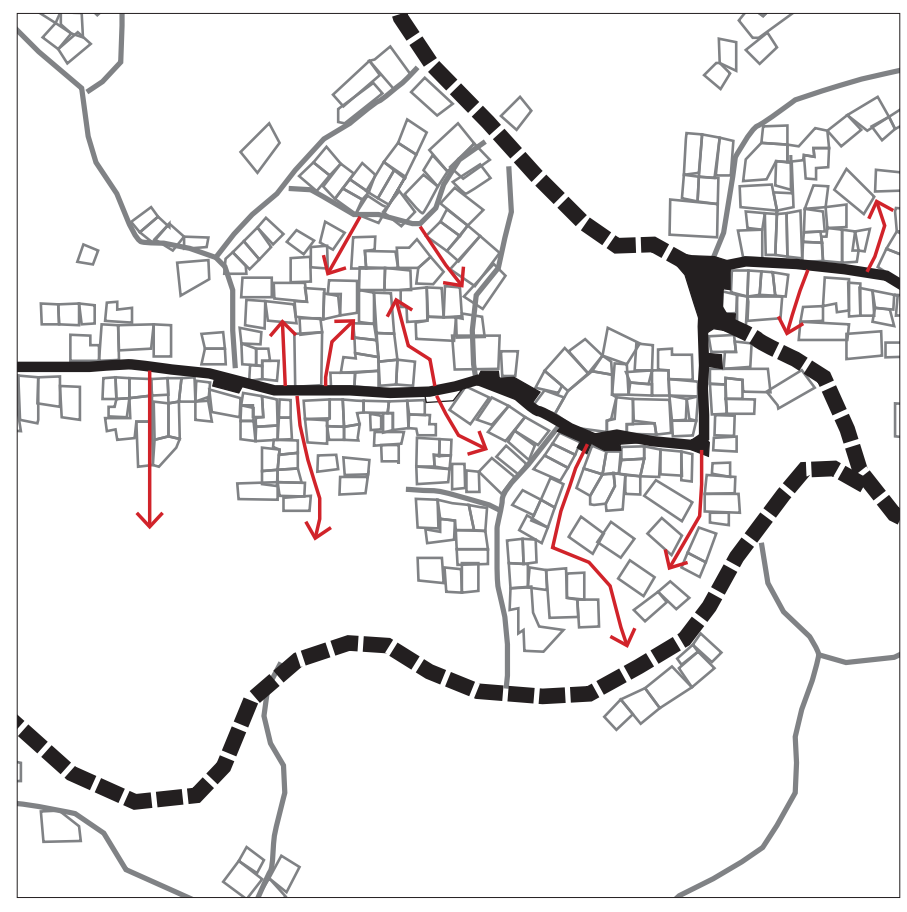

Tertiary access routes: in ddition to the primary and secondary pedestrian access network of streets, develops down the billsides as informal pathways

$<$ fig: 2.7 Sifnos informal access Source: Base map after Analysis by Author

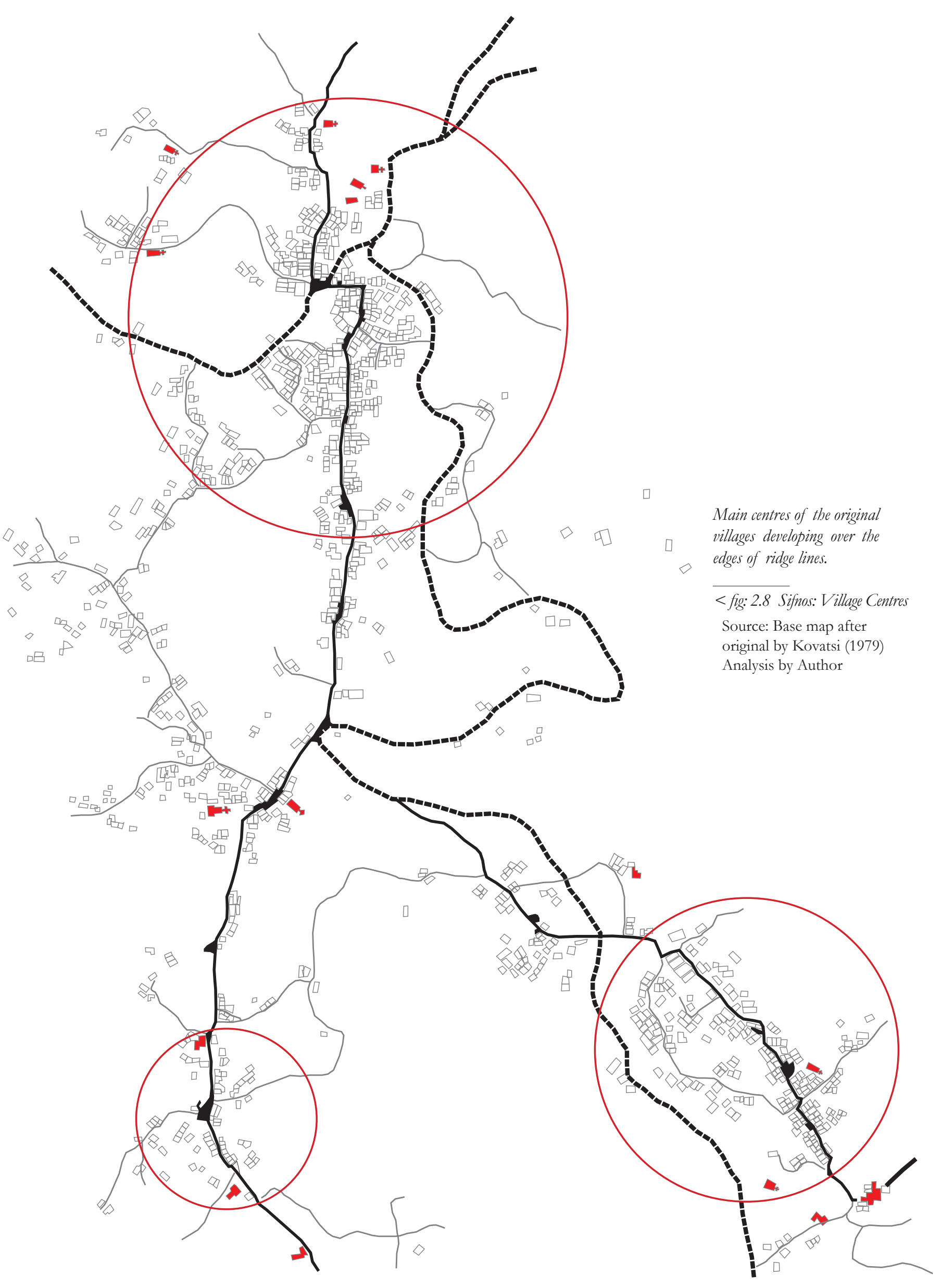



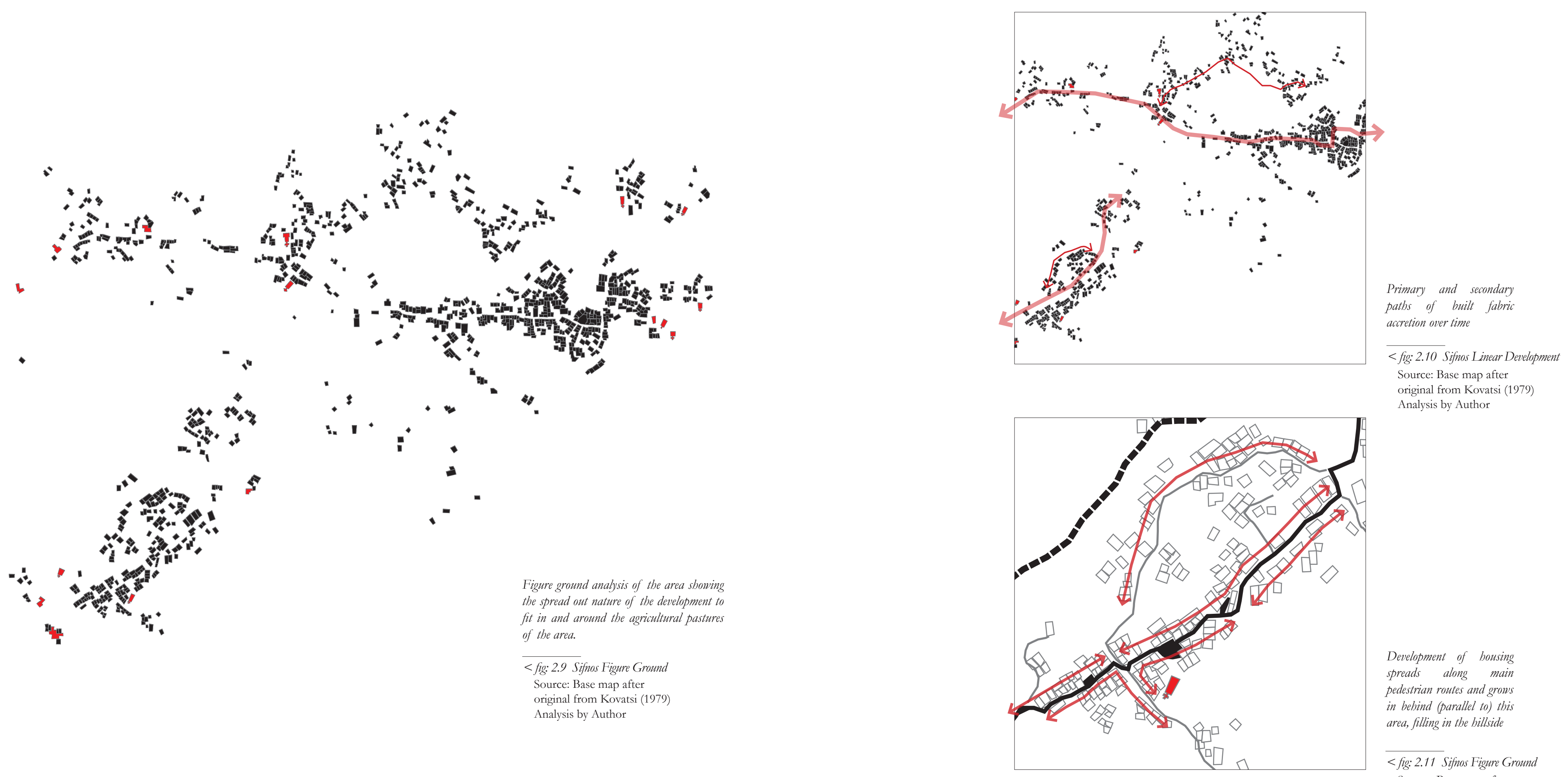

original from Kovatsi (1979)

Development of bousing spreads along main in behind (parallel to) this area, filling in the billside 

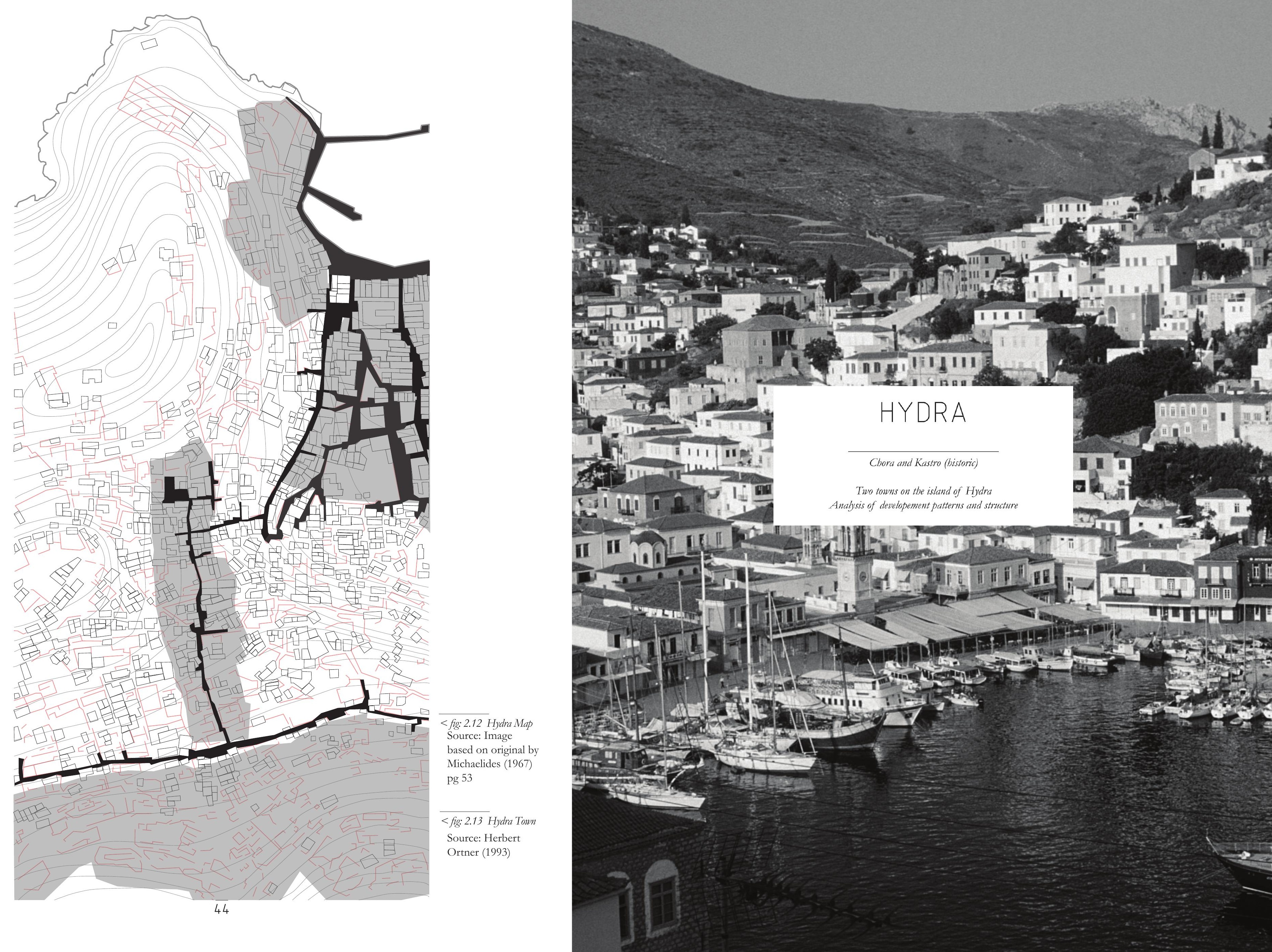


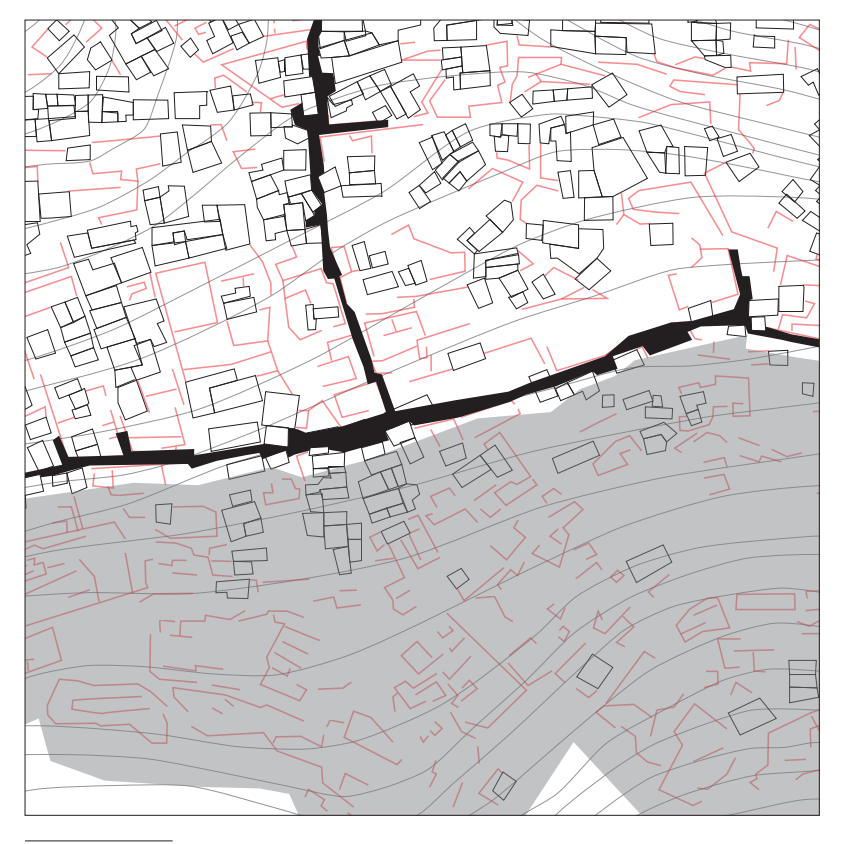

<fig: 2.14 Hydra: Fortified town

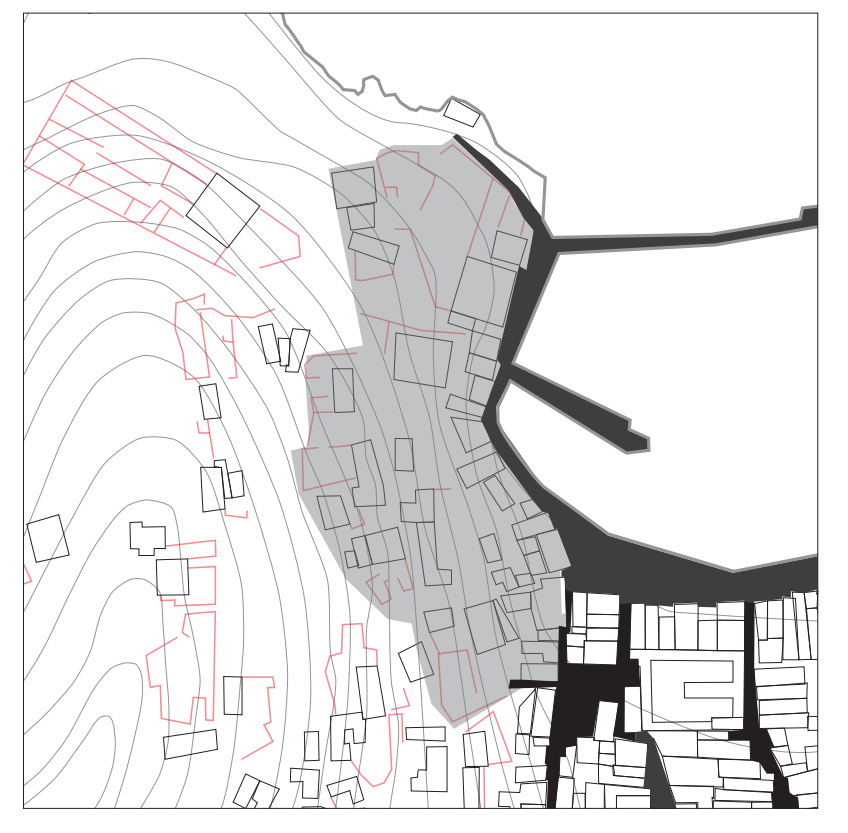

< fig: 2.16 Hydra: Hilltop/Cliff town

Source: Images based on original

by Michaelides (1967) pg 53

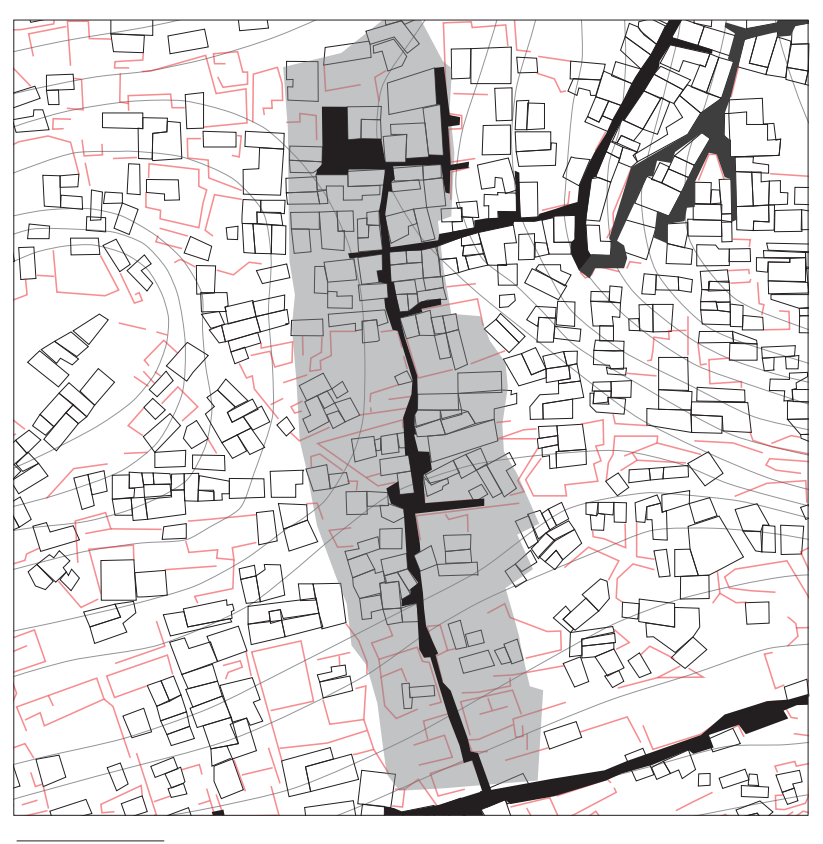

< fig: 2.15 Hydra: Saddle town

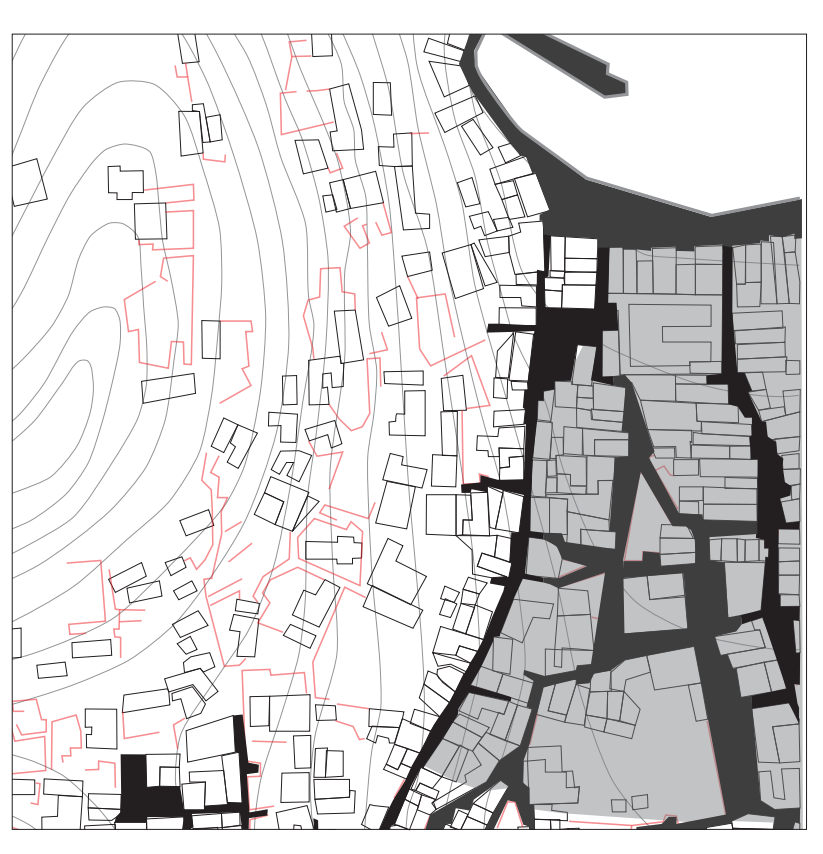

< fig: 2.17 Hydra: Valley town
2.2

HYDRA: CHORA AND KASTRO

On the island of Hydra, the original settlement (Kastro, meaning fortified town) was built away from the port on a steep section of hill to avoid pirate attacks. Following the tability brougt by town grew outwars fom this o. cha 2.17). The man access from 2.17). The main ac growth, creating a saddle town along the ridgeline, after this a valley town developed next to the port where the majority of inhabitants made their living. Finally the upper classes used the area to the north west of the port as a hilltop town, making use of the view and proximity to the port to build Archontika (mansions). 


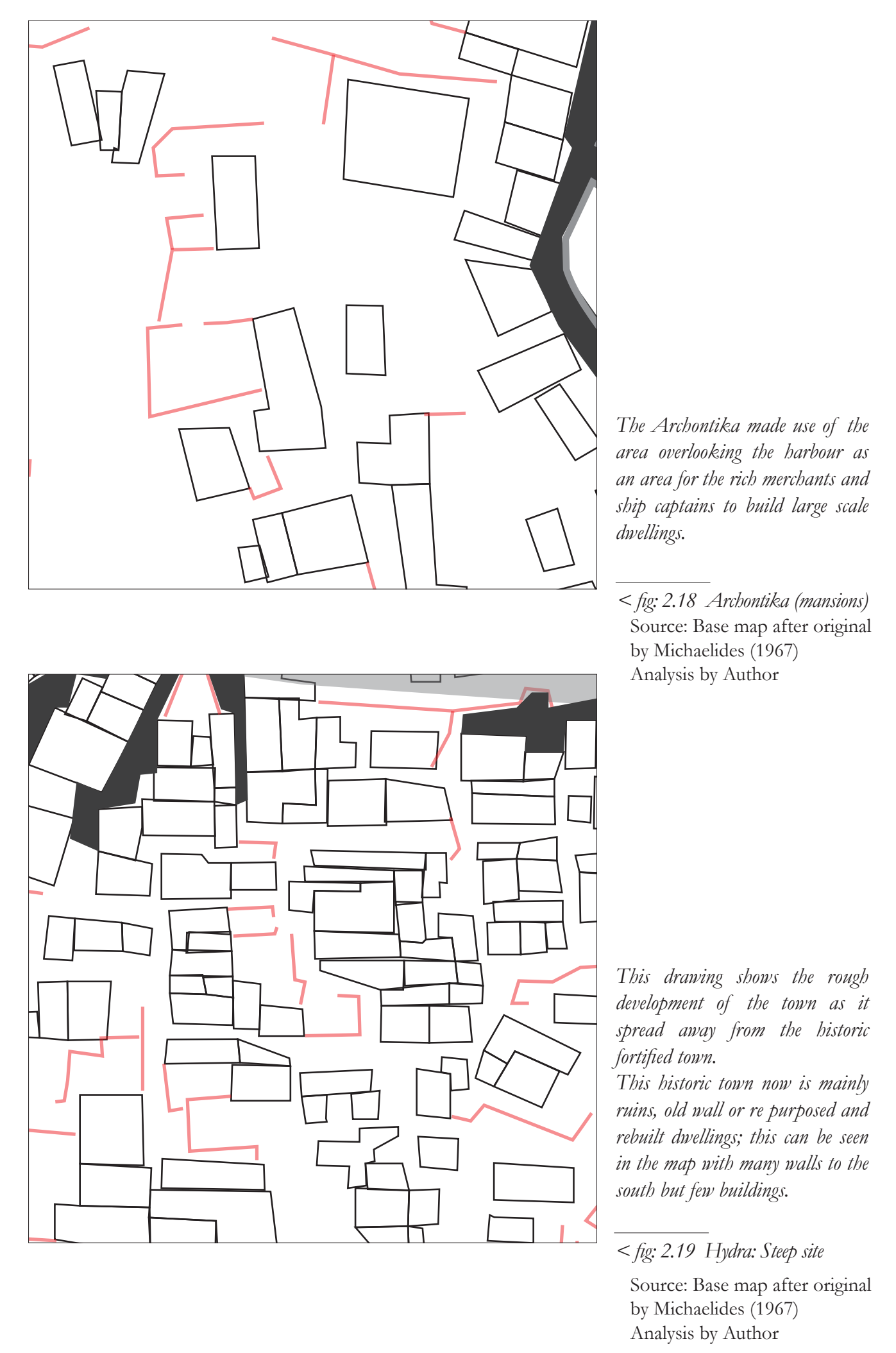

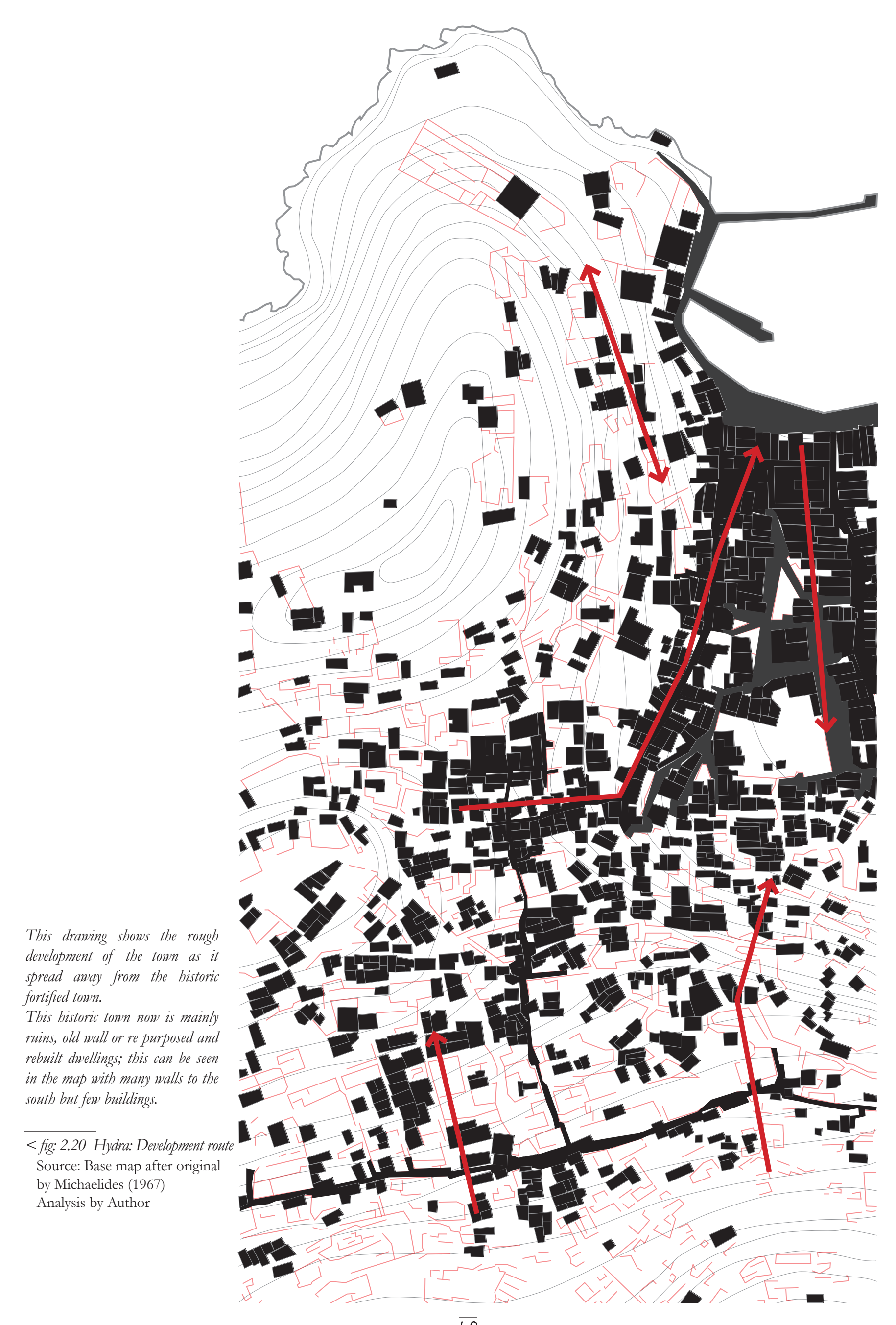




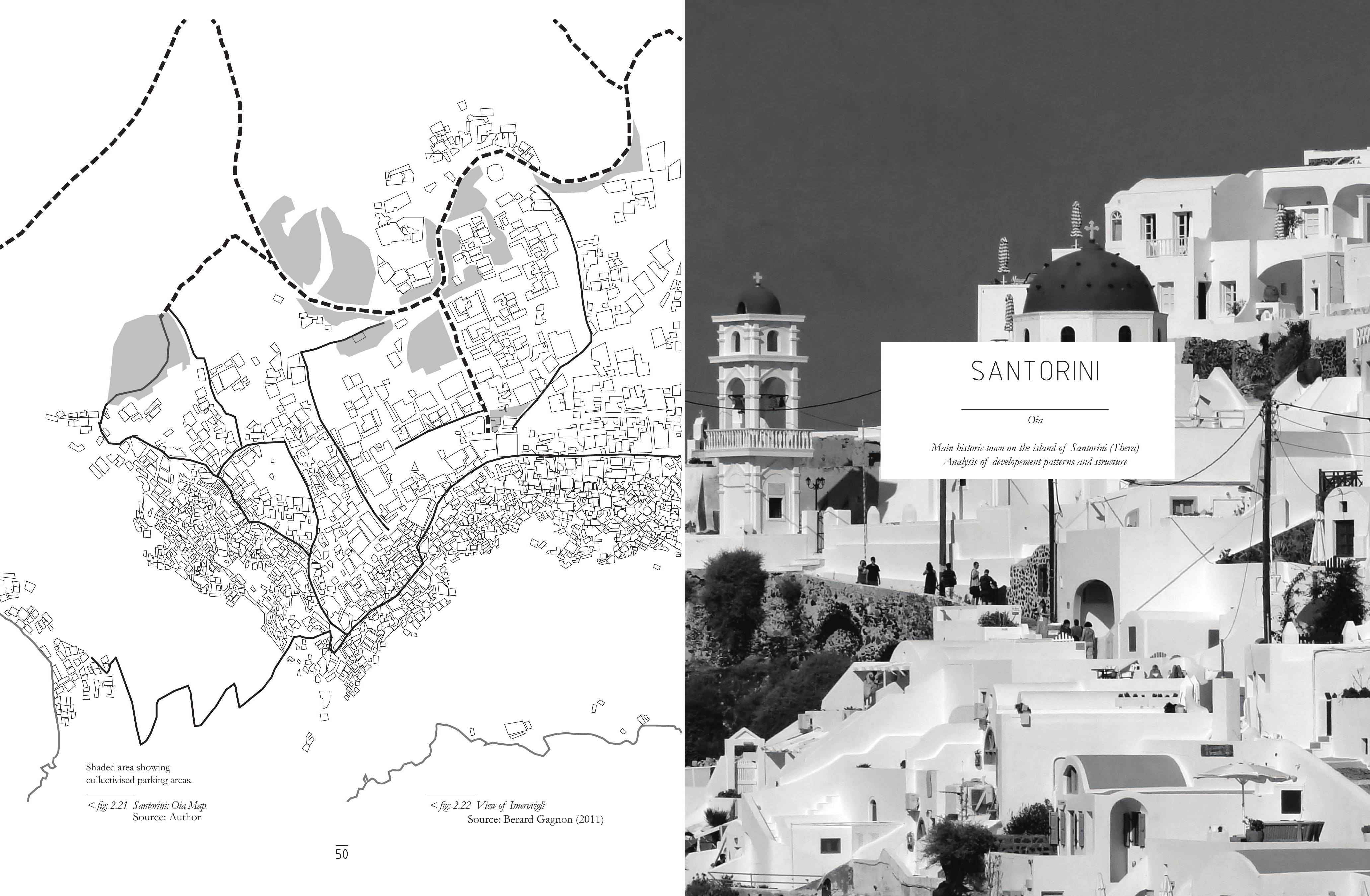



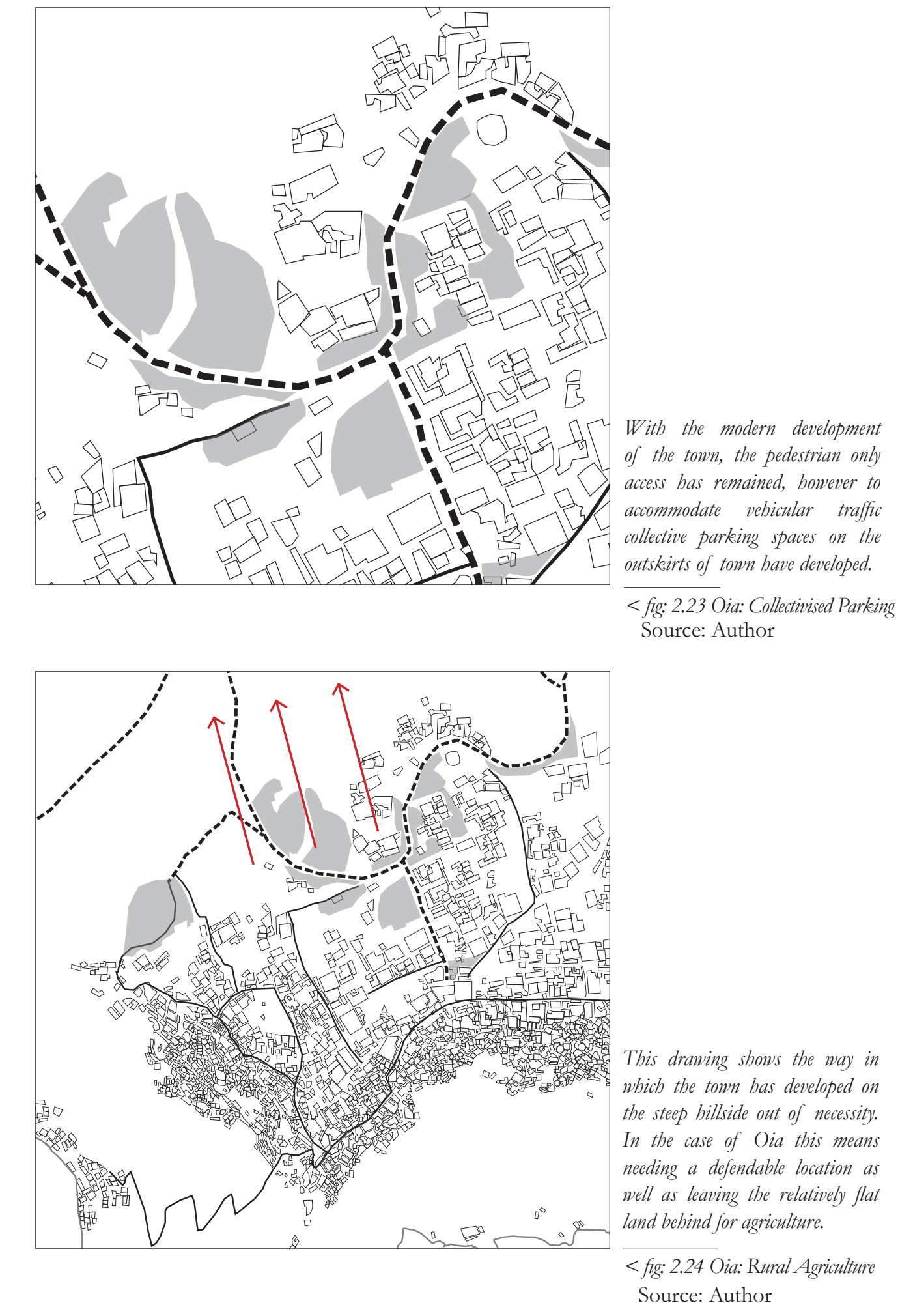

2.3

SANTORINI: OIA

Santorini (Thera) is a particularly arid, volcanic island and as such lacks timber for construction, the development of this town relied on the famous Theran cement to form an arched construction as well as the use of dug in, troglodyte housing. Oia is built on the steepest hillside of the three sites I look at here, while some others have vehicular access close to the dwellings, Oia has developed a system of collectivised parking (fig 2.23) to keep the access ways vehicle free due to the steep nature of the site. 


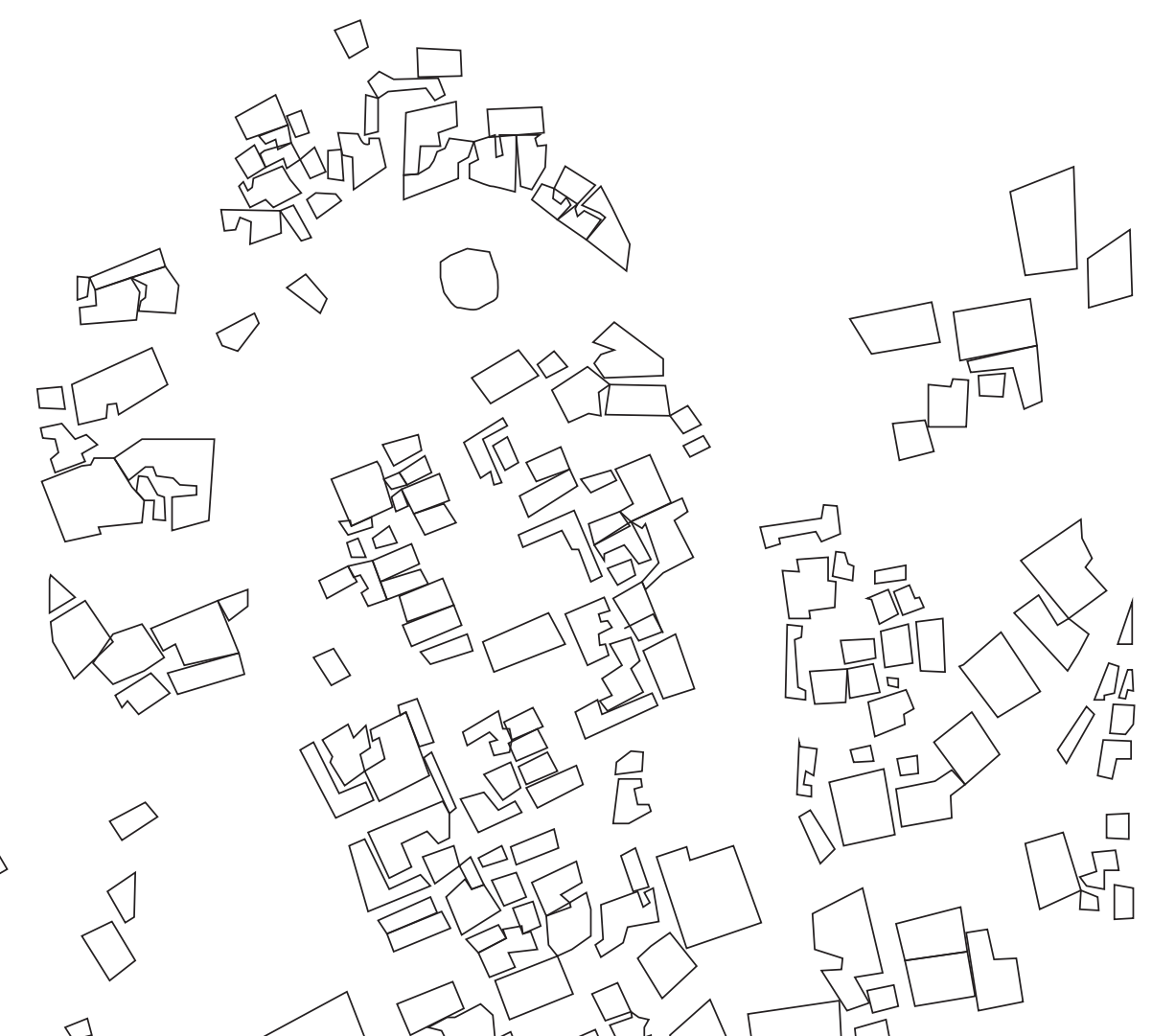

The larger grain development on the flat land housed the upper and captains, able to look down over <fig: 2.26 Oia: Flat Ground Source: Author

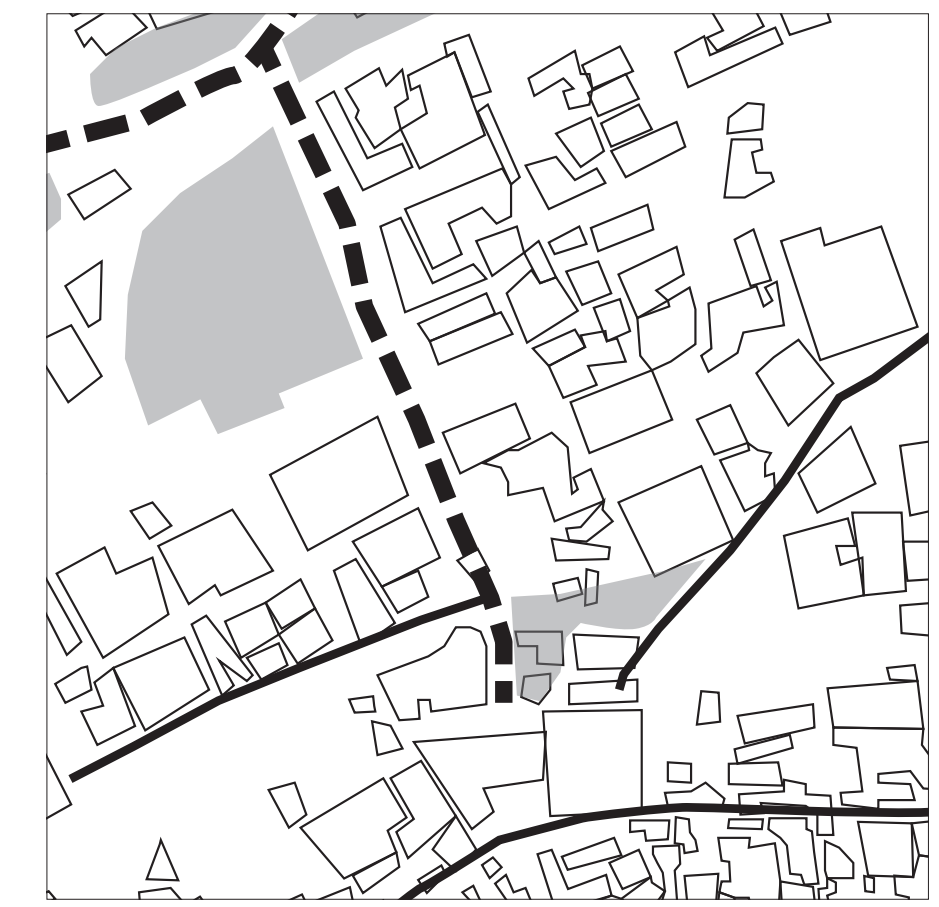
4 IIn⿵

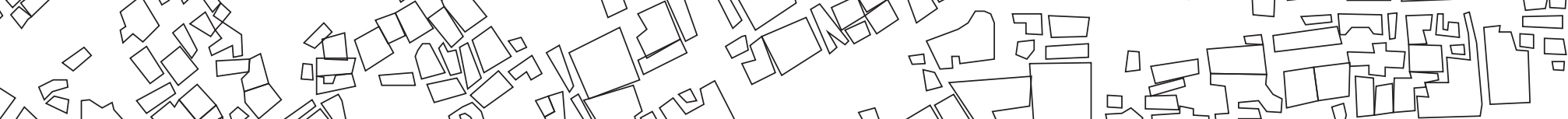

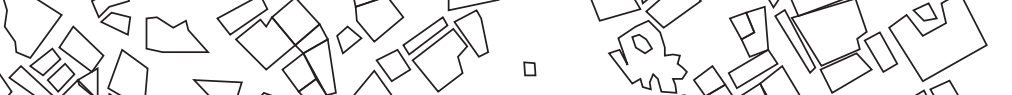
onm sn:

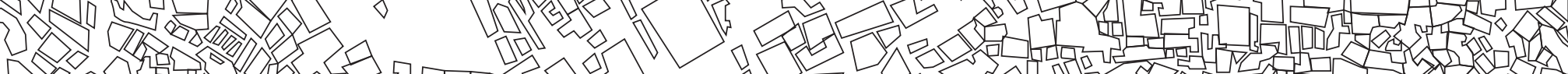
128 (1) (3)

(1)

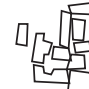

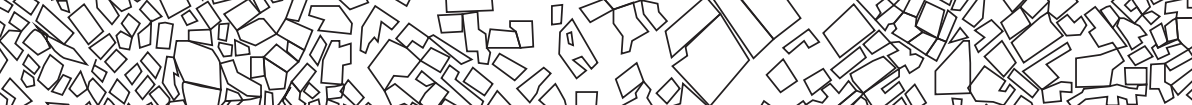

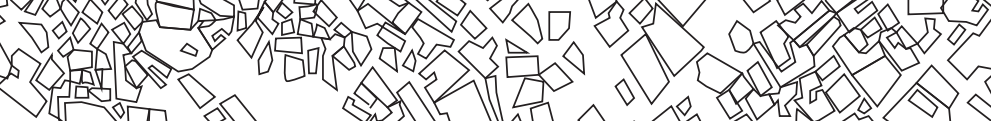

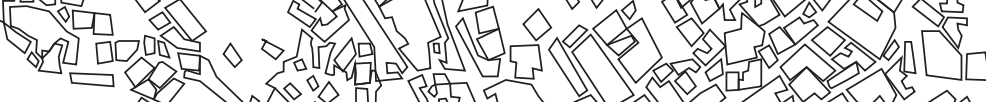

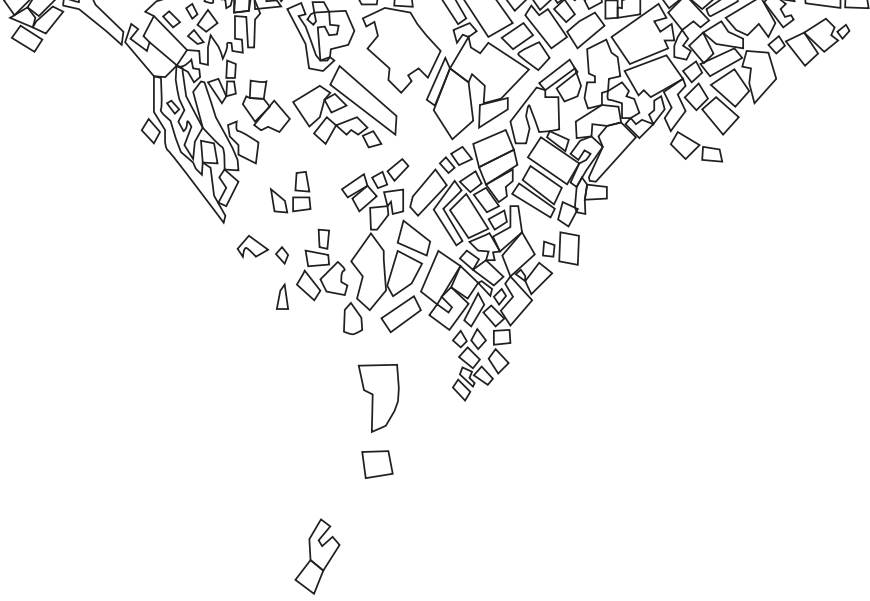

Modern day Oia has developed almost solehy on the flat area of town that would once have been planting and arriculture. The grain of development hovever is still apparent having a marked difference between the flat and sloped areas of the town.

<fig: 2.25 Oia: Figure-Ground Source: Author

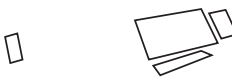

0

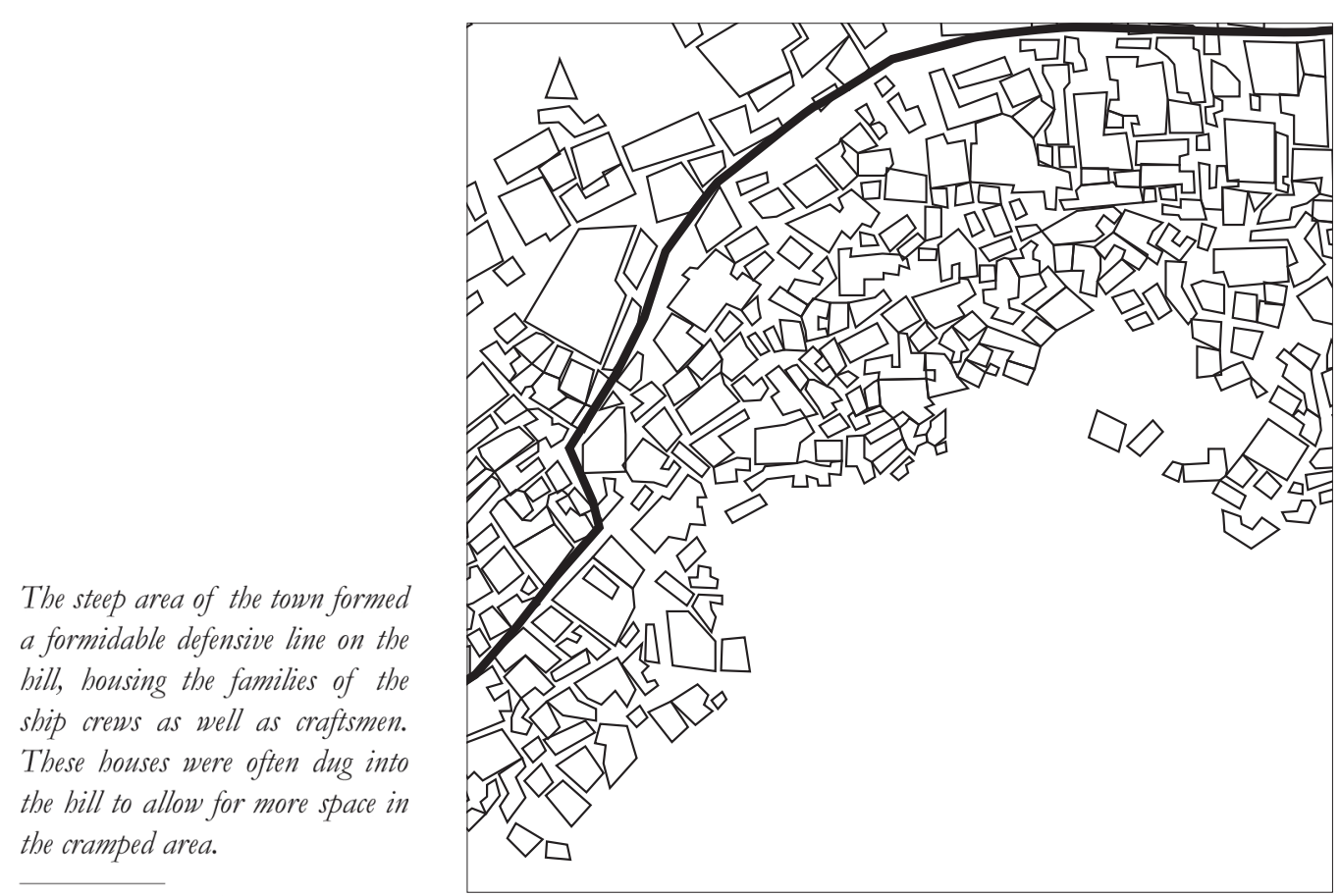



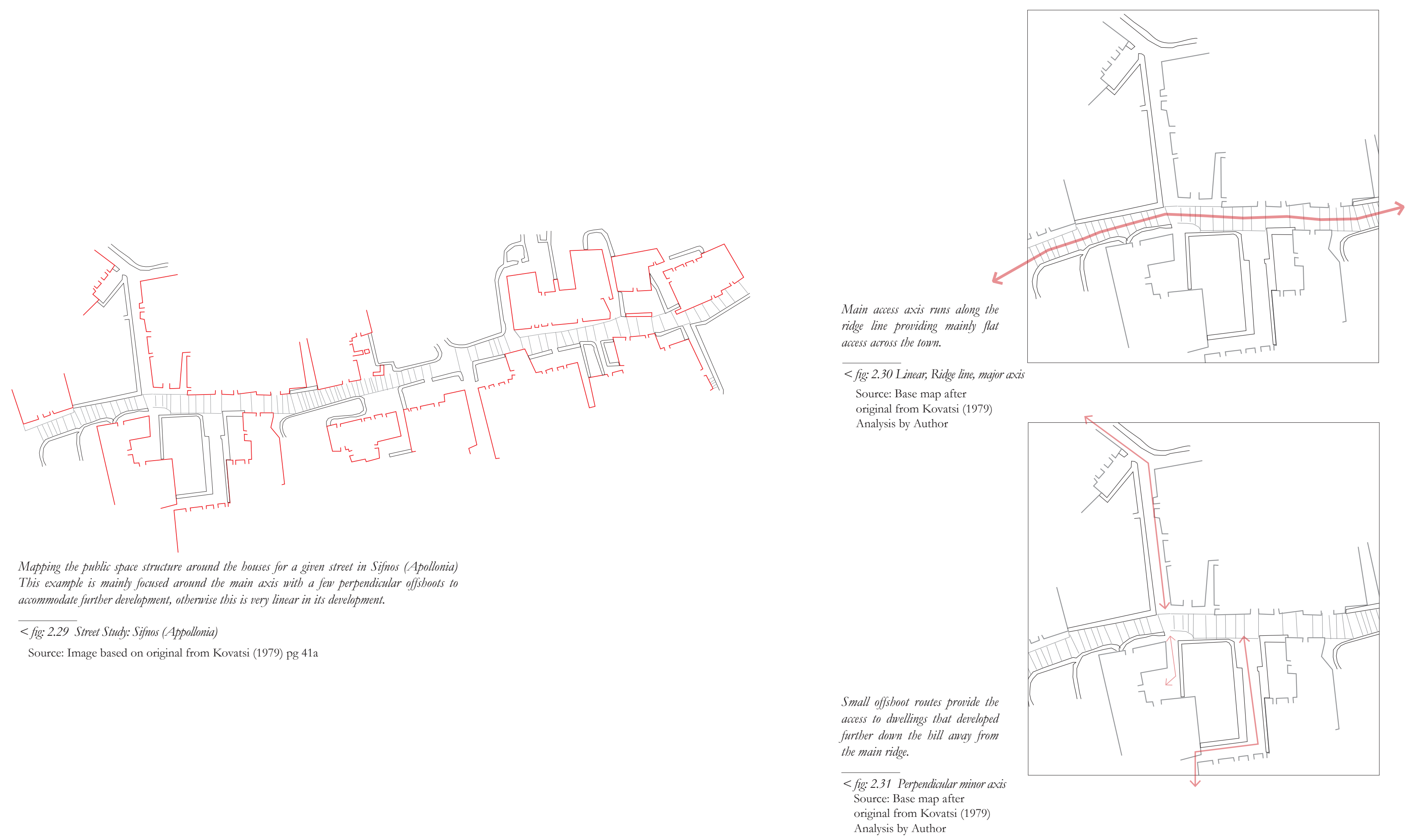


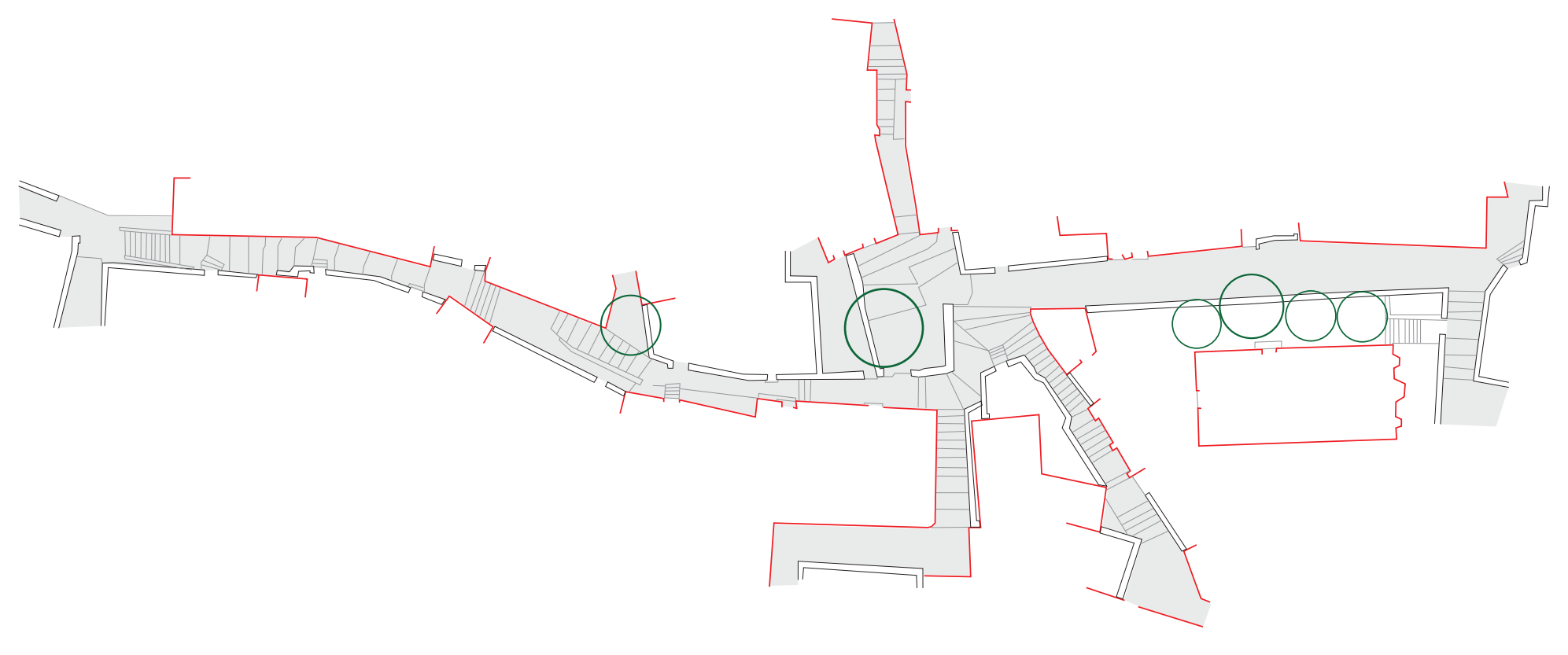

Mapping the public space structure around the houses for a given street in Chora (Hydra) This example shows a higher rellance on a two was street pattern, with the minor axis (perpendicula to contours) playing a larger role in the access/ circulation.

\section{< fig: 2.32 Street Study: Hydra (Chora)}

Source: Base map after original

by Michaelides (1967)

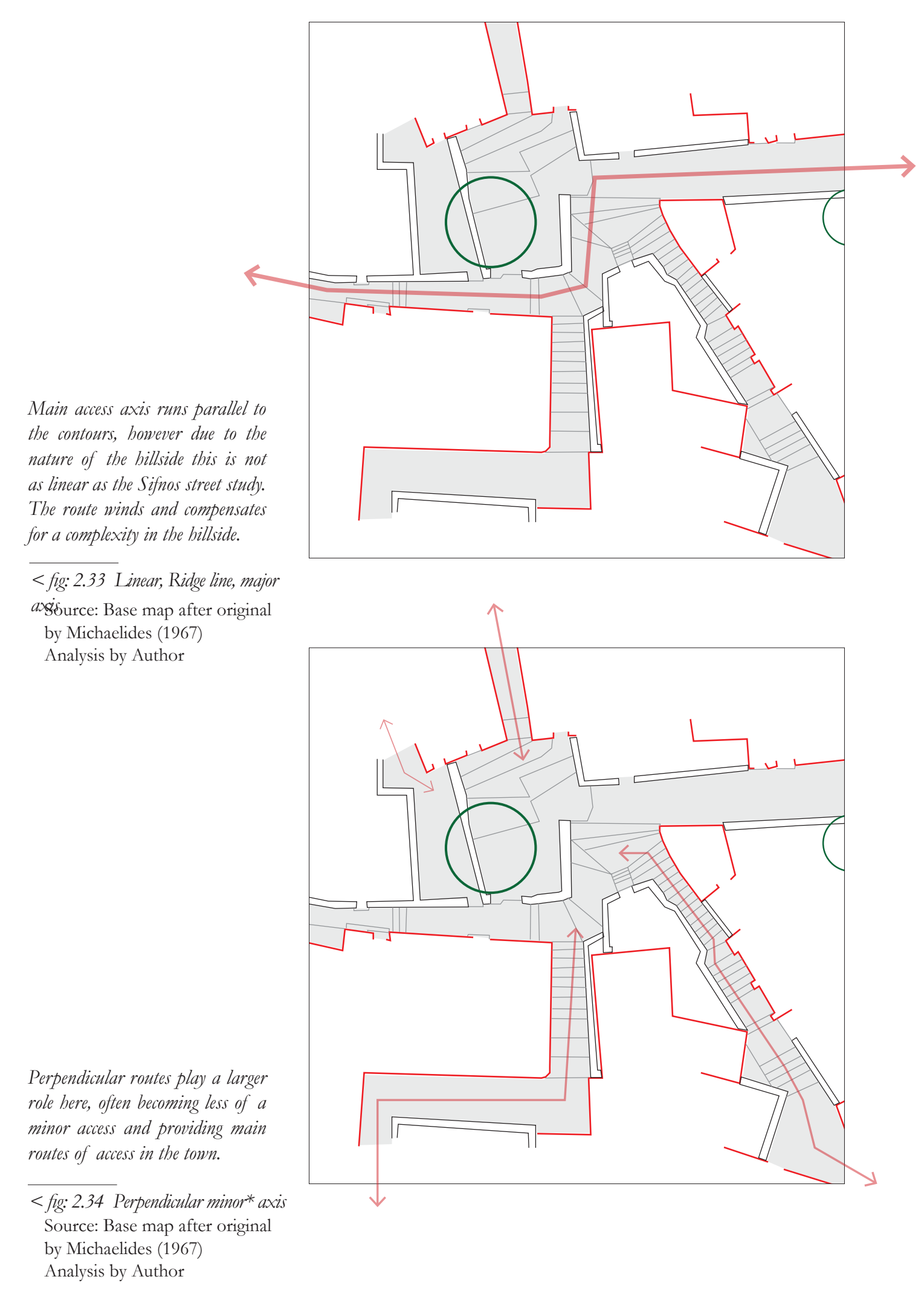




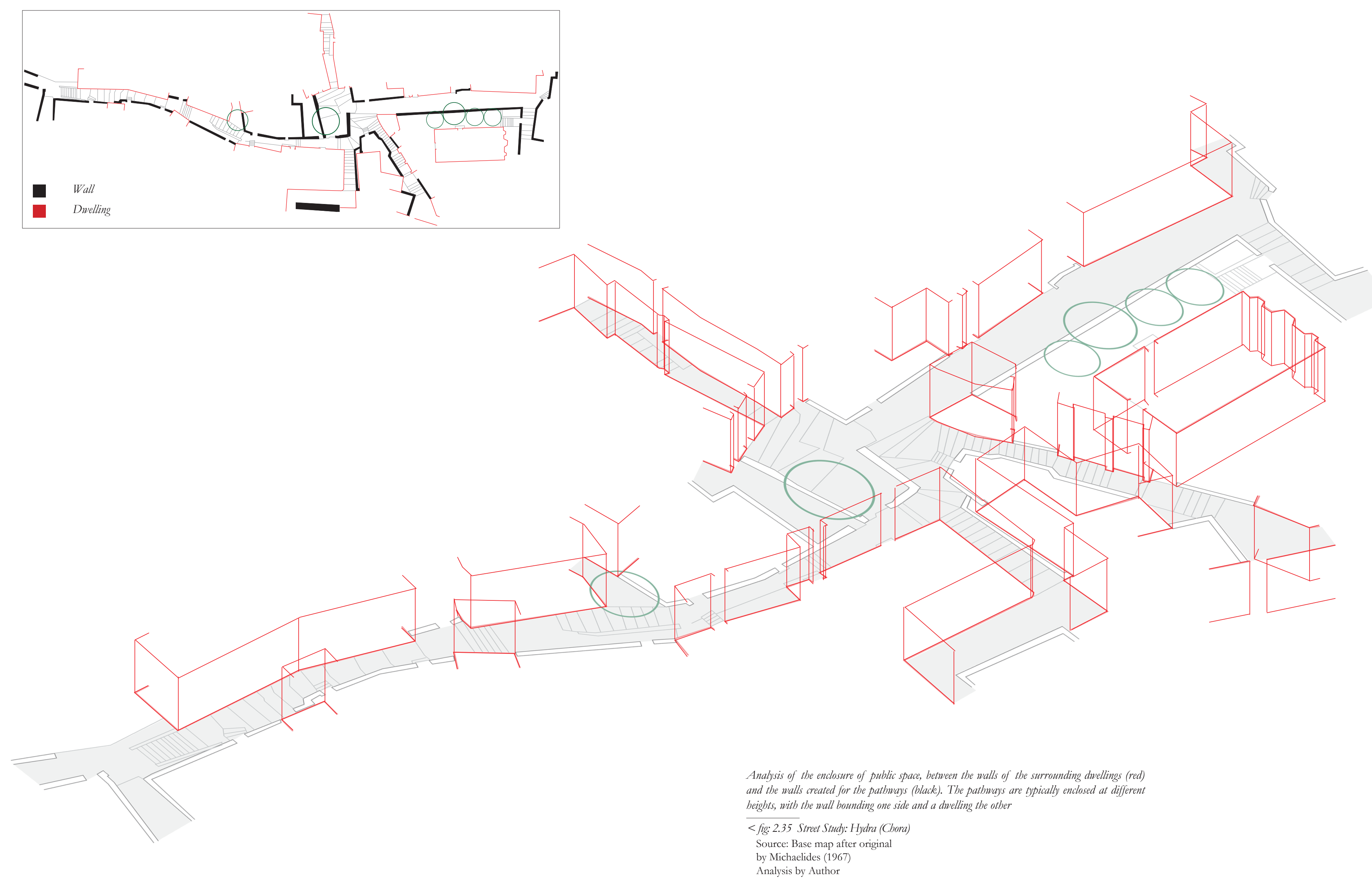




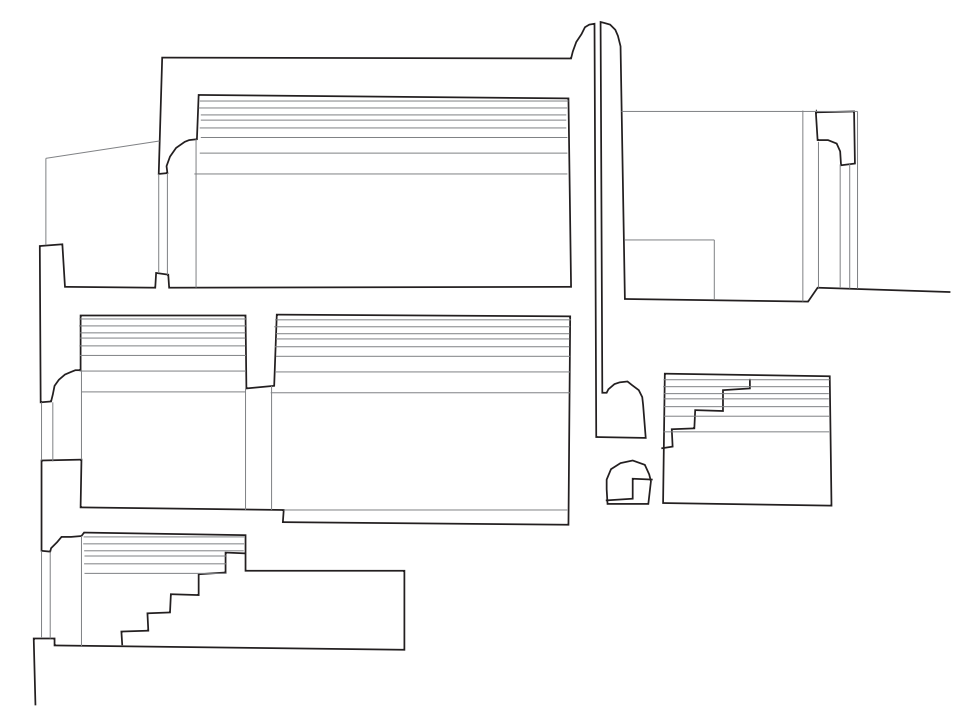

This section is tbrough a variation
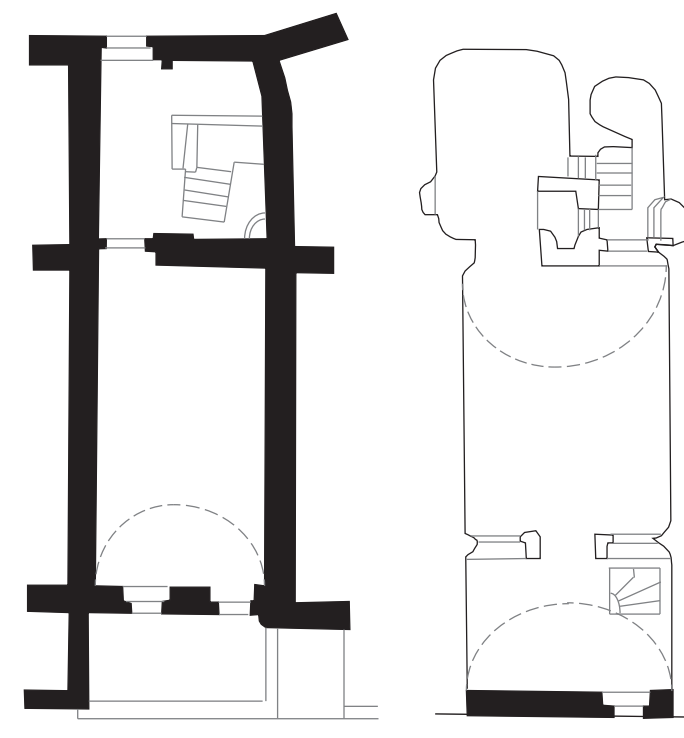

Above images after Kovatsi (1979) pg52 of a wide fronted monospito adapted to deal with the topography of the billside.

$<$ fig: 2.36 Building Section

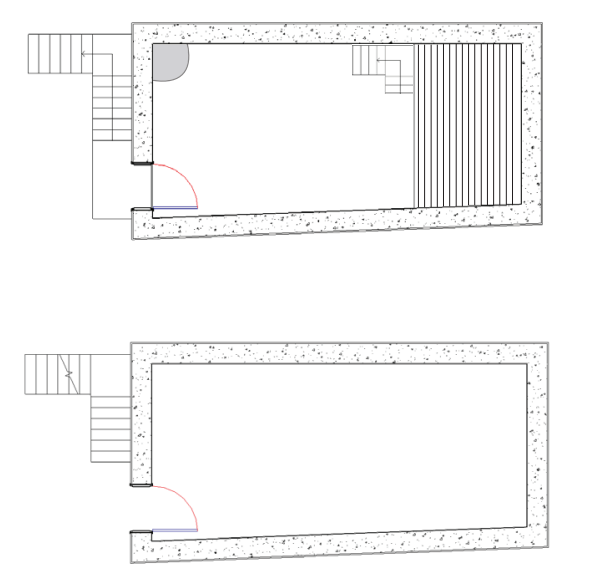

The most common typology of housing in Cycladic vernacular, the double storey narrow fronted monospito had living on the upper storey, storage on the bottom < fig: 2.38 Narrow Fronted Monospito

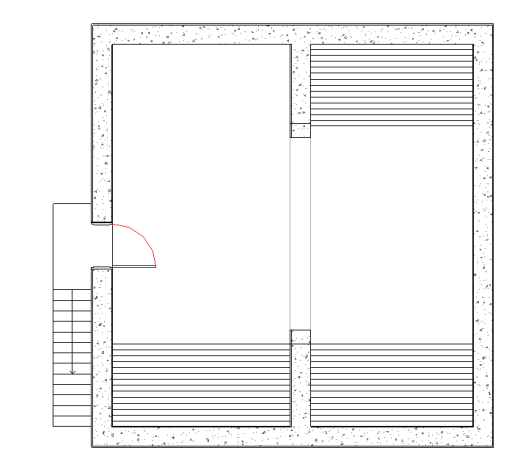
particular on Santorini, buildings were bollowed out of the billside and make use of more spose

<fo: 2.37 Troglodyte building $</ 2.2 .37$ Troglodyte building
tradition

The wide fronted monospito is less common, however

used beavily in sone

< fig: 2.39 Wide Fronted Monospito

ource: Author
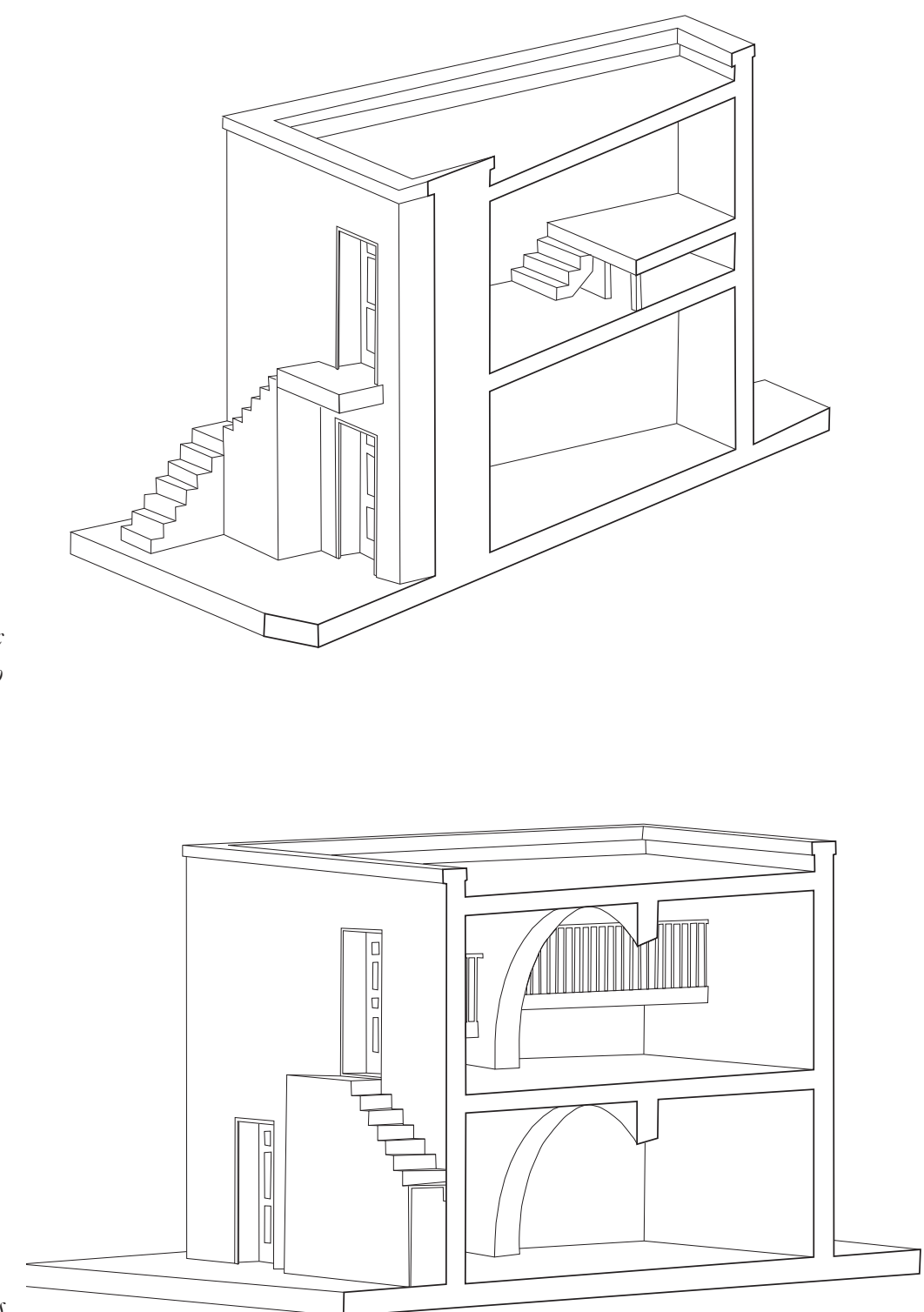

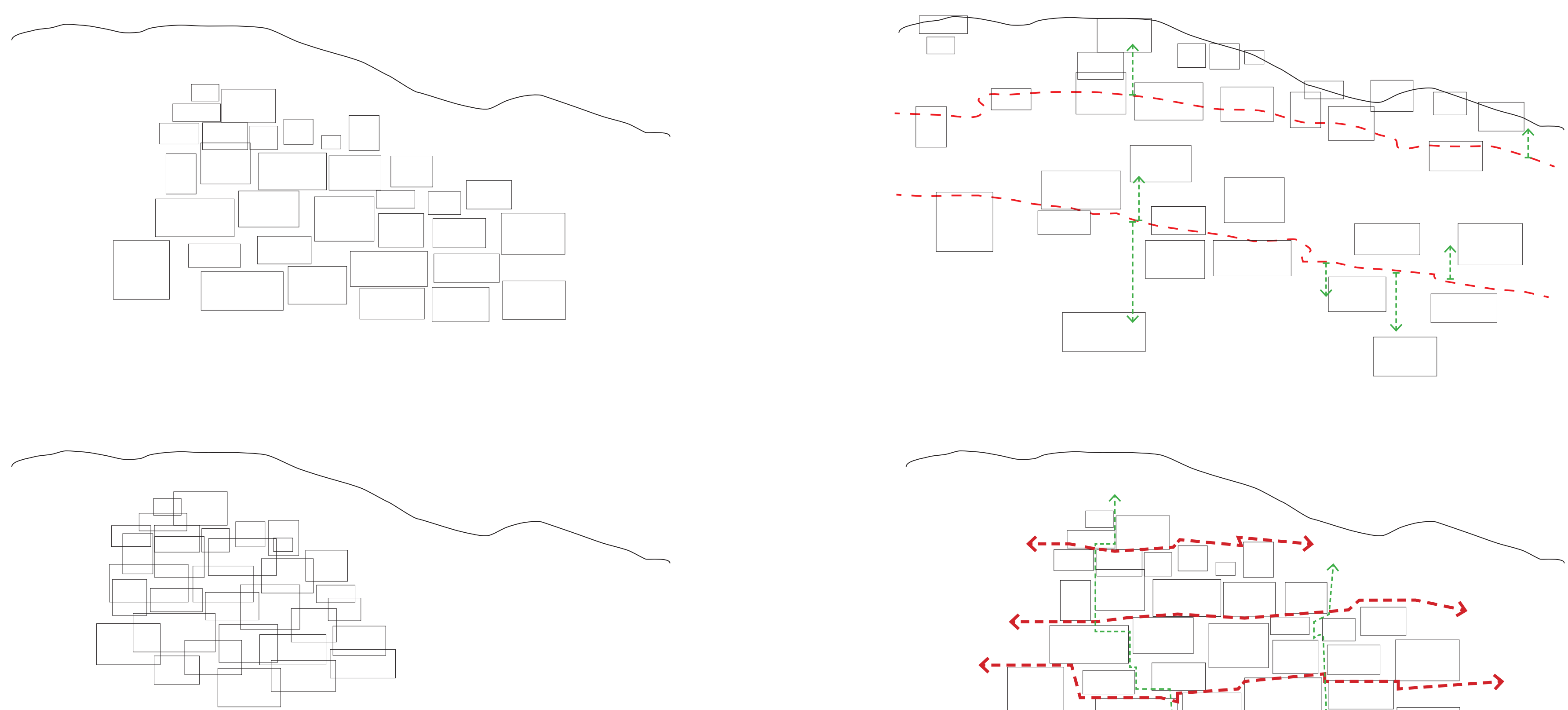

Comparing the above study, these

drawings condense the same building

drawings condense the same building

with a butting relationship (top) and a

overlapping relationship (bottom)

<fig: 2.41 Wellington billside study

Source: Author

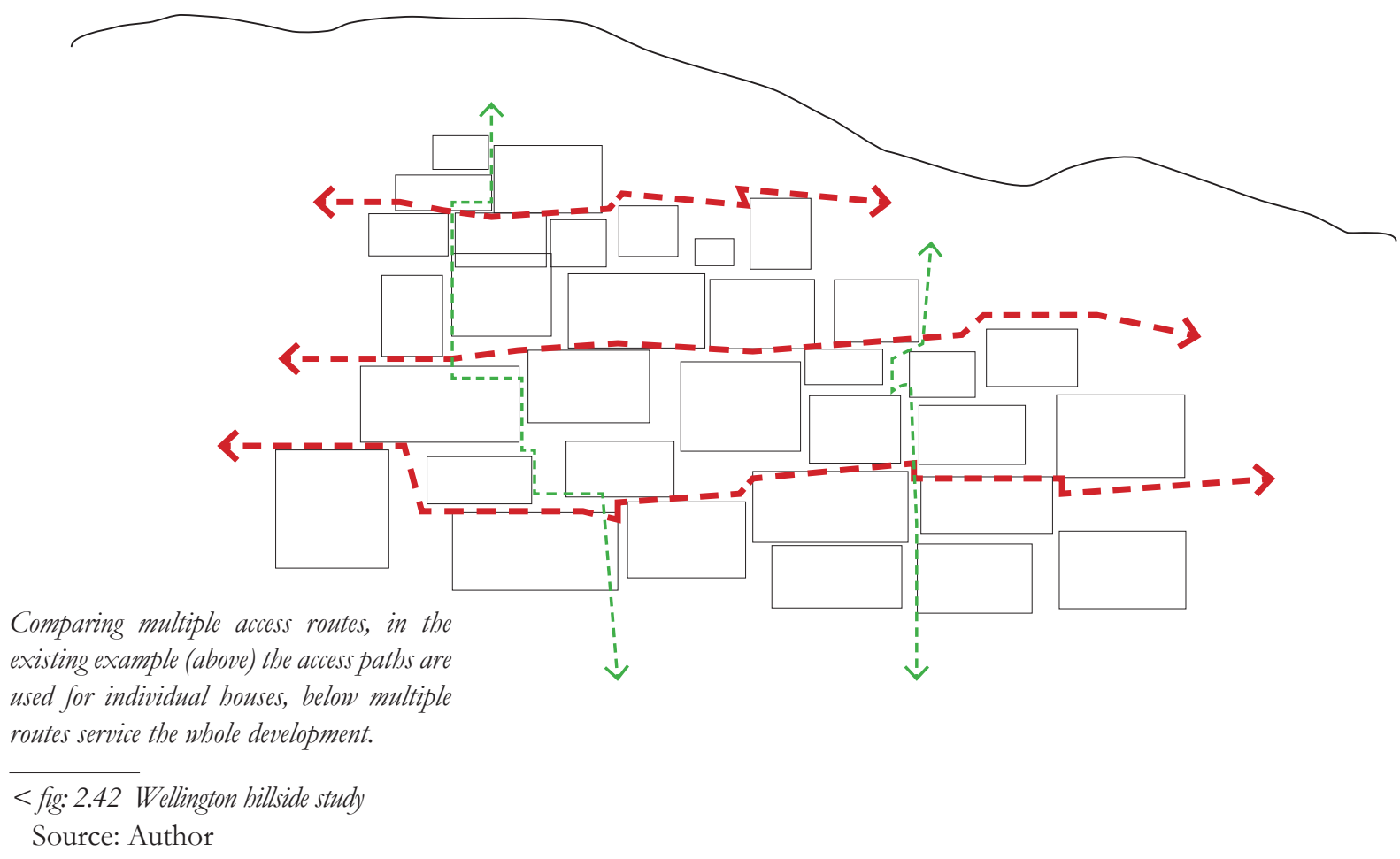




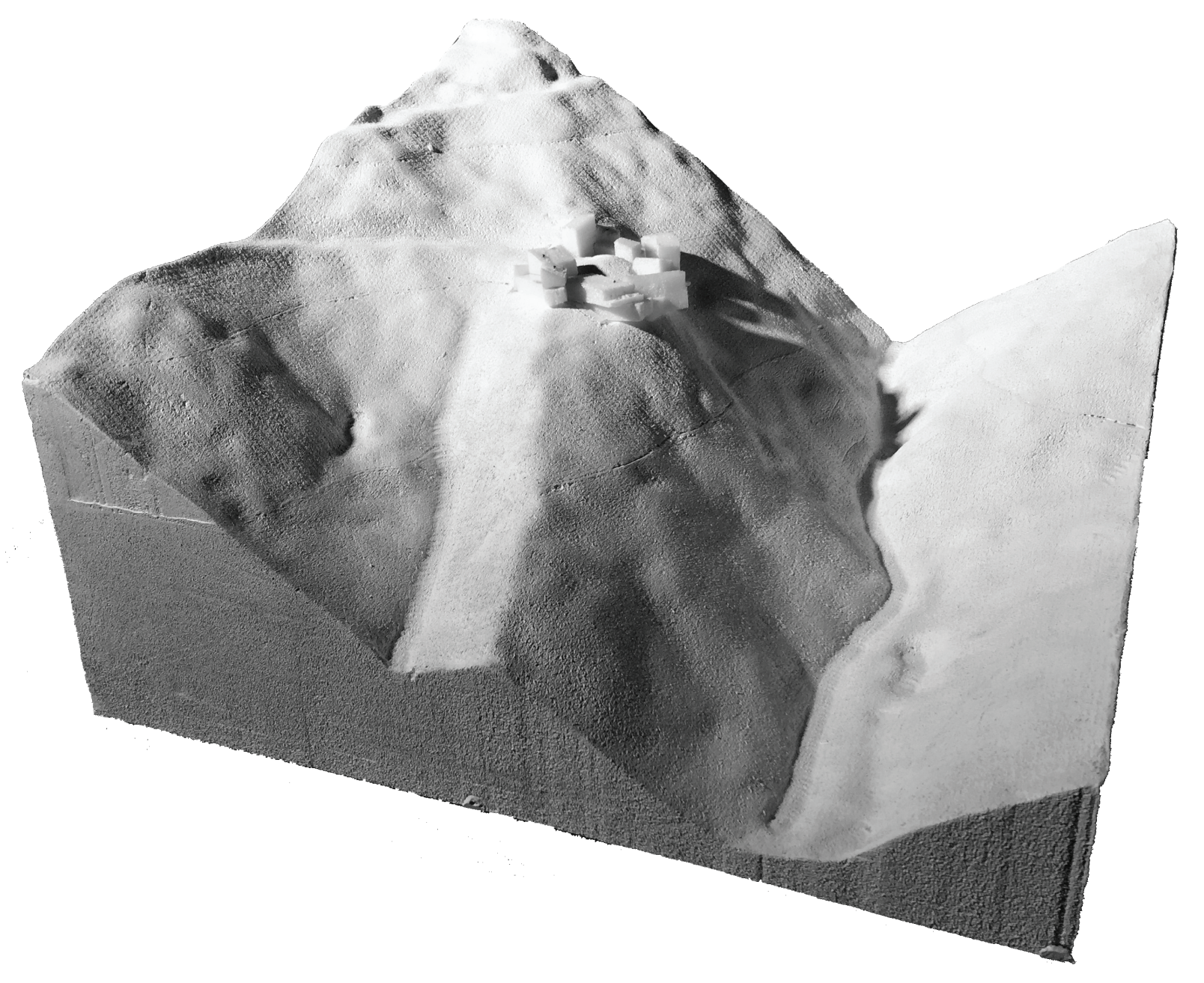

\section{CHAPTER 3: PILOT STUDY \\ Test Framework,
Pilot Study Methodology Preliminary Simulation results}




\section{$\left(\begin{array}{c}\text { PILOT STUDY } \\ \text { Initial design Simulation testing process }\end{array}\right)$}

AGGREGATIVE SIMULATION

Involvment from outside designers to design/plan

each new stage of development

DESIGN STAGE 1
[Initial dwelling design by the author as
the seed to development]

$\downarrow$

DESIGN ST AGE 2
[Second dwelling design by other autbor to
build on first stage]

$\downarrow$

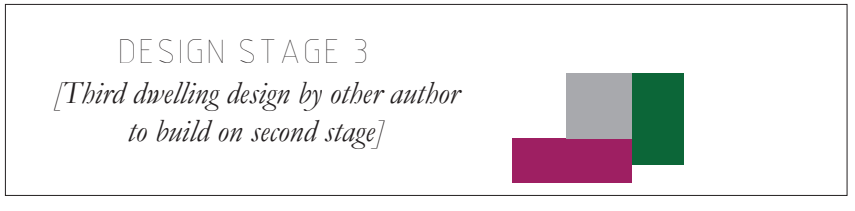

$\downarrow$

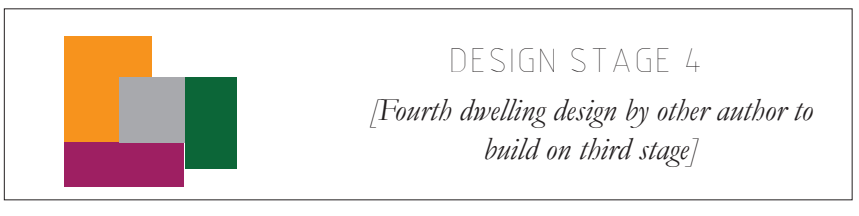

COMPREHENSIVE CONTROL

Single author control of the aggregative process, simulating

multiple authors by designing in discrete stages

\begin{tabular}{|l}
\hline $\begin{array}{l}\text { DESIGN STAGE } 1 \\
\text { [Initial dwelling design by the author as the } \\
\text { seed to develpment] }\end{array}$ \\
$\qquad \downarrow$
\end{tabular}
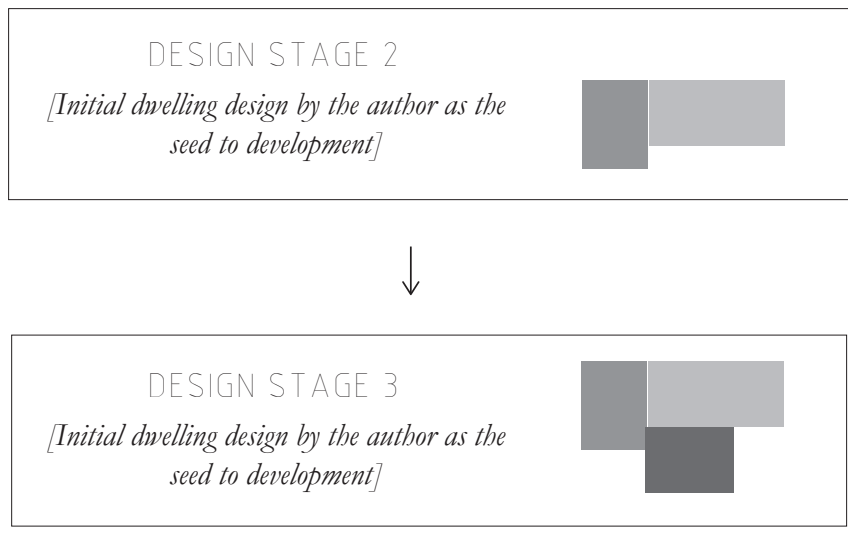

$\downarrow$

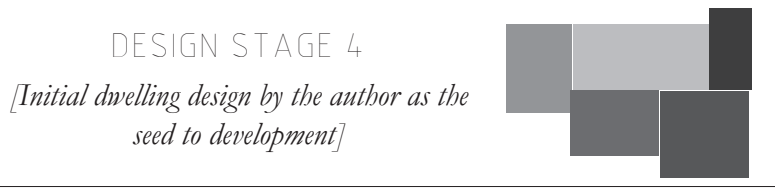

3.0

PILOT STUDY: TEST FRAMEWORK

\section{TEST FRAMEWORK}

The initial framework to run alongside the pilot study was

designed to be as open as possible, with little clarification of the rules or their intentions in order to analyse the interpretations and deviations of the participants. In this way the main tenets of the framework could be tested without the designers being limited by the specifics. As a test case the openness of the initial framework was also de-
signed to address the amount of time participants would give up during the process and as such is closely tied with the simulation methodology used. The limitations of this approach are discussed later in the conclusions chapter.

The main aspects of the framework that were tested during this phase of the project were mainly the ideas surrounding the aggregative build up, namely the land division, sharing of a common wall, and the access network/public open space. These together frame a development methodology that differs significantly from the western norm. The other more specific rules are developed further in subsequent stages following the results of this study.

\section{PILOT STUDY}

The pilot study phase of this project was intended to test both the initial tenets of the development framework and the initial idea of simulating an aggregative process. This process took part in two parallel simulations, the first of which was an aggregative approach, where solely outside designers were used to propagate a design. Each designer was given - in stages - the existing site and dwellings and asked to design a new dwelling based on the due to the common wall tule in the guidelines. This troclil are working with desion professionals from practice as well as final year thesis students took longer than expected and therefore precipitated a change in the simulation methodology going forward. In addition to this, several tendencies of the designers were identified that created undesirable conditions within the design. These included the use of stilt construction which alienates the dwell- 

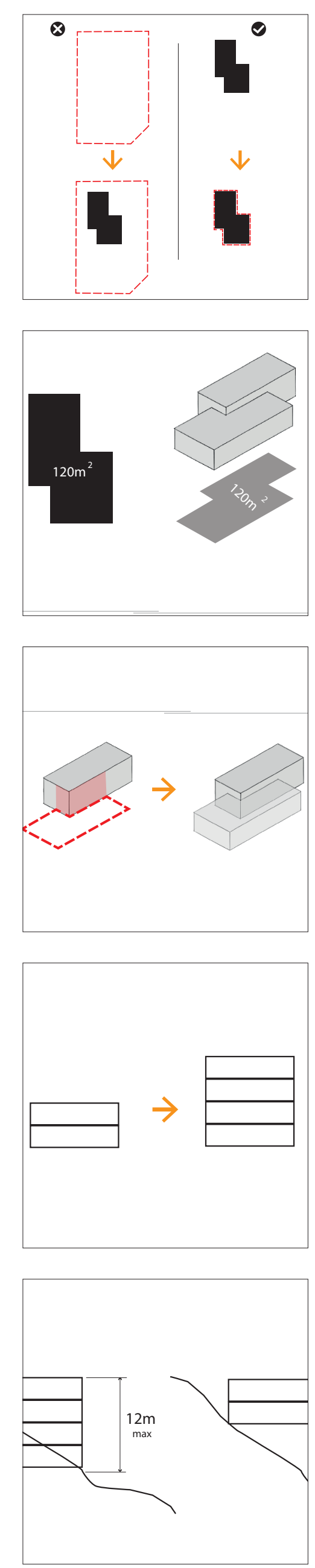

LAND OWNERSHIP

Land division follows a building concept,

rather than preceding it.

\section{BUILDING F0OTPRINT}

Each dwelling has maximum building footprint area of $120 \mathrm{~m} 2$

\section{PARTY WALL}

Dwelling must be based around existing party wall (unless good grounds for another site are made and accepted)

\section{HEIGHT RANGE}

All building to be between two and four storeys.

\section{MAX HEIGHT}

Maximum height from the ground at any given point of $12 \mathrm{~m}$

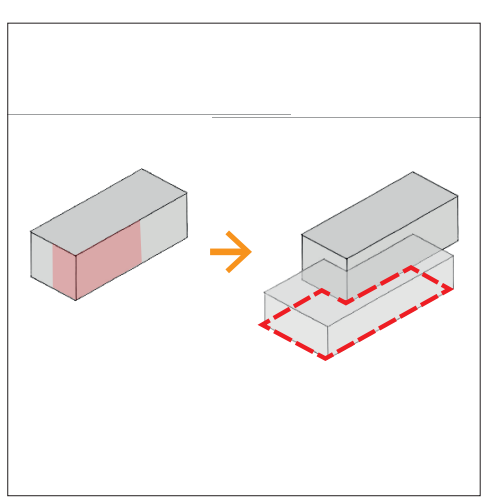

\section{PARTY WALL}

Each dwelling to allow for (at least) one common wall for future dwellings.

VIEW/DAYLIGHT ACCESS

Each new dwelling will, in principal, allow for sight lines and sun shading of other buildings, whether existing or future.
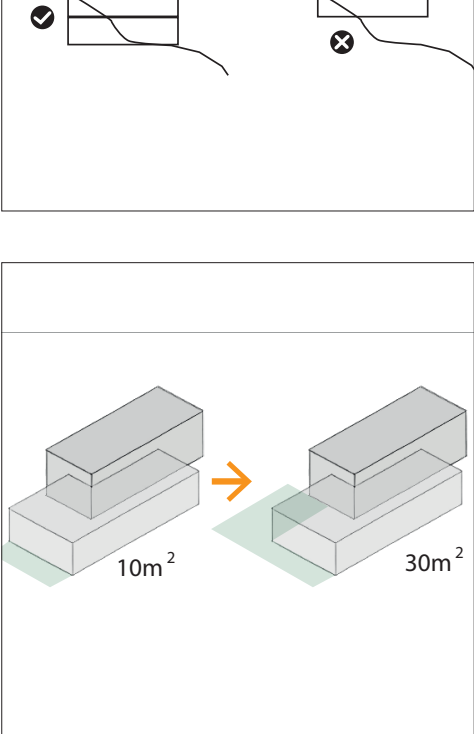

\section{OUTDOOR PRIVATE SPACE}

Each dwelling is to provide for between $10 \mathrm{~m} 2$ and $30 \mathrm{~m} 2$ of private outdoo space.

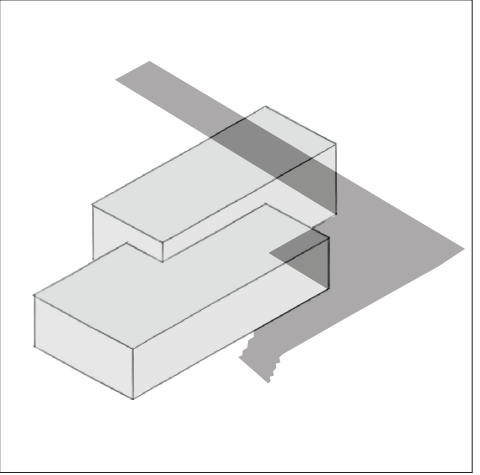

\section{ACCESS NETWORK}

Each dwelling is to continue/add to the communal pedestrian acces infrastructure, providing access to the new dwelling.

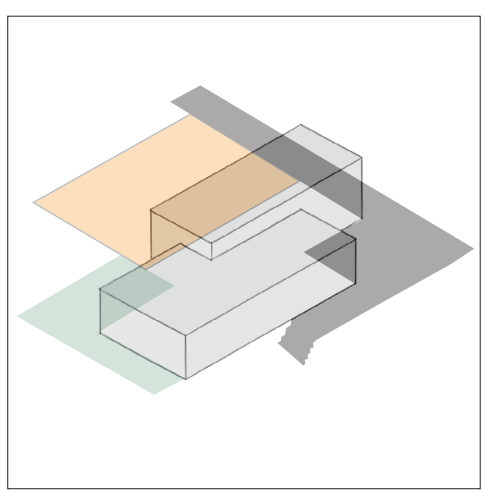

\section{PUBLIC OPEN SPACE}

Each dwelling will add a semi-public open space or add to an already existing open space adjacent to the new dwelling. 

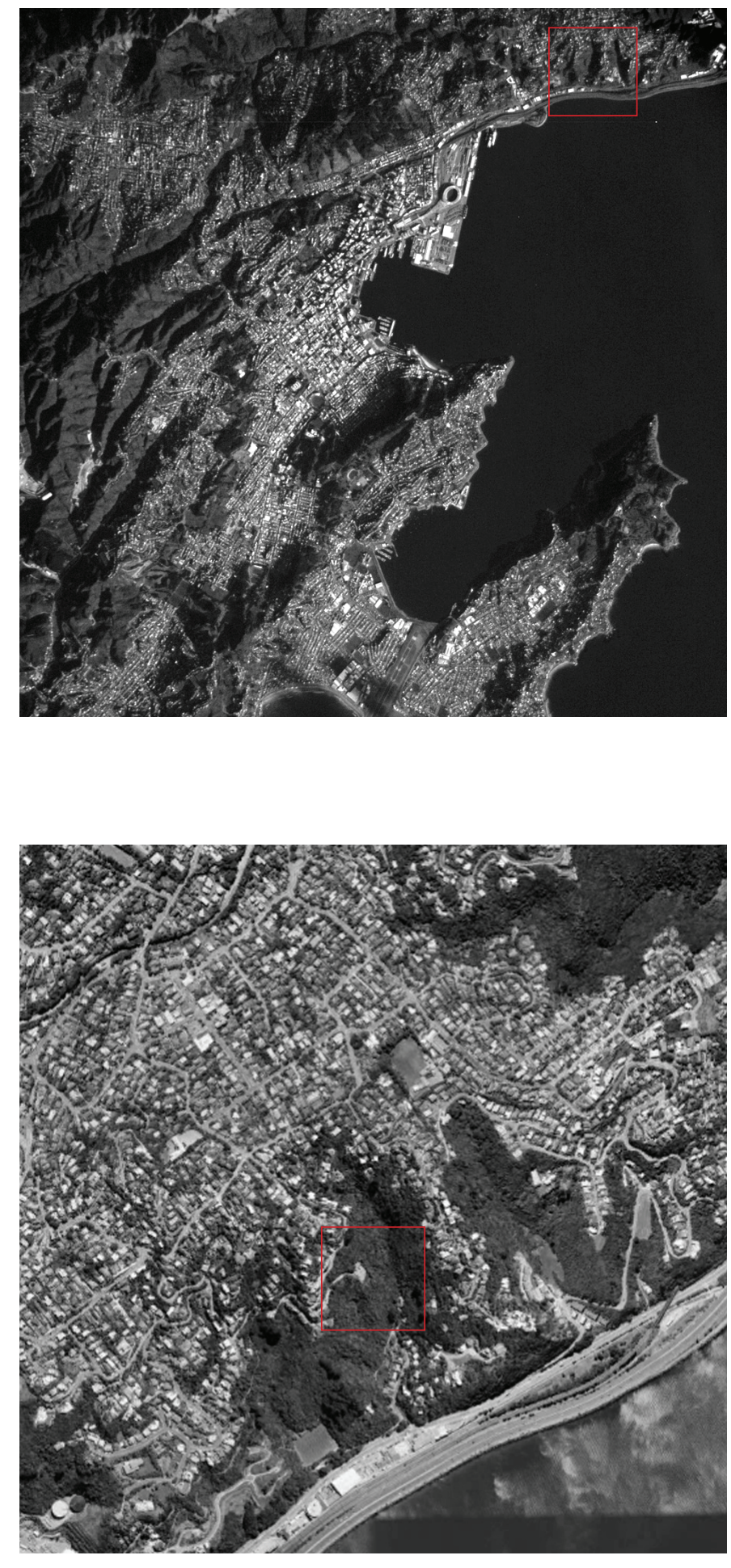

Around the Northern Suburbs

the site sits in Khandallah on a south facing billside with a vien

fig: 3.1 Wellington Satellite Imase Source: Image based on original

Zooming into the site further showing it relative to the rest of the suburb.

<fig: 3.2 Wellington Satellite Image Source: Image based on original
content from Google Earth (2009)

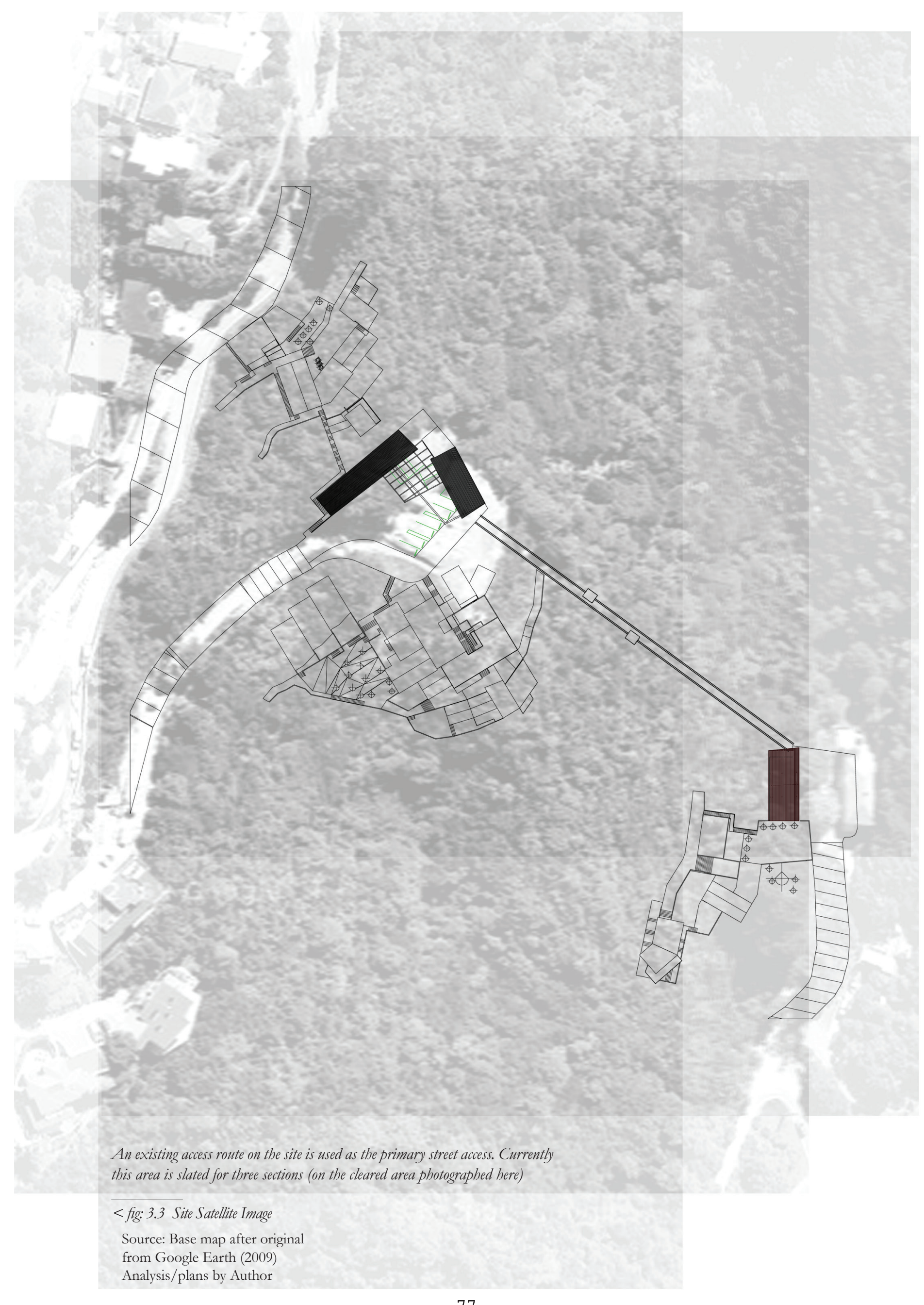




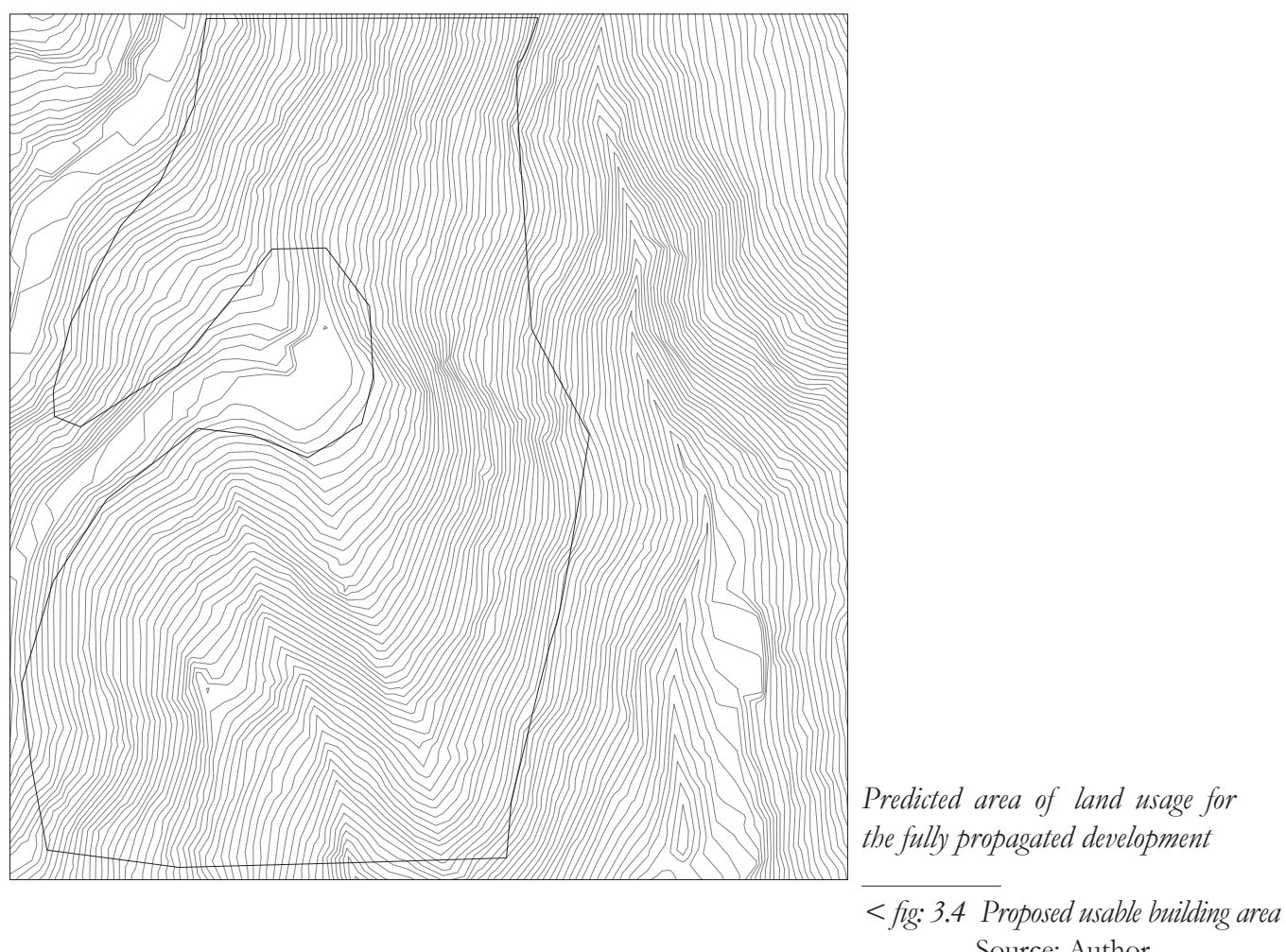

Source: Author

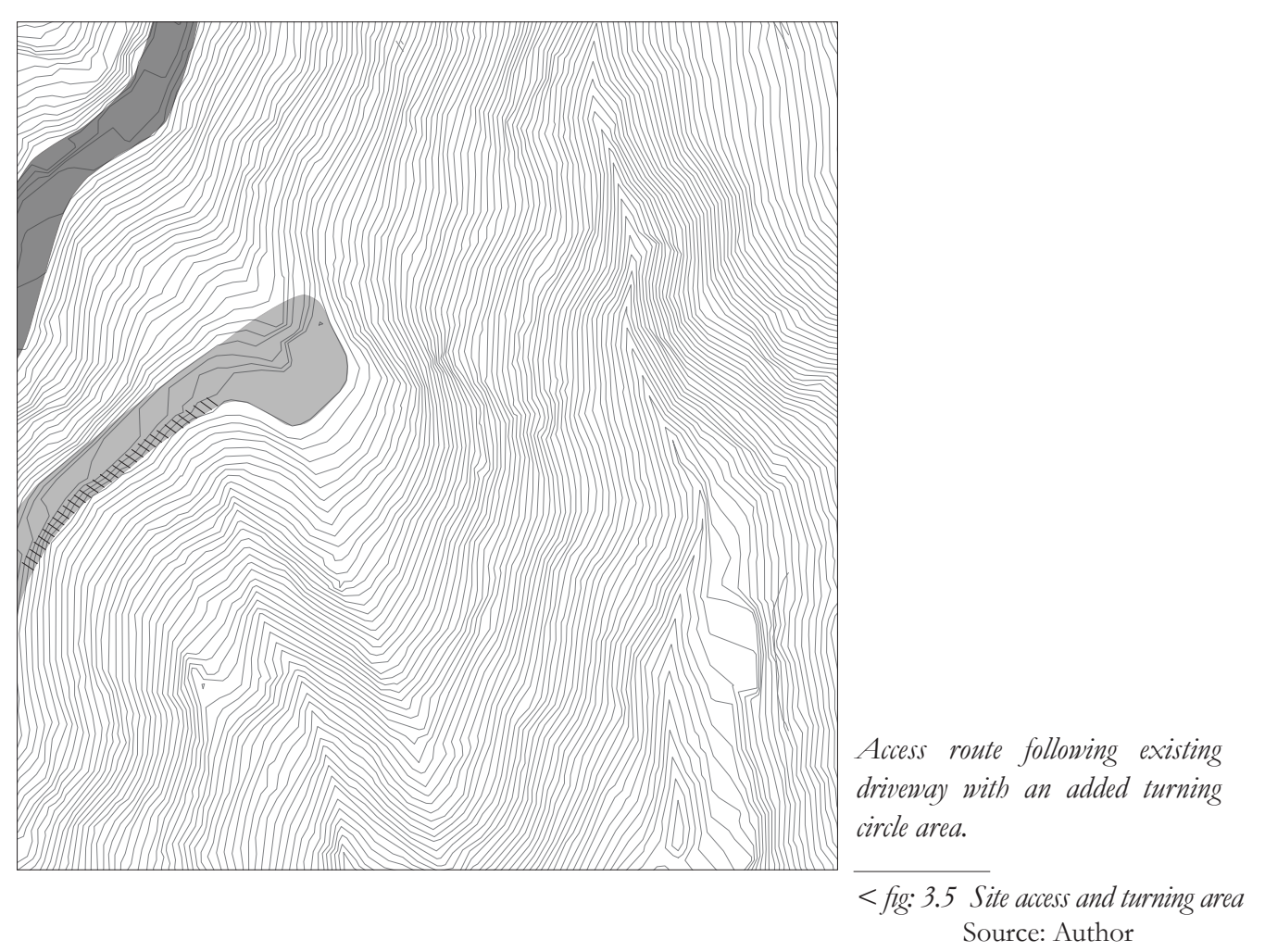

Superimposition of figure/ground of surrounding Khandallab neigbbourbood to compare site coverage.

< fig:3.6 Comparative Density: Kbandallab

Source: Author

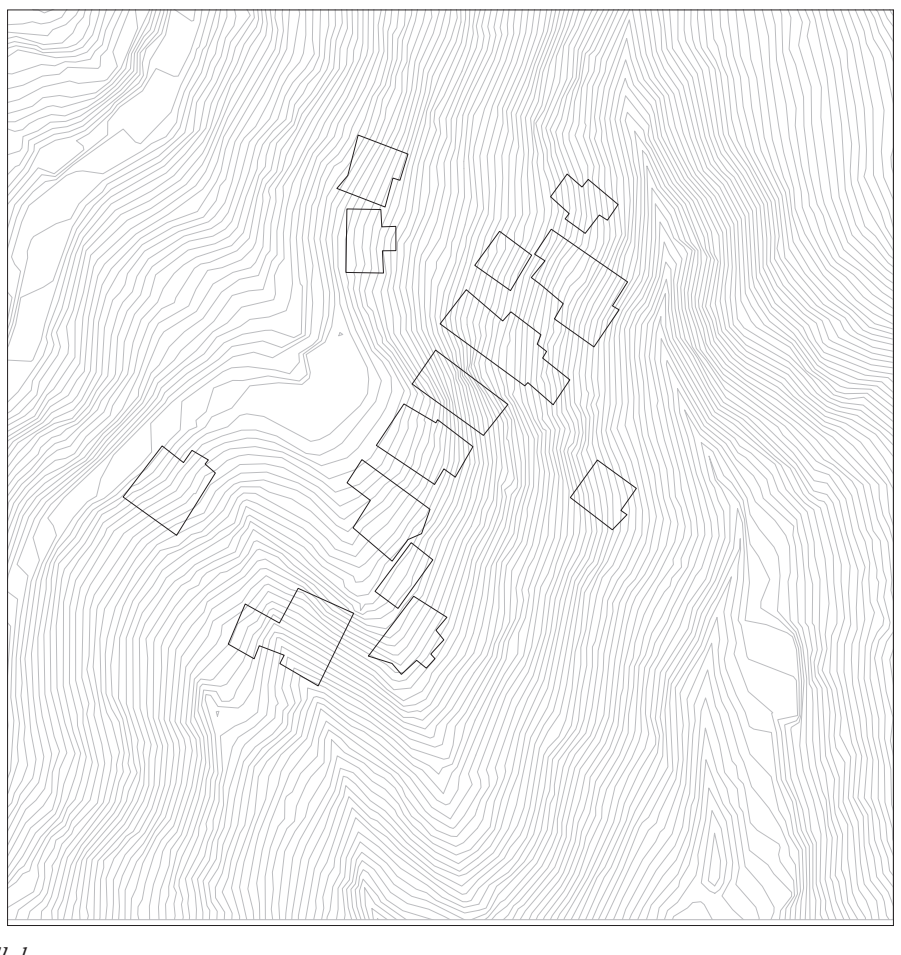

Figure/ground of dwellings from Hydra superimposed onto site.

$<$ fig: 3.7 Comparative Density: Hydra
Source: Author

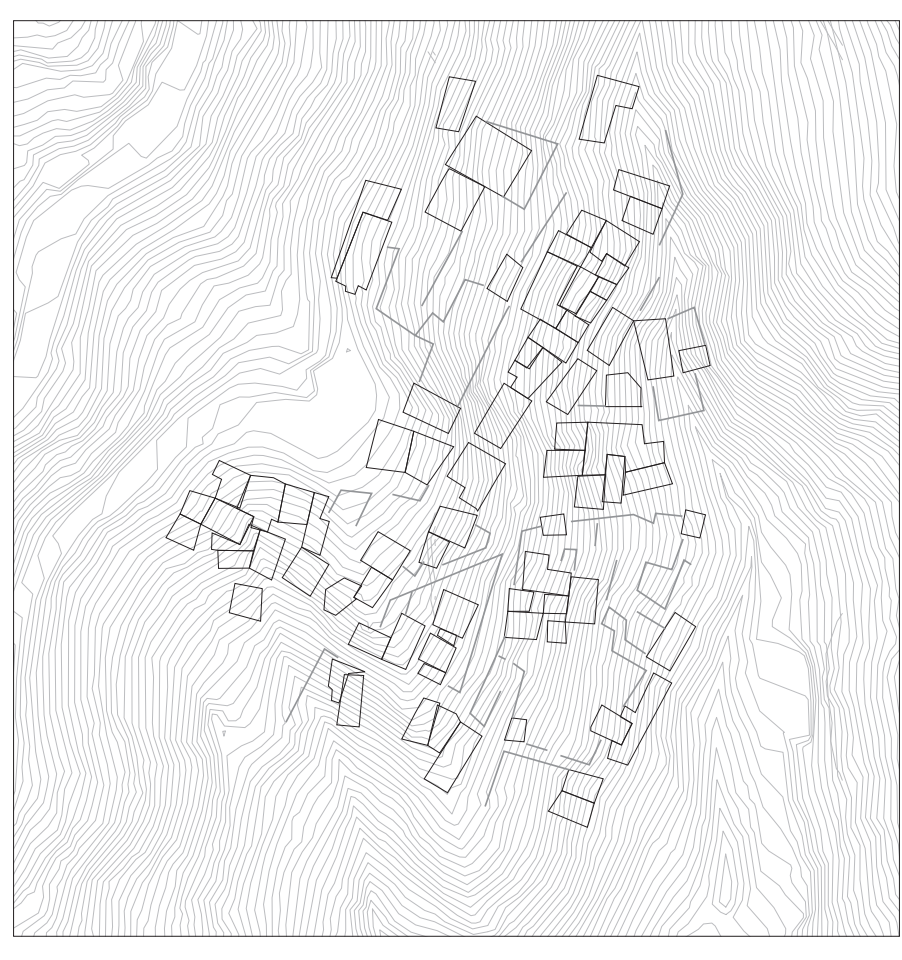



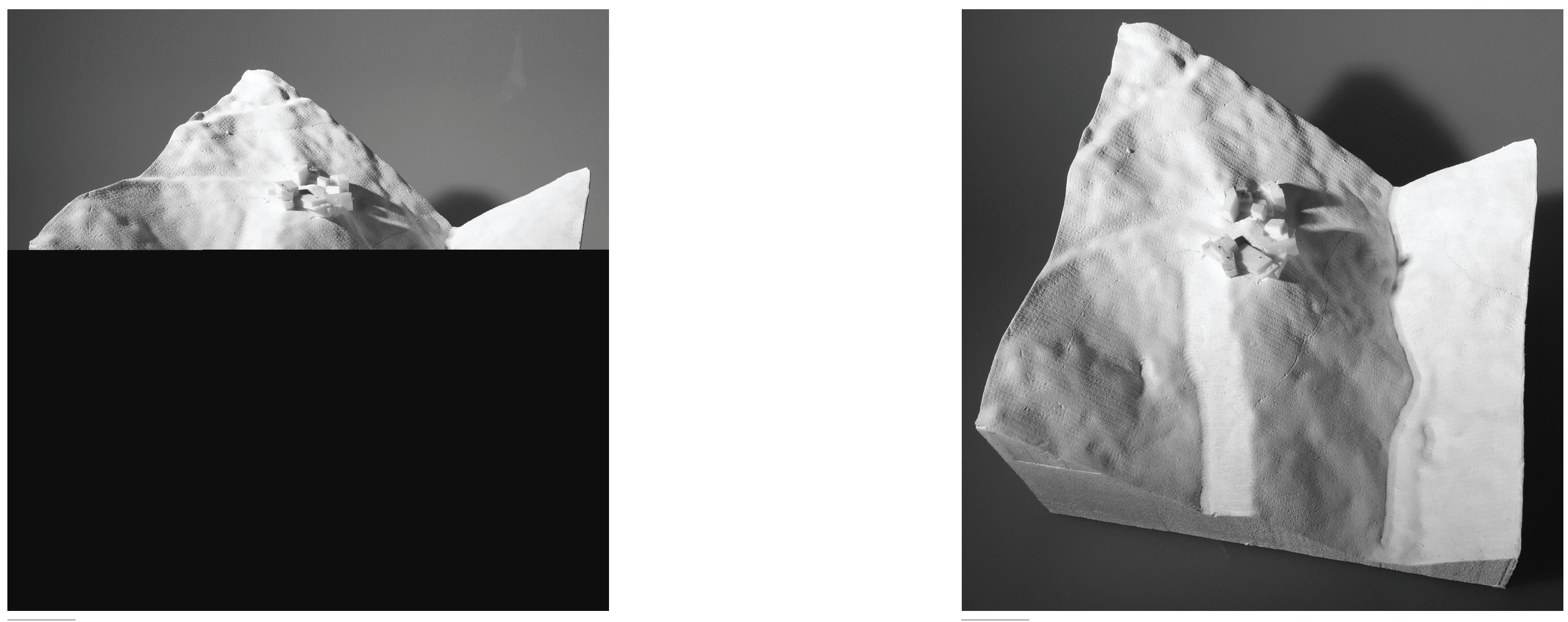

$<$ fig: 3.9 Physical model: This model was given to participants
to show massing relationship of dwellings and topography Source: Author 


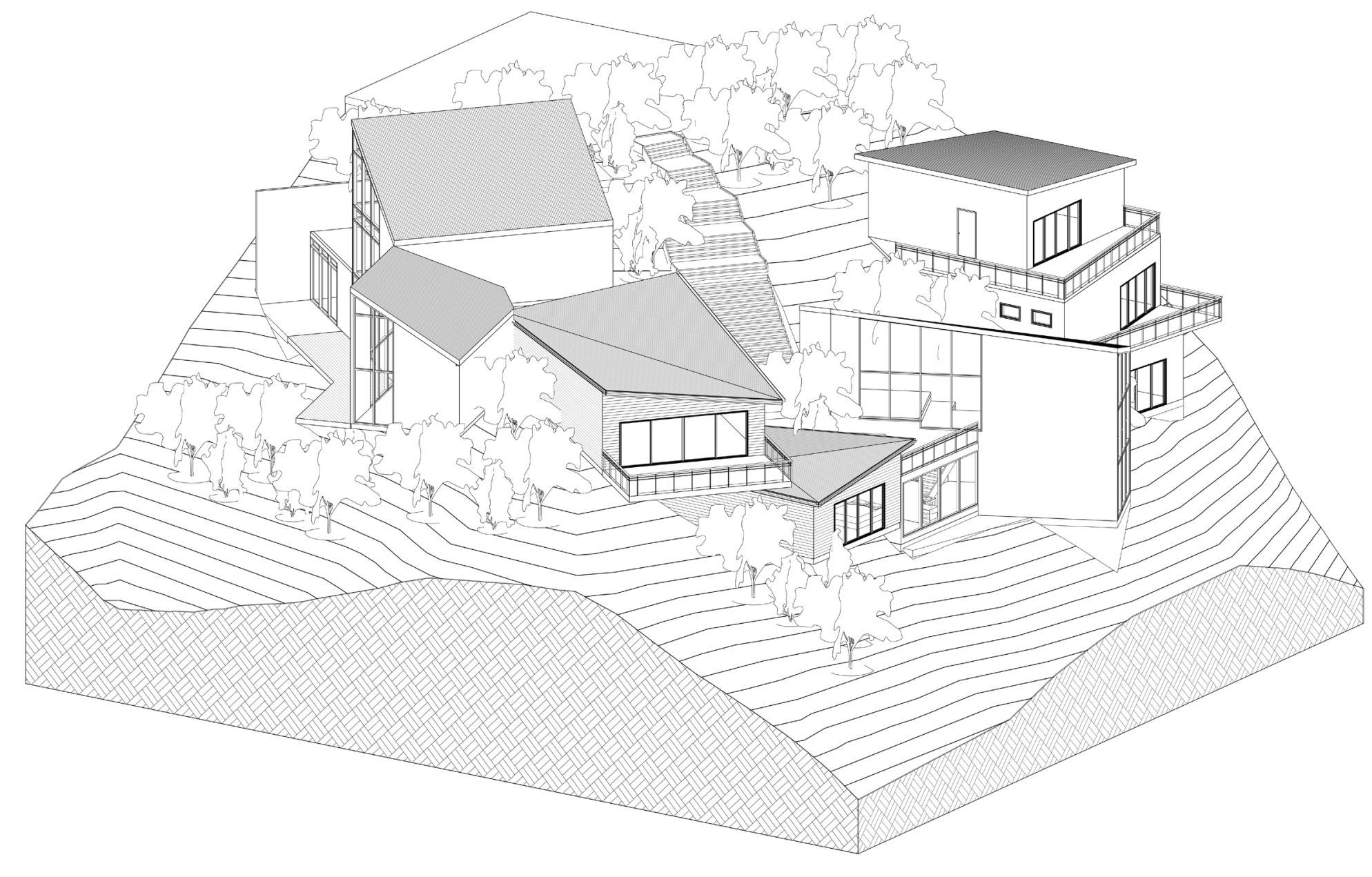

$<$ fig:3.10 Agregative study section

Source: Author
3.1

AGGREGATIVE SIMULATION STUDY

ings from the ground and limits the ability of further dwellings to propagate due to the left-over spaces underneath these dwellings. daylighting rules ${ }^{1}$ were identified by almost all of the participants. The other simulation was again done in stages, but was designed
by myself, the author. This allowed me to compare the idea of aggregation versus comprehensive control. This process was intended to simulate the same aggregative build-up, with each stage being designed in sequence rather than as a whole.

A limitation that became readily apparent is that with a single uthor this idea of designing in discrete stages does not have the same complexity and spontaneity of a multi author system. How In the guidelines and produced a much less dense result that was almost completely missing any form of shared public space in the access infrastructure. The final result here was a much denser development with much better use of public open space. As shown impact on the hills

1 The rules surrounding privacy, view and daylighting for this were little more than "try to be nice" and lacked any form of real or technical control. 

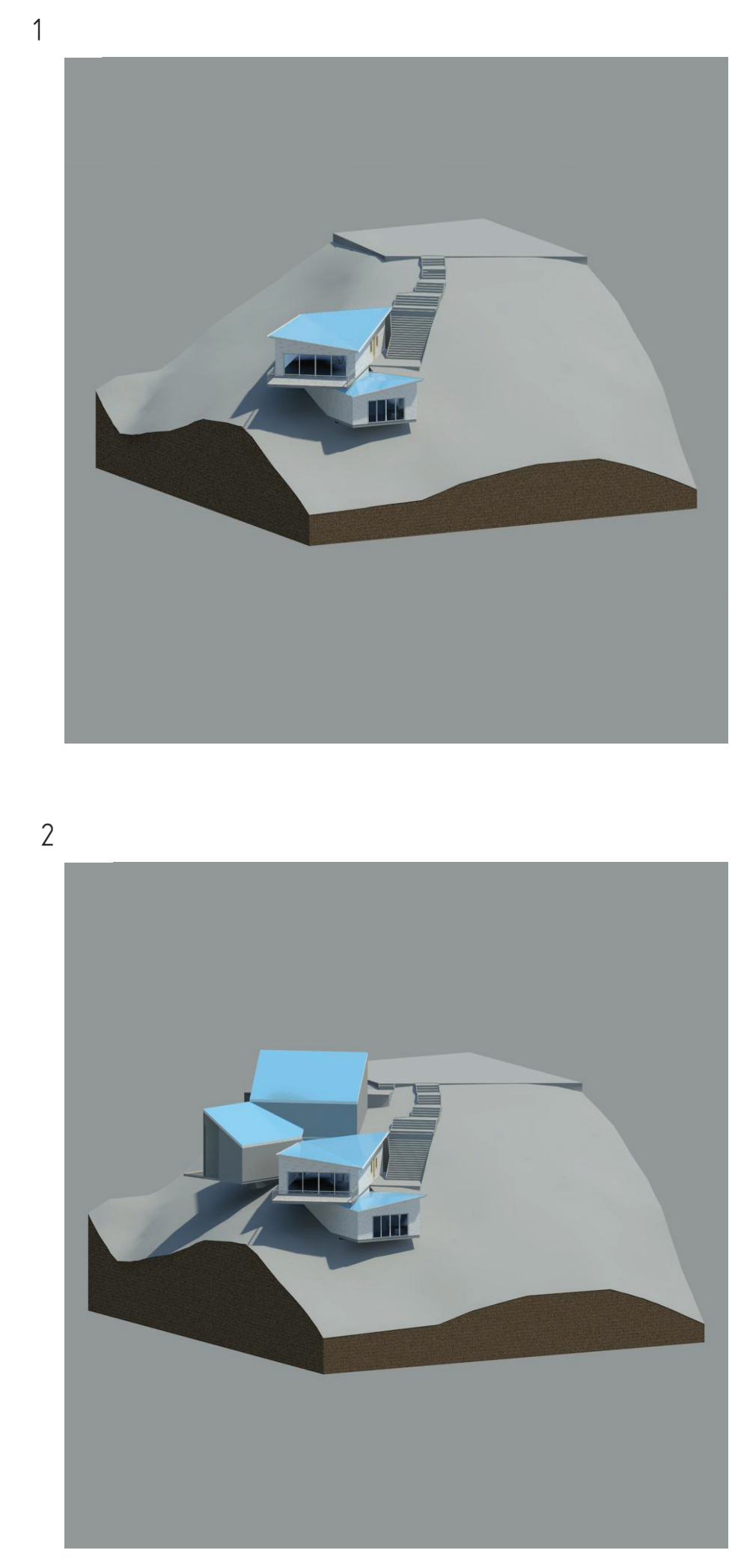
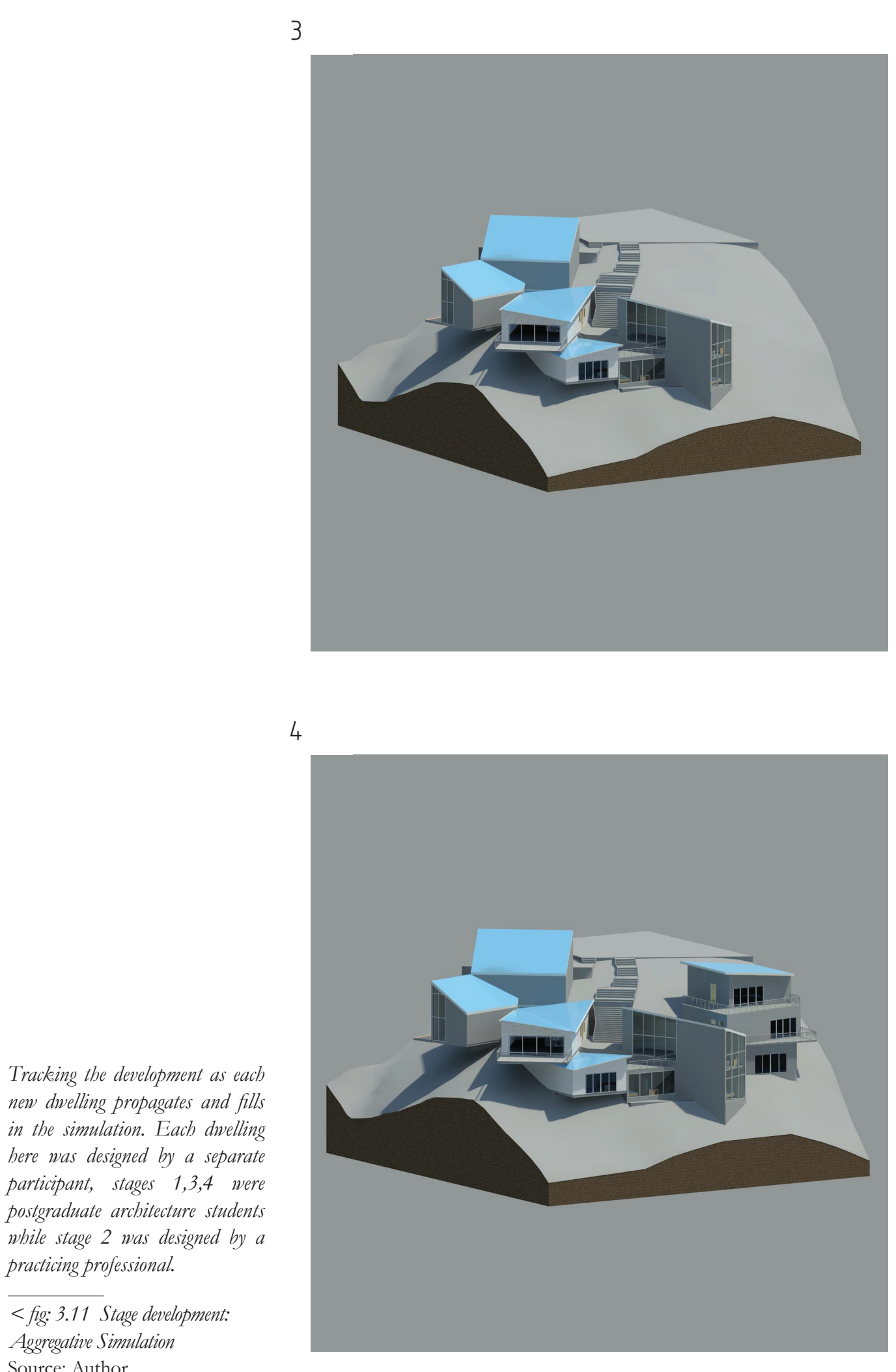

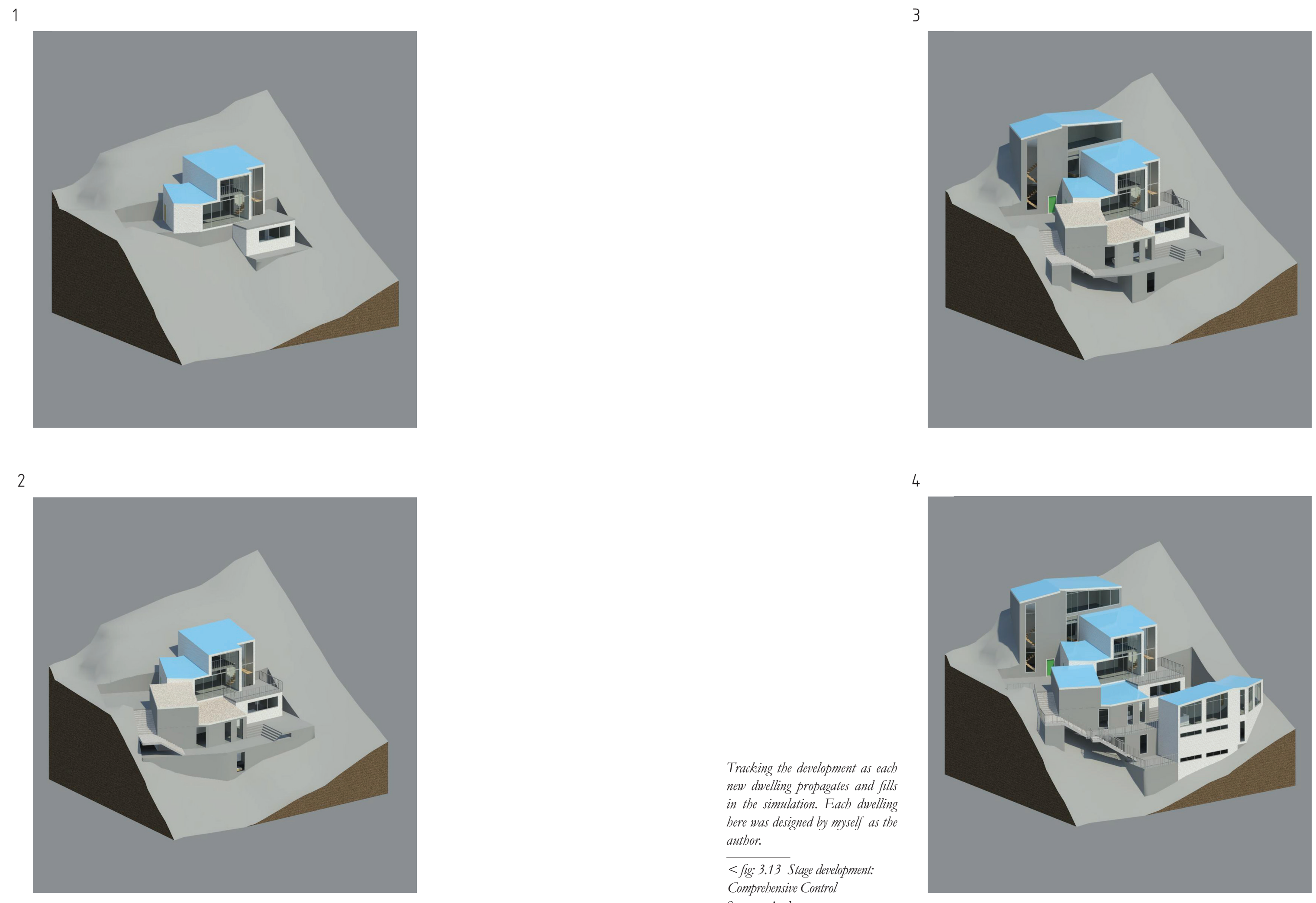

Tracking the development as each in the simulation. Each dwelling bere was designed by myself as the $\frac{\text { author. }}{<\text { fig: } 3.13 \text { Stage development }}$ Comprebensive Control Source: Author

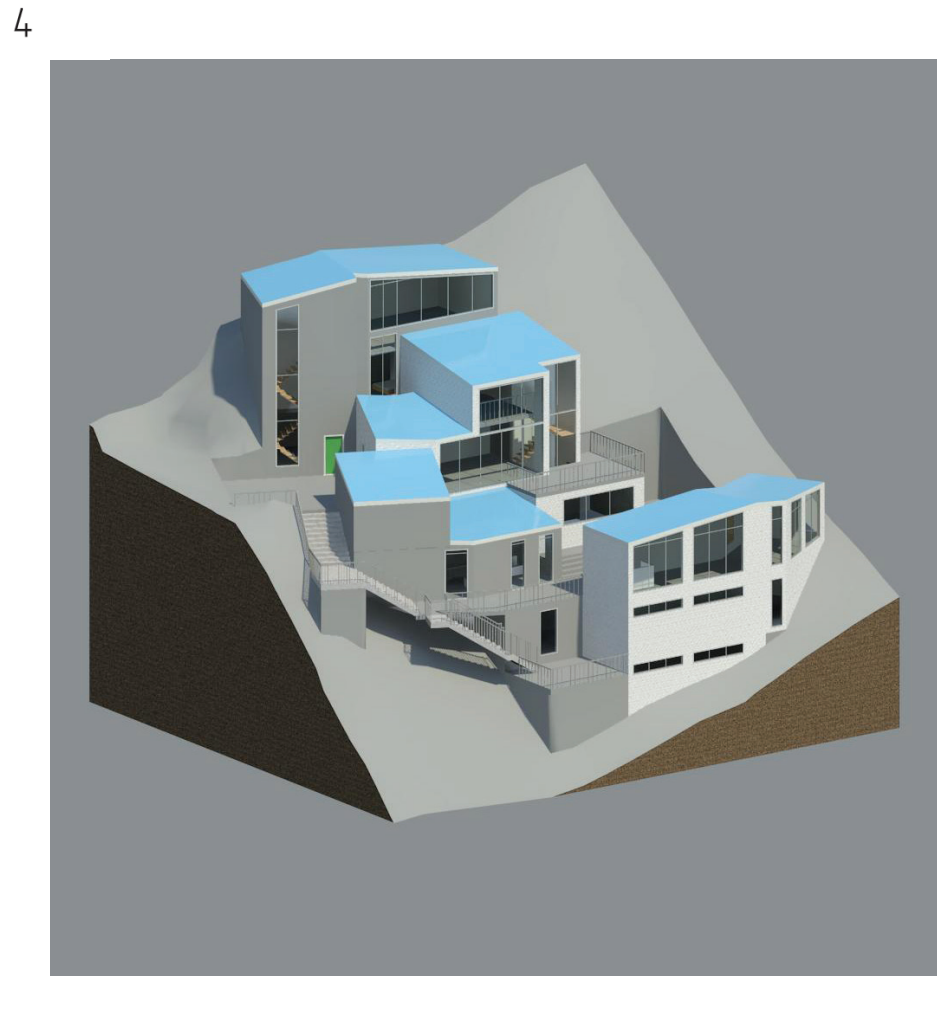


AGGREGATIVE STUDY

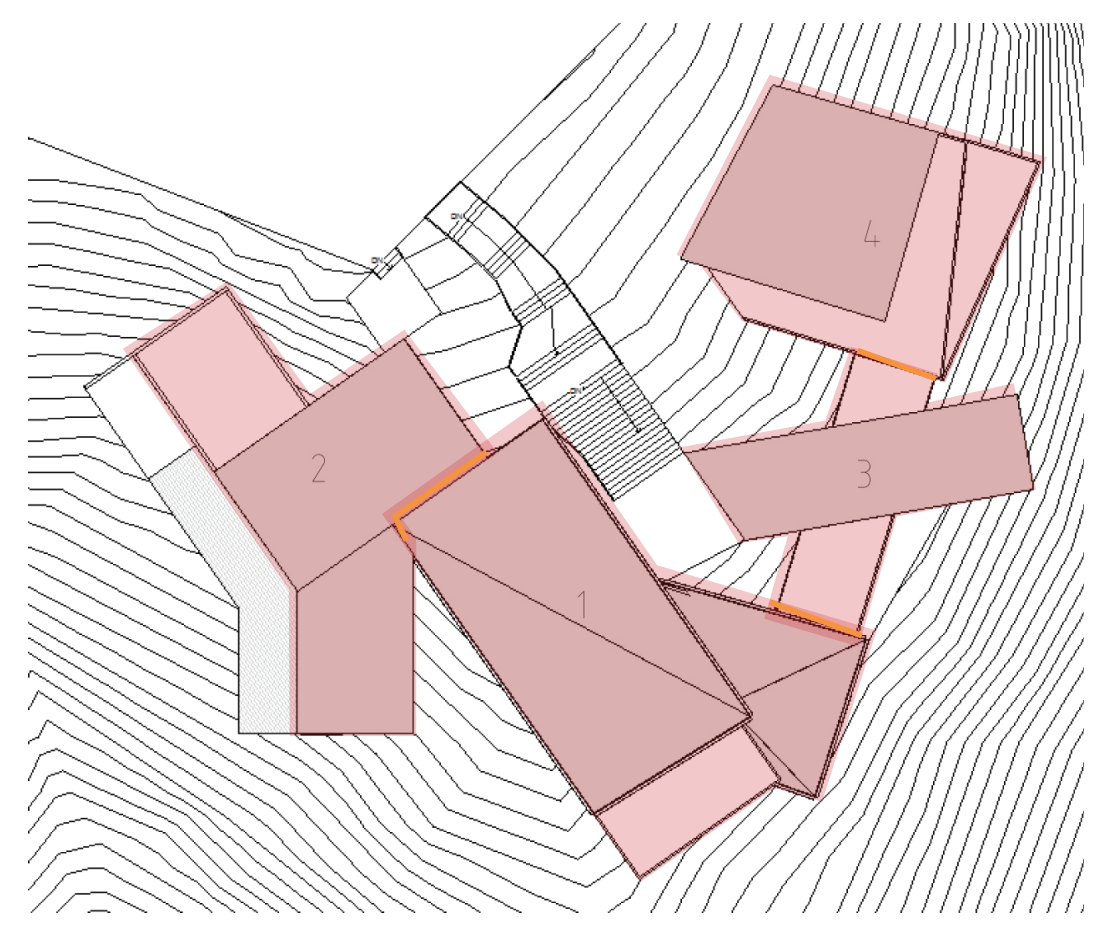

Dwelling Outline

Shared (party) Wall

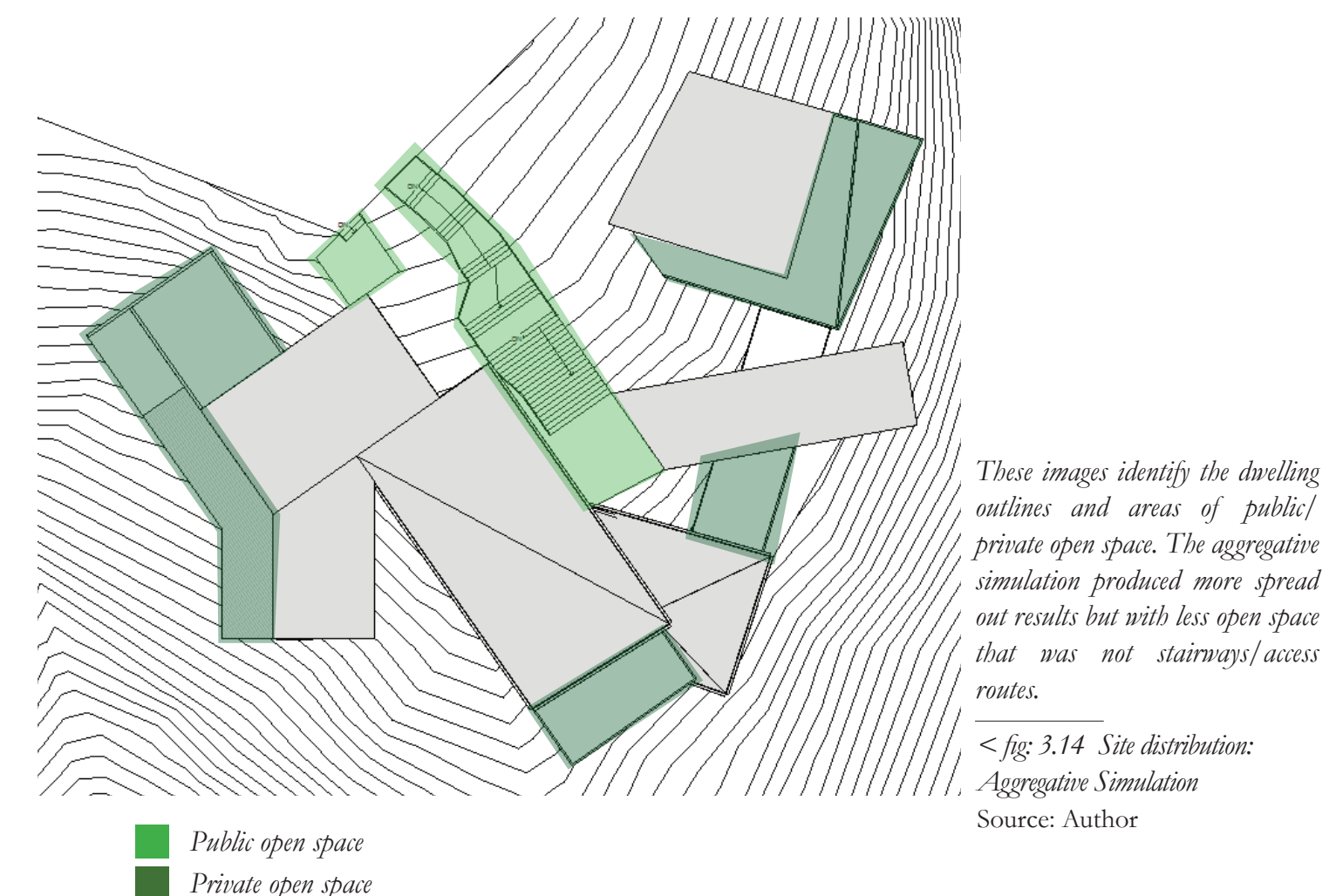

COMPREHENSIVE CONTROL STUDY
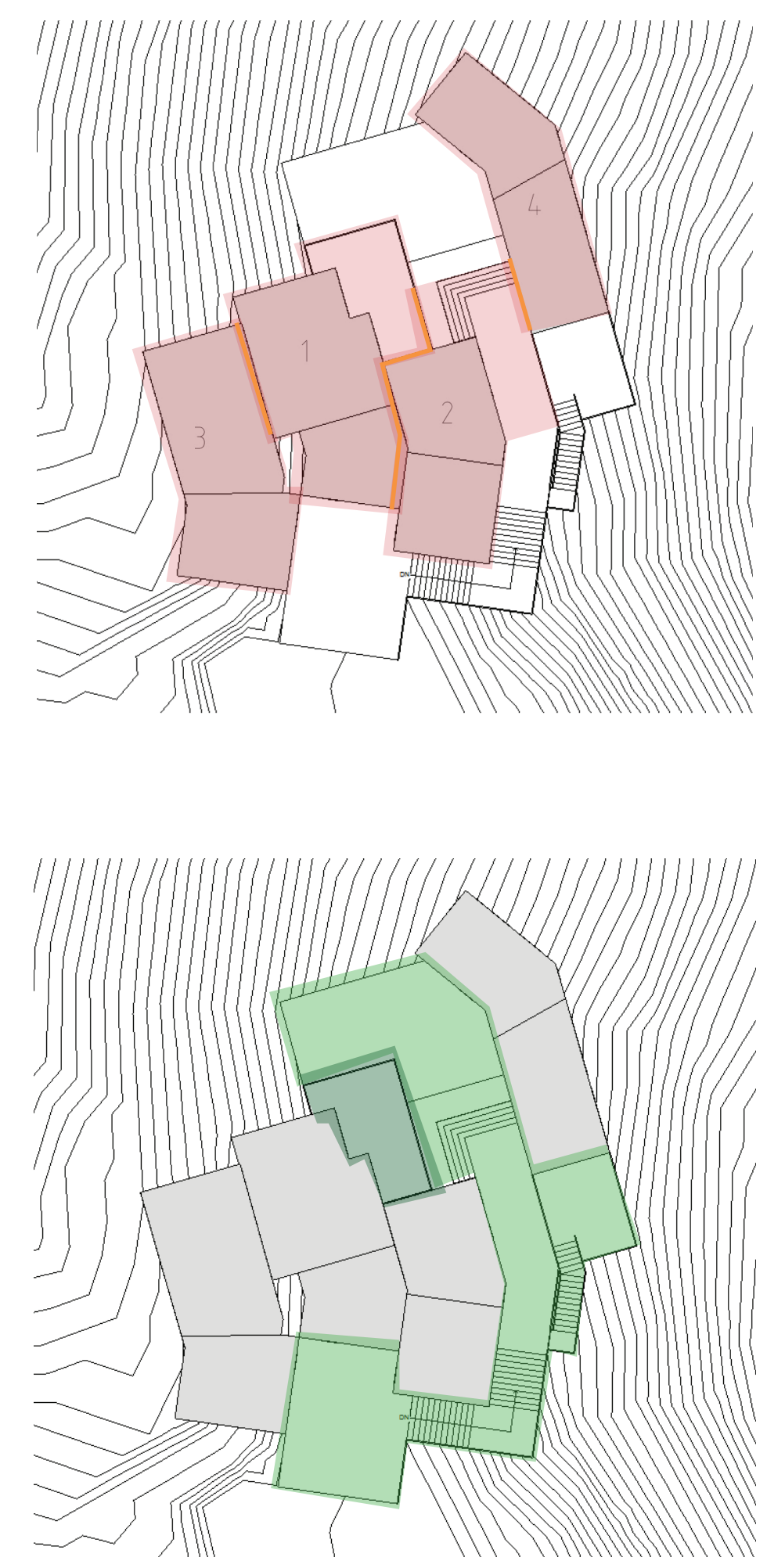
AGGREGATIVE STUDY
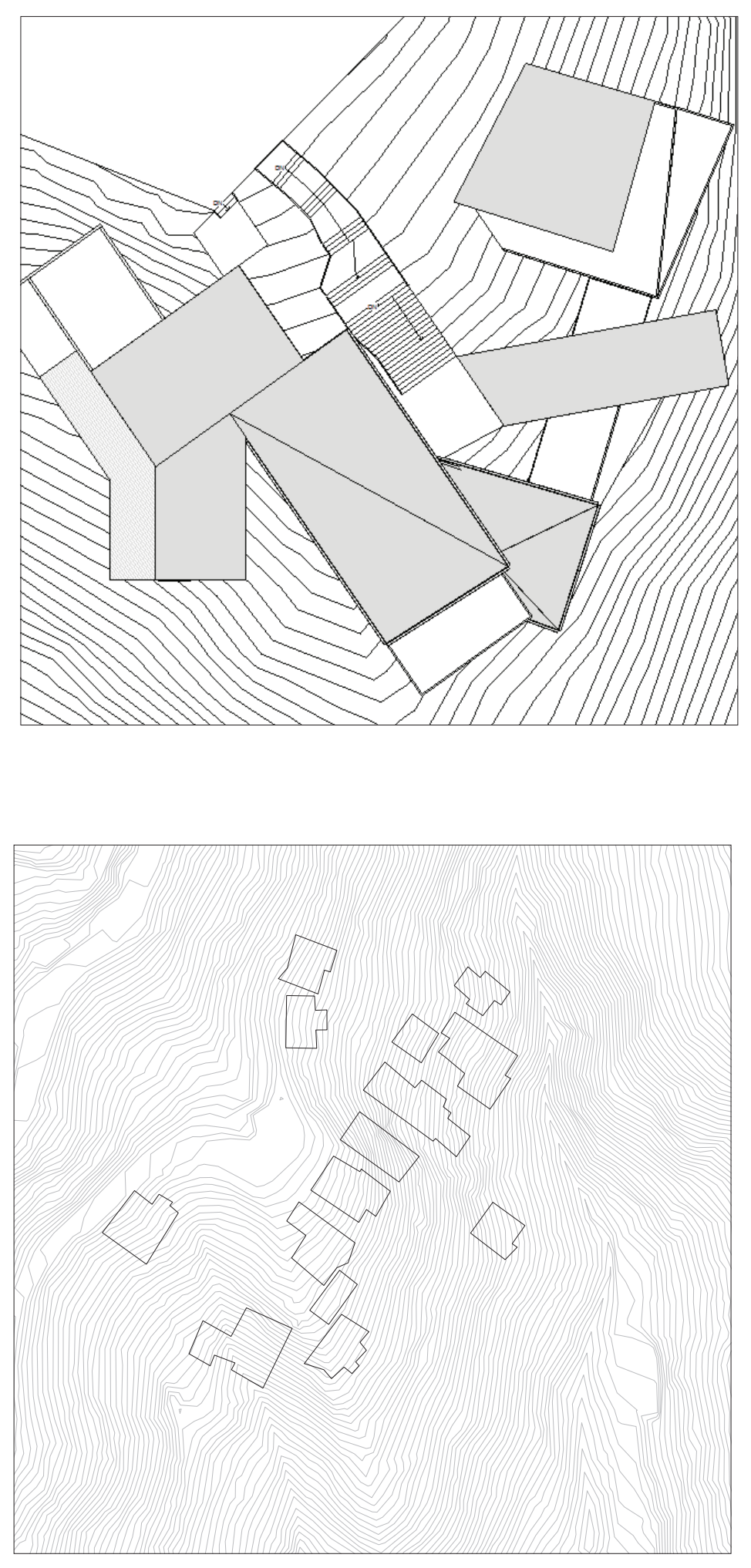

Another look at the figurel ground distribution of the aggregative simmaicon of comparison to surrounding Khandallah suburb. < fig: 3.16 Site Coverage: Agrergative Simulation
Source: Author
This image compares the comprebensive control simulation to an existing Cycladic village. $<$ fig: 3.17 Site Coverage. Source: Author
COMPREHENSIVE CONTROL STUDY
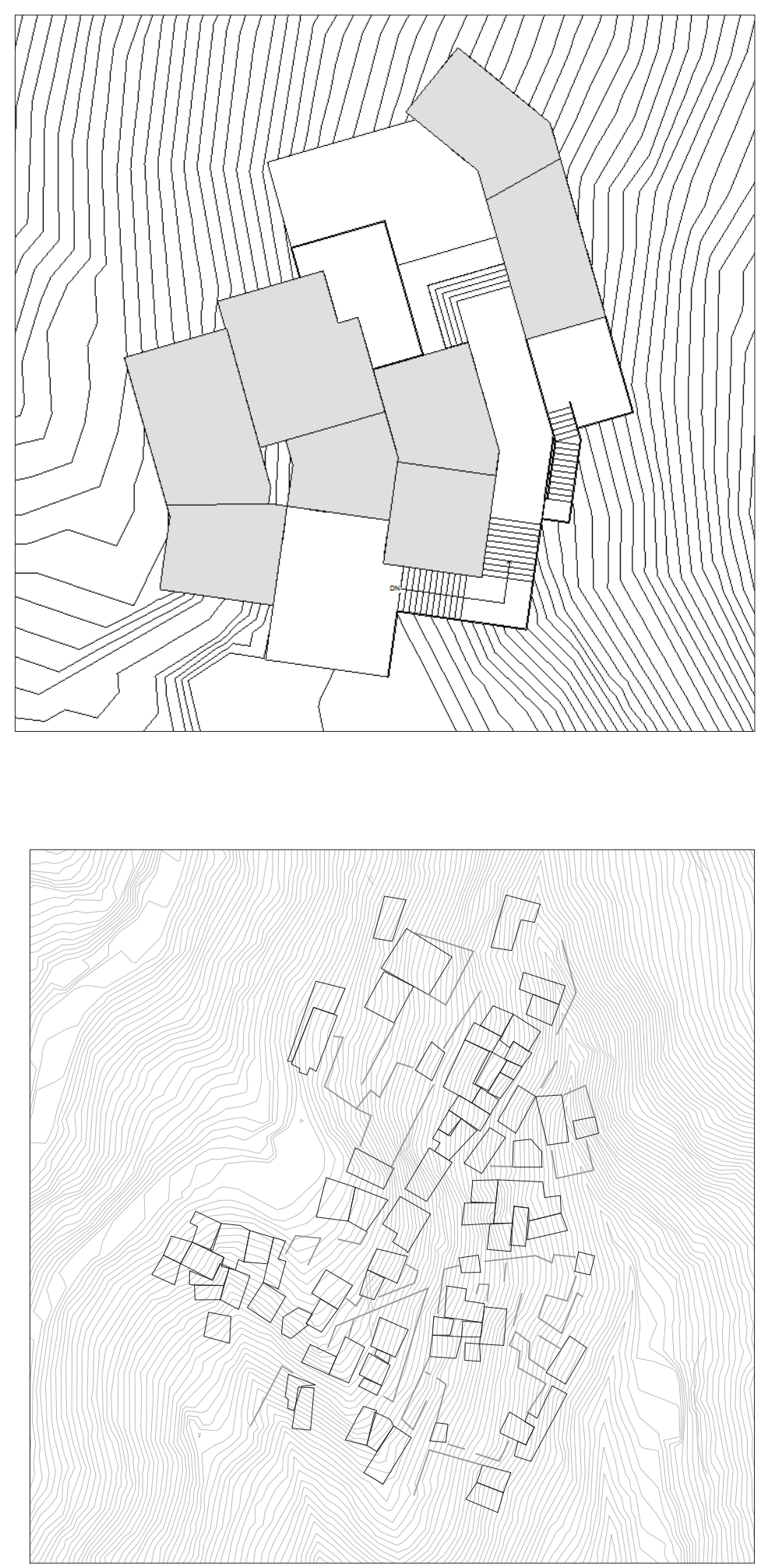


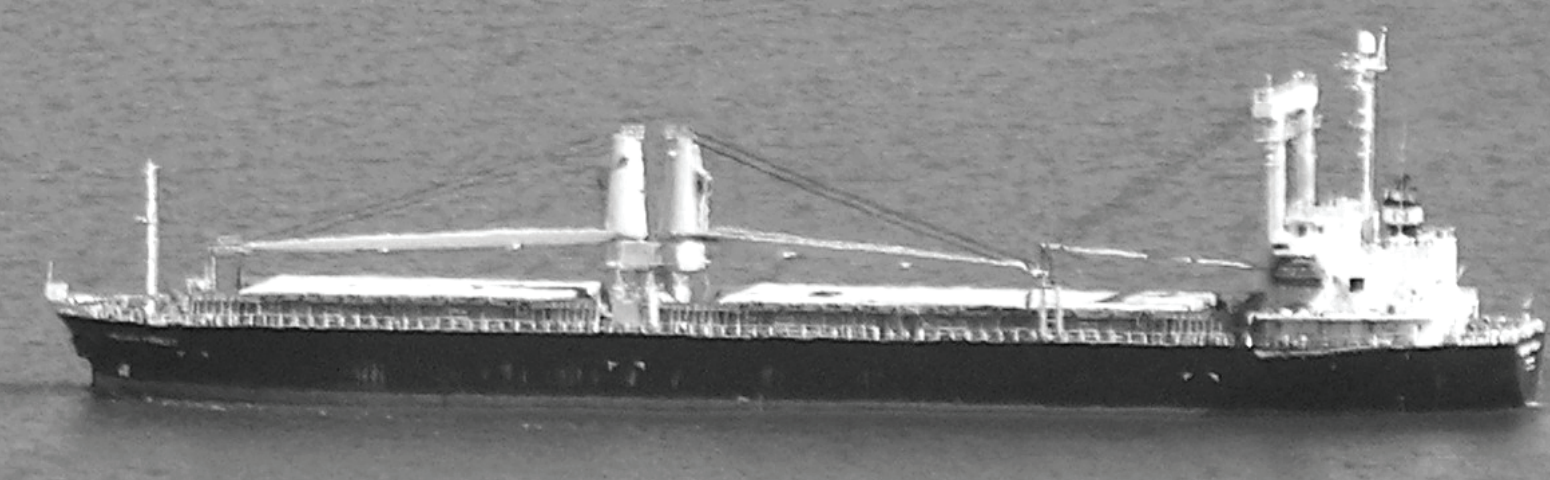

19.6.

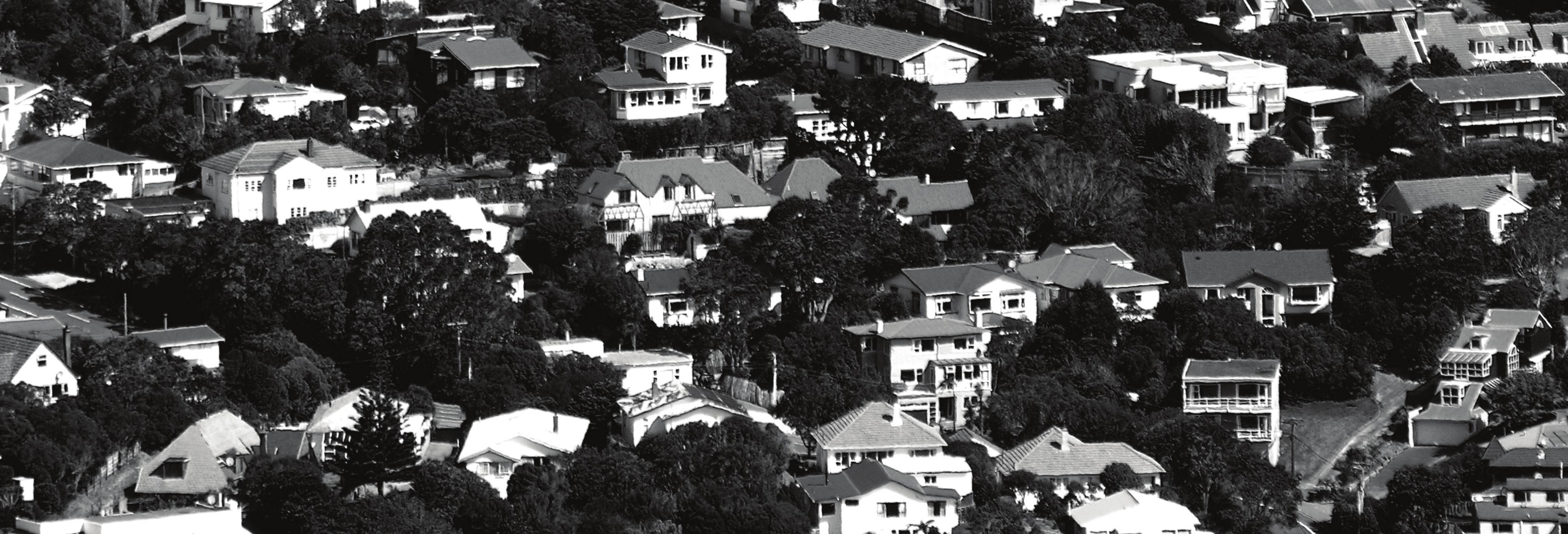




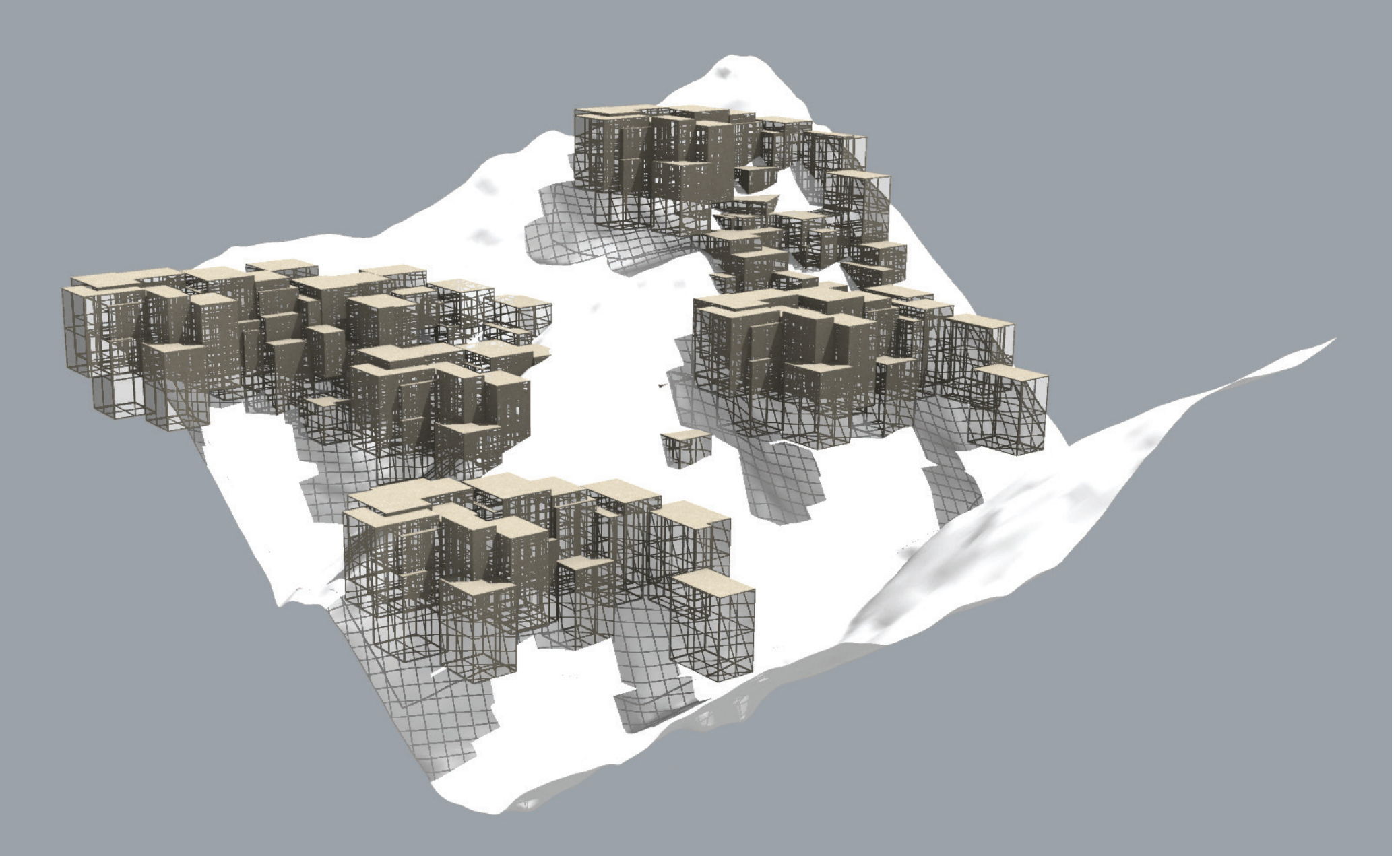

\author{
DESIGN EXERCISE: \\ PARAMETRIC \\ MODELLING \\ Parametric Simulation \\ Building Articulation
}

< fig:3.19 Parametric Model

Source: Author 

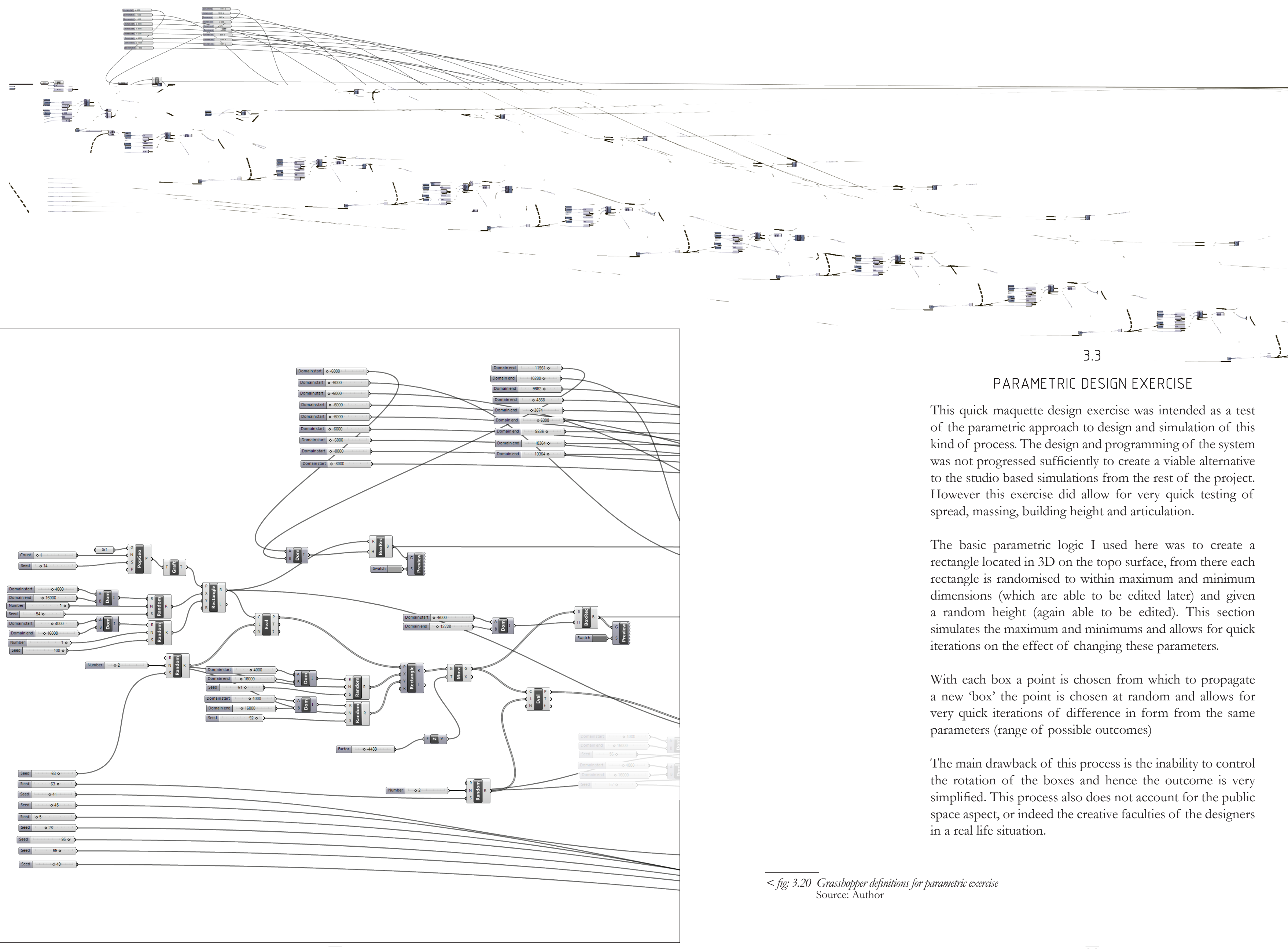

PARAMETRIC DESIGN EXERCISE

This quick maquette design exercise was intended as a test of the parametric approach to design and simulation of this kind of process. The design and programming of the system was not progressed sufficiently to create a viable alternative to the studio based simulations from the rest of the project. However this exercise did allow for very quick testing of spread, massing, building height and articulation.

The basic parametric logic I used here was to create rectangle located in $3 \mathrm{D}$ on the topo surface, from there each rectangle is randomised to within maximum and minimum dimensions (which are able to be edited later) and given a random height (again able to be edited). This section simulates the maximum and minimums and allows for quick iterations on the effect of changing these parameters.

With each box a point is chosen from which to propagate a new 'box' the point is chosen at random and allows for very quick iterations of difference in form from the same parameters (range of possible outcomes)

The main drawback of this process is the inability to control the rotation of the boxes and hence the outcome is ver simplified. This process also does not account for the public space aspect, or indeed the creative faculties of the designers in a real life situation. 

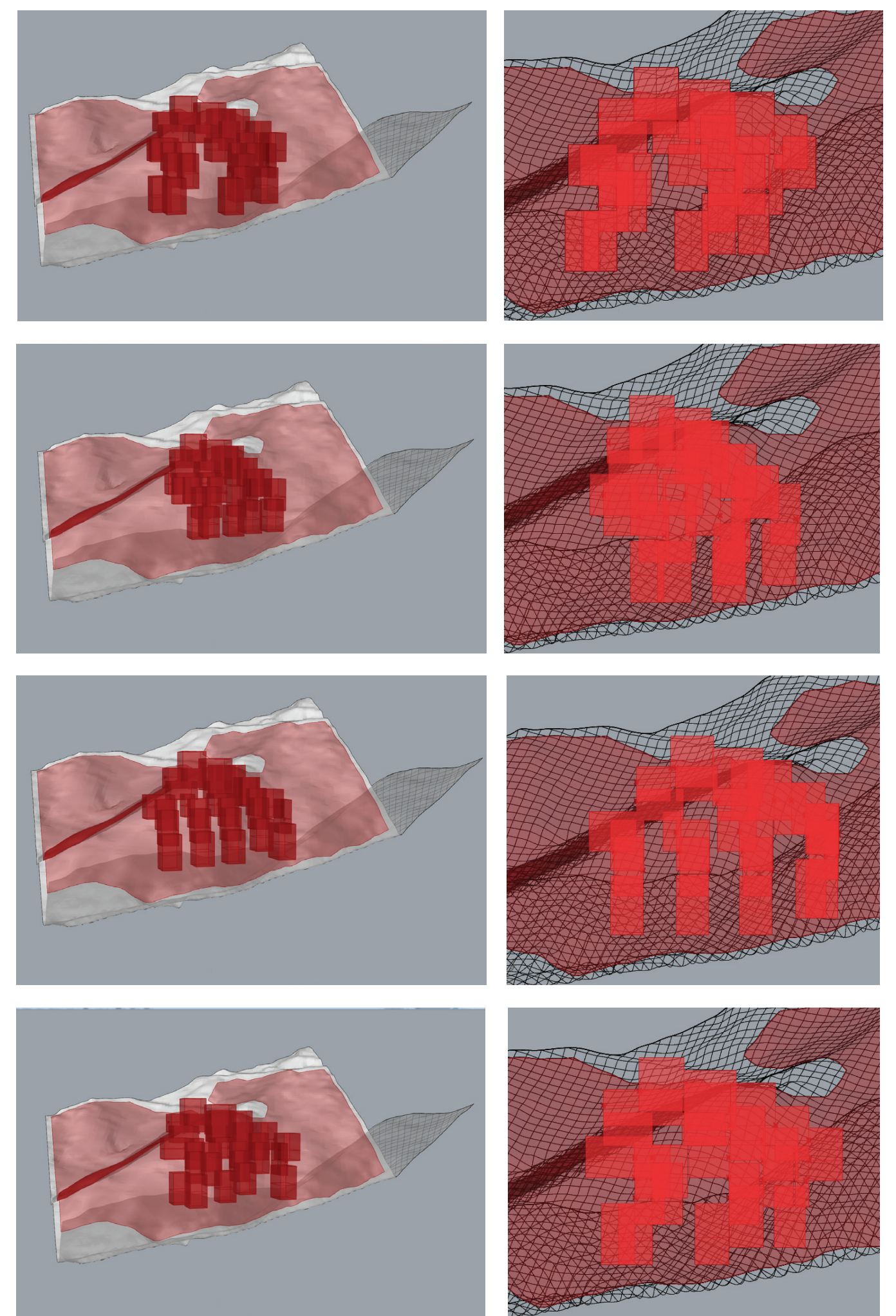

Comparing constant dimensions and beights, altering randomiser seed to see varying outcomes <fig: 3.21 Parametric Study: Range of spread Source: Author
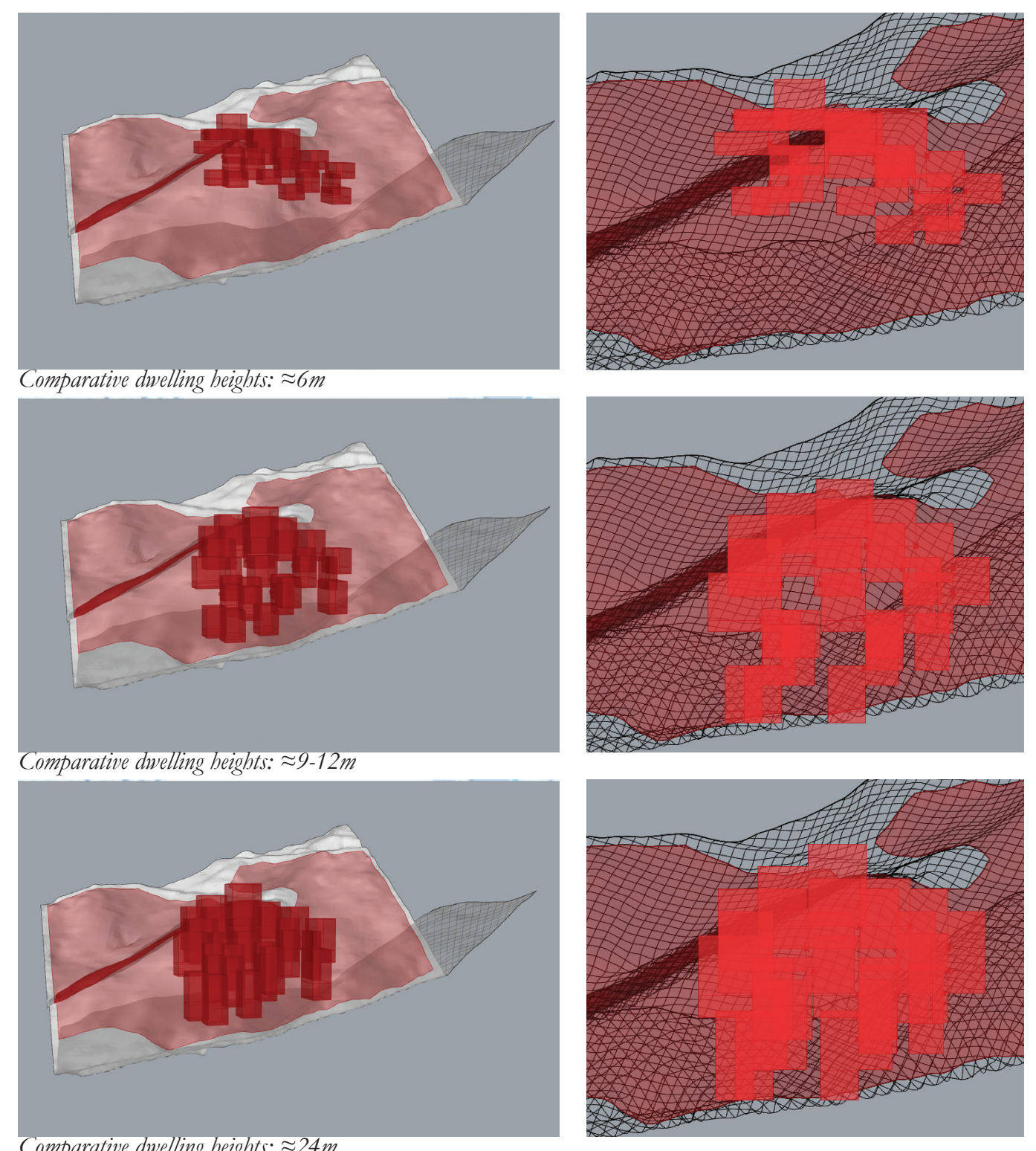

Comparative beights, from $\approx 6 m$ to $\approx 24 m$. Other dimensions constant

< fig: 3.22 Parametric Study: Massing (Height) Source: Author 


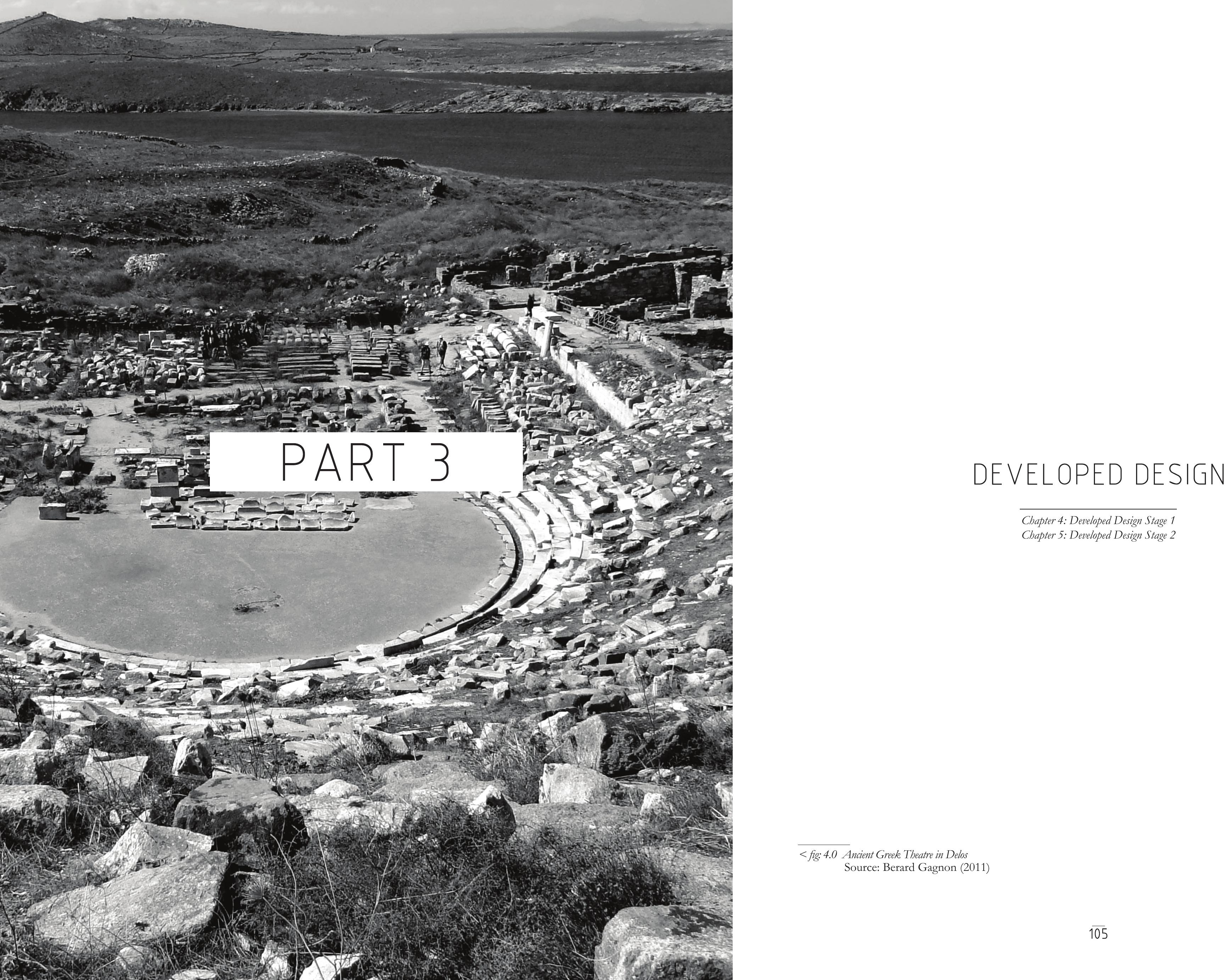


CHAPTER 4:

SIMULATION STAGE 1

Test Framework
Pilot Study Methodolo

Preliminary Simulation result 


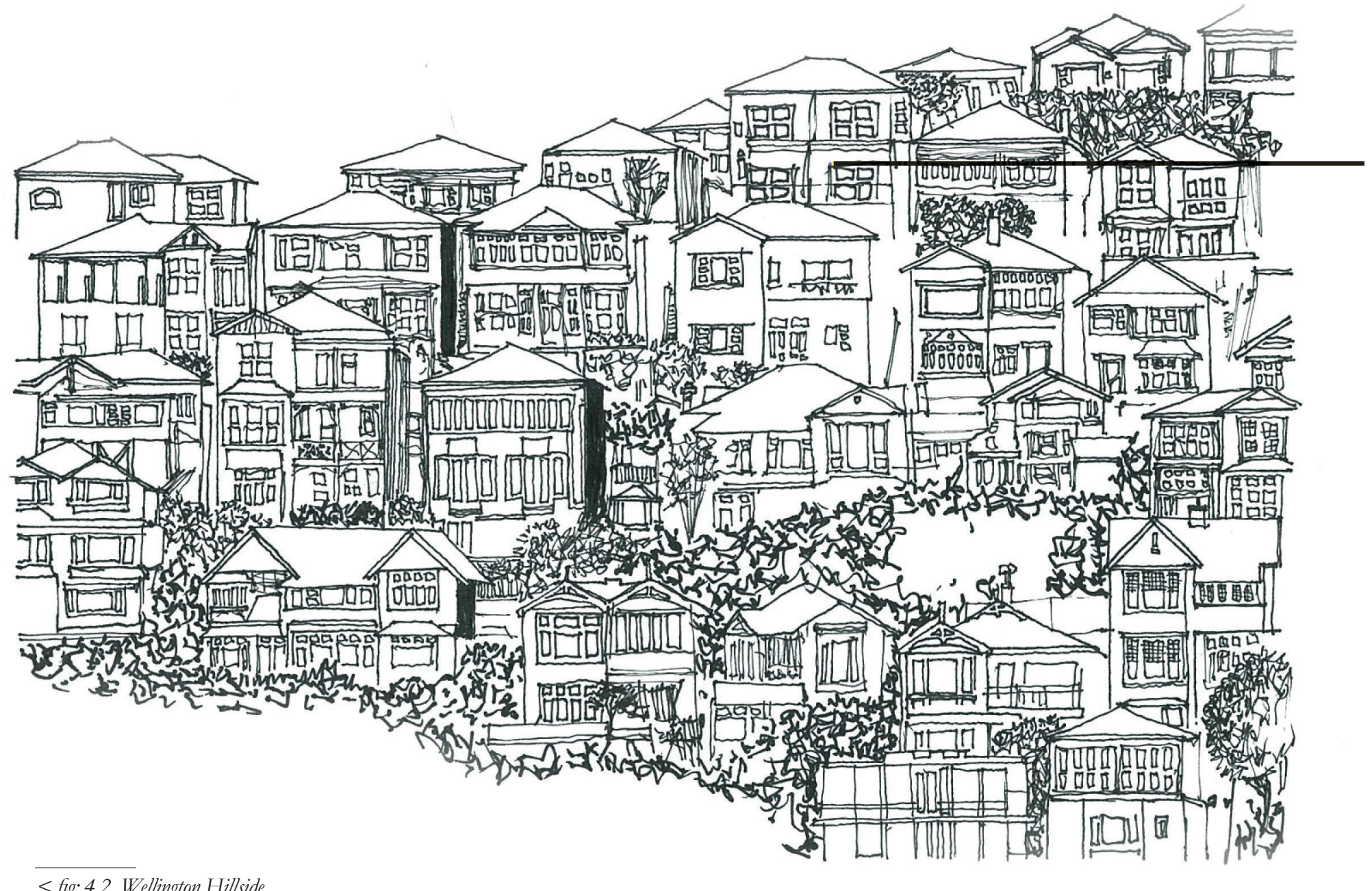

Wellington Hillside
Source: Author
DEVELOPED DESIGN

This next phase of the design started on the same site but from a clean slate. In order to set up the development and begin the aggregative build up in such a small and difficult area to access the amount of infrastructure that is required was significantly more than was provided for the pilot study. The initial setup and initial seed dwellings.

The issue of vehicular access to within a reasonable distance to the dwellings is a major concern for the viability of a development such as this. Conversely for the desired density to work in site conditions such as these, dirct access palling to not an option of collectivised parking based around car stacking buildings at the top and bottom access routes (fig 4.8-4.10). The lower access road was added following the pilot study in response to the tendency of designers to locate any new dwelling as close to the access road as possible, as such the spread of the development needed a base point to allow for a condition where the development could meet in the middle (fig 4.7)

In order to provide access for people with disabilities as well as ease of access for other residents, a cable car has been included in connecting the upper and lower parking decks (fig 4.13). This cable car is intended to cross the primary pedestrian dwelling a tart run parallel to the site topography, giving most a

of the design, rather than relying on the initial designer to site the beginning phase of the project, the hypothetical not only create a base platform from which other designers can propagate new dwellings (in line with the shared wall rule) but also begin to give intuitive cues as to the intent of the design guidelines. From a purely pragmatic and to the ability the plans, creating a moreting tol and also a way of generating capital to finance and offset the other initial infrastructure.

1 Cityscope consultants (need to add reference)

2 Here represented by myself as the author 


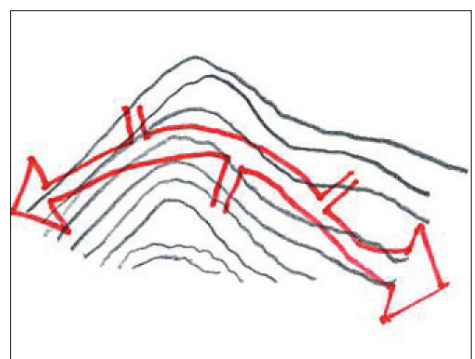

2.1.2 The major axis of the pedestrian network will fall generally parallel to the site contours/topography

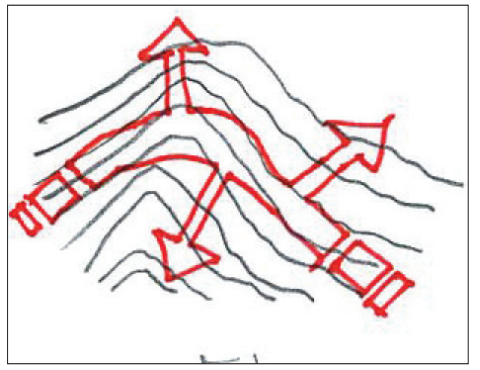

2.1.3 Minor axis of pedestrian network will fall generally perpendicular to the site contours to act as vertical access
circulation through the development

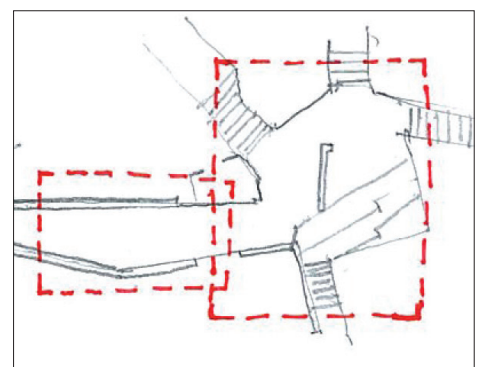

2.1.4 Irregular path width is recommended to avoid monotonous access routes and allowing for spaces of pause where the path widens, even allowing for corry

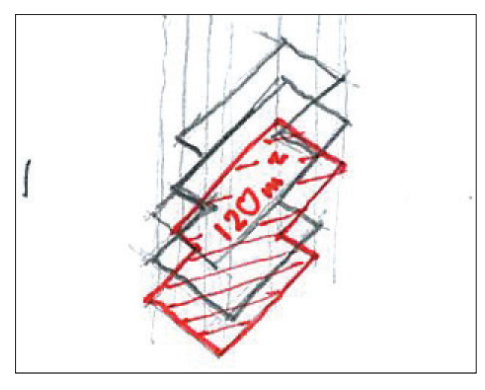

3.1.1 Ma $120 \mathrm{~m}^{2}$

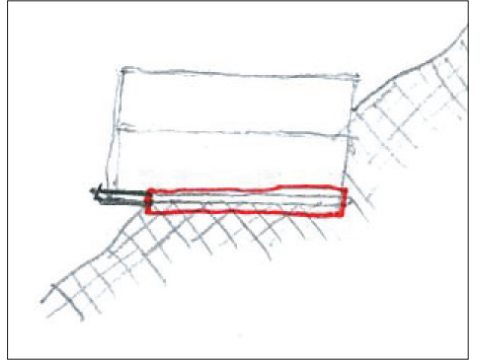

3.1.3 Buildings are to be grounded [defined here as contact with the ground throug slab construction] for at least $70 \%$ of their footprint area

\section{DEVELOPMENT FRAMEWORK}

This new framework was written in a much more comprehensive form than the previous draft framework, with added detail on the intention and specifics of each rule. Additional rules to cover aspects of the framework that were identified as lacking control and could lead to undesired results. Due to the nature of this thesis and the limits on word count I have not included this framework in the text a it would have been $1 / 4$ of the total allowed words. However this iteration of the framework is in the same format as the included final framework in appendix 1.

The challenge throughout this process was finding the balance between the control required to satisfy the constraints of the ant his project is based on. From this stage in the qualities that of framework, many of the changes made relate to fine tuning this, with the ability for exceptions and ways in which an architect can stretch or break the rules to crete a richer architectural outcome. This in turn leads into the simution methodology and the way in which I test the project but a

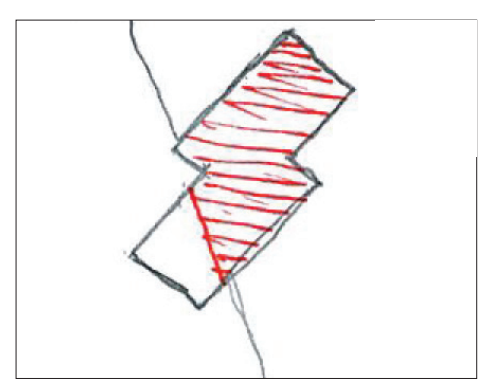



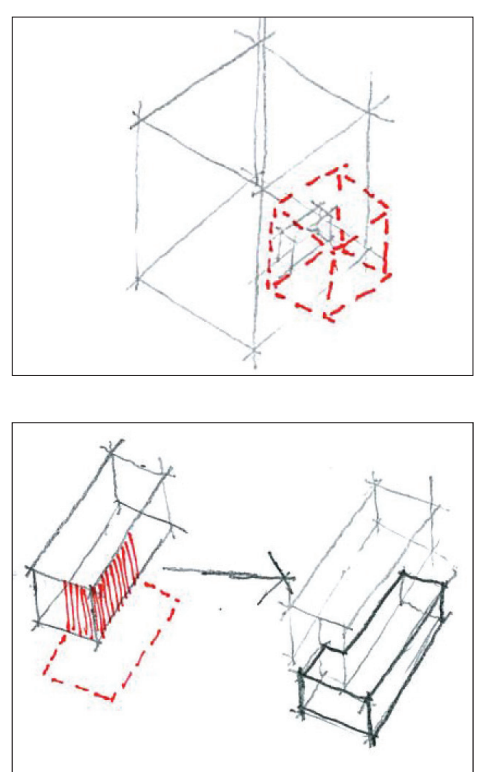
footprint to allow for architectural elements that contribute to building design and articulation, as long as this does not interfere with development of future dwellings

3.3.1 Dwellings must be based around a connection to an existing party wall as

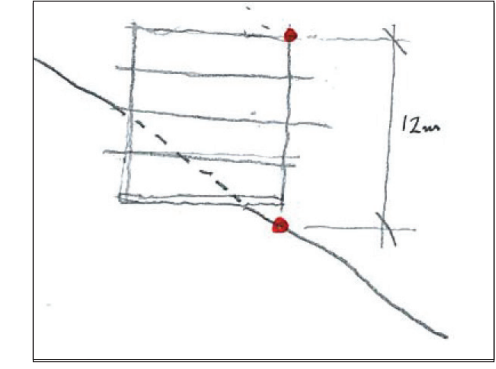

grounding element of the built fabric

Maximum height from natural ground plane of $12 \mathrm{~m}$ at any given point
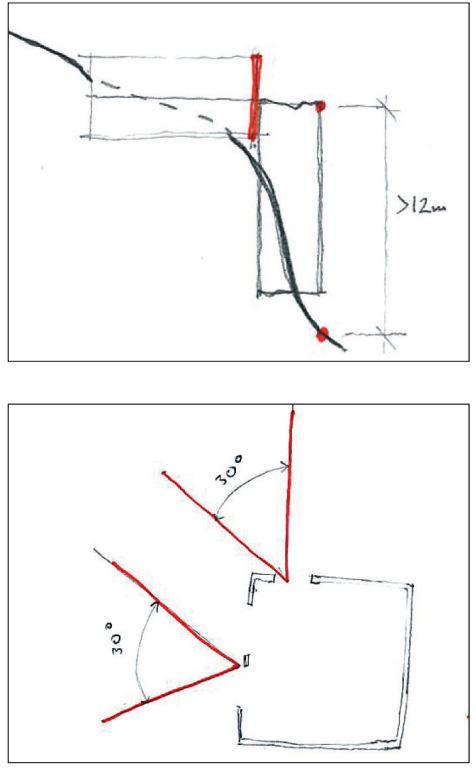

4.4 Exceptions may be made to maximum height where the topography of the site does not allow for the building to be grounded at the natural ground level provided the building makes contact with an adjocent/existing party wall.

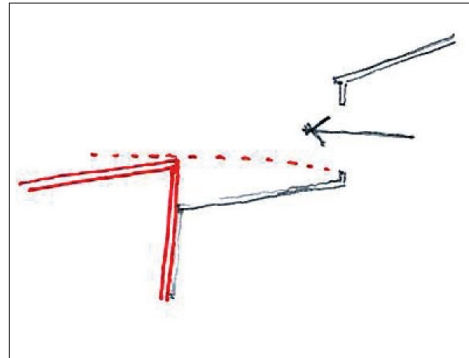

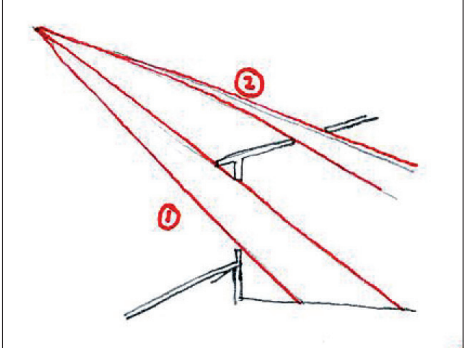
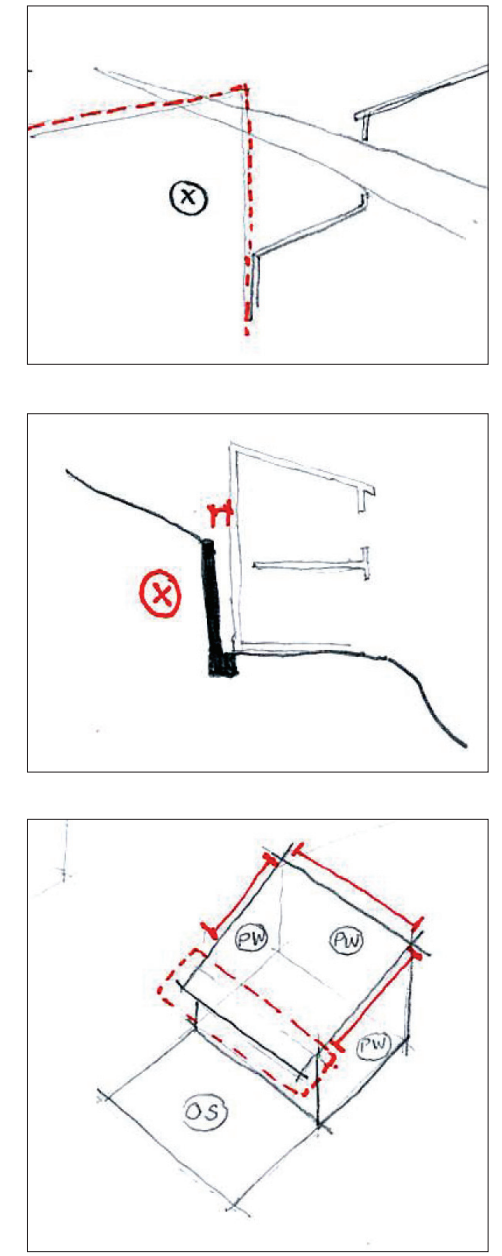

3.6.4 Any retaining for buildings [not including public spaces] is to be included in the building structure. (no retaining off from the walls of a dwelling)

3.7.3 Eves or roof overhangs are not permitted where roof line intersects with party walls. This allows for extension of new built elements past the existing roof line. 


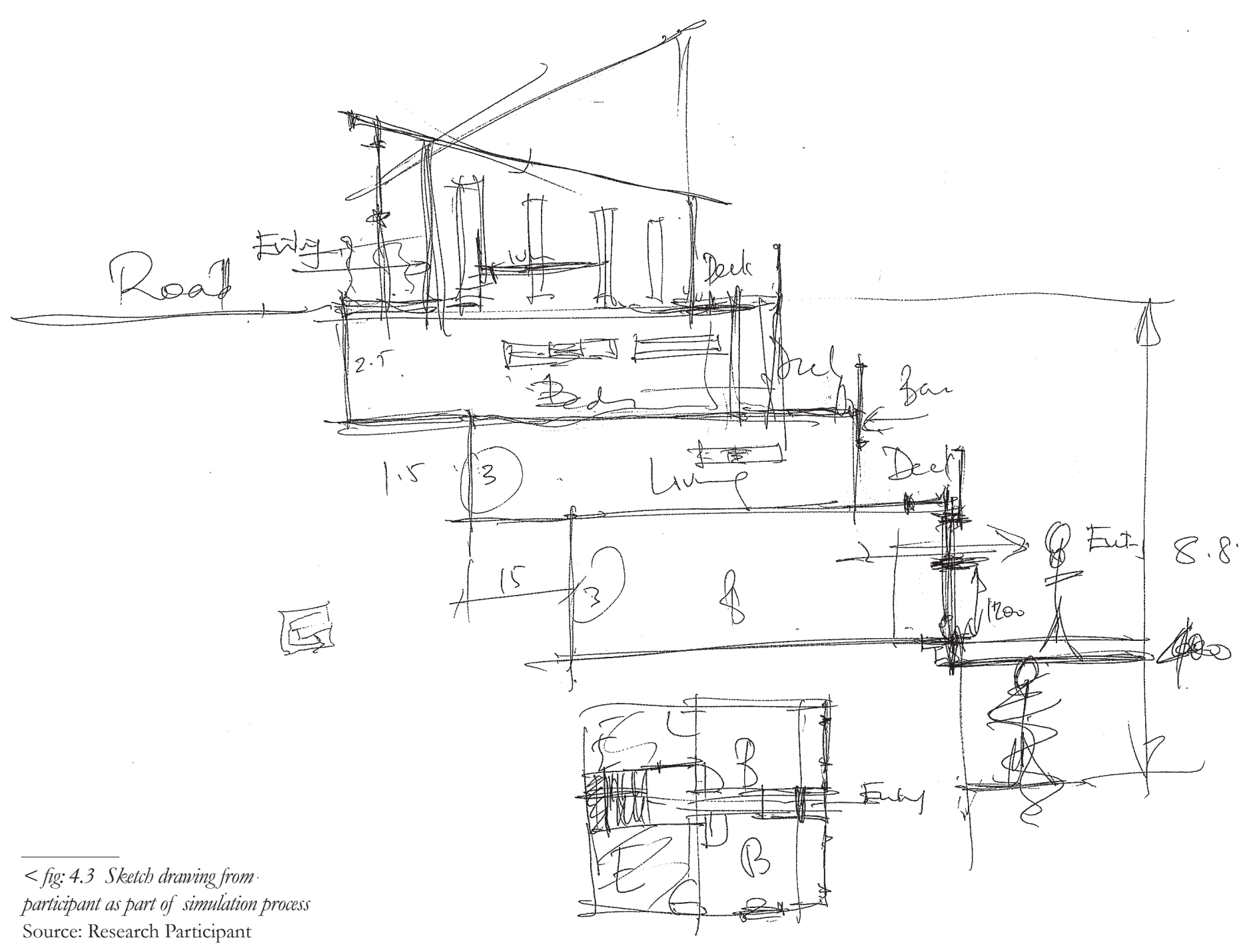

SIMULATION METHODOLOGY

This stage of the design the methodology is a combination of the comprehensive control strategy and aggregative study from the pilot study. One of the major concerns from the pilot study was the time taken to organise input from outside participants that did not have the same financial tie in that a designer would have in a real project. In order to minimise this, the designs were undertaken either solely by an outside designer, or by a designer in collaboration with myself. This collaborative process consisted of the designer spending a few minutes to give siting, use of shared walls, sizes and massing and then I would model and develop the design with input from the participant when major design decision needed to be made.

In addition to the changes in the method by which the designs were completed, the overall role that I play as curator of the project changed to reflect a decision that additional oversigh a third party such as a design committee would be needed given the difficulty of the site and the desire for complexity and flexibility of the framework in addition to the pragmatic concern of compliance with the framework. As such the role that I take in the simulations is similar to this, where changes would be submitted to the designer in the real process, am making the changes myself to ensure compliance with the framework. Additionally I am present during the desion process and am able to answer questions around exception to rules that would be otherwise submitted to the design committee. In practice the majority of these changes that took place during the first stage of developed design were to do with access and public outdoor space, with many designers privileging the dwelling over the access network. 


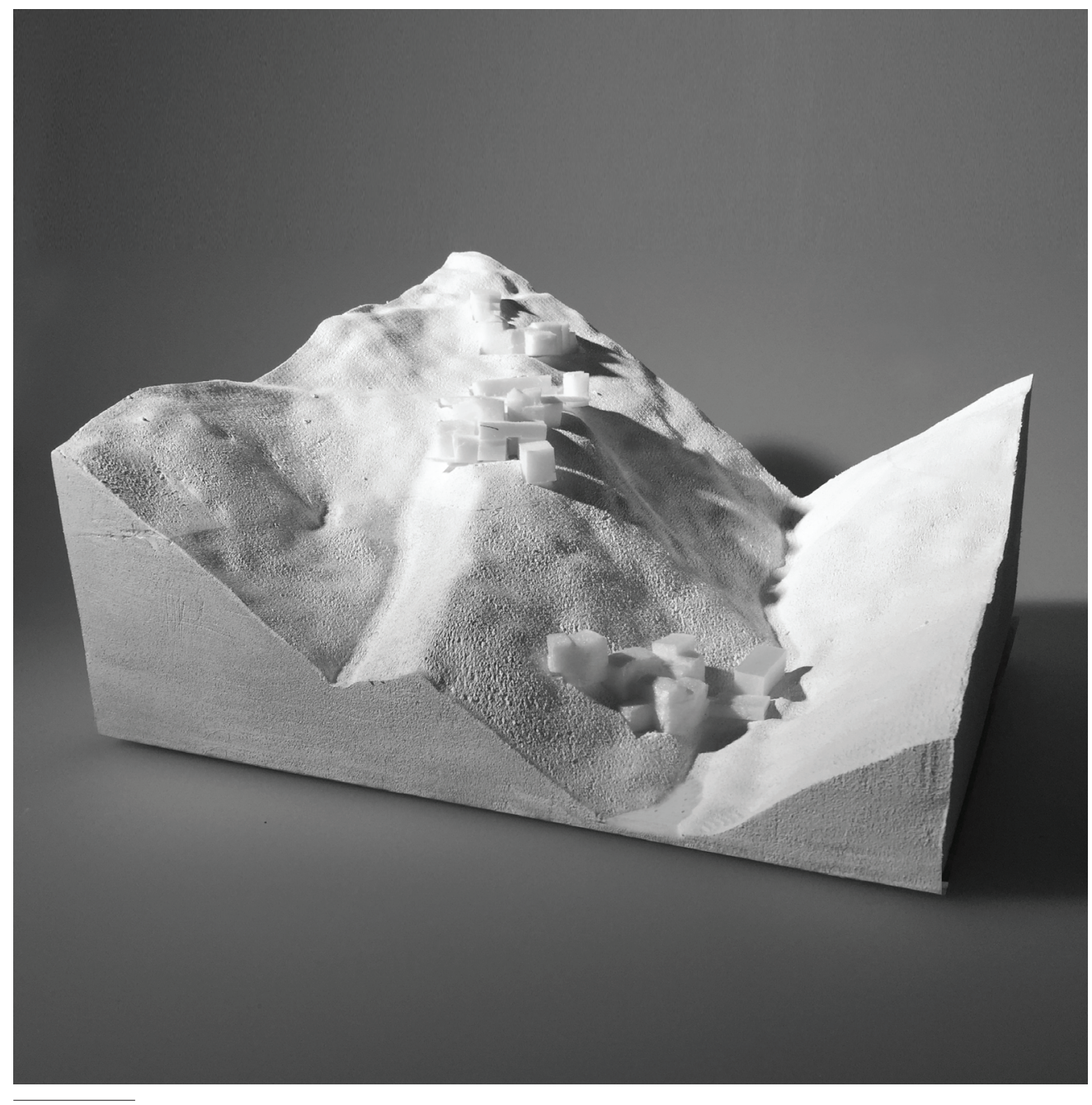

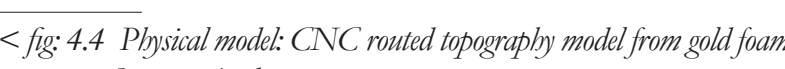
Source: Author

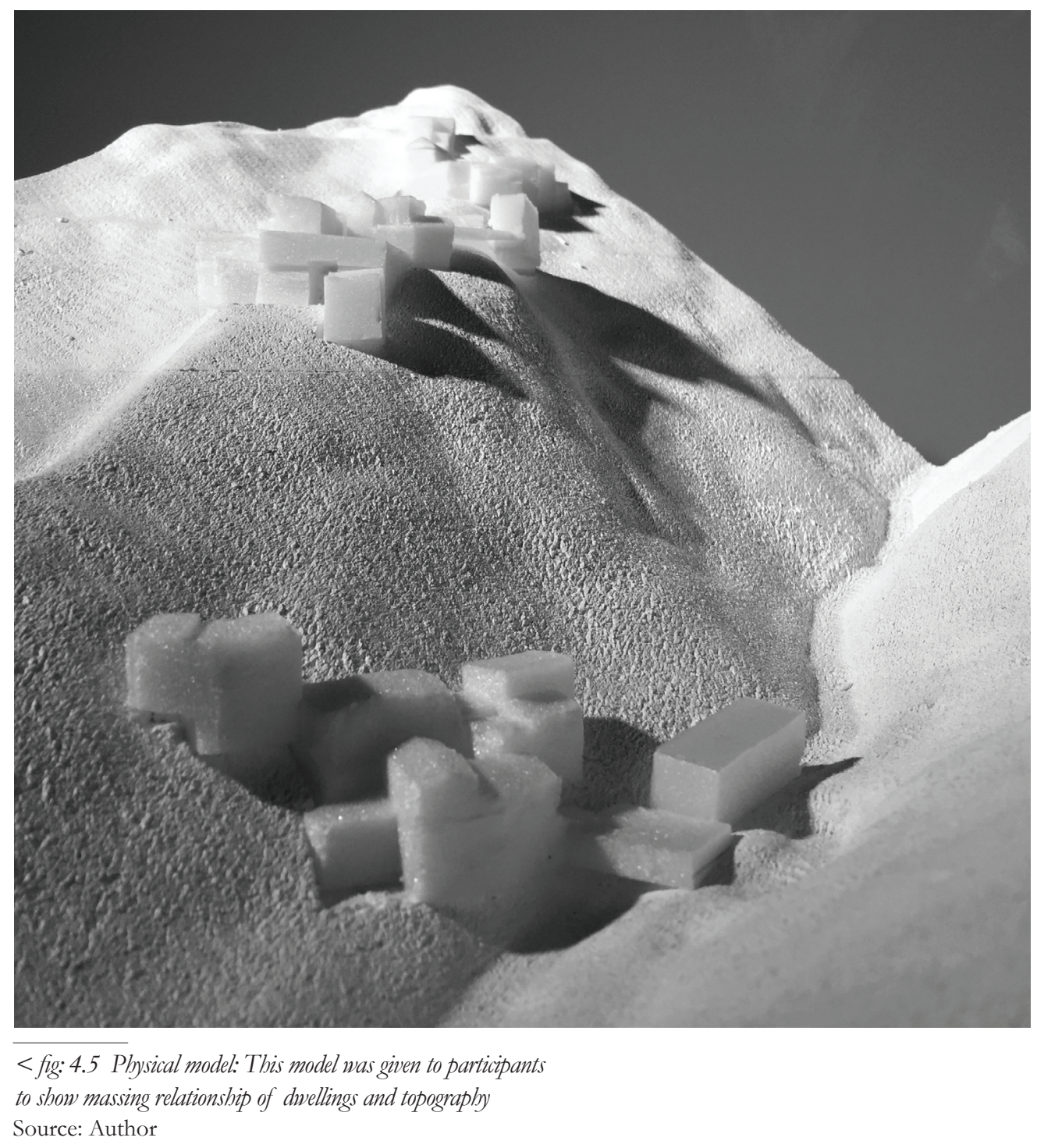



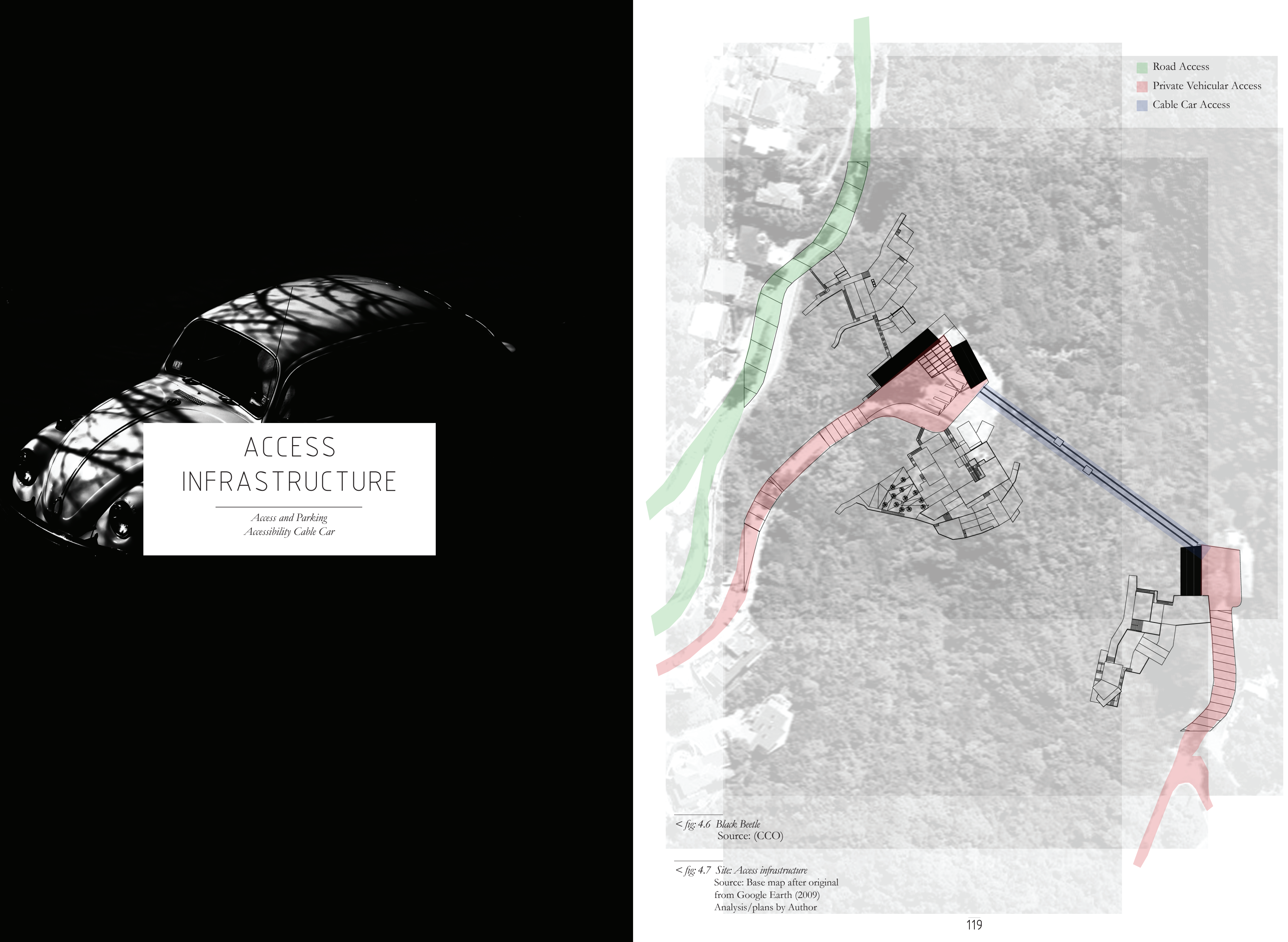


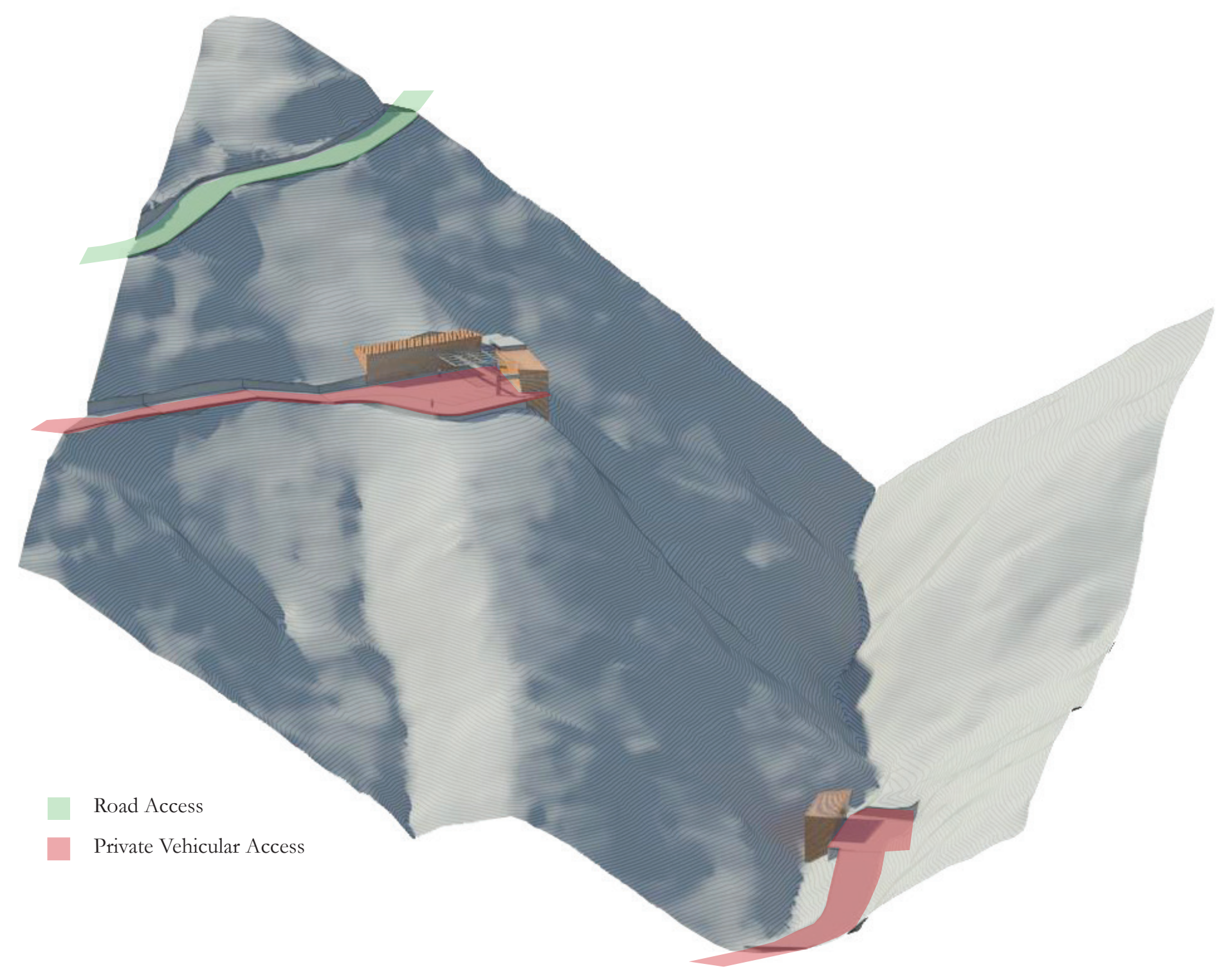

<fig: 4.8 Site Access: Parking Infrastructure
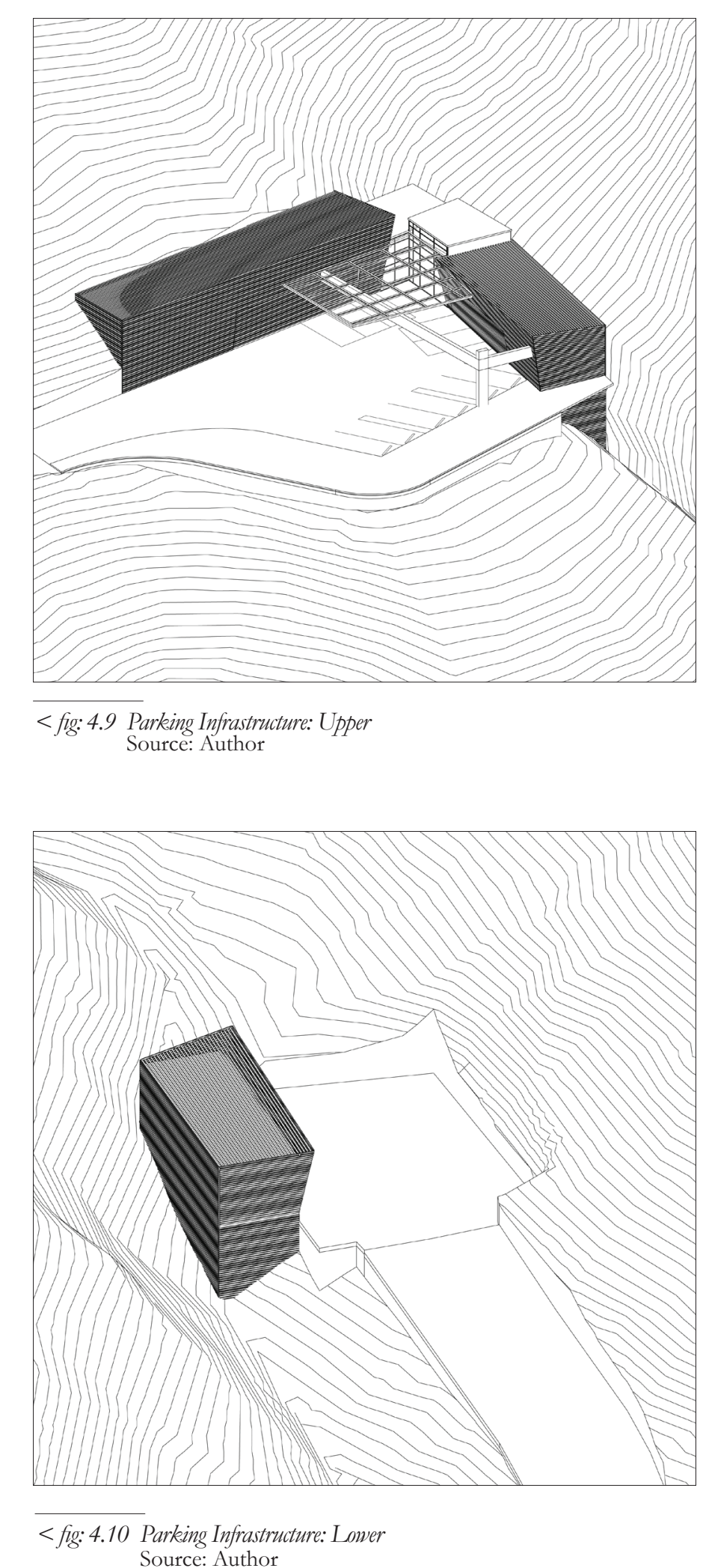


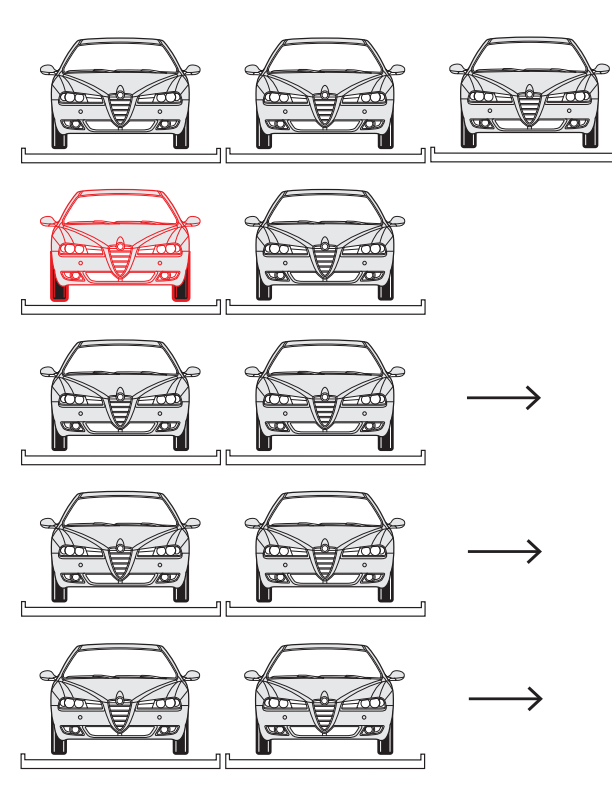

Logic of the car parking stacking. small centralised area.

< fig:4.11 Pu₹zle Stacking Parking Source: Author

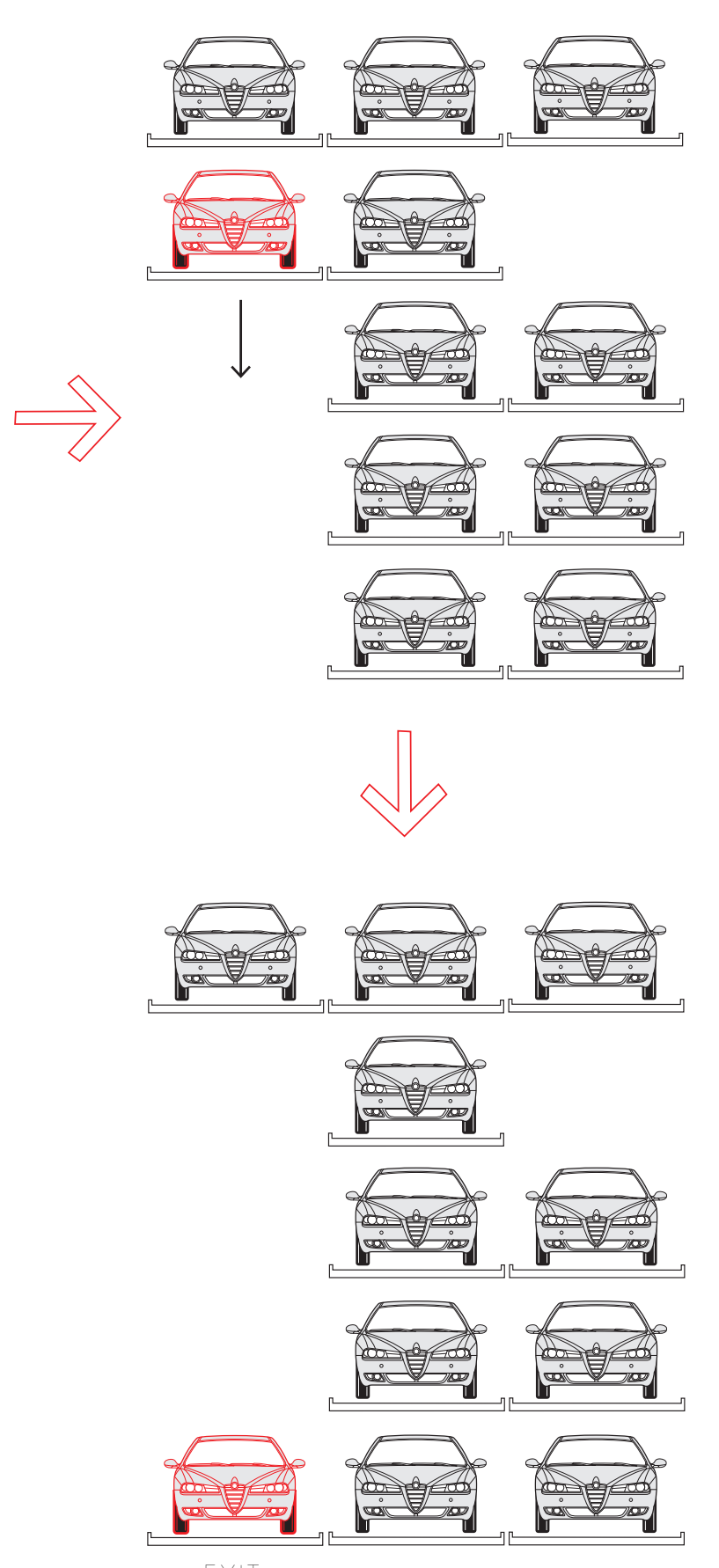

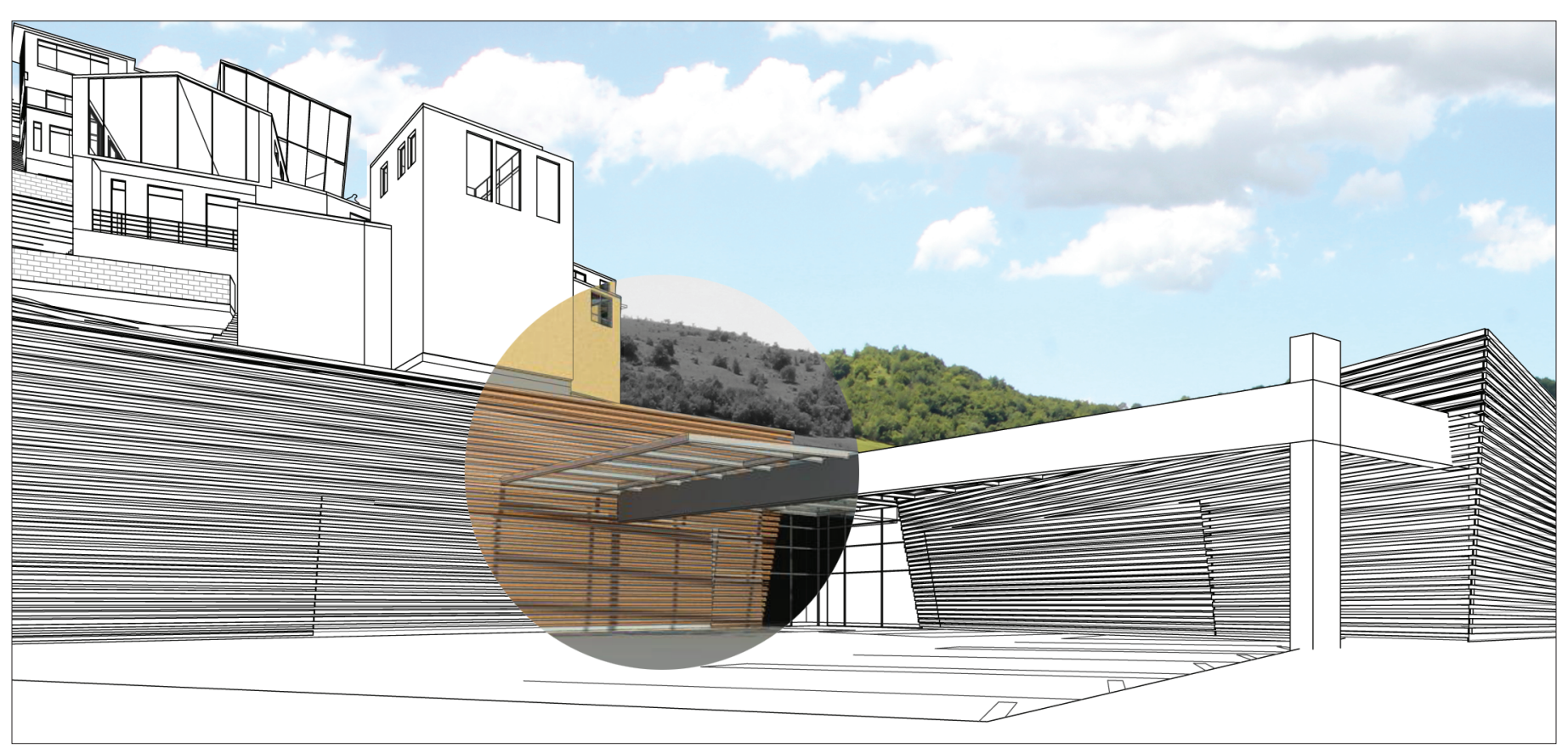

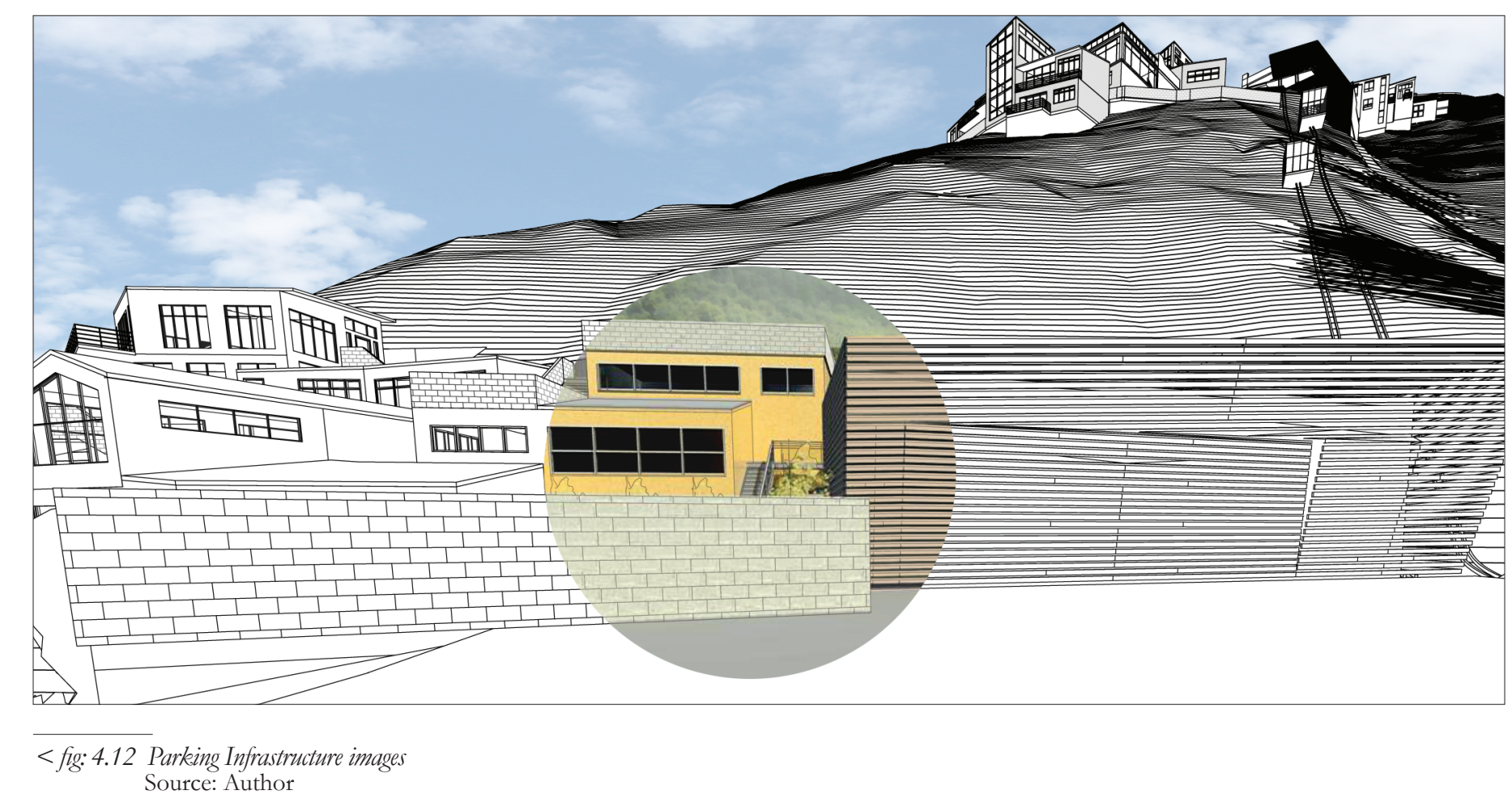
Pource: Author 


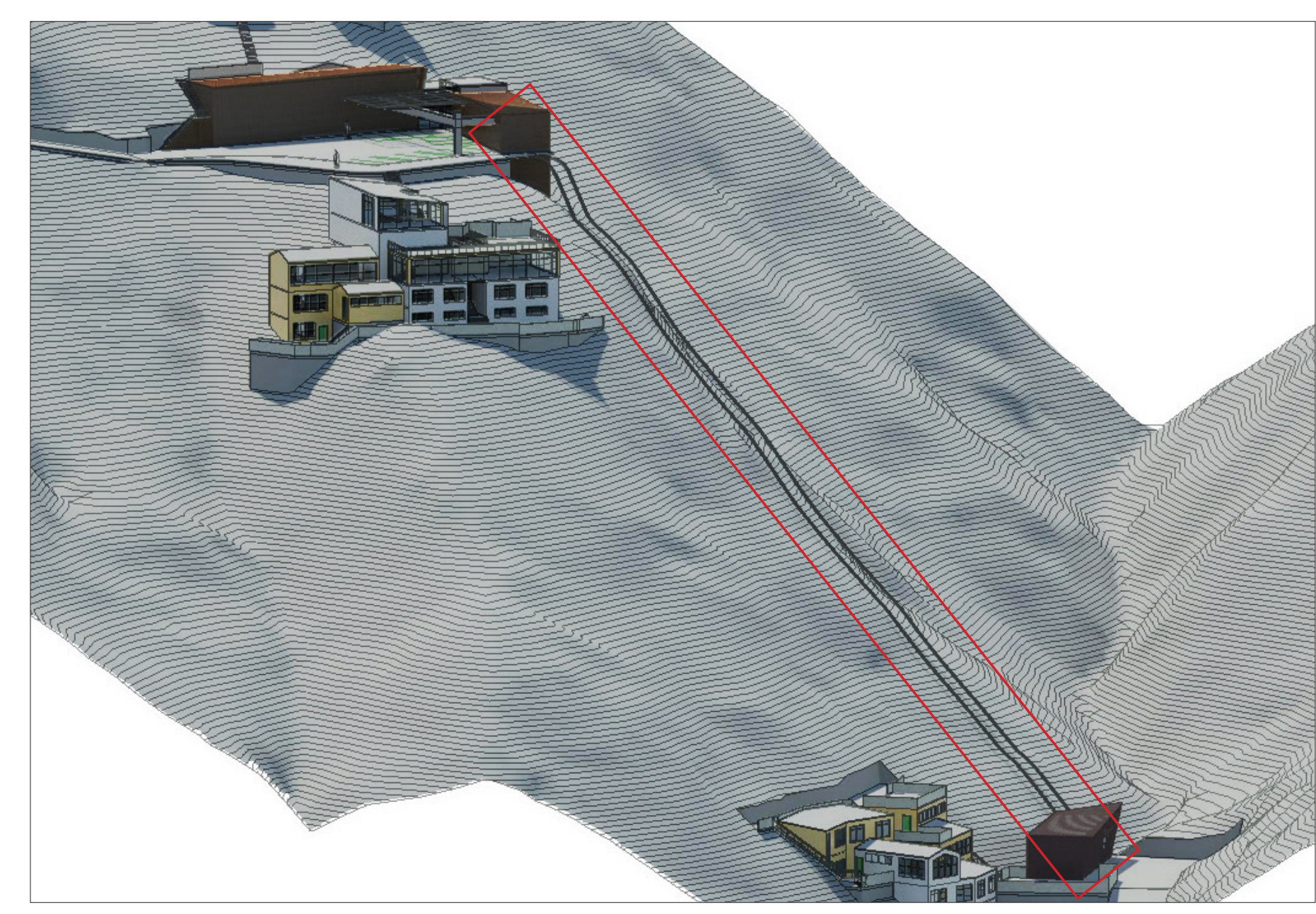

< fig: 4.13 Site Access: Cable Car for access through site Source: Author
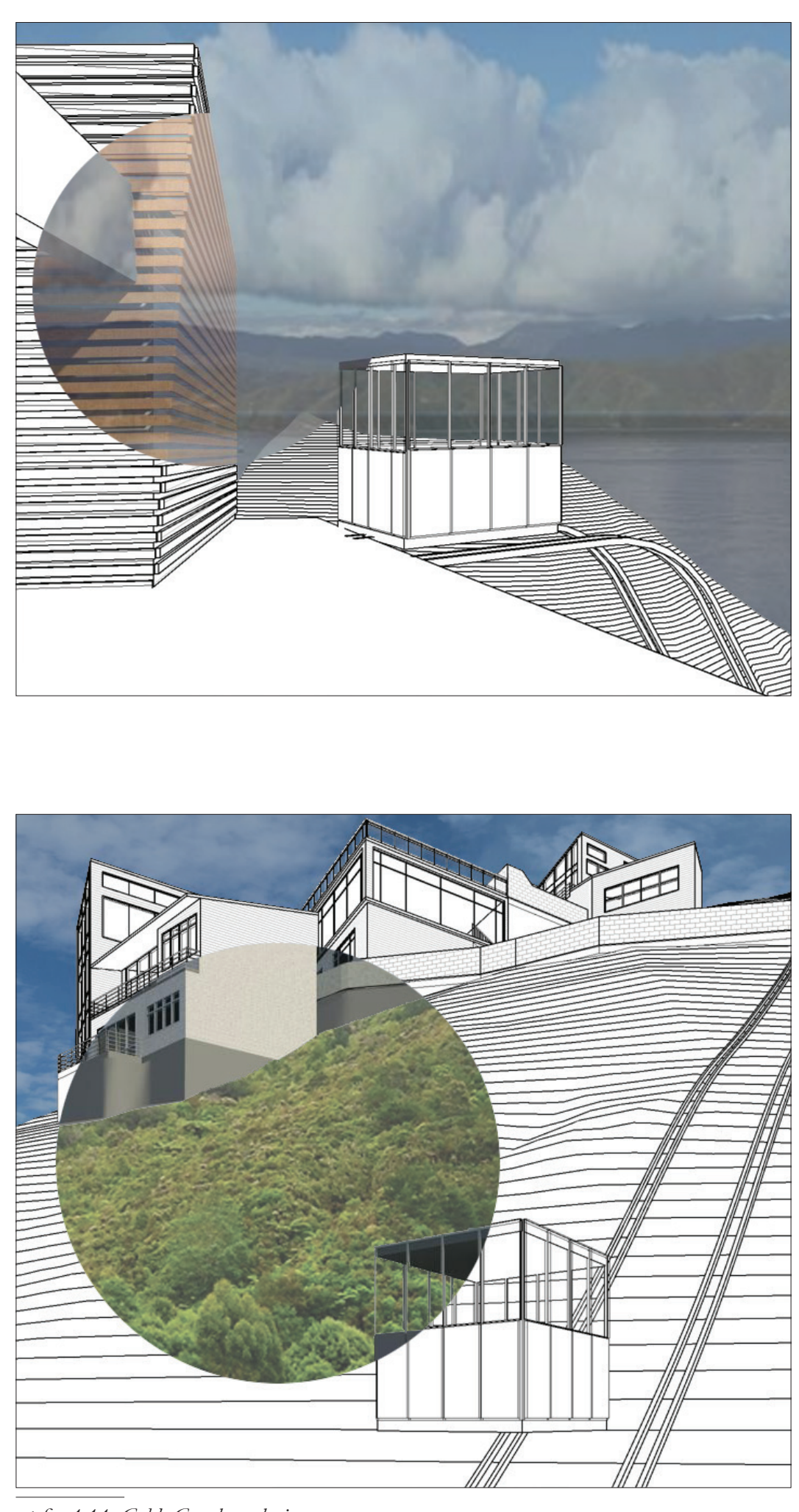

$<$ fig: 4.14 Cable Car through site
Source: Author 


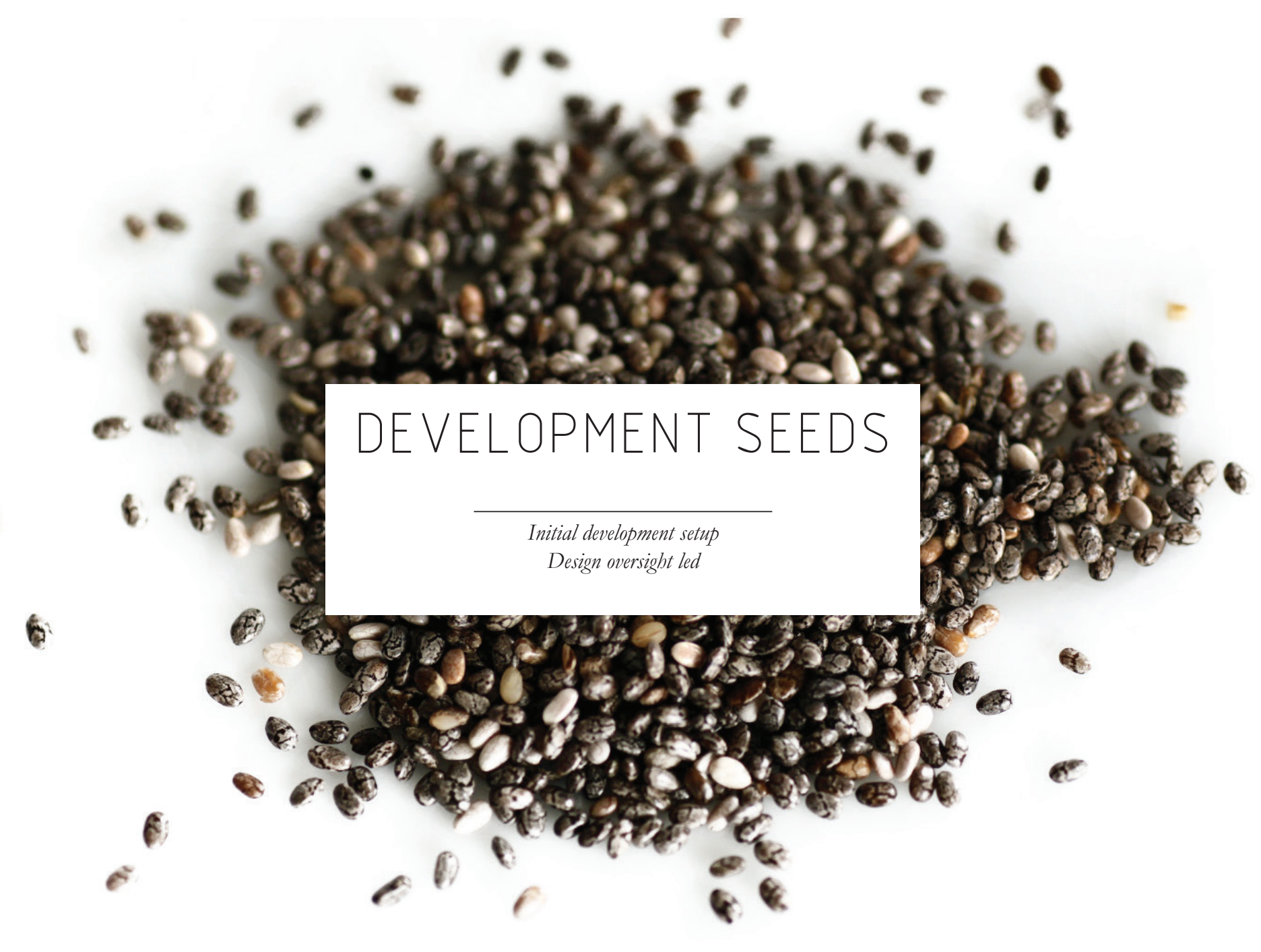

< fig: 4.16 Chia Seeds

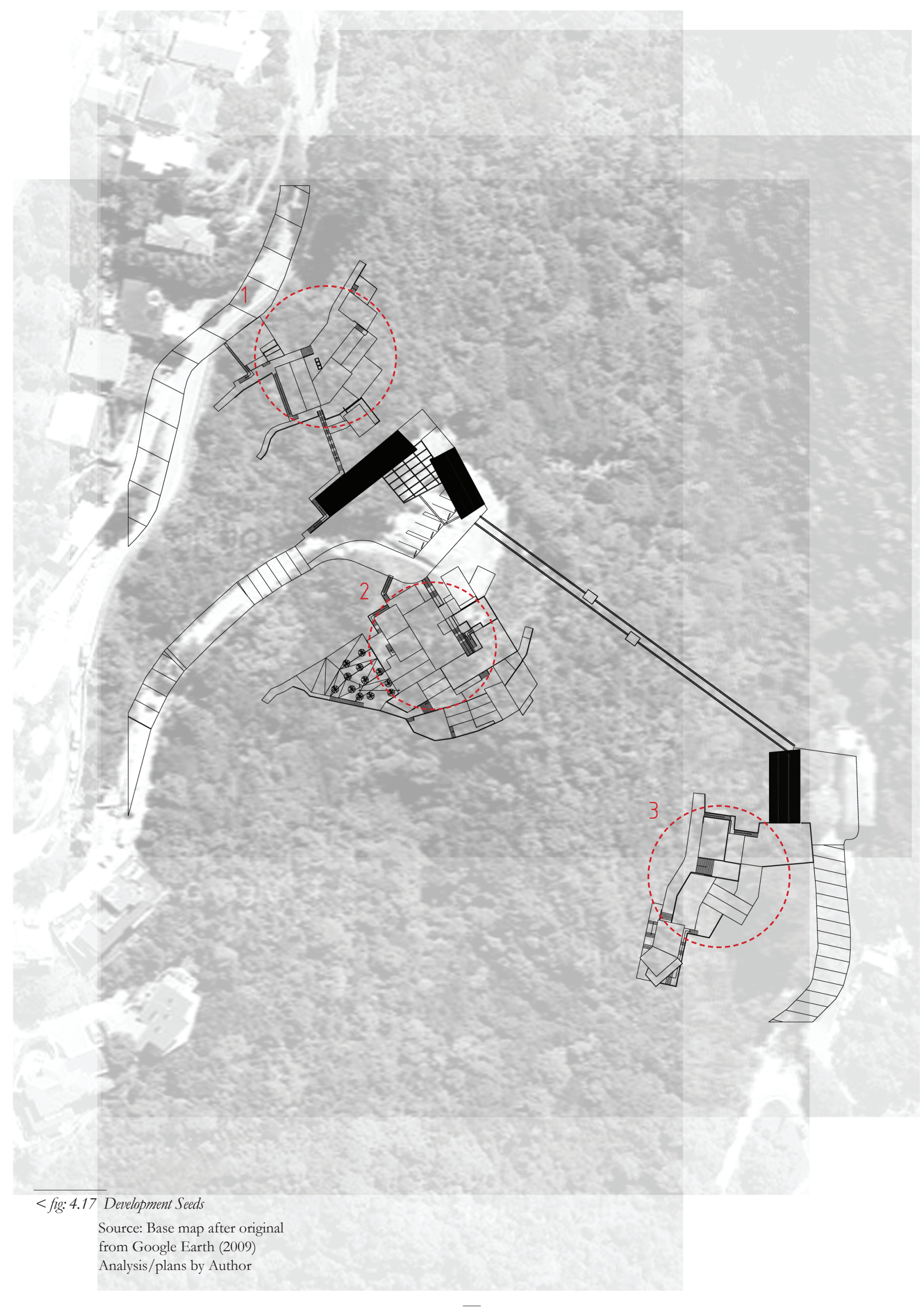



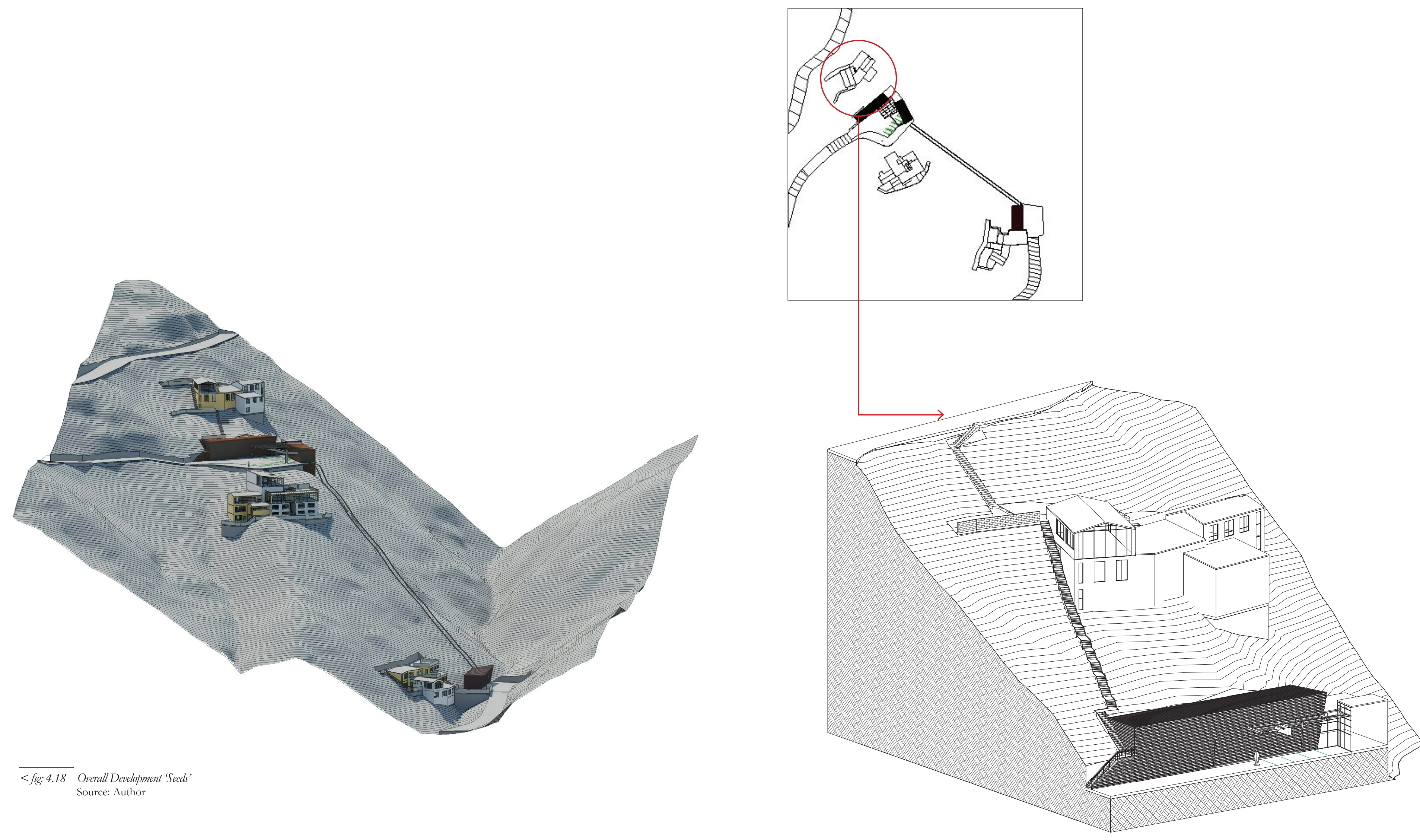

< fig:4.19 Upper Seed Dwellings 


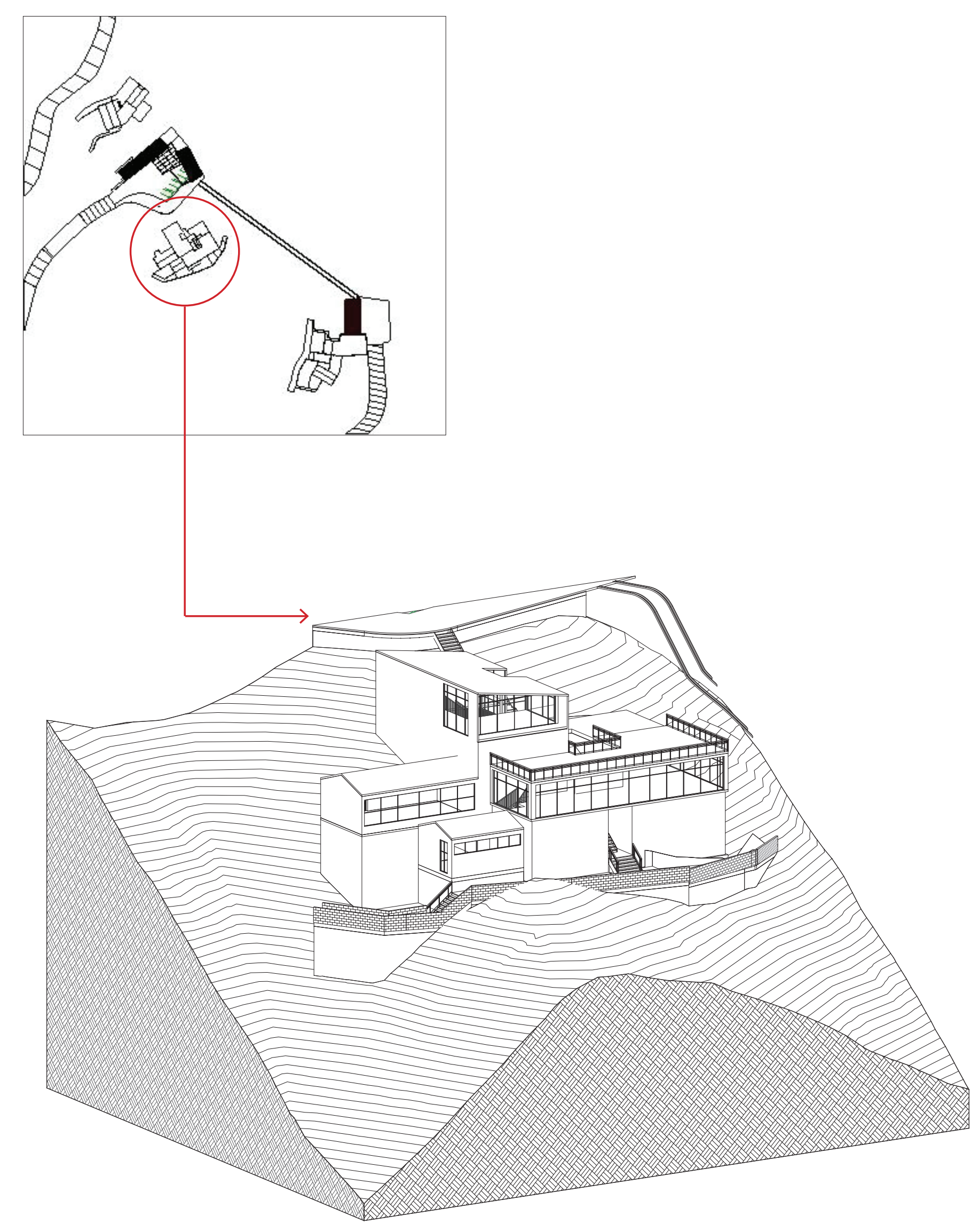

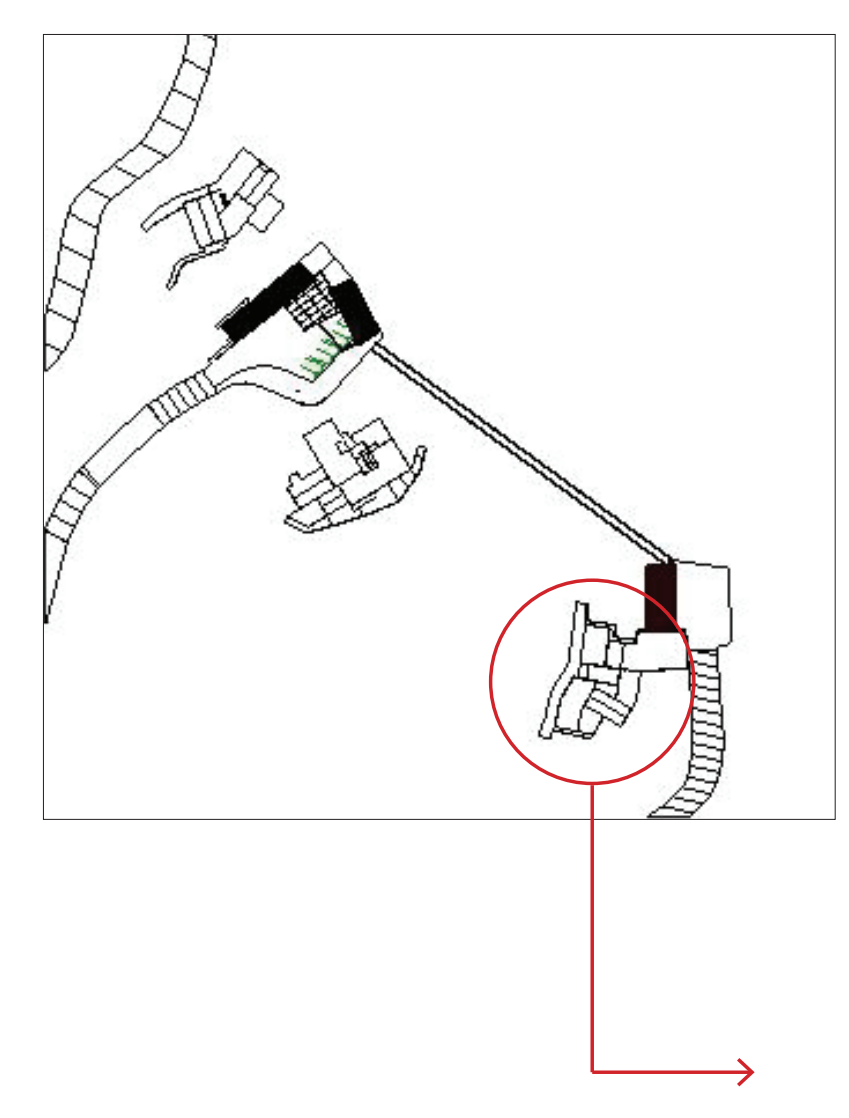

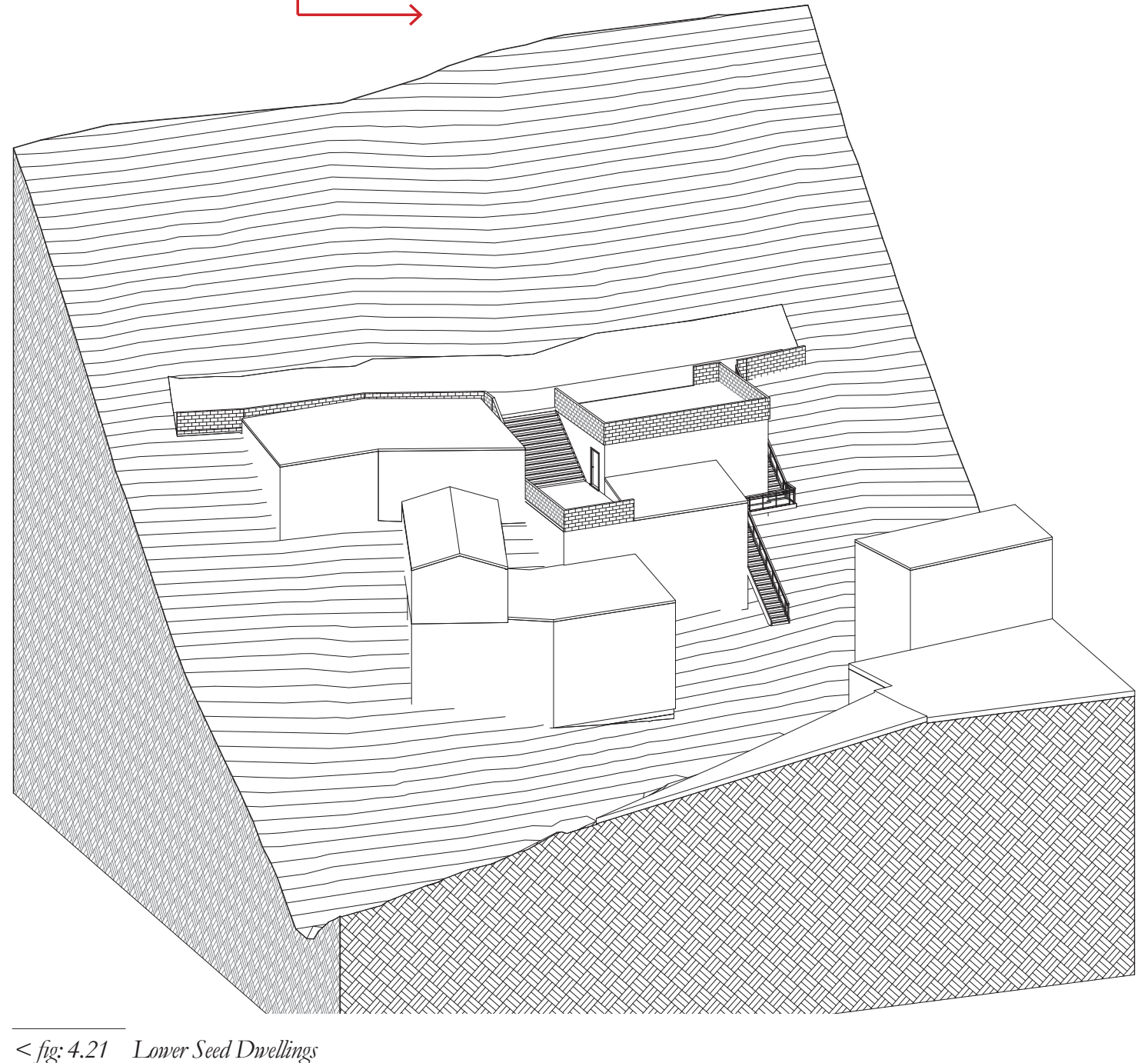

Dwellings 


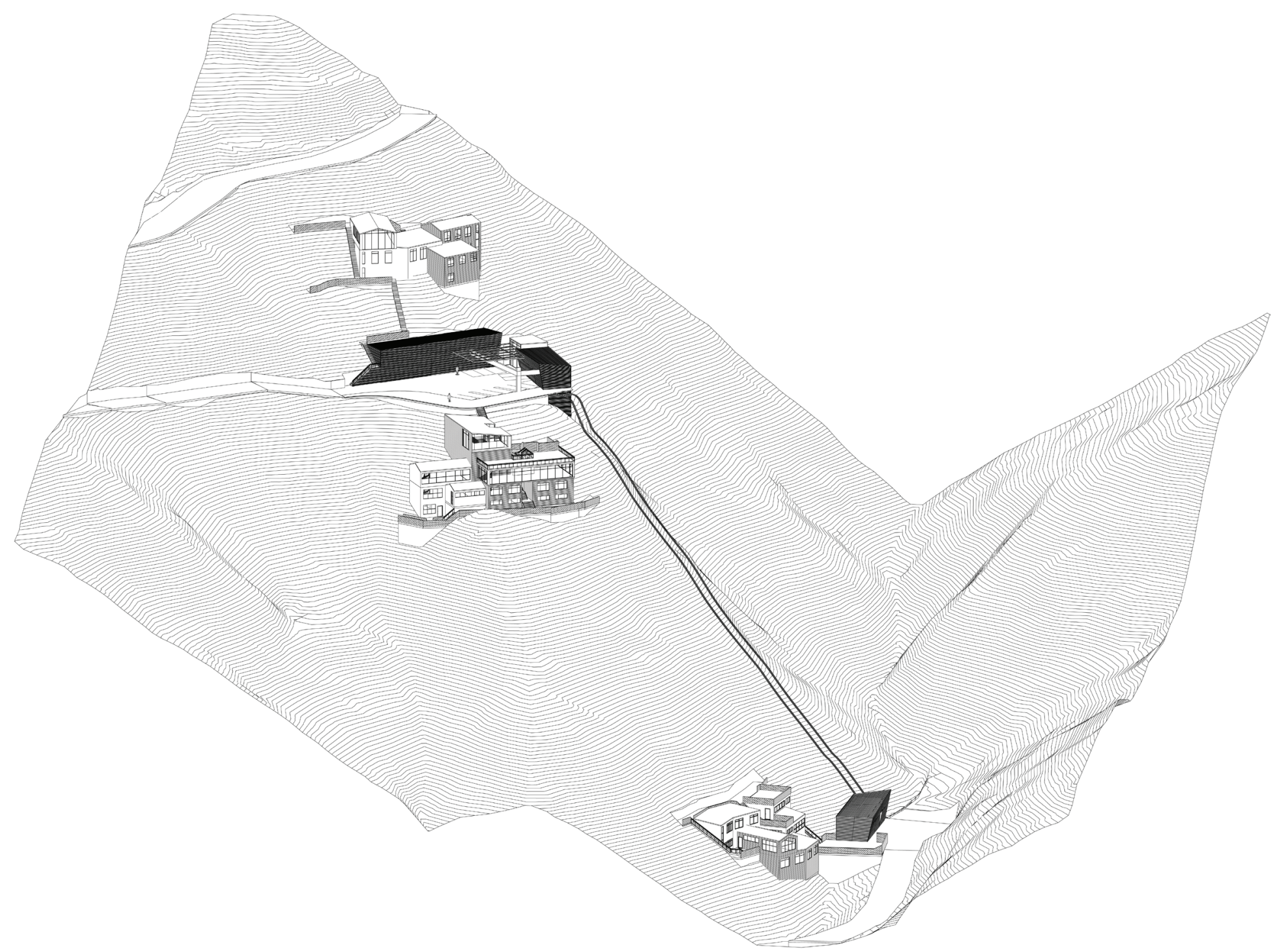

$\begin{array}{ll}<\text { fig: } 4.22 & \begin{array}{l}\text { Seed Stage } \\ \text { Source: Autho }\end{array}\end{array}$

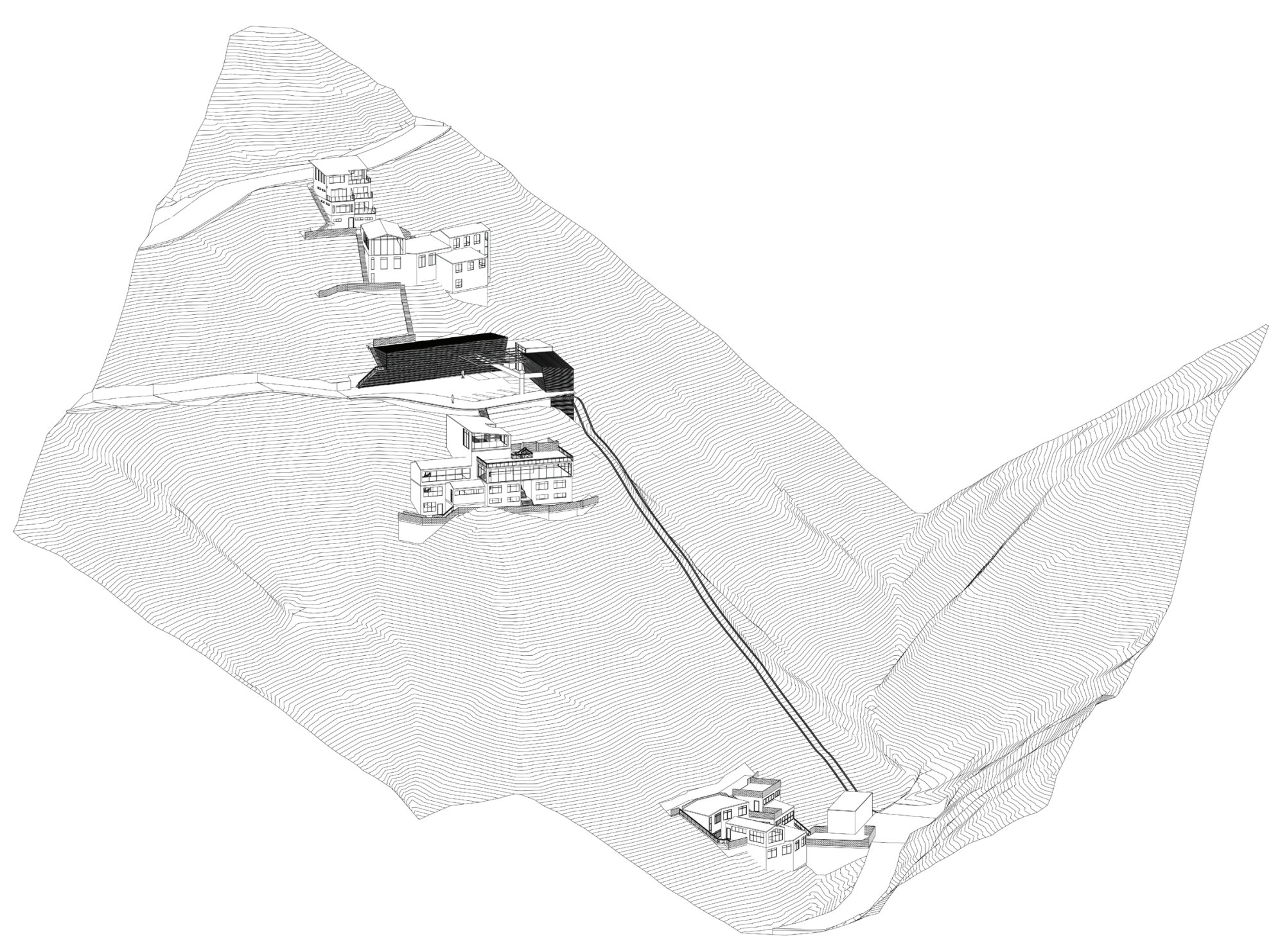

<fig:4.23 Seed Stage + 1 dwelling 


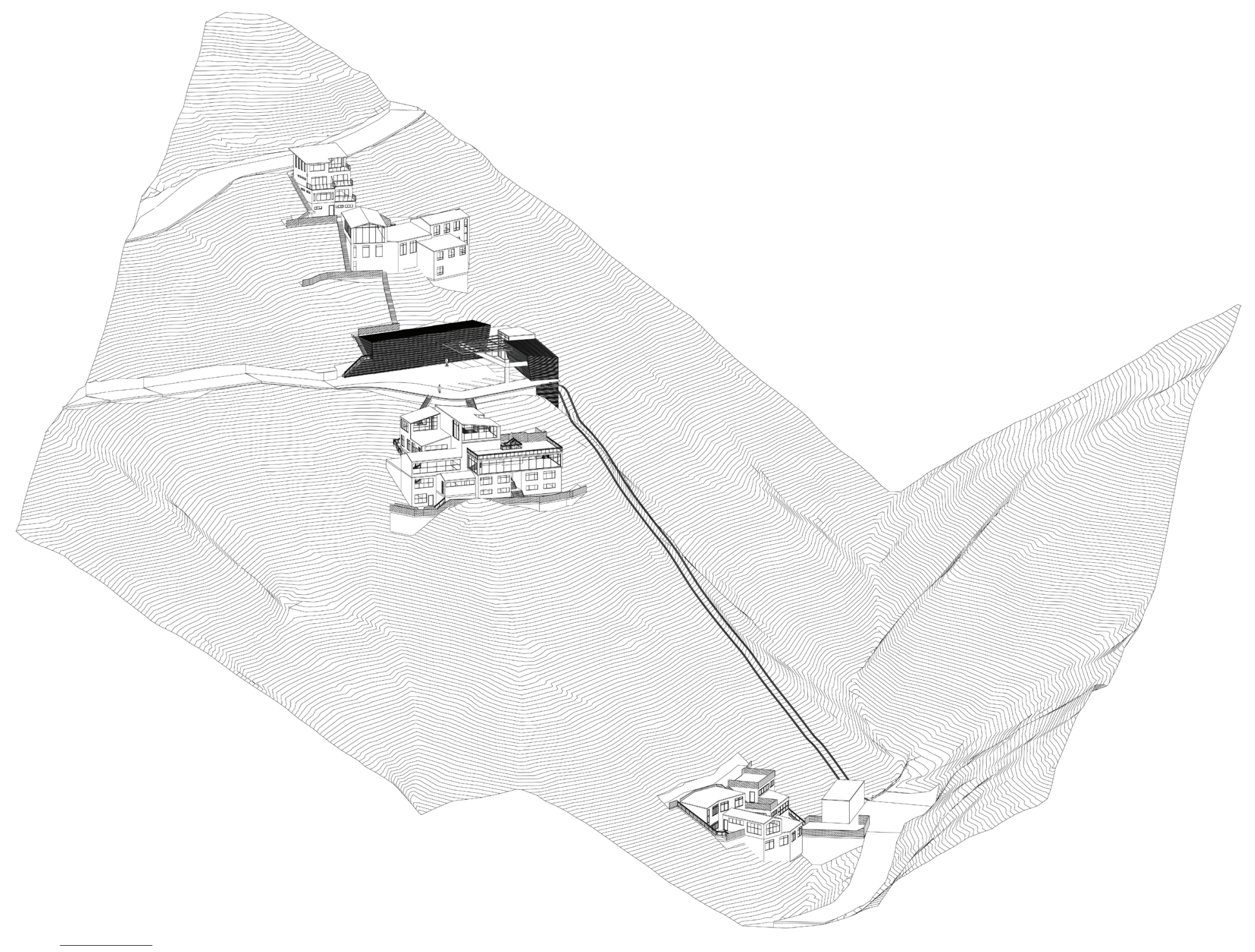

<fig:4.24 Seed Stage +2 dwellings

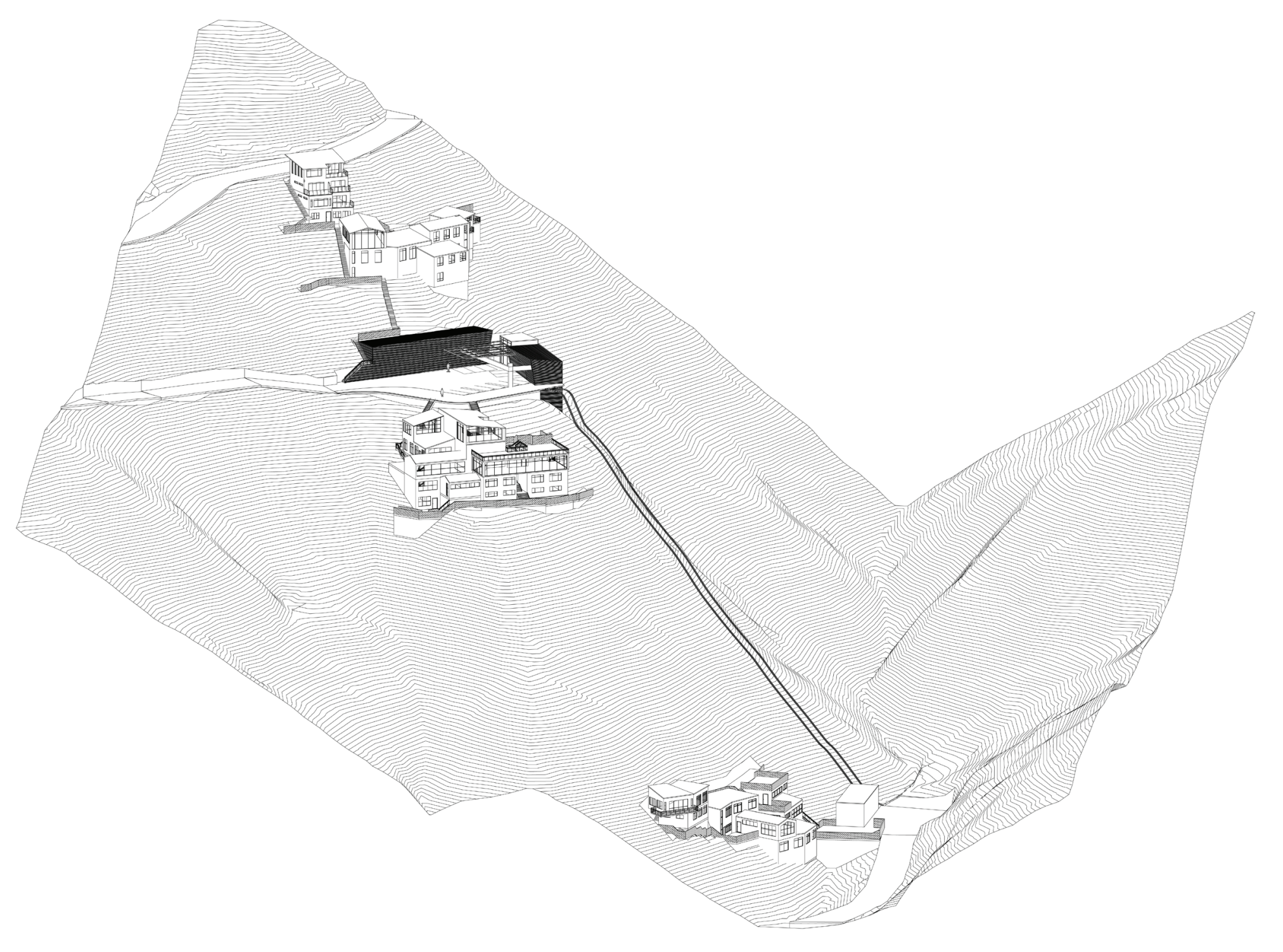

$<$ fig: 4.25 Seed Stage +3 dwellings Source: Author 


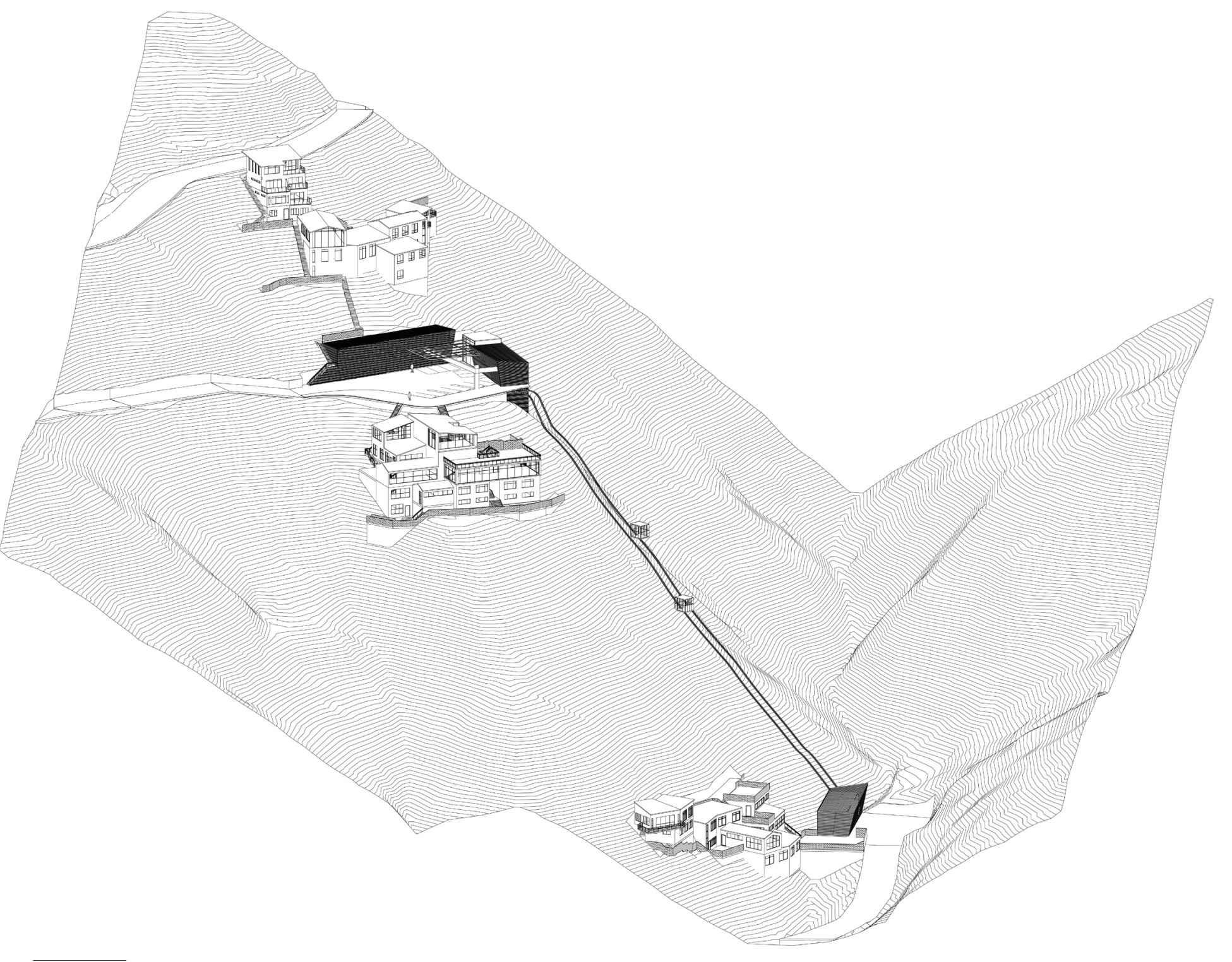

<fig: 4.26 Seed Stage + 4 dwellings Source: Autho

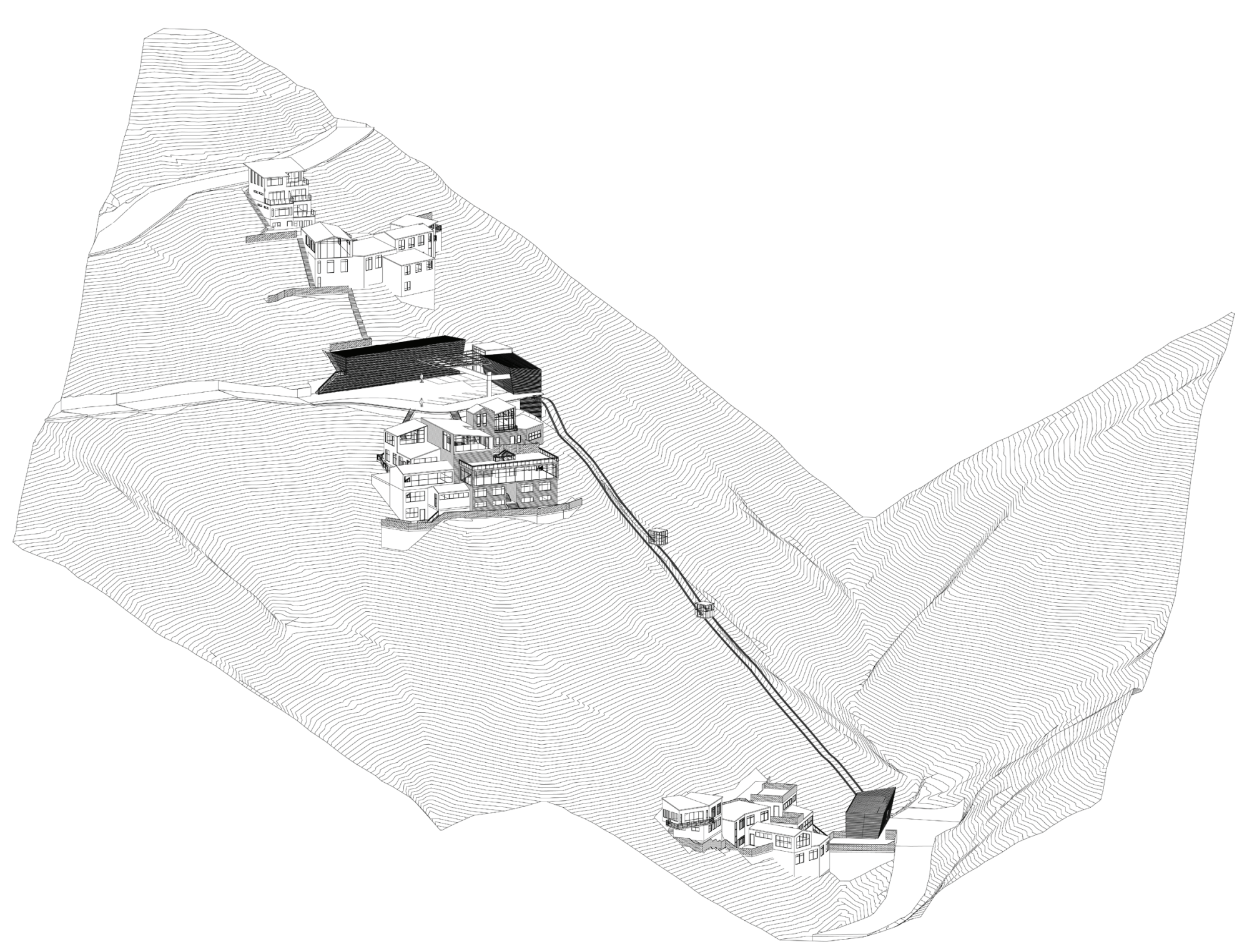

< fig: 4.27 Seed Stage +5 dwellings. 


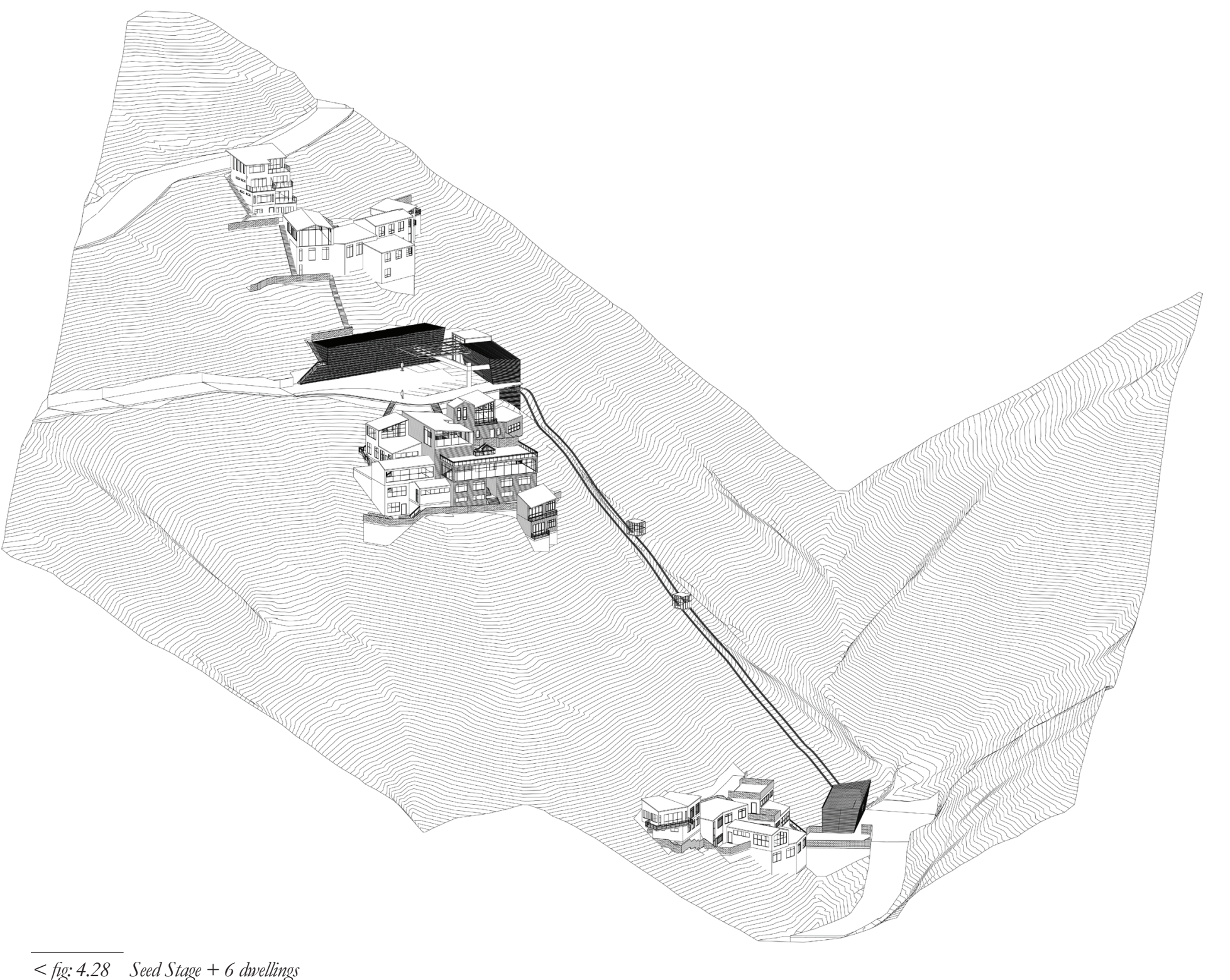

Source: Author

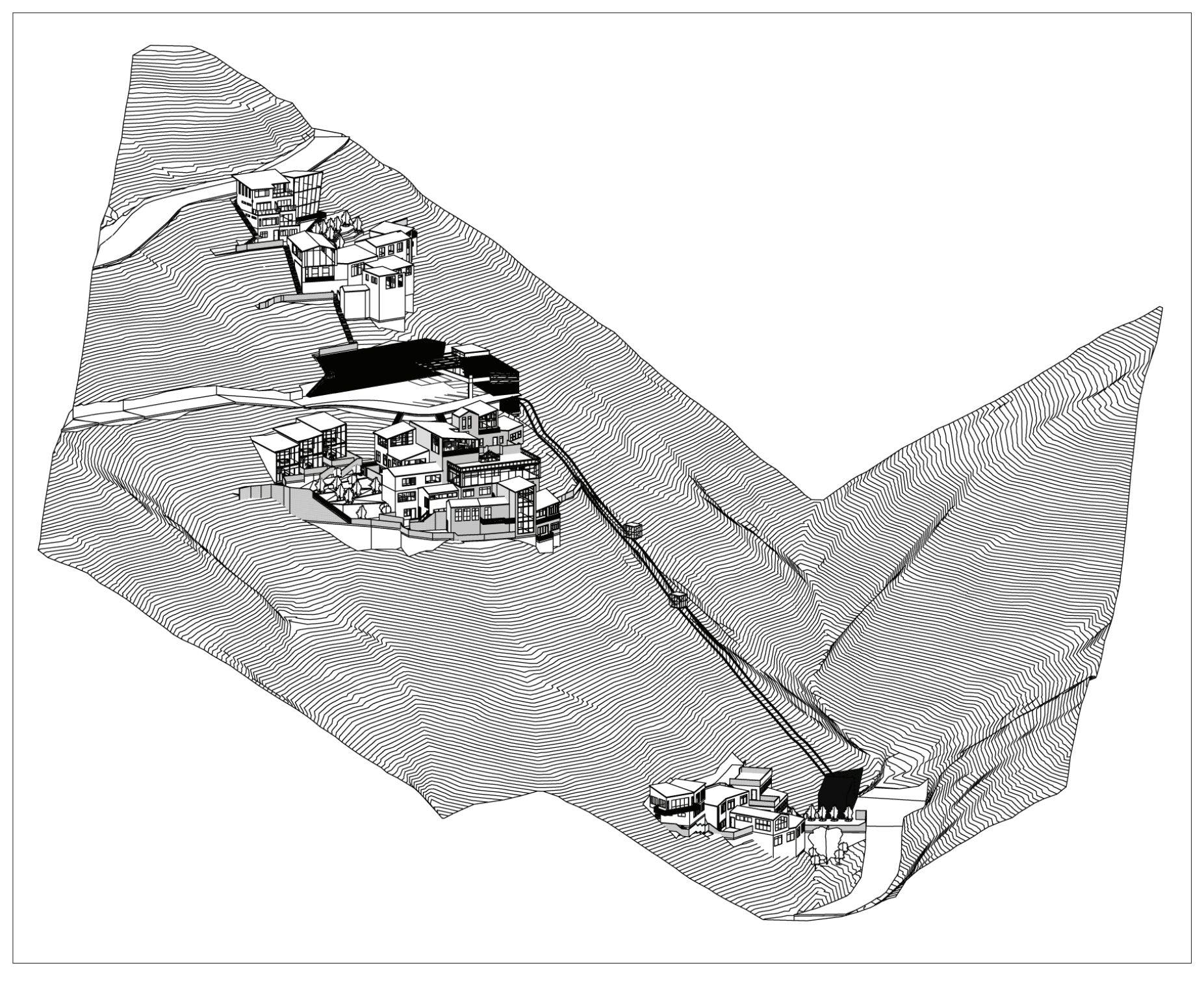

This image looks at the second

stage of the development as a

reference point.

$\overline{<\text { fig: } 4.29 \text { Stage }}$

Stage 2
Source: Author 

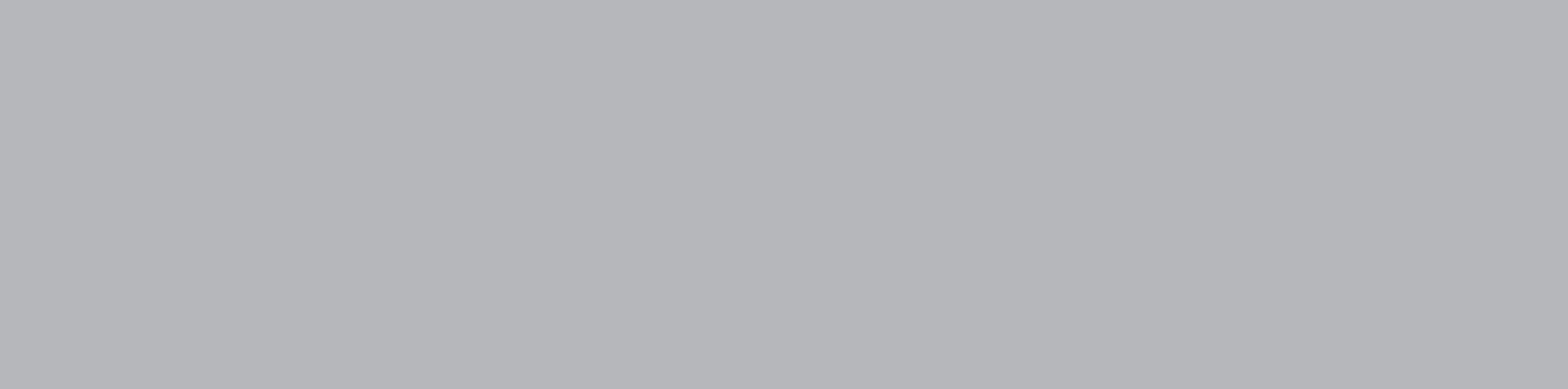

2

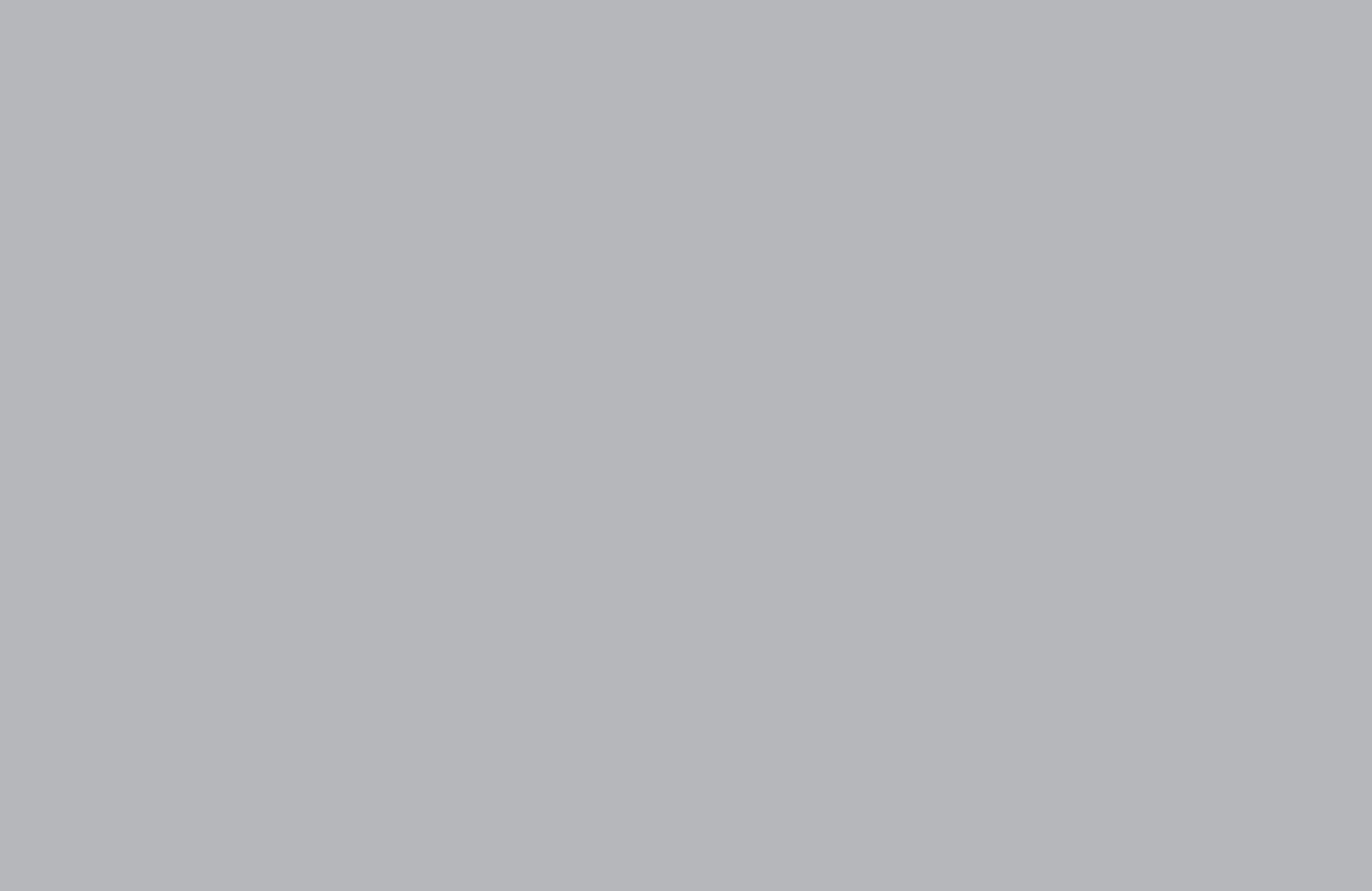



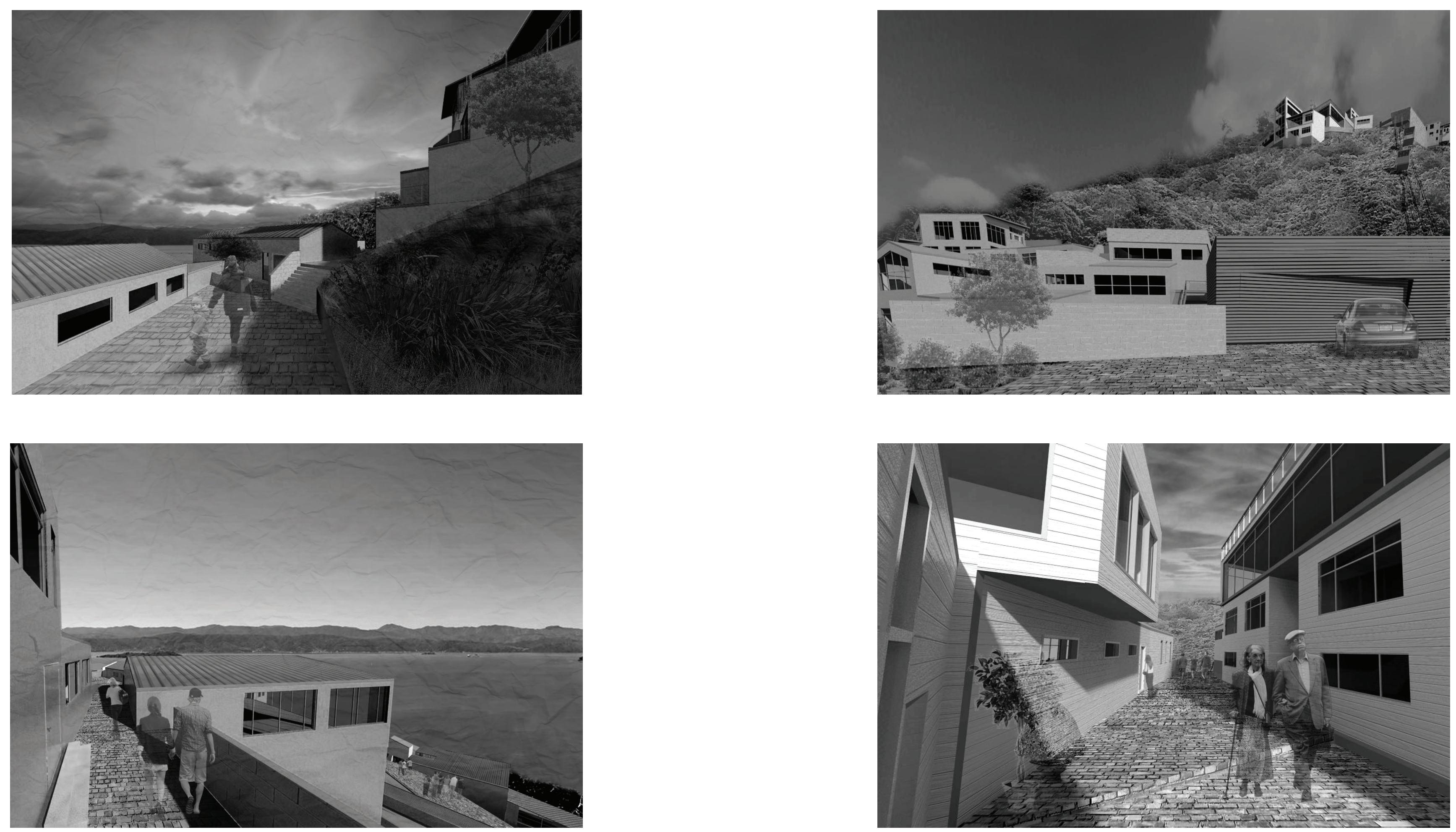


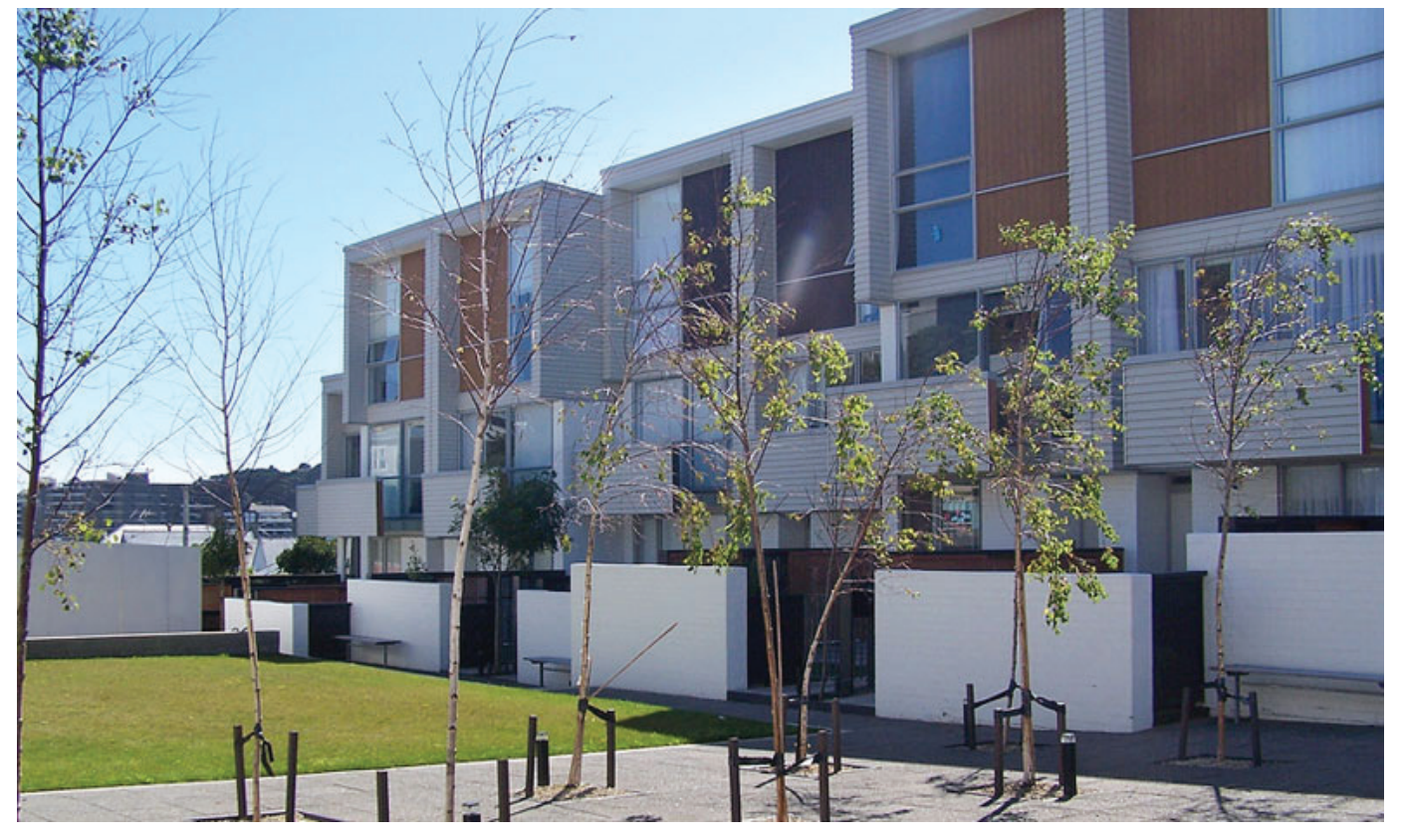

This next stage of the design simulation is focusing less on the propagation of the project and more on the development of certain areas in order to test the amenity of the proposal. The test of the success or otherwise of this project lies in the viability and amenity of the dwellings. Given the designs from stage 1 and with additions both from a curatorial (design committee) role and from outside designers designing new dwellings, this stage looks at taking sketch design phases and testing them at a higher level of resolution and detail.

$<$ fig:5.1 New Zealand Medium Density Houssing

Source: Ministry for the Environment (2016) 


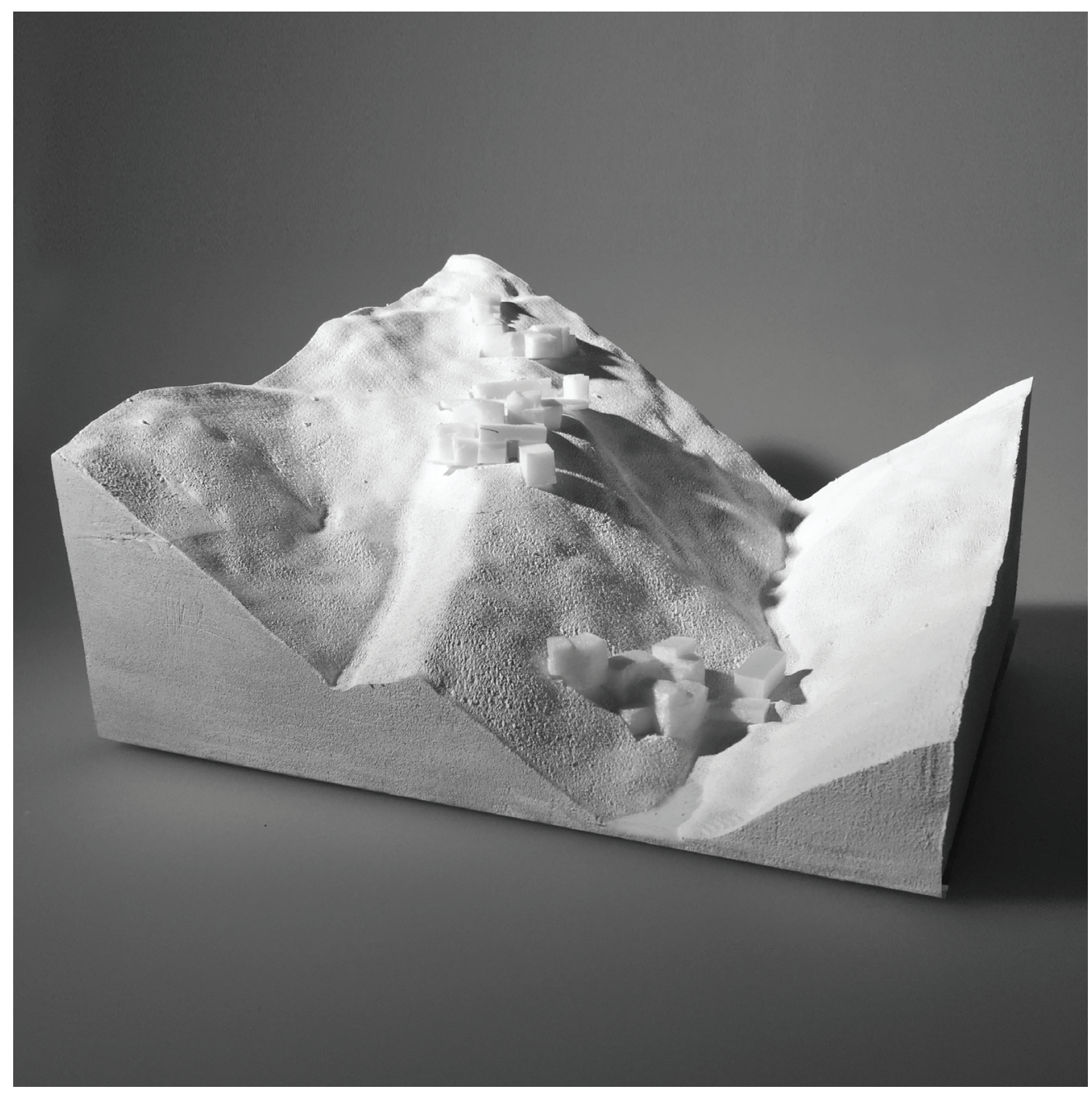

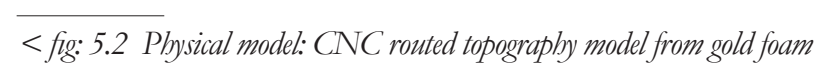
Source: Autho

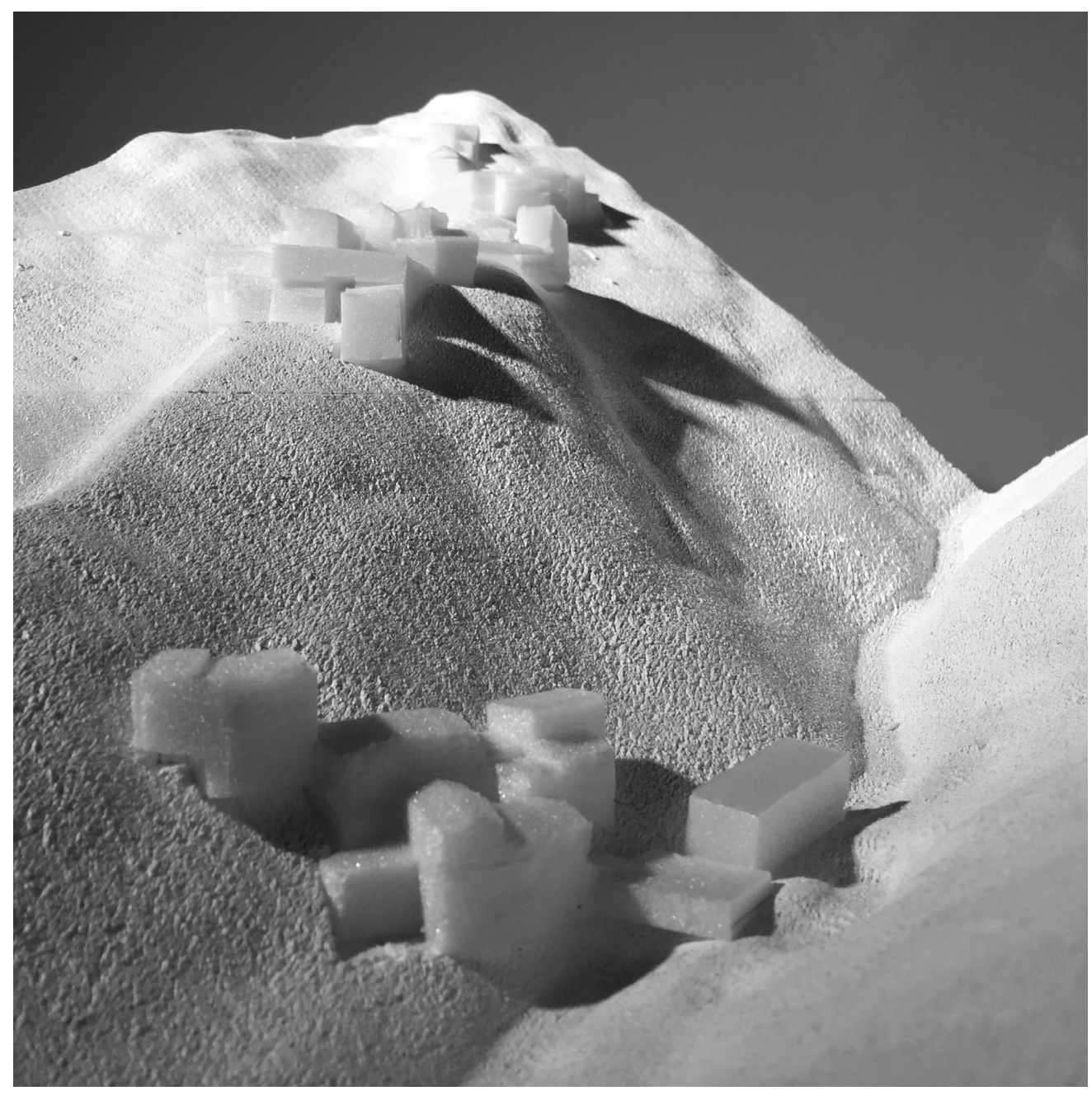

$<$ fog: 5.3 Pyssial modele: This model was given to partitipants to show massing relations ship of duellings and topogranthy Source: Author 


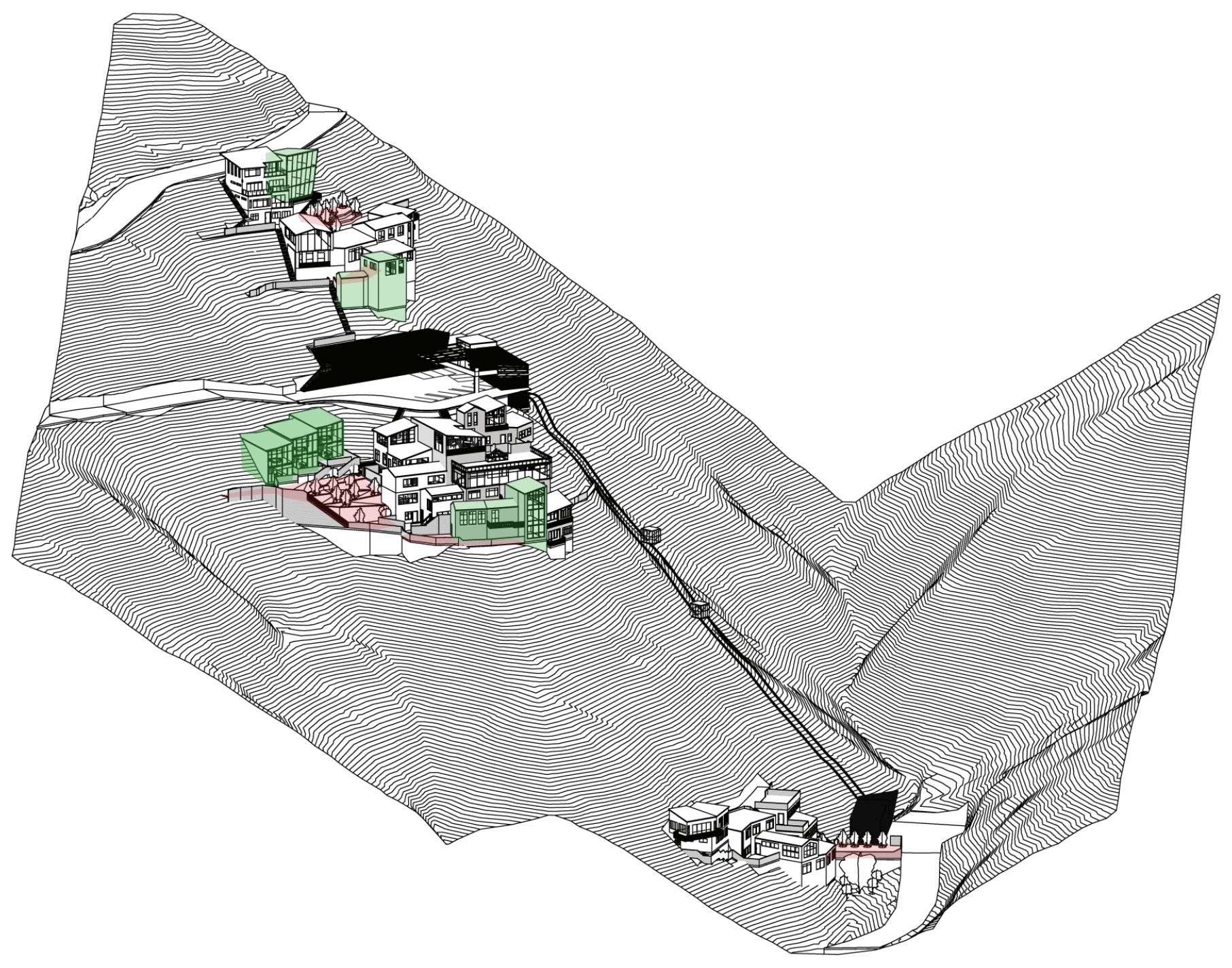



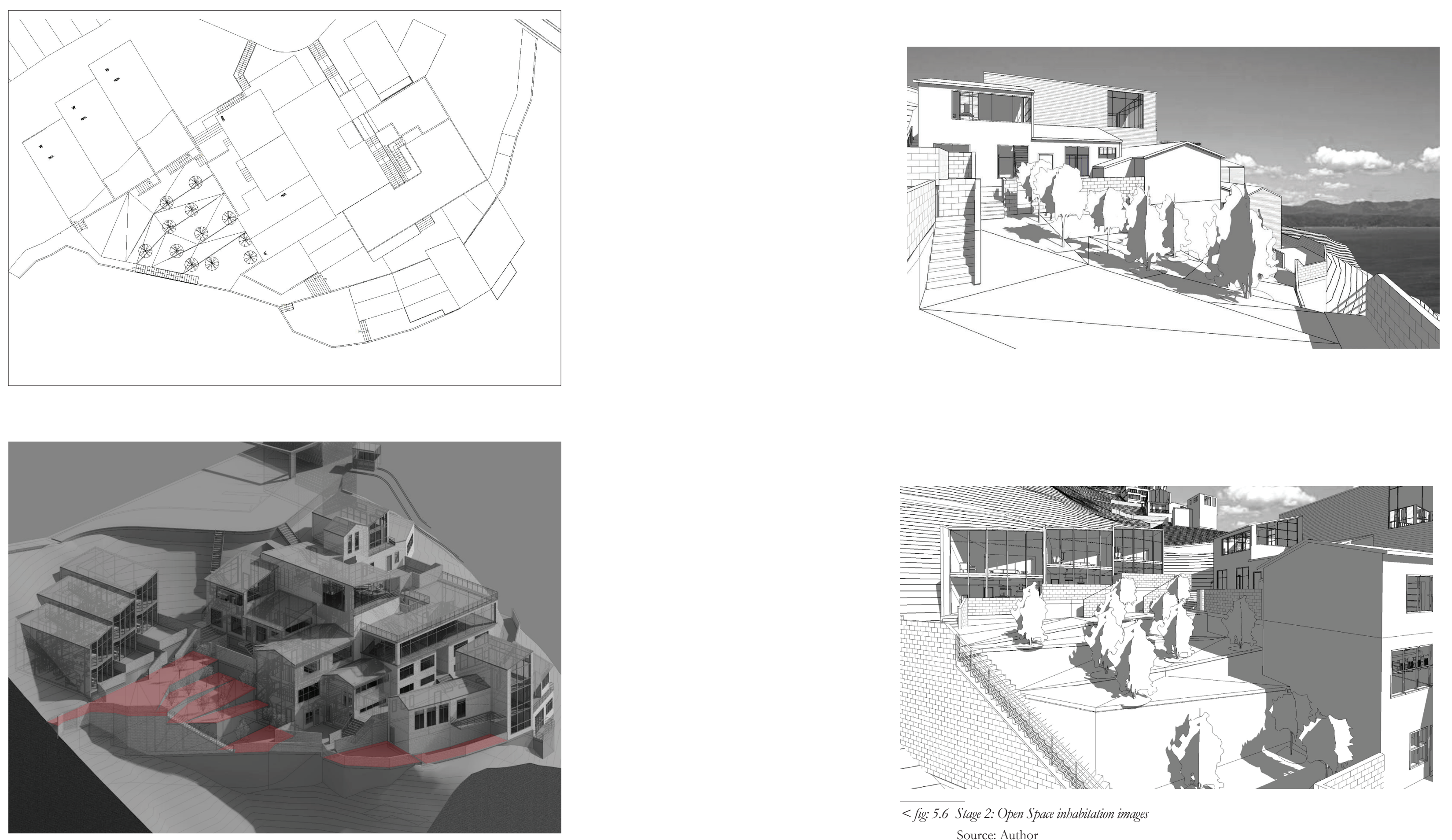

< ffg:5.5 Stage 2: Open Spar Source: Author 


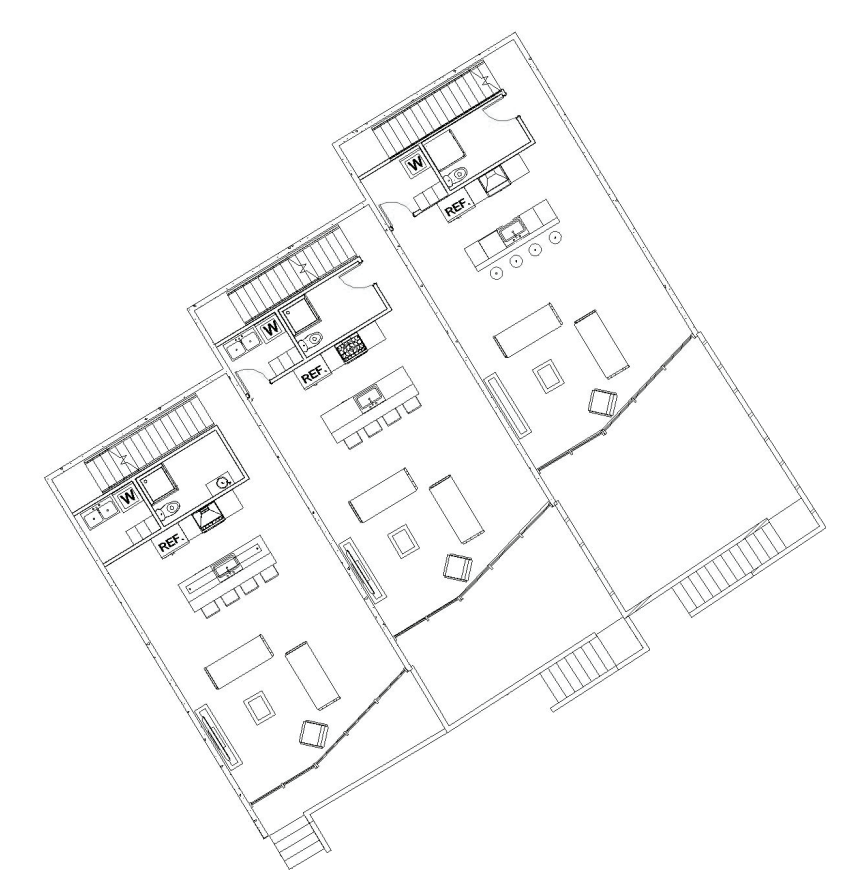

$\overline{\text { Ground Floor }}$

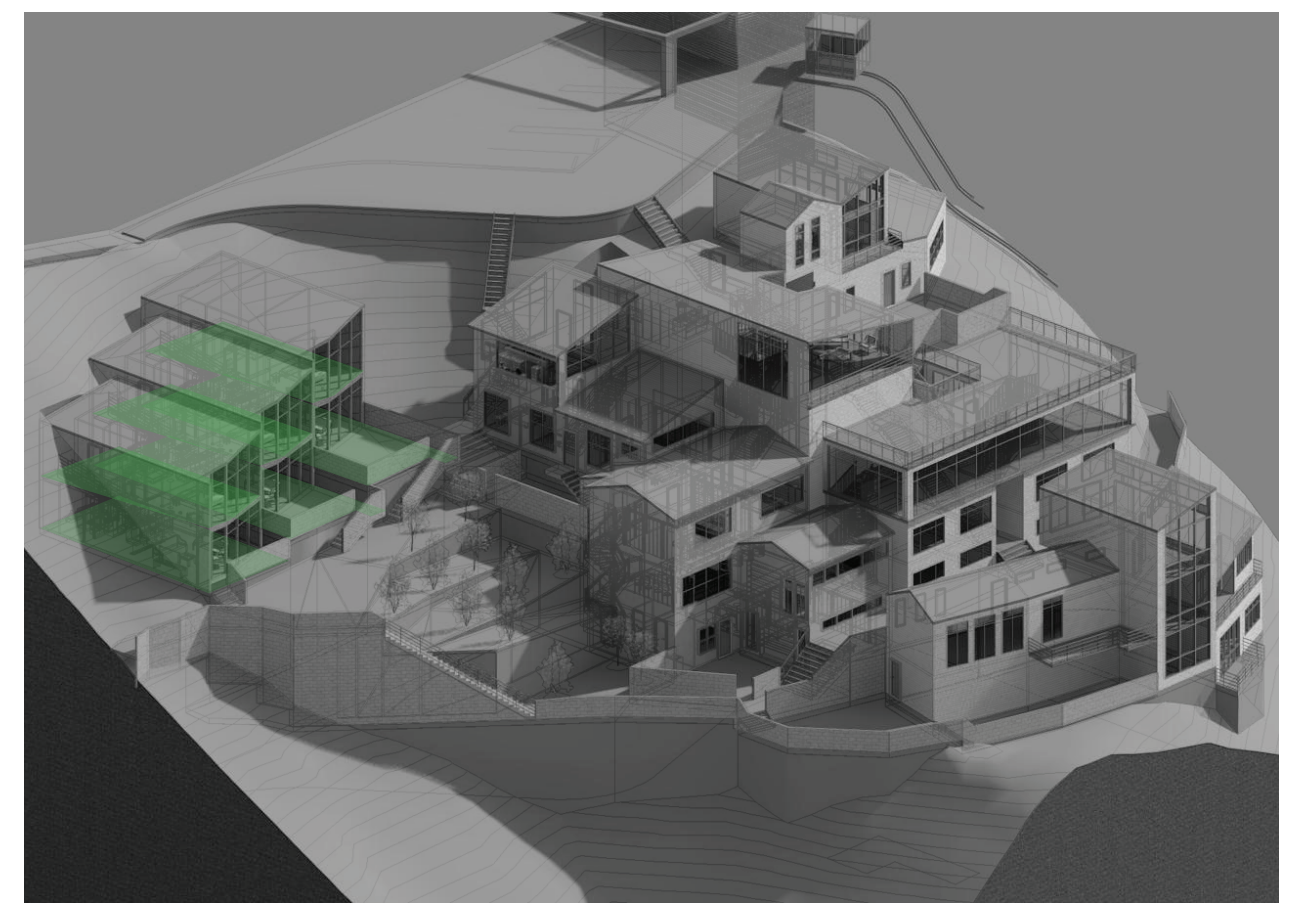

< fig: 5.7 Stage 2: Apartments

Source: Author

First Floor
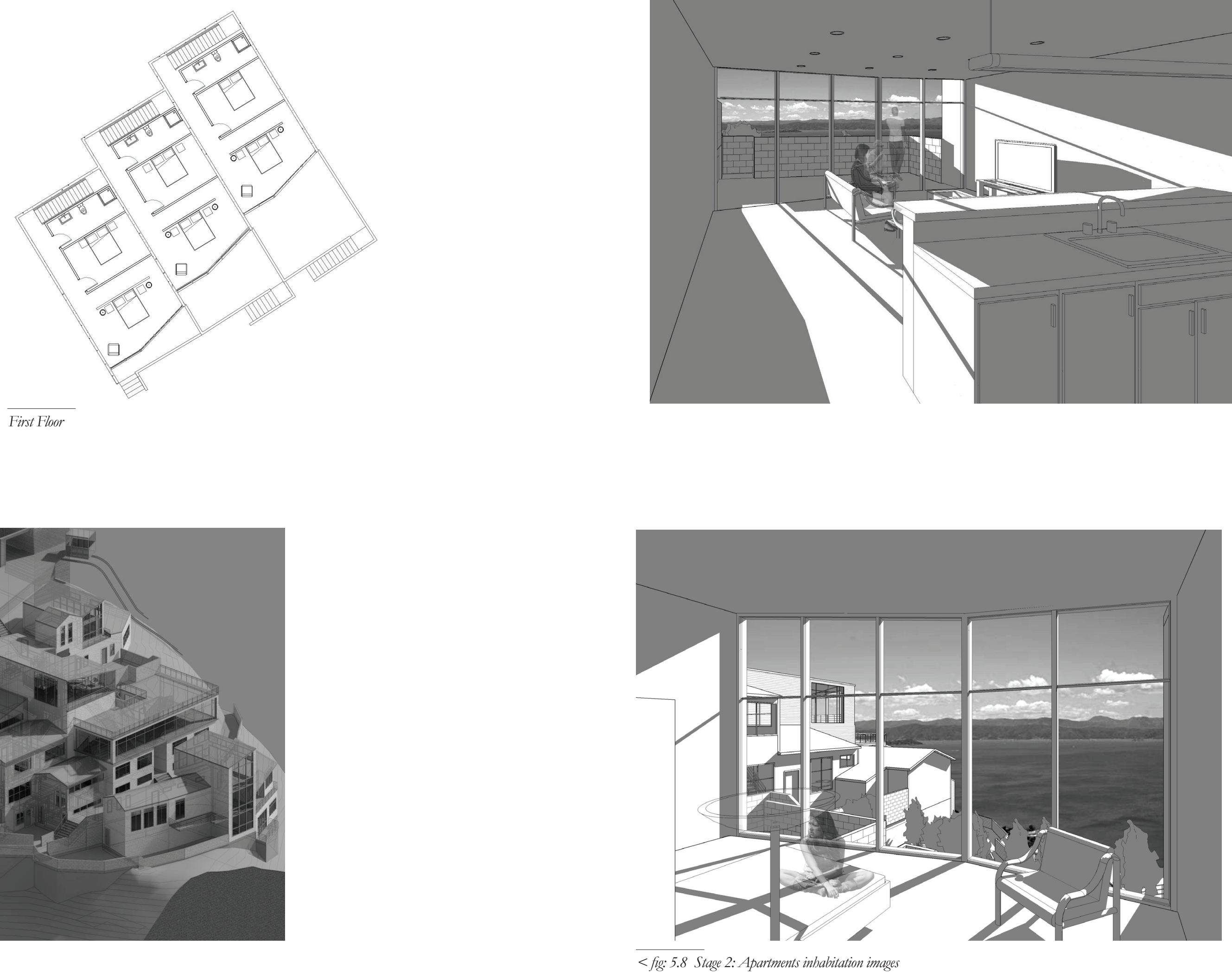

Source: Author 


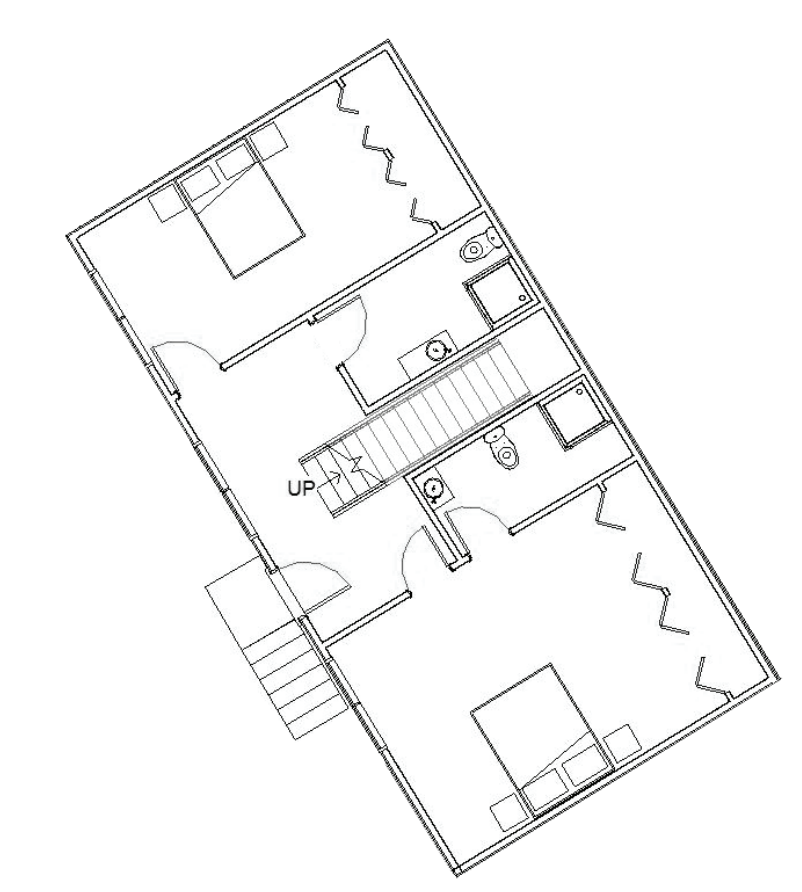

$\overline{\text { Ground Floor }}$

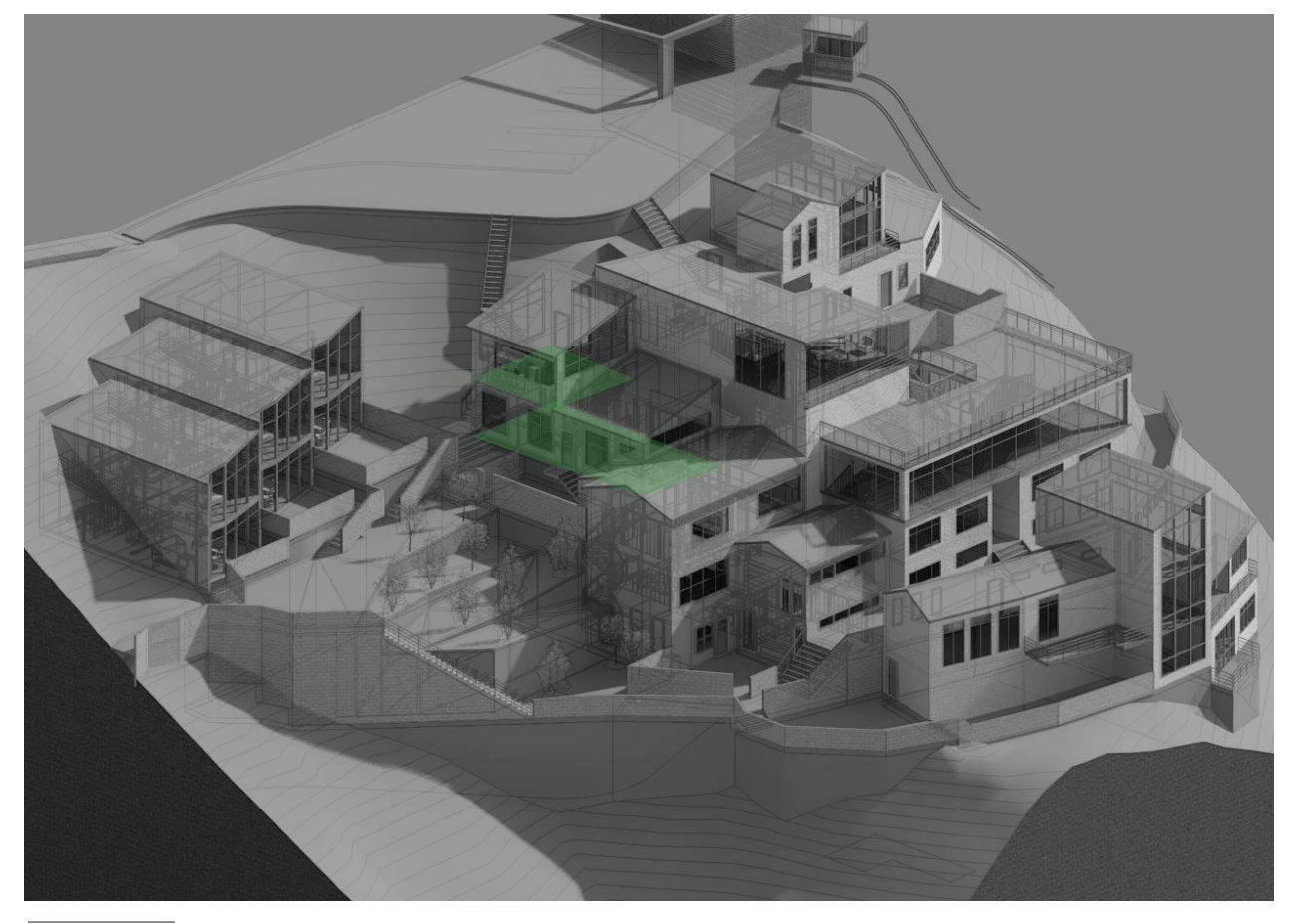

< fig:5.9 Stage 2: House 1

Source: Author
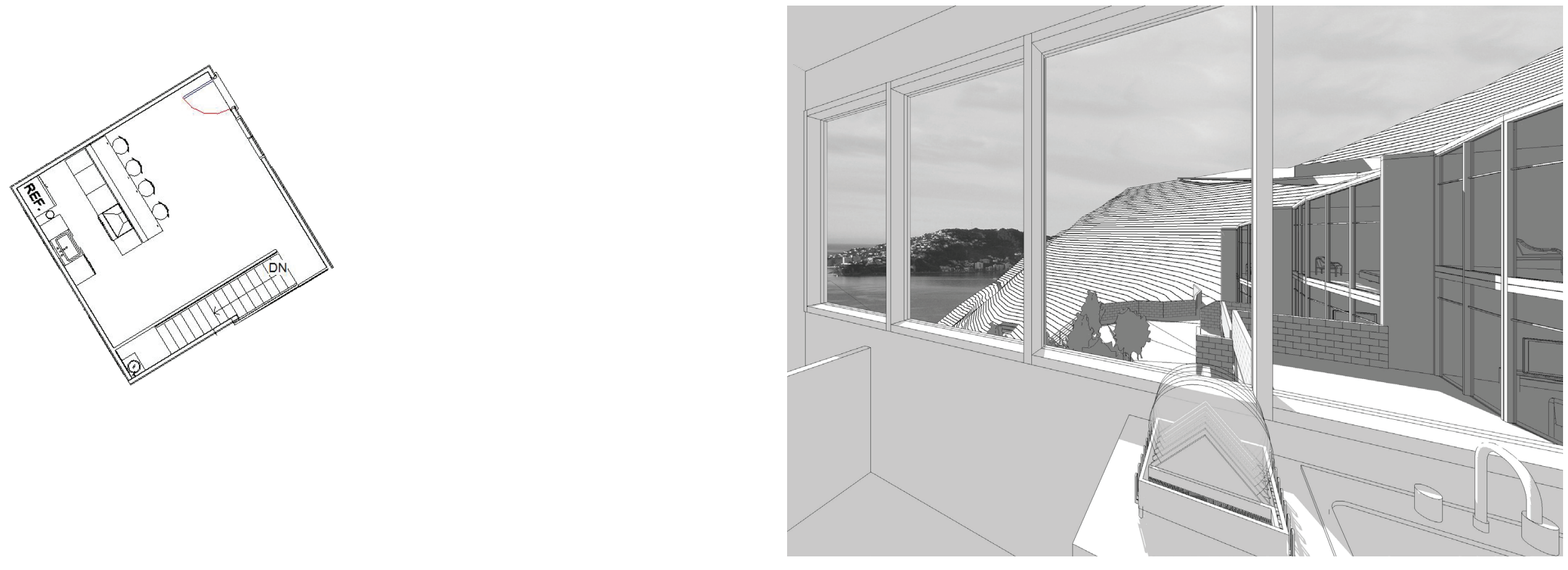

First Floor

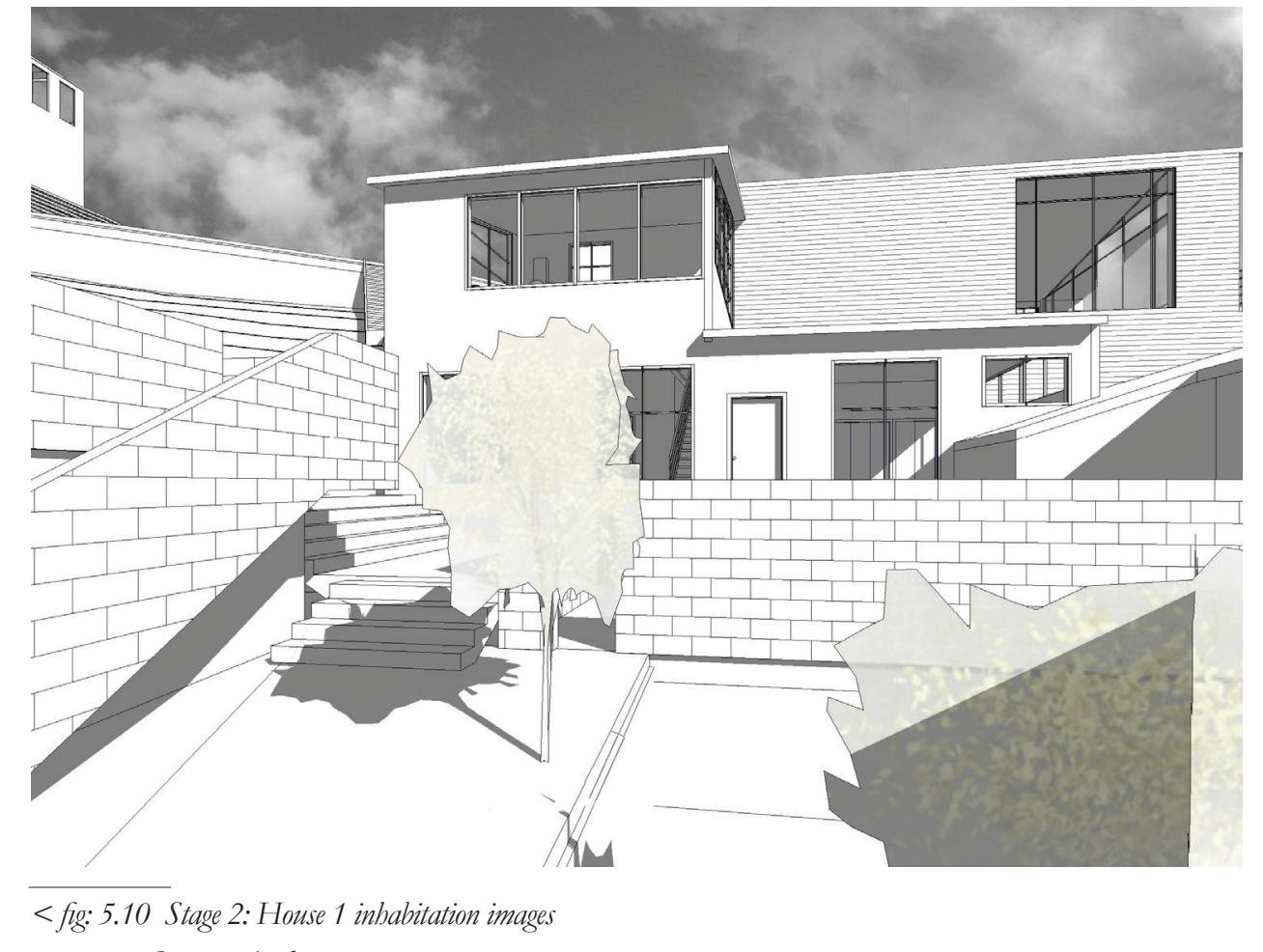

Source: Author 


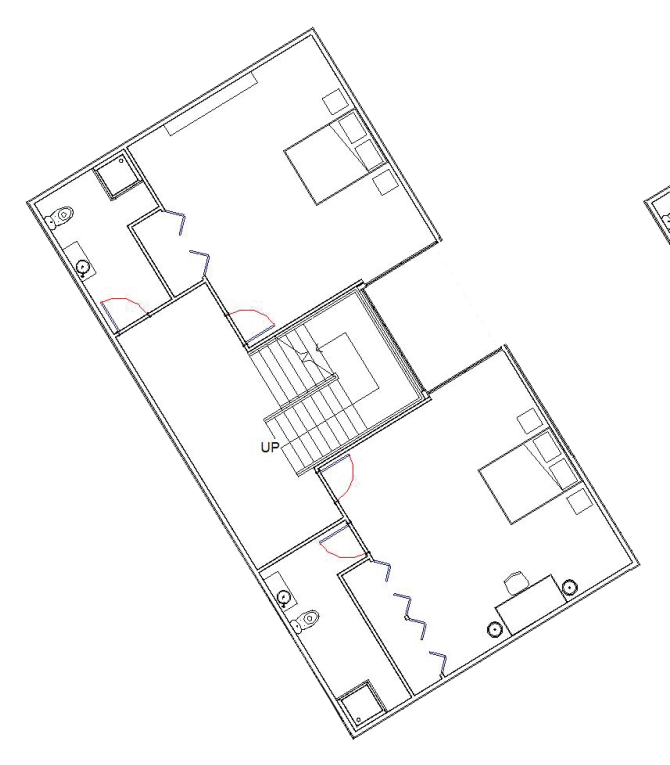

Ground Floor

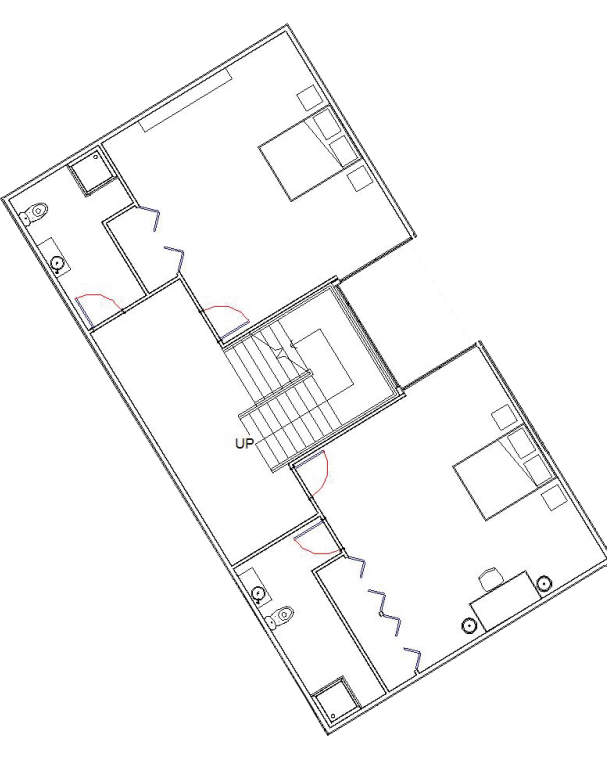

First Floor

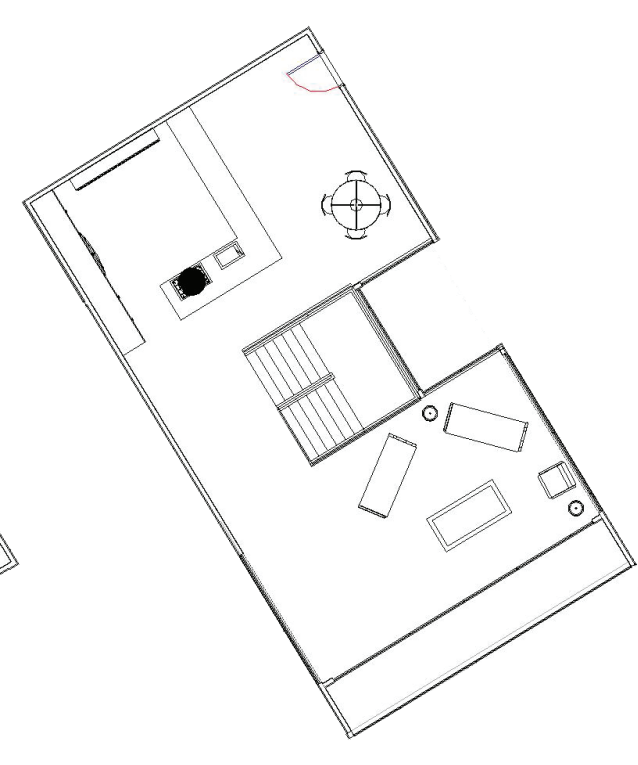

Second Floor
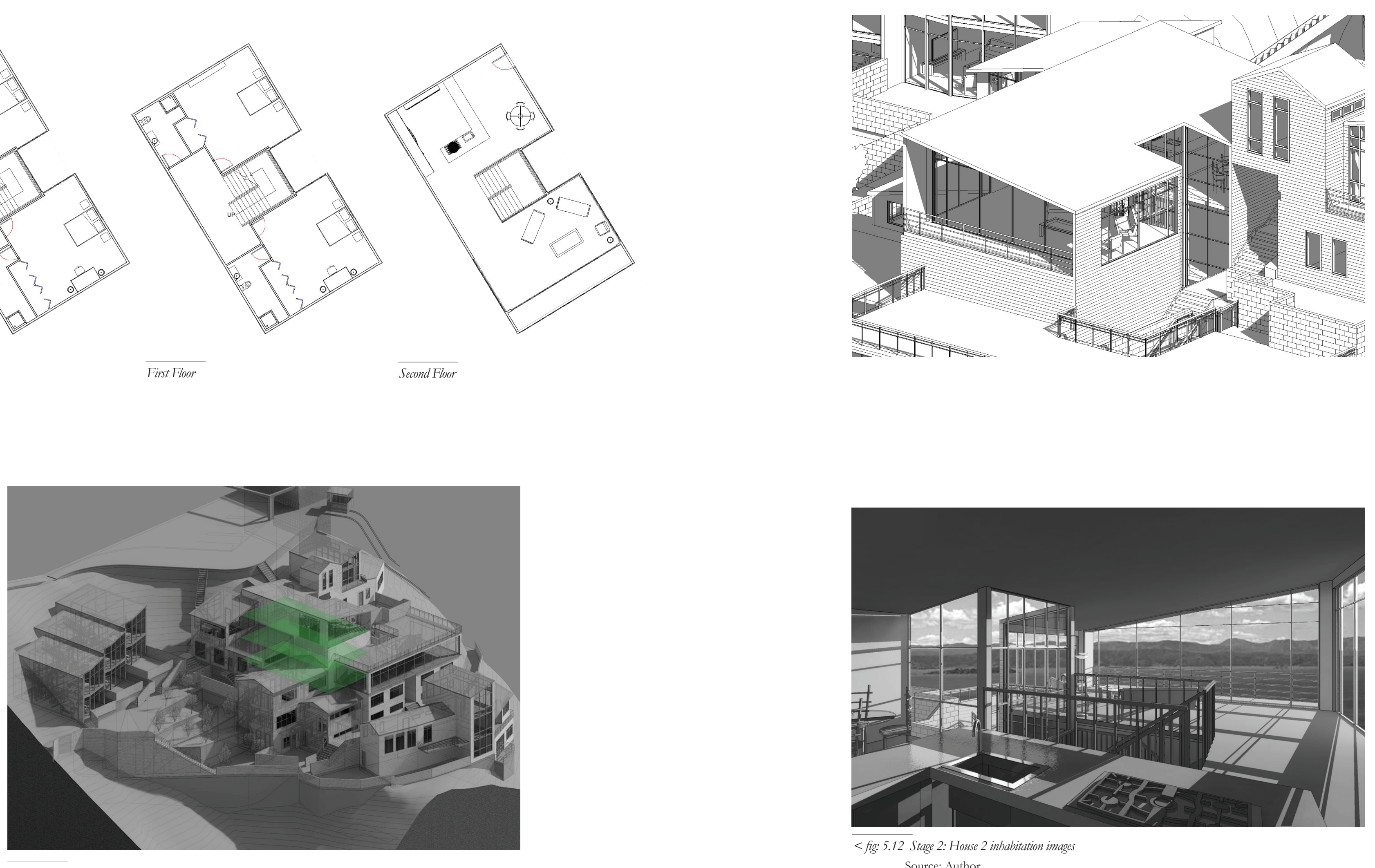


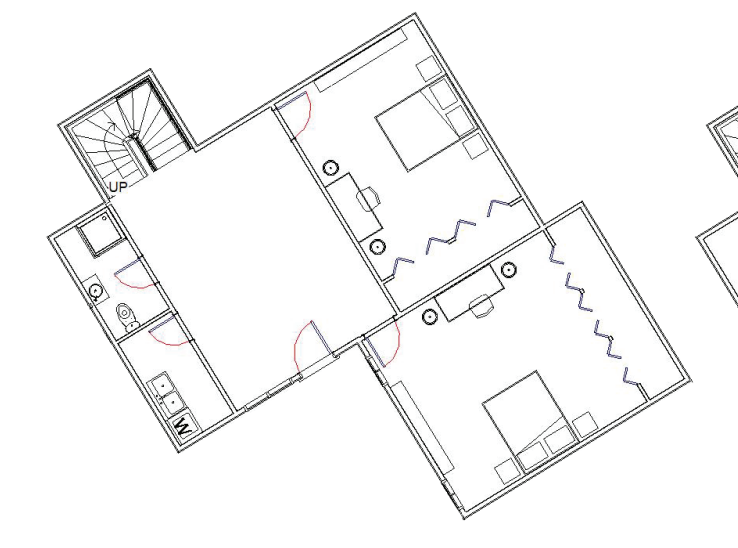

$\overline{\text { Ground Floor }}$

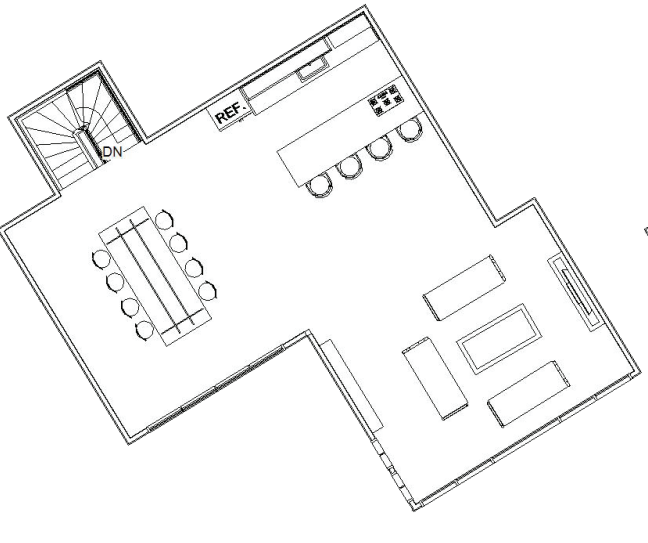

First Floor

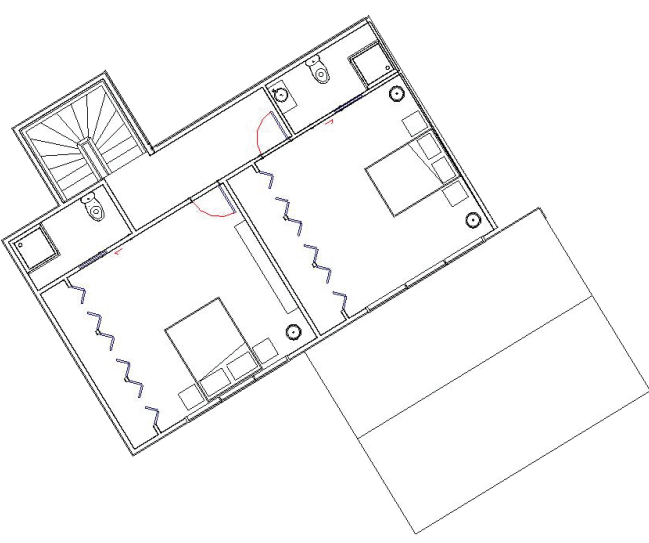

$\overline{\text { Second Floor }}$
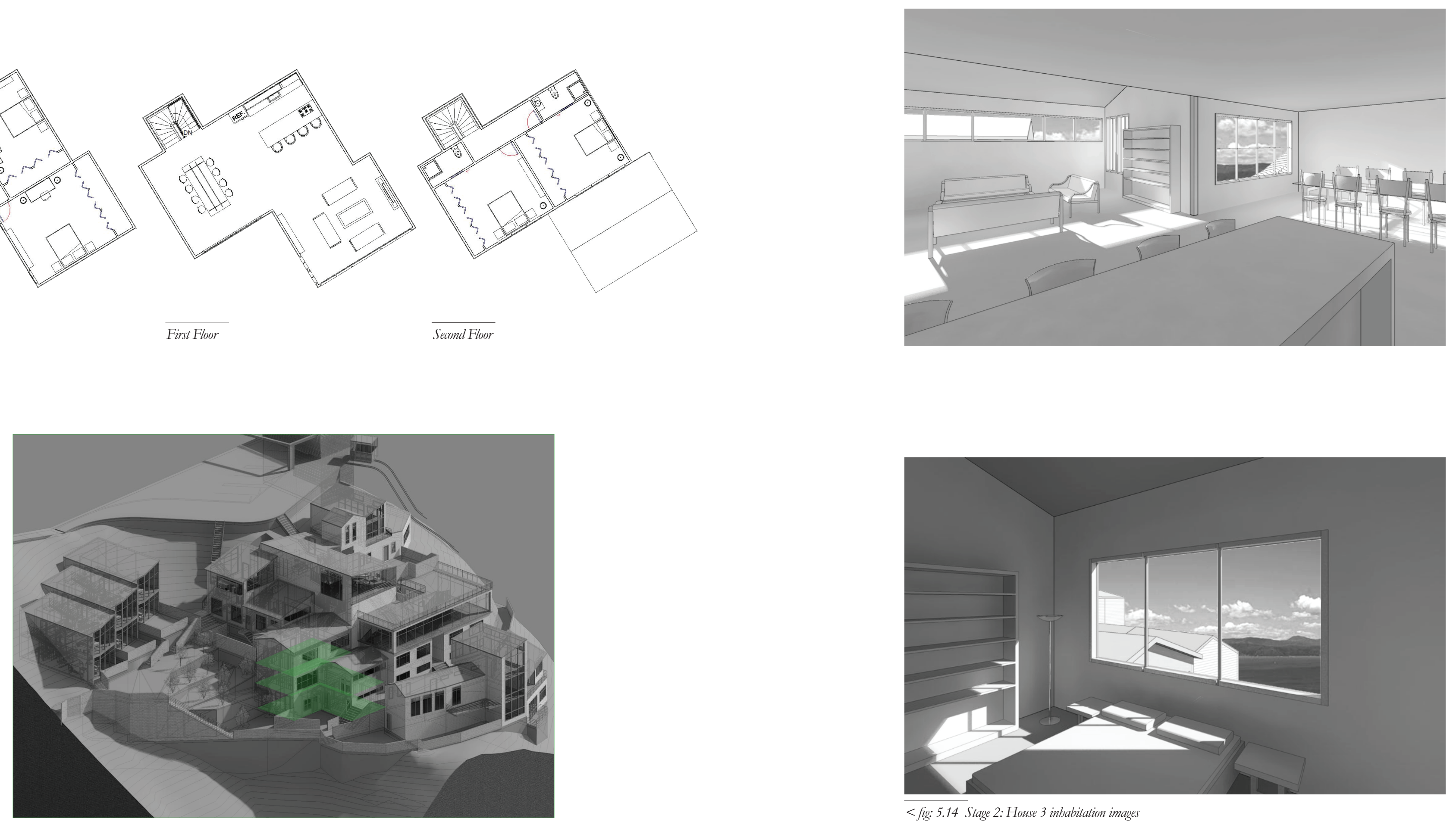

< fig:5.13 Stage 2: House 3 Source: Author

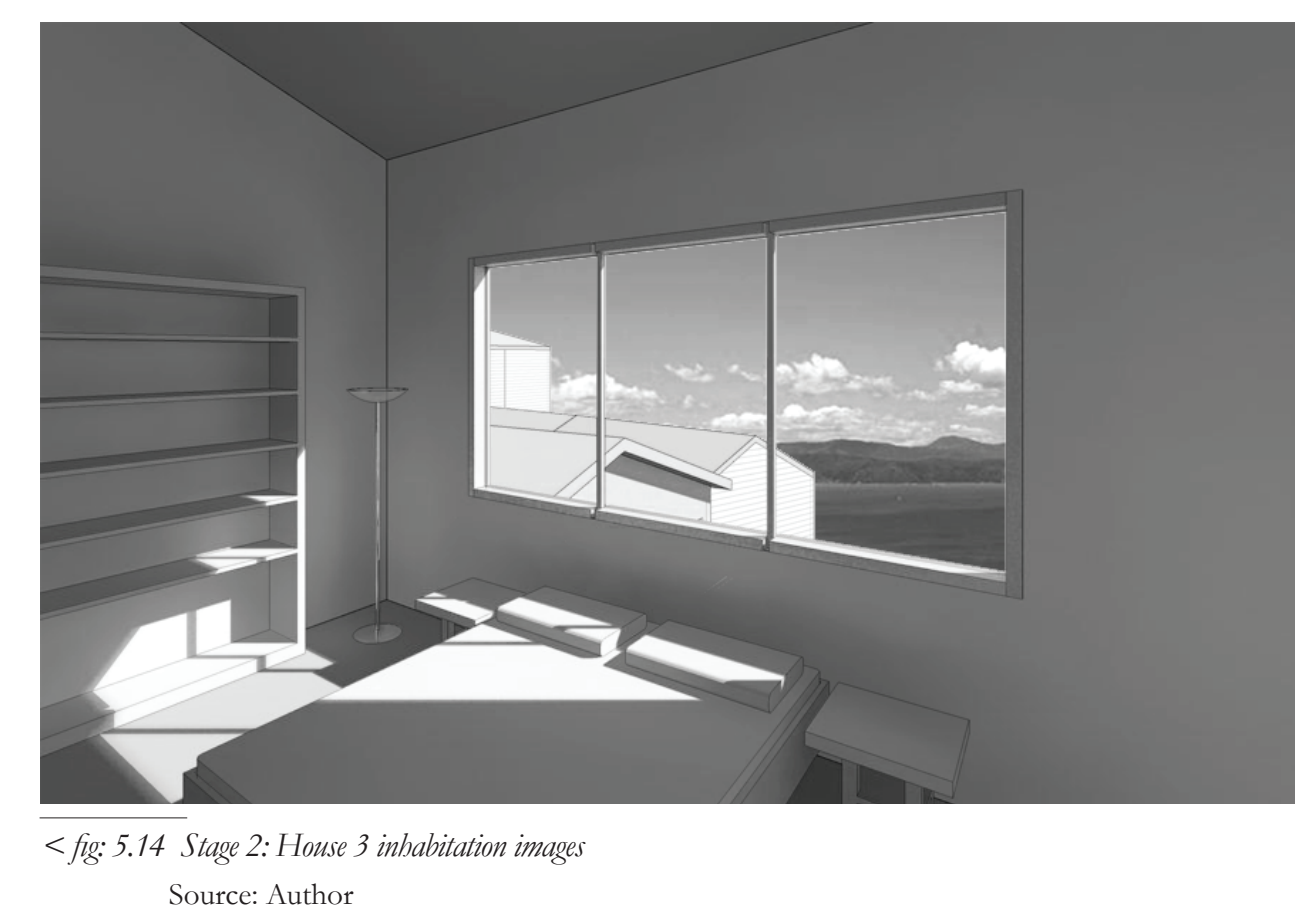




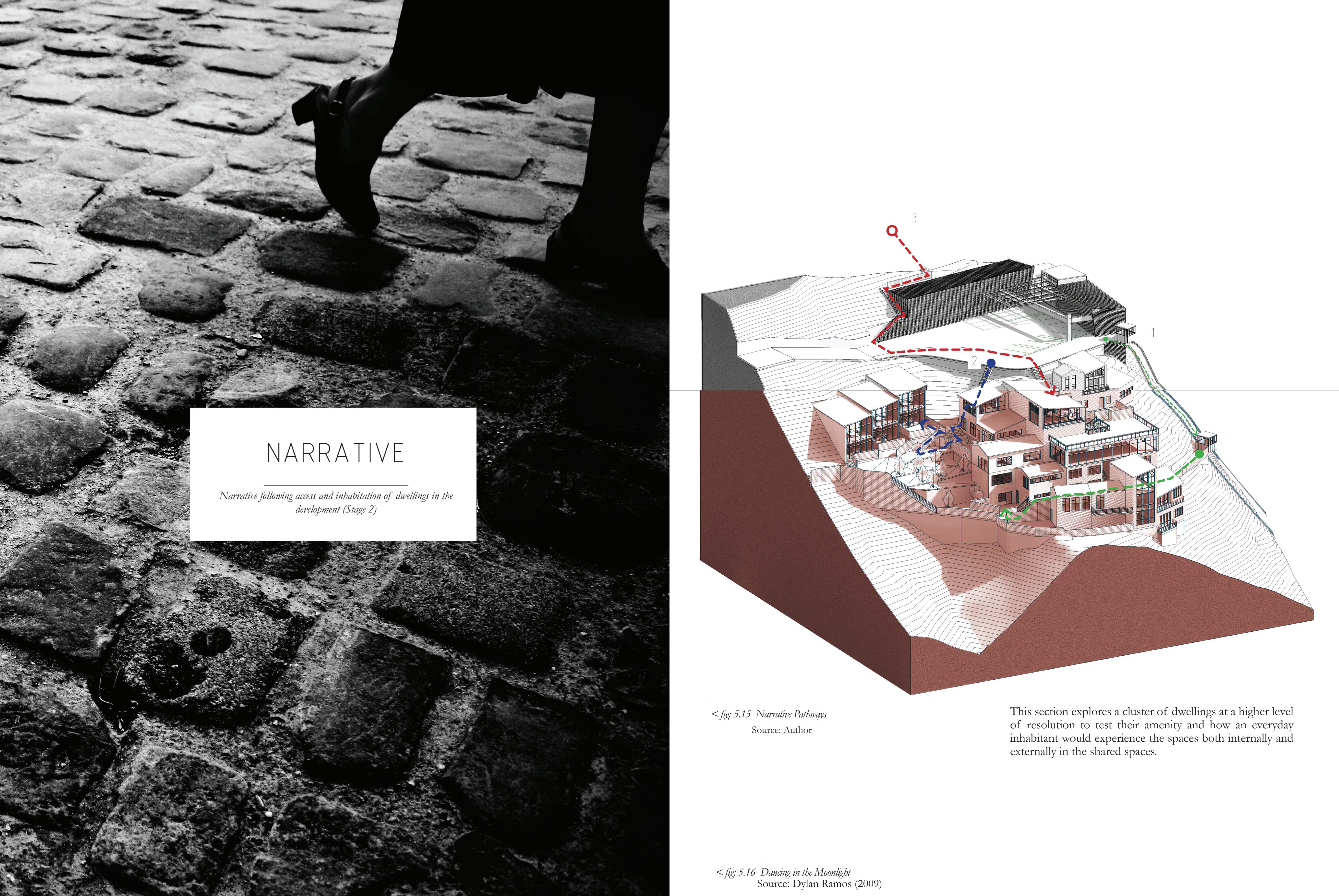




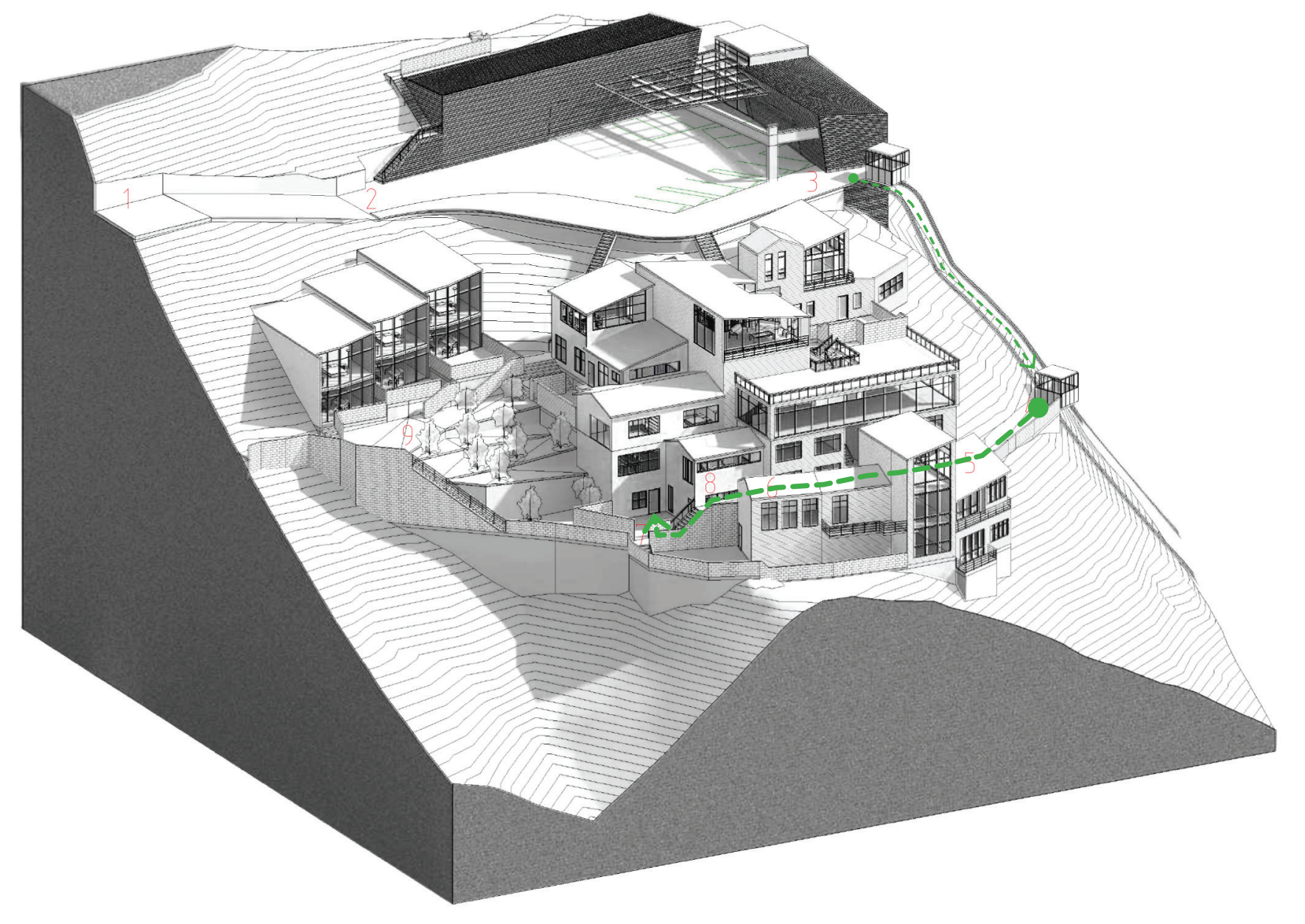

Focus on individual dwellings, demonstrating the narrative of the access pathways and xperiential qualities of these

< fig: 5.17 Pathways/Access Routes
Source: Author
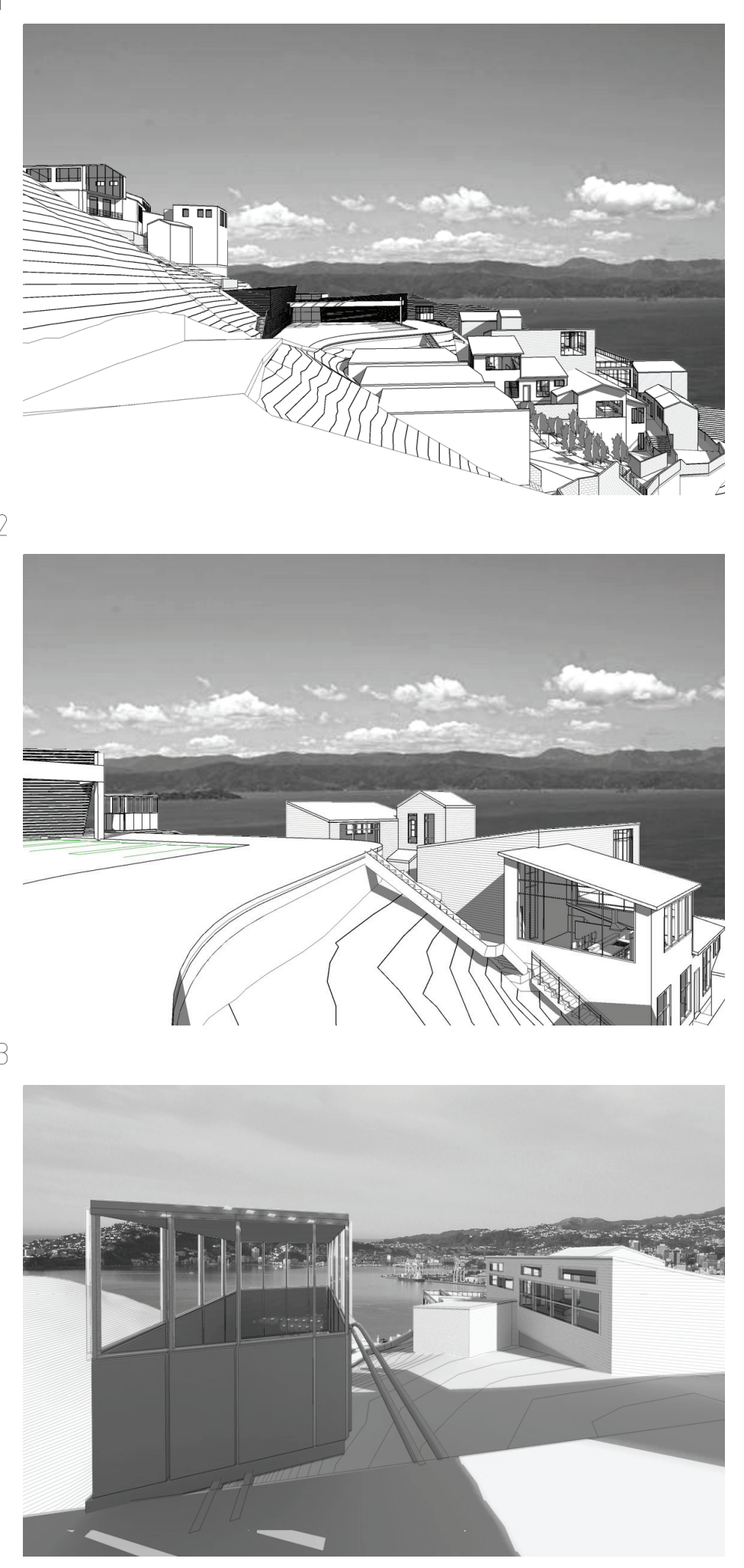

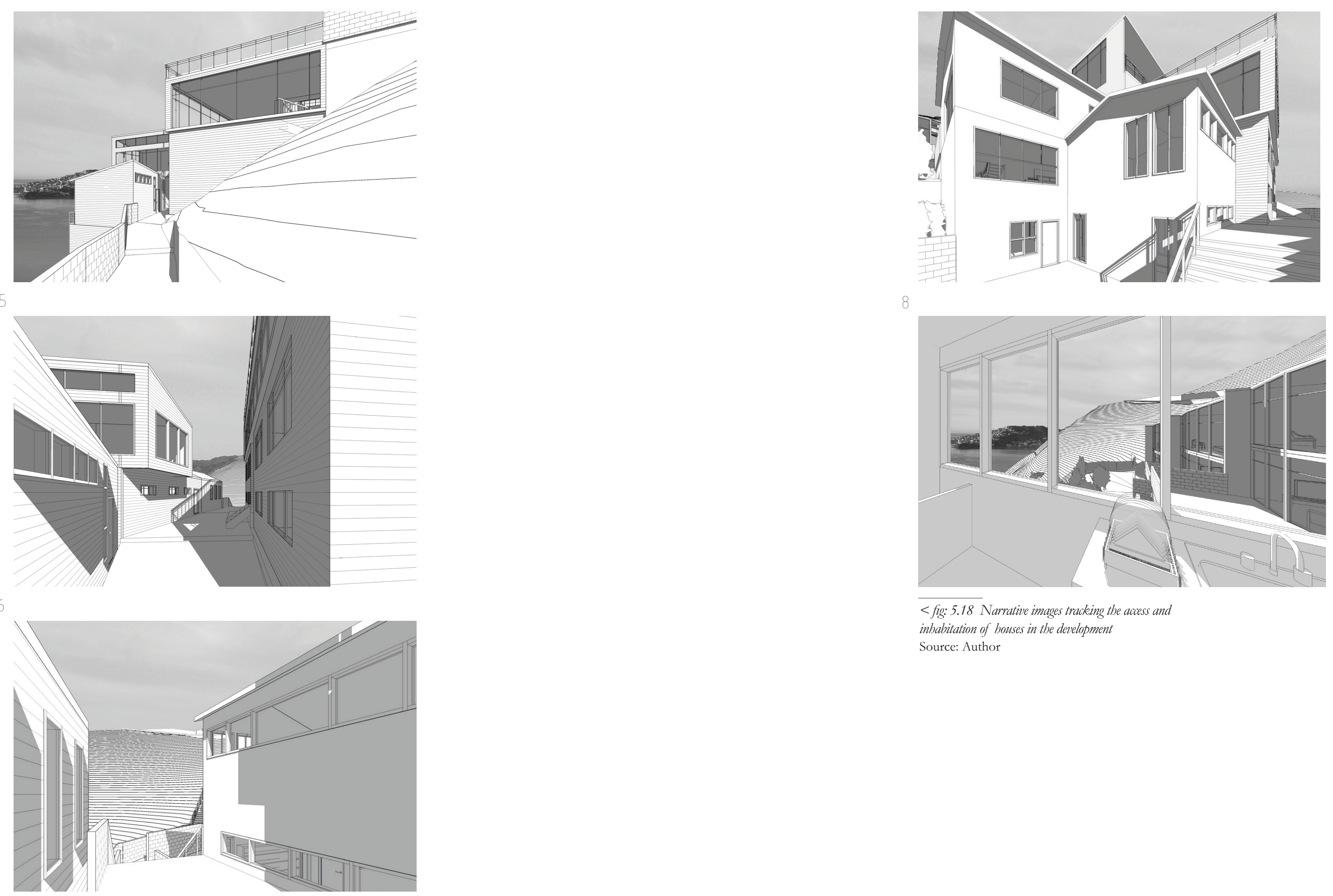

$<$ fig: 5.18 Narrative images tracking the access and

inhabitation of houses in the development

Source: Author 


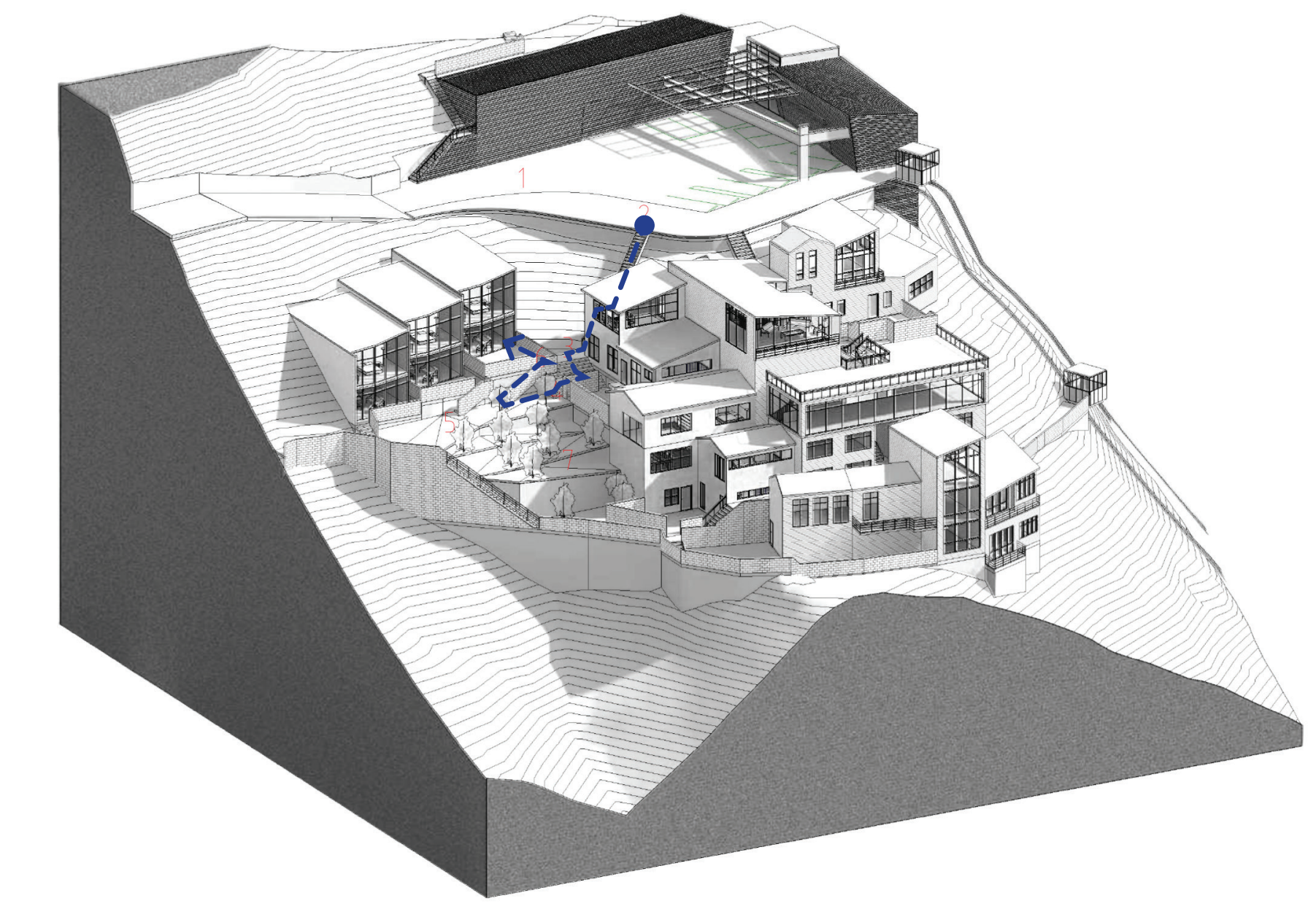

$<$ fig: 5.19 Pathways/Access Routes to apartments

Source: Author
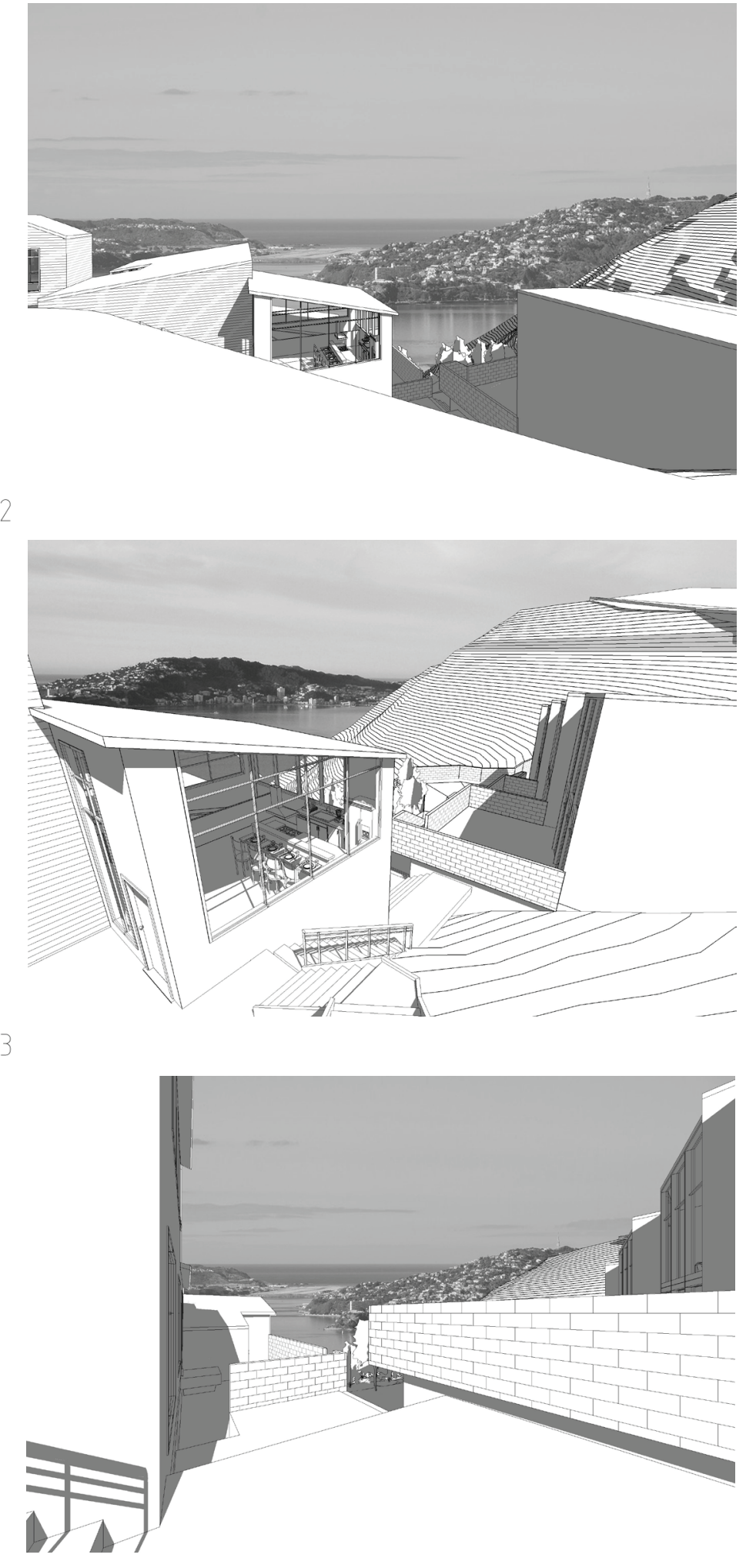

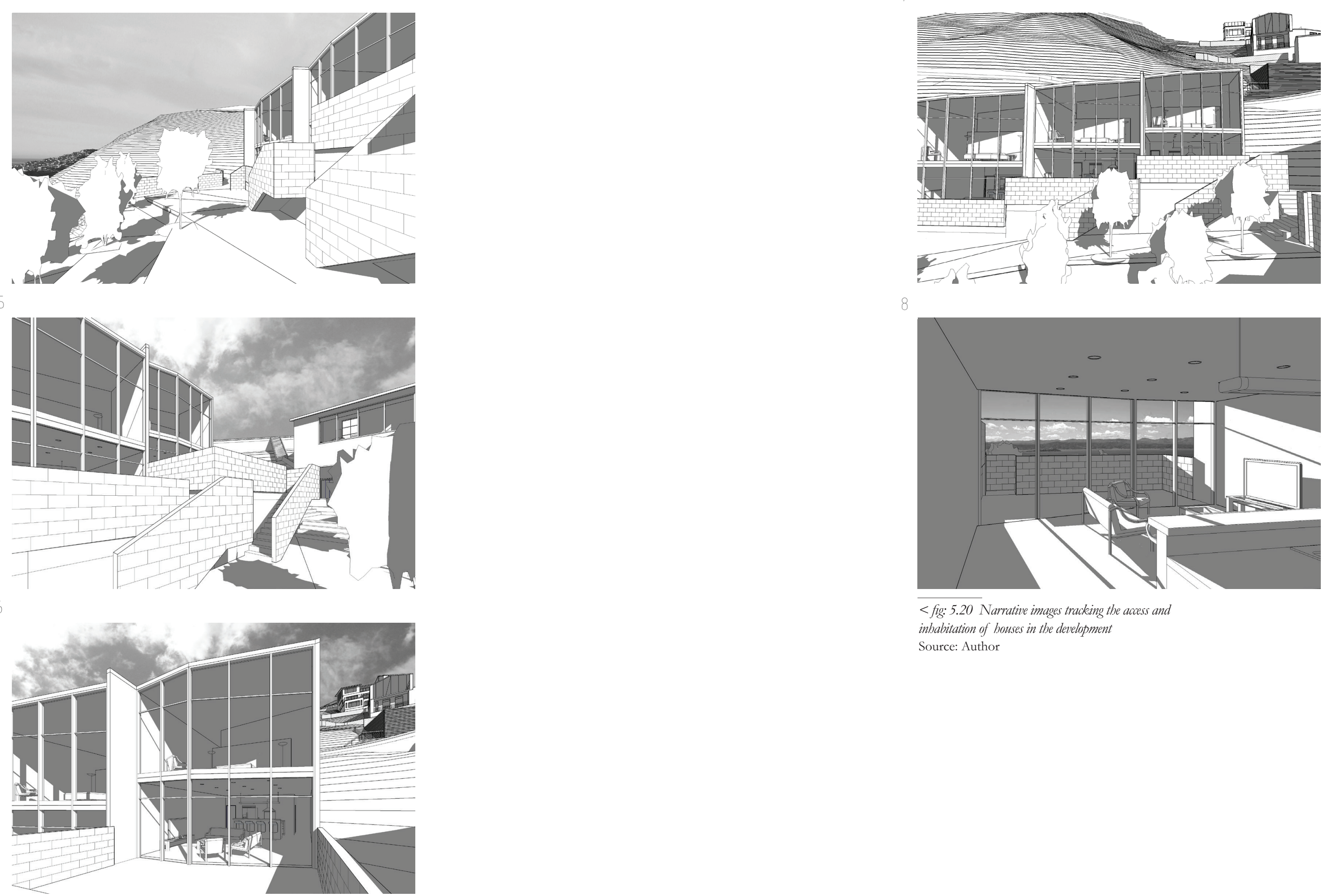

$<$ frg: 5.20 Narrative images tracking the access and inbabitation of houses in the development Source: Author 

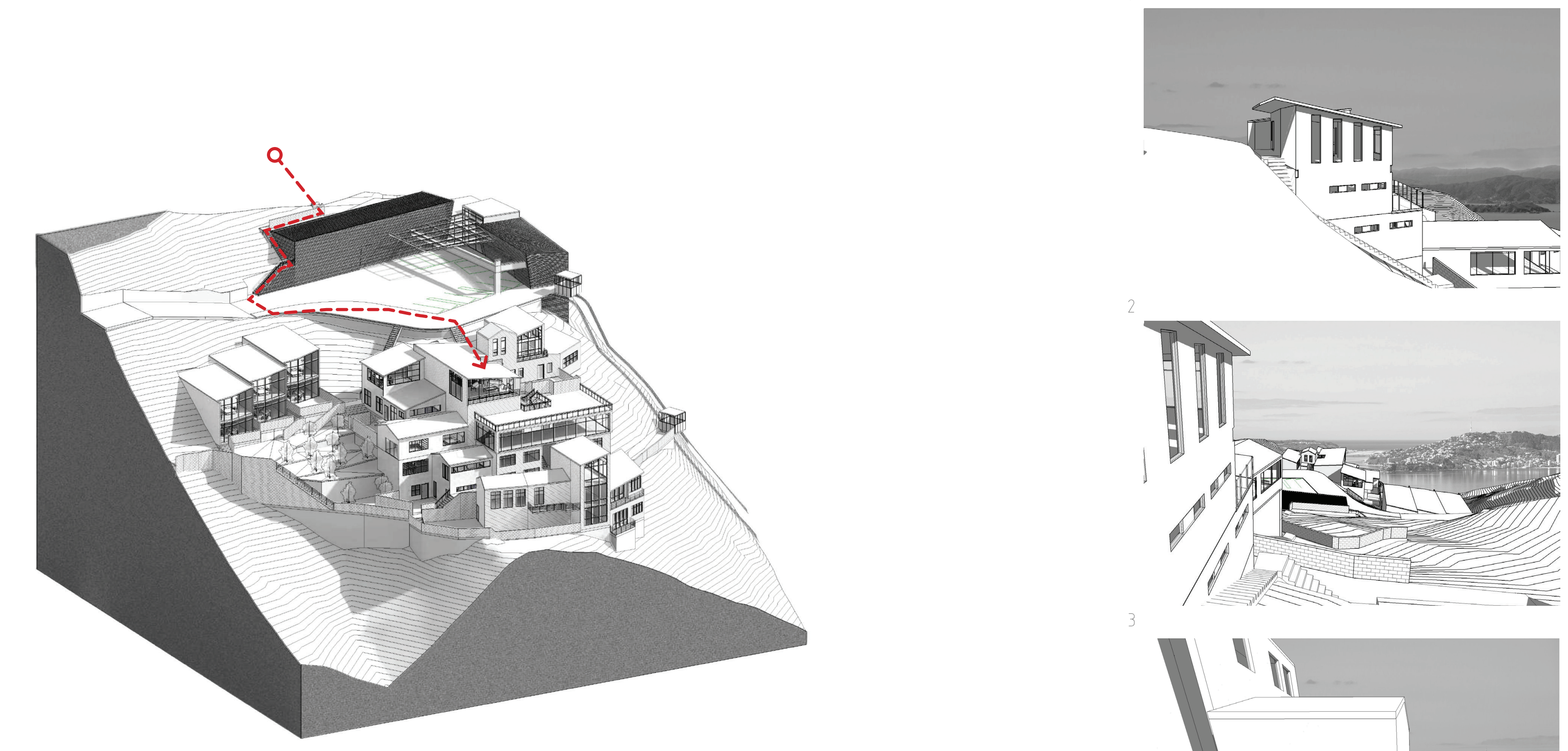

$<$ fig: 5.21 Pathways/Access Routes from upper road to dvelling

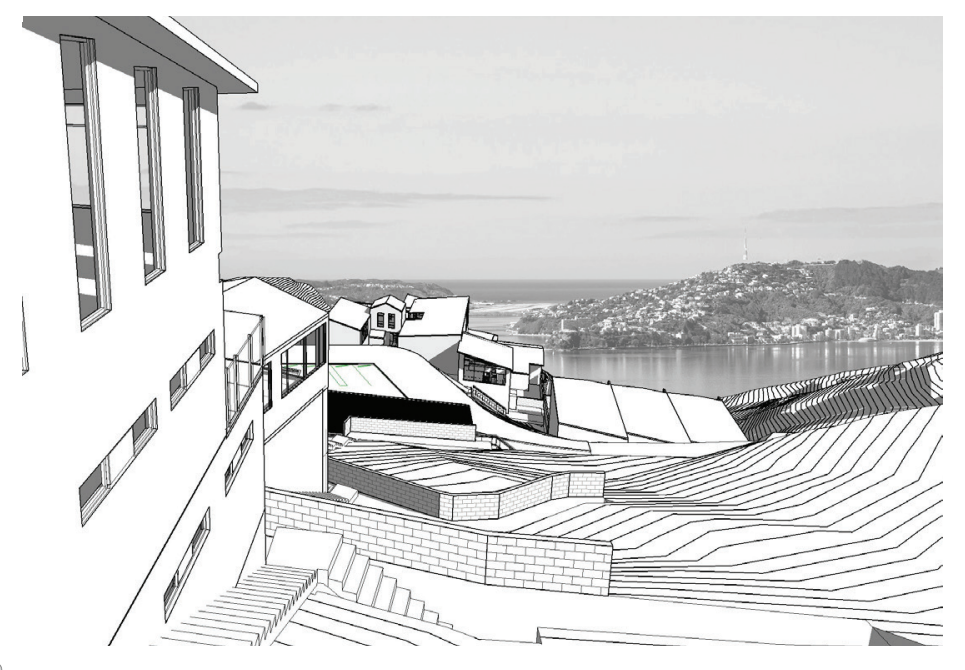

Source: Author

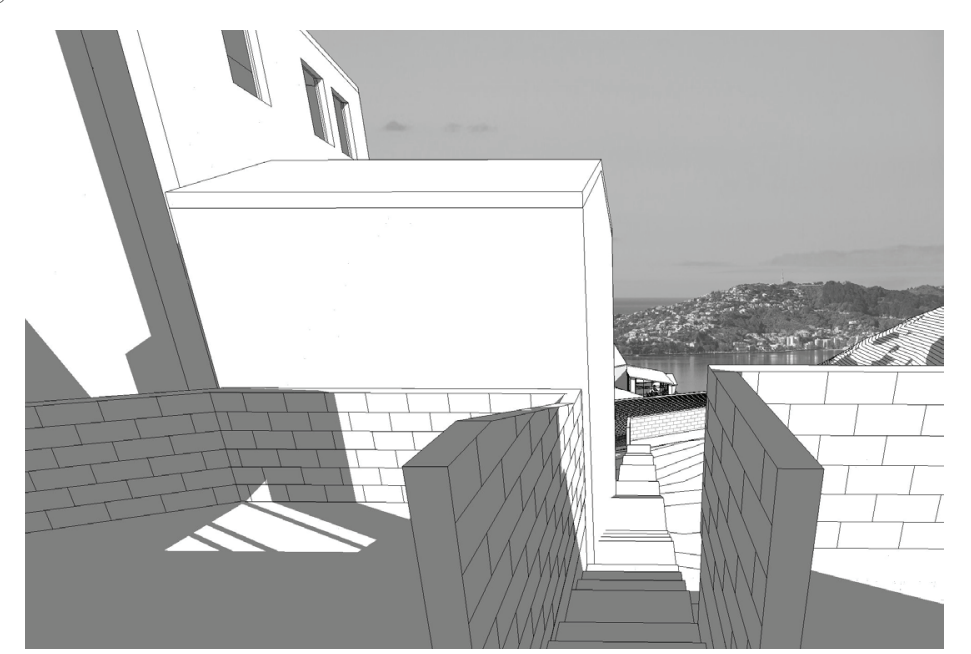



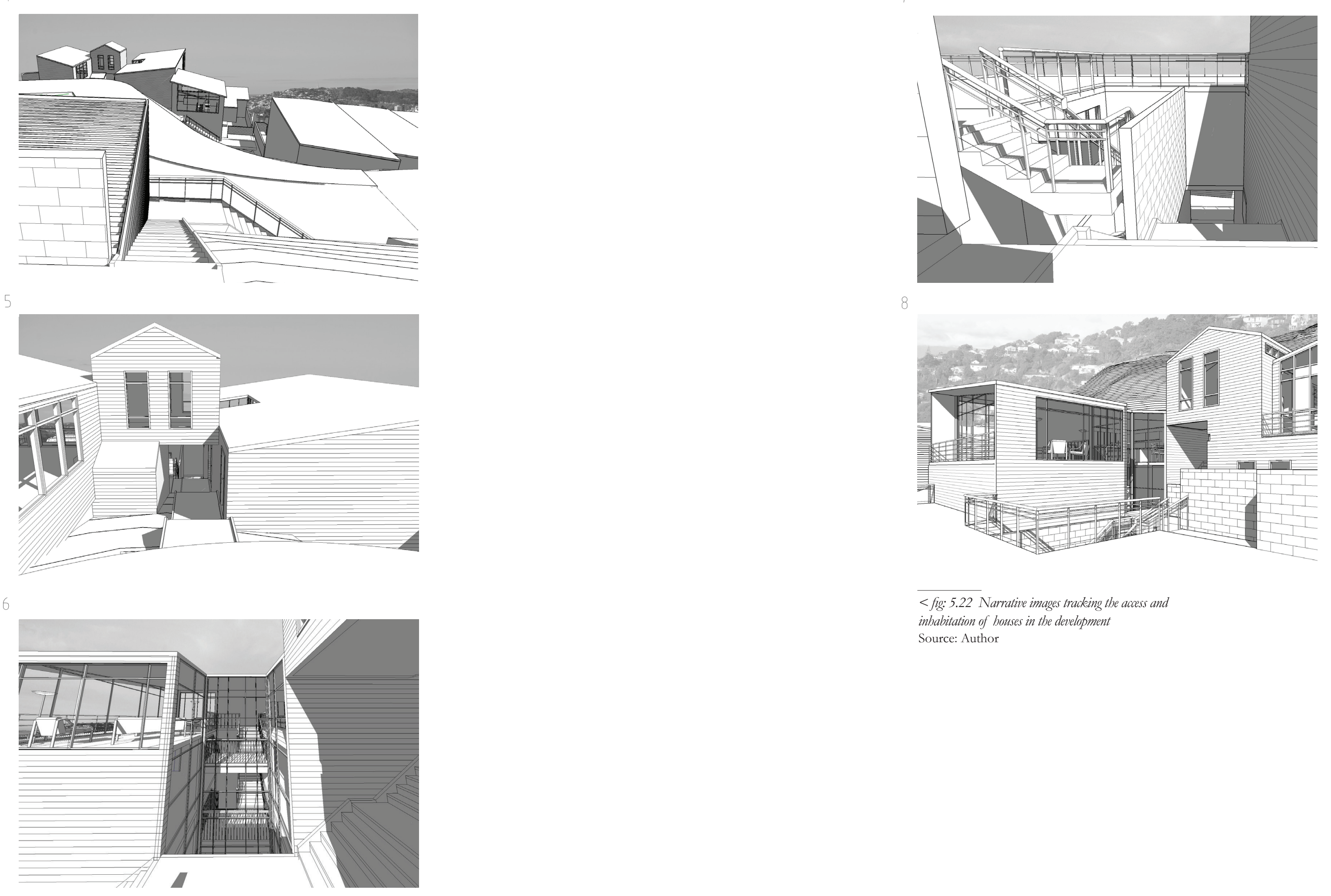

< fig: 5.22 Narrative images tracking the access and inhabitation of bousses in the development 
INHABITATION IMAGES

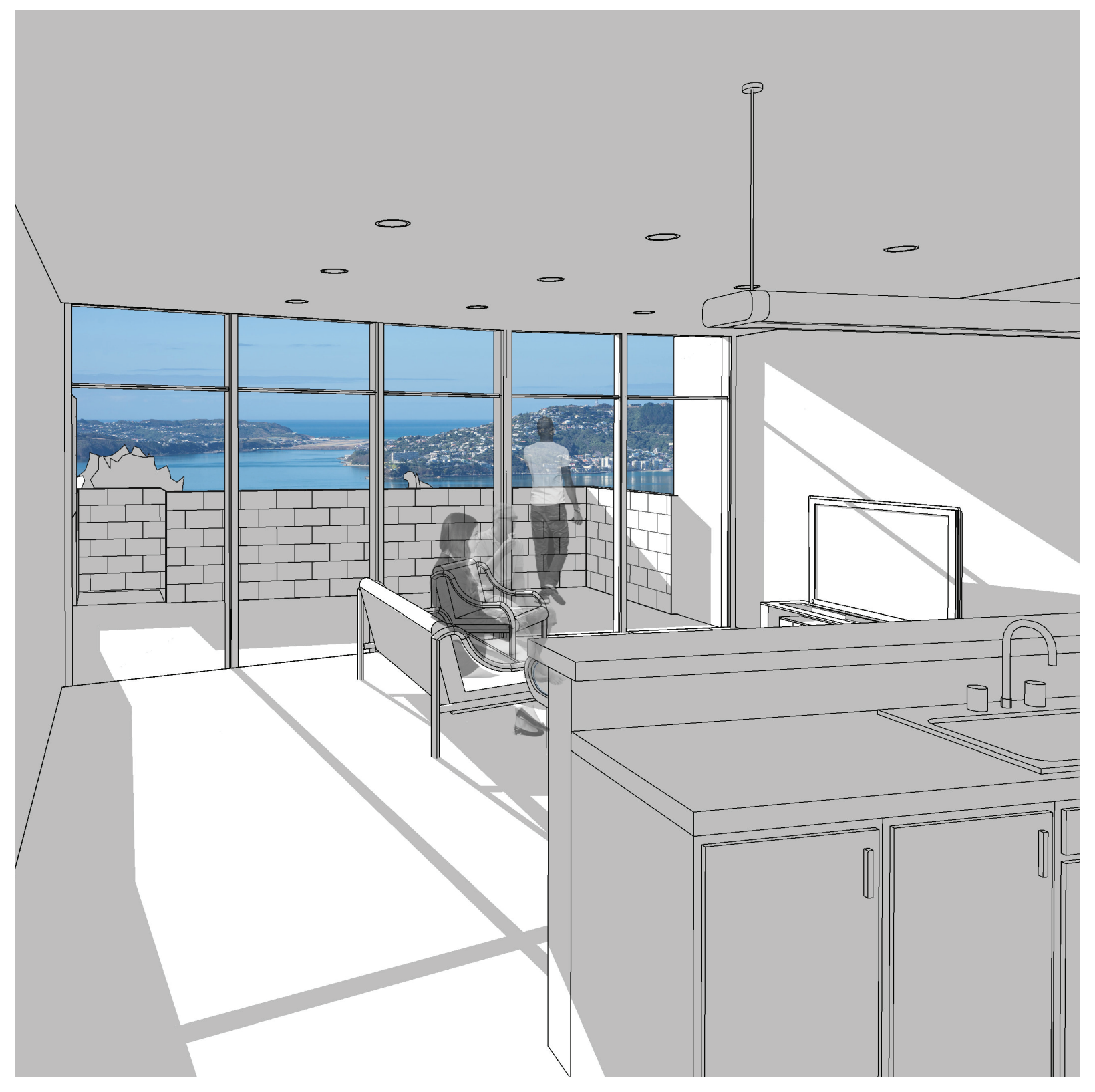

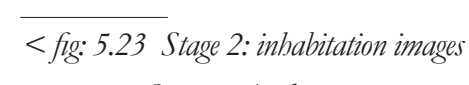
Source: Author

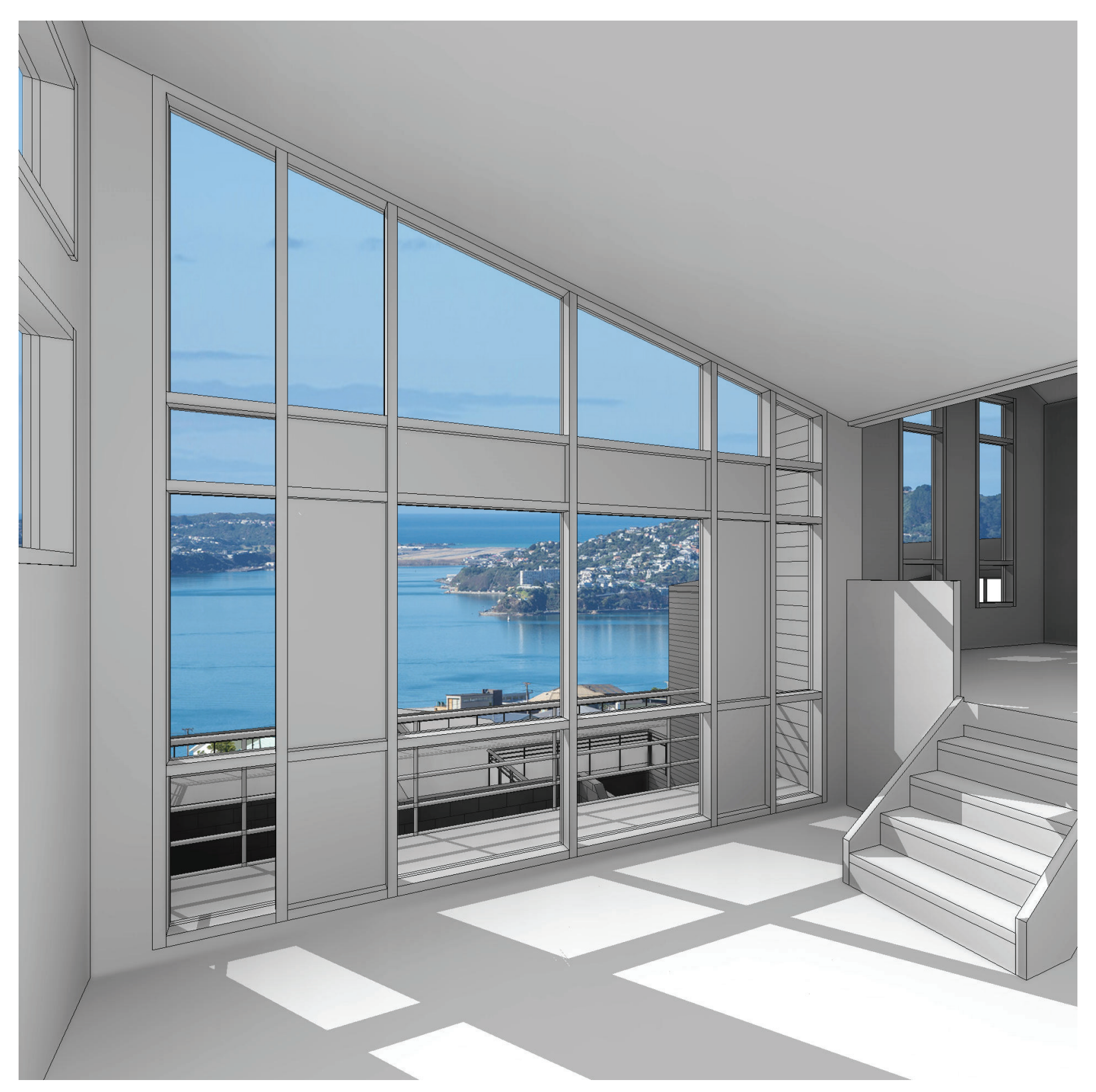

< fig: 5.24 Stage 2: inhabitation images Source: Author 


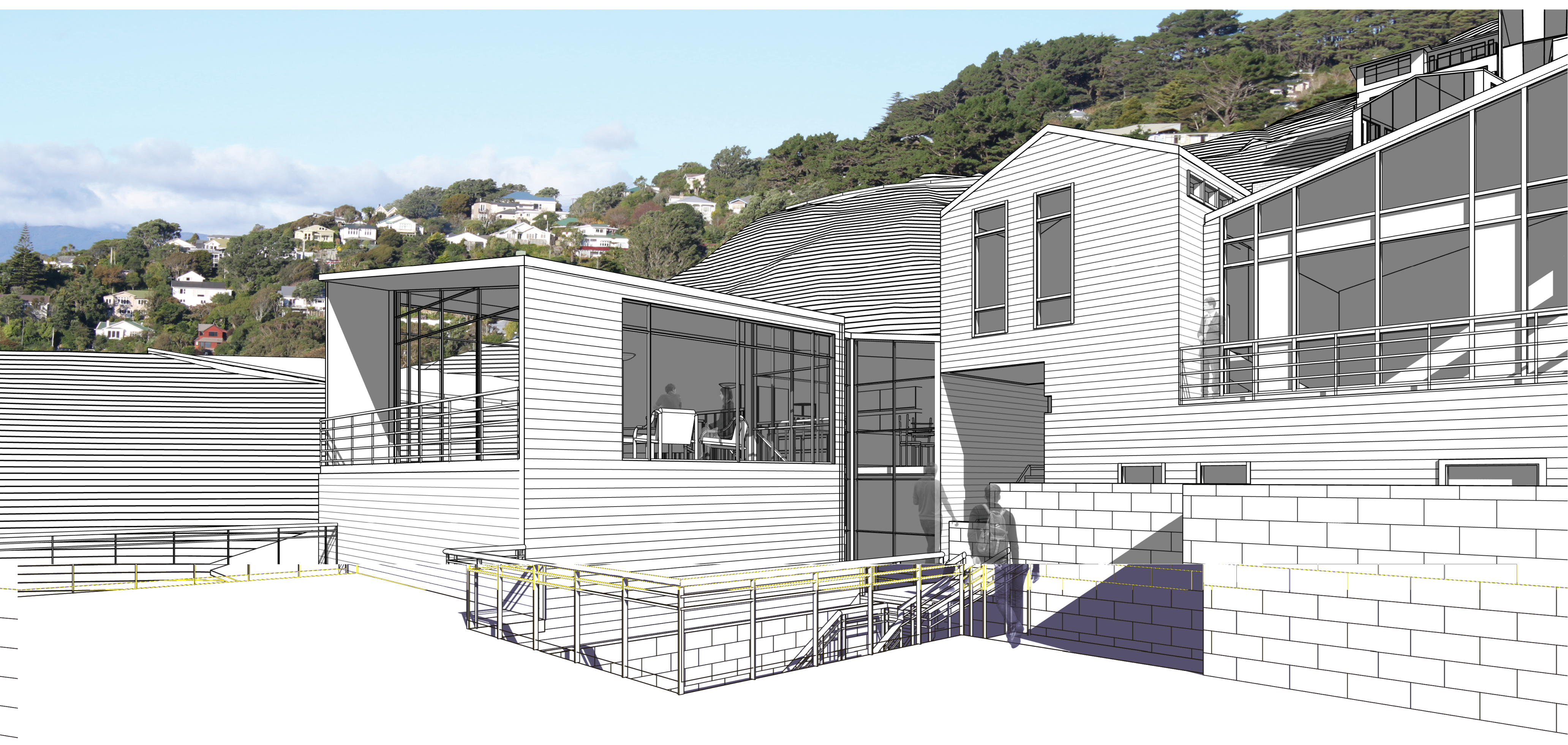




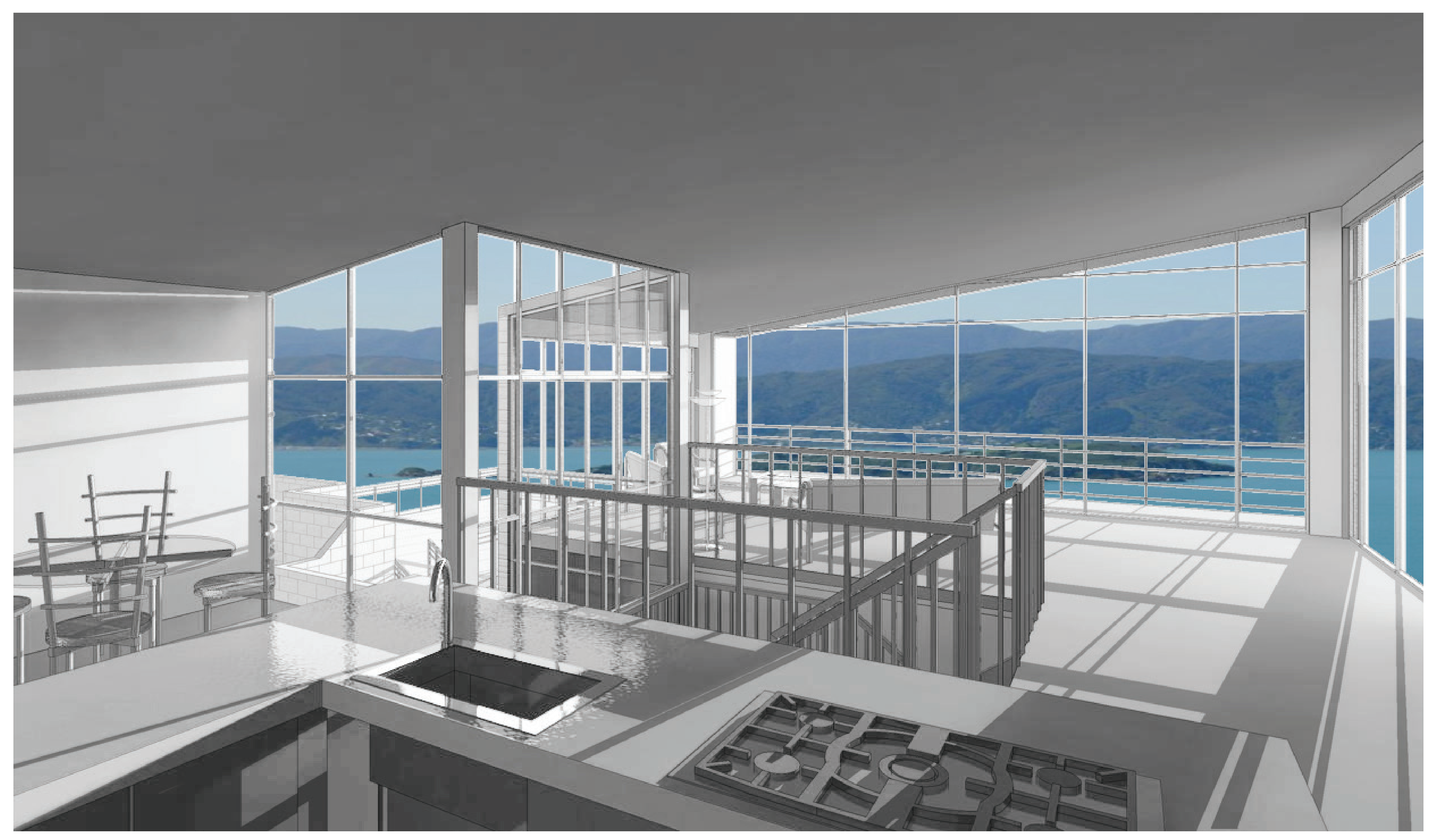



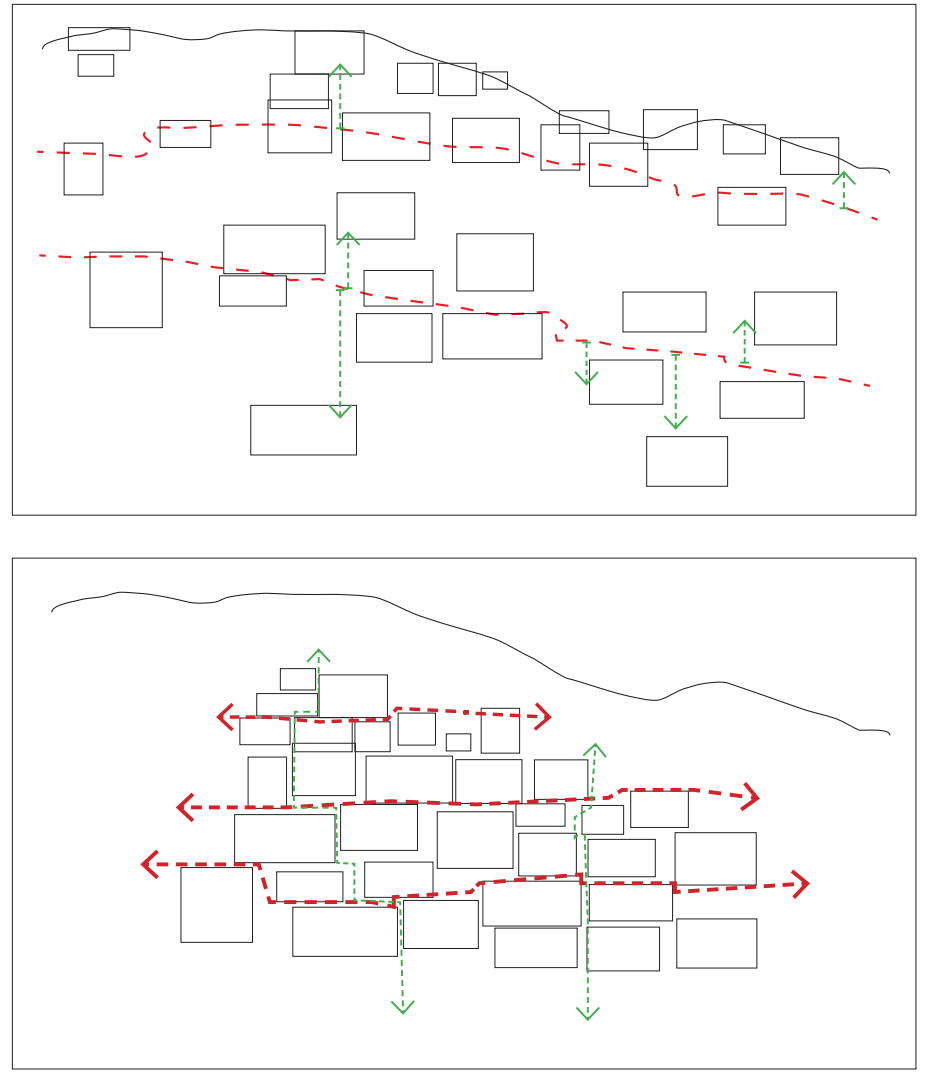

< fig: 6.1 Wellington billside stud
Source: Author

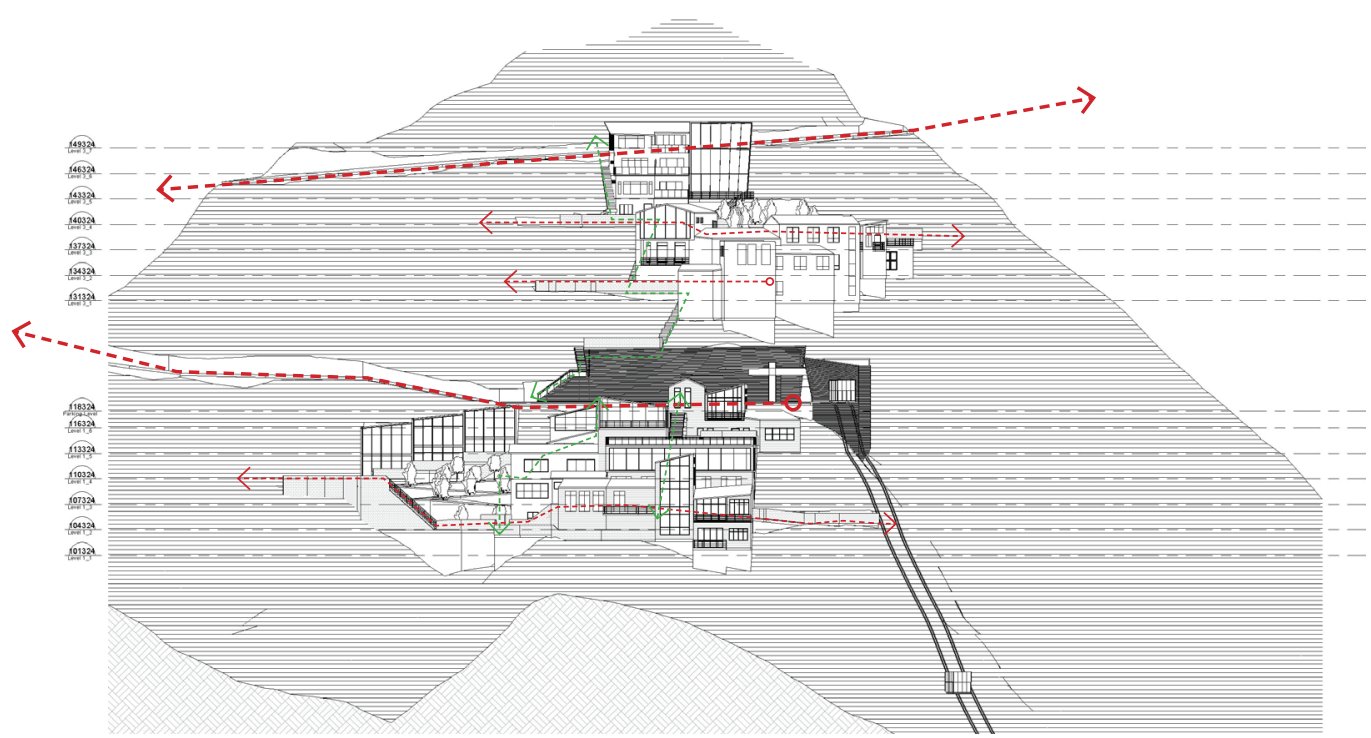

<fig: 6.2 Proposed development
Source: Author
DESIGN EXEGESIS

I have stated earlier in the thesis that the arguments agains urban sprawl and the need for intensification of residential areas has been well documented and have very few opponents within the academic and architectural communities. As such, the basic need for an increased density residential model to make use of under-utilised hillside sites in Wellington is easily argued. The test of the success of this process is in the impact of the proposed model on the Wellington landscape and the potential amenity that the development offers being of the same level or higher that of existing medium density models.

The existing definition of medium density as identified in a report written for the Ministry for the Environment;

...multi-unit developments with an average site area densit stand-alone, semidetaced unit. It can include detacbed (or apartments on either single sites or aggregated sites, or as part of larger master-planned developments.

The design simulations that I have run through the research process has resulted in an average density of $170 \mathrm{~m} 2 /$ dwelling for the main design stages. This calculation is based on the inhabited areas and following the current trends this density should continue for the remaining area to be developed.

One of the main aspects of any hillside city or town is the existing pattern of development and the character of that from very early on. This pattern was taken into account dense clumps of houses over the hill had less impact on the visual aspect of the hillside than a more spread out development (fig.6.1). In addition to this the proposed pattern on the hillside recalls - but does not replicate - the

1 Boffa Miskell Ltd., "Medium-Density Housing Case Study Assessment Methodology," (Wellington: Ministry for the Environment, 2012). 
existing hillside pattern of dwellings following the roads (fig 6.2). The decisions made throughout the development of the framework have displayed an evolution of this hillside massing. Following the parametric exercises (fig 6.3) it wa found that the mass of a building will affect the hillside more than the height as an isolated variable. The difference that a six storey building made to the character of the hillside wa negligible when compared to a three storey building. This finding informed the height rules and exceptions defined in the final development framework

With the findings that the proposed development pattern will have minimal impact on the visual amenity of the city
as a whole, the question of amenity that the individual dwellings possess becomes one of the main tests as to the viability of the proposal. A limitation from the inception of the proposal was that of access. The current $\mathrm{MDH}$ models prevalent around the country provide vehicular access and parking with direct access to each individual dwelling. One of the trade-offs of the steep topography of the sites addressed in this research is the inability to provide this amenity directly to each dwelling. In order to minimise this the design has been developed to allow for collectivised parking and both pedestrian access and flat path access via the cable car. While this still puts this amenity below that of the flat site MDH developments, the design minimises the impact.

The quality of MDH developments plays a large role in interest and adoption of any model. New Zealand as a society comes from a postcolonial background. However, Campbell Gibson Argues that as a 'virgin nation' we had a comparatively high level of urbanization - and in fact suburbanisation -fom wery caly in our colonial history. Due 2 CityScope Consultants, "Improving the Design, Quality and Affordability of Residential Intensification in New Zealand,"New Zealand: Centre for Housing Research, 2011). 3 Campbell Gibson, "Urbanization in New Zealand: A Comparative Analysis" Demorarathy 10, no. 1 (1973).
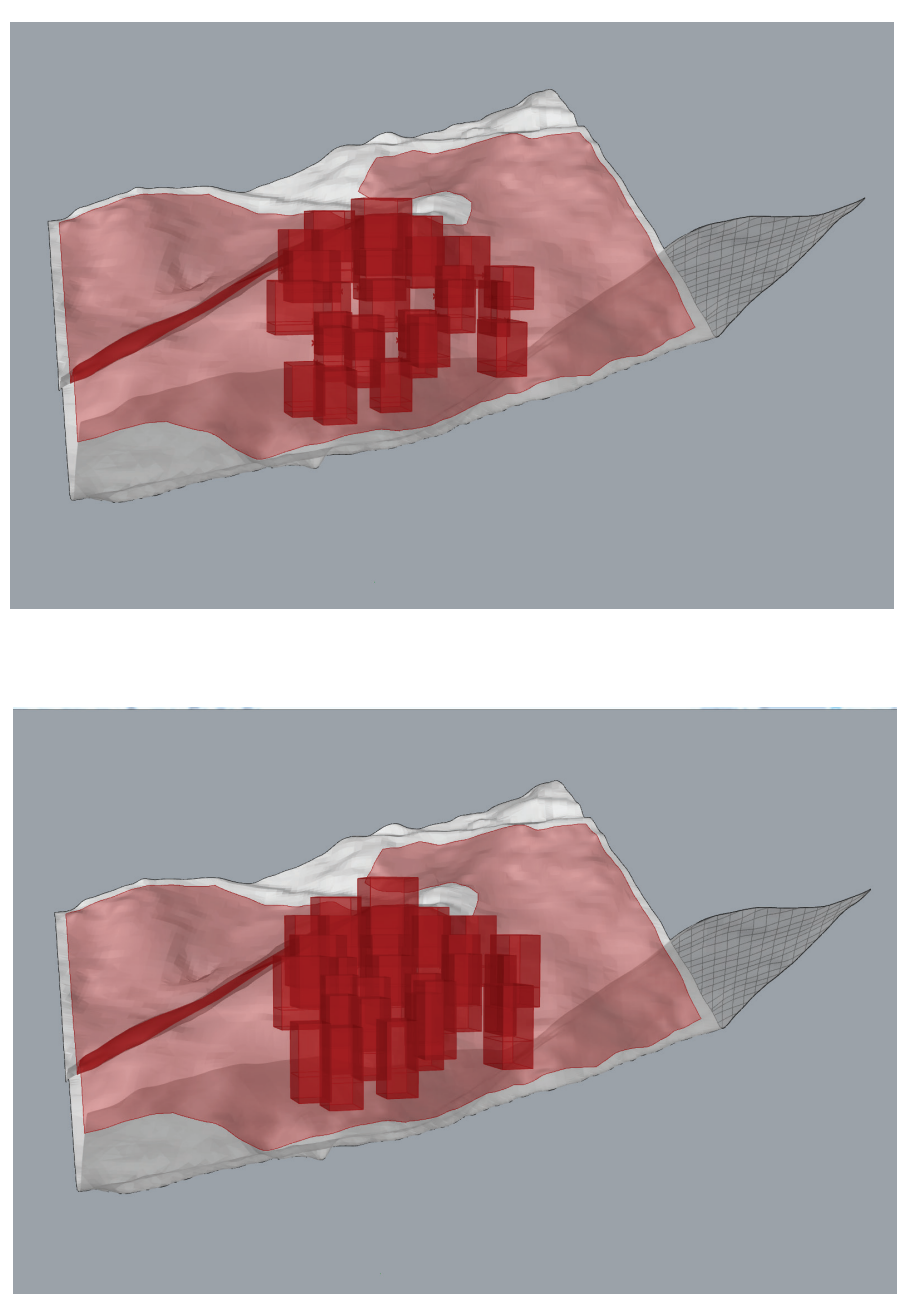

$<$ fig: 6.3 Parametric Study: three and six storey building masses
Source: Author 


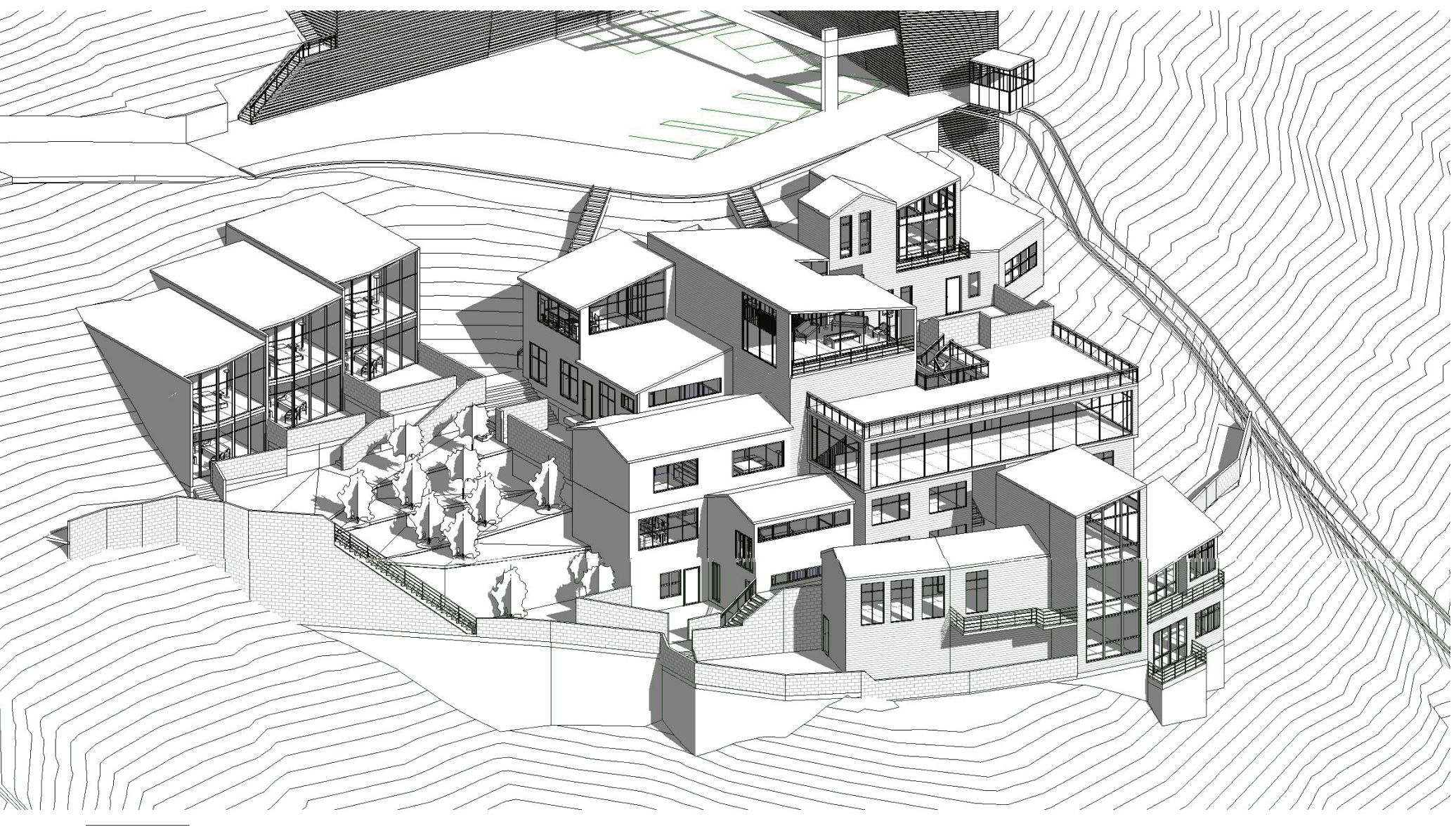

<fig: 6.4 Articulation of building form down bilside.

Source: Autho of the early colonists, owning land has become a large part of New Zealand culture'. The Quarter Acre Dream and the imitation of an English country lifestyle that was present in the early colony ${ }^{5}$ has evolved, however this still leaves New Zealand with a different social and cultural approach to areas where hill towns and aggregative growth are abundant The intentional looseness of control over materiality and building form (outside of meeting massing objectives) allows for some personalisation of dwellings and some form of architectural expression so as to create a more interesting and complex final outcome. This is intended to allow for - through aggregation - the personalisation that is seen as an important motivator for New Zealand buyers. The limitation here, which will be discussed later, is that of the amount of control over this process and finding the balance between qualiy of the bult environe the complex aggregative system to run its own course.

From an architectural stand point, the amenity of these dwellings can be viewed in terms of access to views/ sunlight, public outdoor space, and privacy. The site chosen for this project is a south facing hillside, so access to sun is limited, however the majority of the buildings have sufficient (as evidenced in chapter 5) access to the sun due to the articulation of the forms down the hillside (fig 6.4) The design of these dwellings for the simulation has been done very quickly and the detailing to maximise sun access is inherently undeveloped. During the developed design phase six of these dwellings have been advanced further to show how small architectural gestures (that would normally be developed along with the design of the dwelling) can further improve daylighting access.

4 Cheleen Ann-Catherine Mahar, "Creating New Zealand from Aotearoa," Pacific Coast Philology 49, no. 2 (2014).

5 Ibid.

6 Consultants, "Improving the Design, Quality and Affordability of Residential Intensification in New Zealand," 

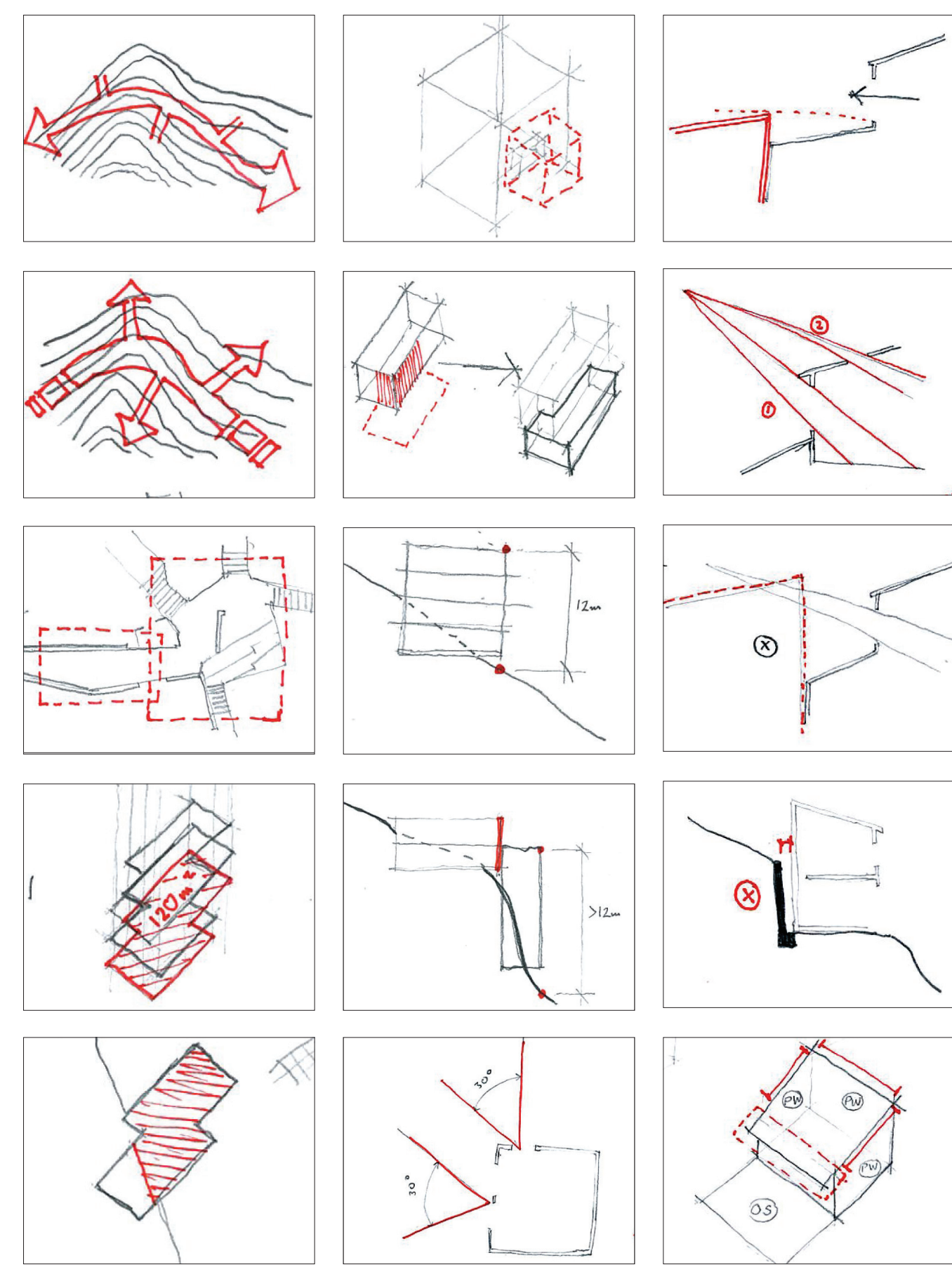
$<$ fig: 6.6 Development Framenorke rule diagrams
Source: Author
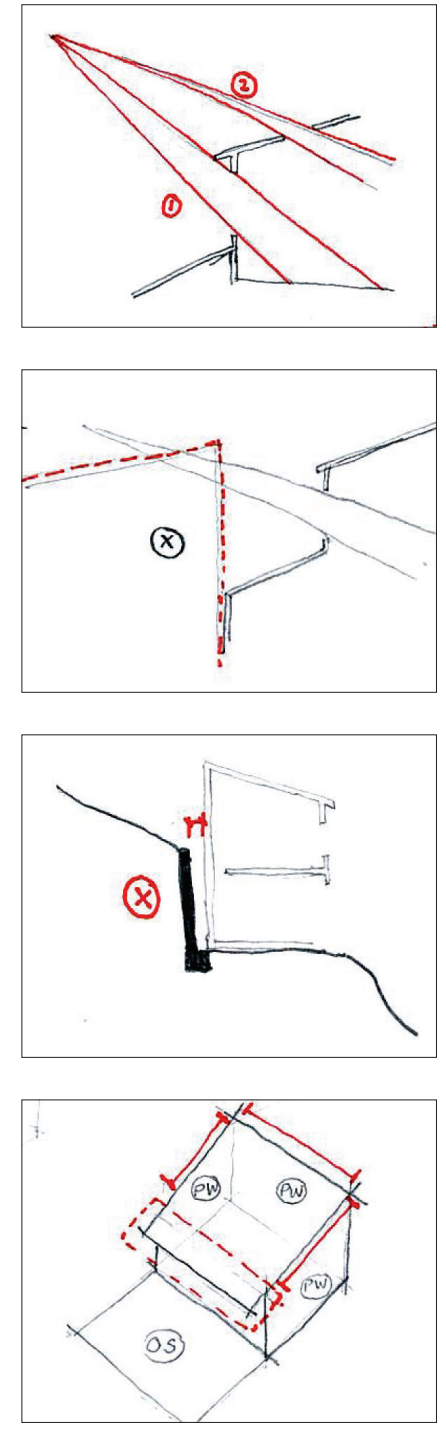

6.1

\section{DEVELOPMENT FRAMEWORK}

The final written development framework has been included in the appendices (appendix 1) however here I will discuss some of the major points of difference for the framework, their limitations and implications. The first of these is the idea of land division, where this follows building concept rather than preceding it. In effect this would do away with the traditional lot pattern that has limited hillside development due to the complexity of superimposing a two dimensional boundary onto a site sloped in three dimensions. The research has shown this creates a development pattern that both greatly increases available density on the site and produces a pattern that will fit in with and enrich the visual amenity of the hillide (fig 6.226.3). This idea is also the major framing principal of the aggregation of the (through complexity ${ }^{8}$ ) but a (hensty urben infll given the current residential matkets

However this rule does have limitations. Firstly, th approach calls for much higher levels of design oversight than currently exists within the residential building market. Given the trend towards more and more draconian regulation and legislation within this sector, this could be seen as a negative outcome. However, oversight would probably not come from regulating bodies but from either a panel, or architectural firm engaged to work on behal of the collective body corporate. While this extra level of control could harm efficiency of production, it would also allow for architectural supervision and inherently a higher quality of the built fabric.

The second point of contention with this idea is the legal frameworks behind property ownership. While the intricacies and would rope of this thesis -

${ }_{8}^{8}$ See chapter One on the work of Christopher Alexander and Lucien Kroll. 
The second idea of this framework is that of the access network. The hillside topography and the desired density This could create a barrier to adoption by the market. The design has shown that access is posible to each dwelline With the addition of the cable possible to each dwelling With the addition of the cable car, primarily flat acces

Massing, form, and architectural articulation of the dwellings in this framework have been a challenge throughout the project, with the dichotomy between control and aggregation continually clashing. I have responded to this by giving number of tight controls but also allowing areas where exceptions can occur to allow for a richer, more complex outcome. As I have stated above this project does not seek to minic or recreate a vernacular architecture rather it proposes a new development model within which th building traditions and practices of the Wellington industry can work to produce MDH for these sites.

\section{New Zealand Unit Tittes Act 2010}

10 Hazel Easthope, Sarah Hudson, and Bill Randolph, "Urban Renewal and Strata Scheme Termination: Balancing Communa Management and Individual Property Rights," Environment and Planning $A$ 45, no. 6 (2013).

11 Consultants, "Improving the Design, Quality and Affordability of Residential Intensification in New Zealand."

PROJECT CONCLUSION

As discussed above, this project has had many successful points and has produced a viable basic principal from which to build a development framework for this type of MDH development for hillside sites. However due to the nature of the project timeline and format there are several limitations and inherent assumptions that have had to be made to go forward and would require further research to either solve or to test the project in such a way as to negate them.

The main issue that has arisen at each stage of the process has been that of the dichotomy between control and aggregation. A free process has the potential to allow for more complex and interesting outcomes as well as giving good designers and architects more freedom of expression. requirements of the discipline to lowe the risk of a poonal quality outcome. For this research I have taken a poo position on allowing for maximum freedom of siting anc creating some massing/stylistic rules ${ }^{12}$ while allowing for freedom around materiality and architectural articulation doing so, I have attempted to keep the individuality of the Wellington built environment. One of the major criticism of Ian Athfield's Amritsar St property is the single ownership of the property and the social and financial implications of trying to transplant that model elsewhere. In addition, the 'foreign'/'exotic' appearance of Athfield's house is another reason why it has not been adopted as a development precedent.

The theoretical basis on which this project has been founded follows Christopex Alexander's New Theory of Urban ( Ian Athfeild's Amritsar St house. These theories have been discussed earlier in the thesis. Patticular reference is made to their somewhat contrived design processes. While this

12 See roof pitch and massing/height restrictions appendix 1 13 See chapter One 
research steers away from these authors in some respects it is still based on the work of these writers/architects.

In the same vein, the use of a vernacular architecture to inform contemporary architecture has been widely criticised. ${ }^{14} \mathrm{Thi}$ hesis has consciously avoided the aesthetic interpretation Consequently the systematic and analytic approach talen Cos attempted to avoid these traps. However, with any study of the vernacular some aspects of a false and imagined past must be present This occurs becouse analysis is often tast from multiple sources, and their biases interpretations and part in the picture the

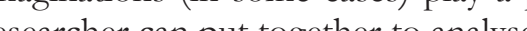
gether to analyse.

For the simulation portion of the thesis the ideas of aggregation and land division were able to be successfully tested and returned useful results for the evolution of the development framework. However the resulting architectural outcomes were often not of the quality one would expec from participants with architectural traning. This problem of uninteresting and relatively undeveloped forms results from the methodology. Each participant in the simulation was given around an hour to design (at a conceptual level) their dwelling for the proposal. This hour of independent work was taking the place of what would normally be a collaborative process undertaken over weeks or months as the design of the dwelling evolved. On top of this lack of time, there is the issue of minimal investment in the design process. Designing in the real world has consequences, for

14 Ernest Sternberg, "An Integrative Theory of Urban Design," Journal of the American Planning Association 66, no. 3 (2000).

15 Dimitri Philippides, ed. Greek Traditional Architecture: Eastern Aegean, Sporades, Ionian Islands, 1st ed., vol. 1(Athens: "Melissa" Publishing House, 1983).

16 Bernard Rudofsky, Architecture without Architects: A Short Introduction to Non-Pedigreed Architecture(London: Academy Editions, owners and occupants and for the designer's reputation ion. However designing in this simulation process holds none of those consequences, complieations and motivations. As such it does not allow for a real leve of interaction and commitment with the design. For the purposes of this research this issue is less important as the simulation provided the requisite information to continue to work on the framework outcome. However, the final design work is not up to the standard that would be achieved in a real life process.

To continue this research to a point where it was implementable for a built project there are several areas that
would require more development. Firstly the ownership structure of the development would need to be addressed in more detail, making specific reference to New Zealand Unit Titles Act 2010. In addition to this, the technica requirements surrounding compliance for a multi-stage development would need to be addressed. For this project the current building codes - with the assumption that each building would be consented separately - have been followed in regards to fire separation, access and water tightness etc. While these issues have been kept in mind during the design of the project, they were not its main focus, so were treated as a base assumption and not specifically developed. In terms of implementation, the role and composition of the oversight committee and their legal relationship to the body corporate would need to be further developed.

If time had allowed, I would like to have applied the framework and process to another site. I would also have given the participants a longer time to develop their designs. The ancent of the spent by each designer (as discussed above) lowered the quality of the designed outcome. If put have produced richer results and a more accurate reflection of how to evolve the frameworks and processes furthe Similarly application to another site would have re fucthe site-specific nature of the case study/test/random outcomes, again allowing for a fuller picture of the implication of 
From the outset of this project, the development framework and an indicative implen intended outcome of the thesis. Rather than foregrounding the design - which in this case has been a simulation to tes both the process and framework - the intent of the research is to propose a new model that could be used for a range of different sites and locations within Wellington, but also conceivably elsewhere in New Zealand.

The thesis has achieved these goals and has been shown to have provided a credible model for hillside development of amenity to potential inhabitants of the development, as well as making use of the abundant sloped sties around the Wellington area. The success of this project lies in the potential for creating a discussion around utilising these steep hillside areas for development in an attempt to negate any further urban sprawl.

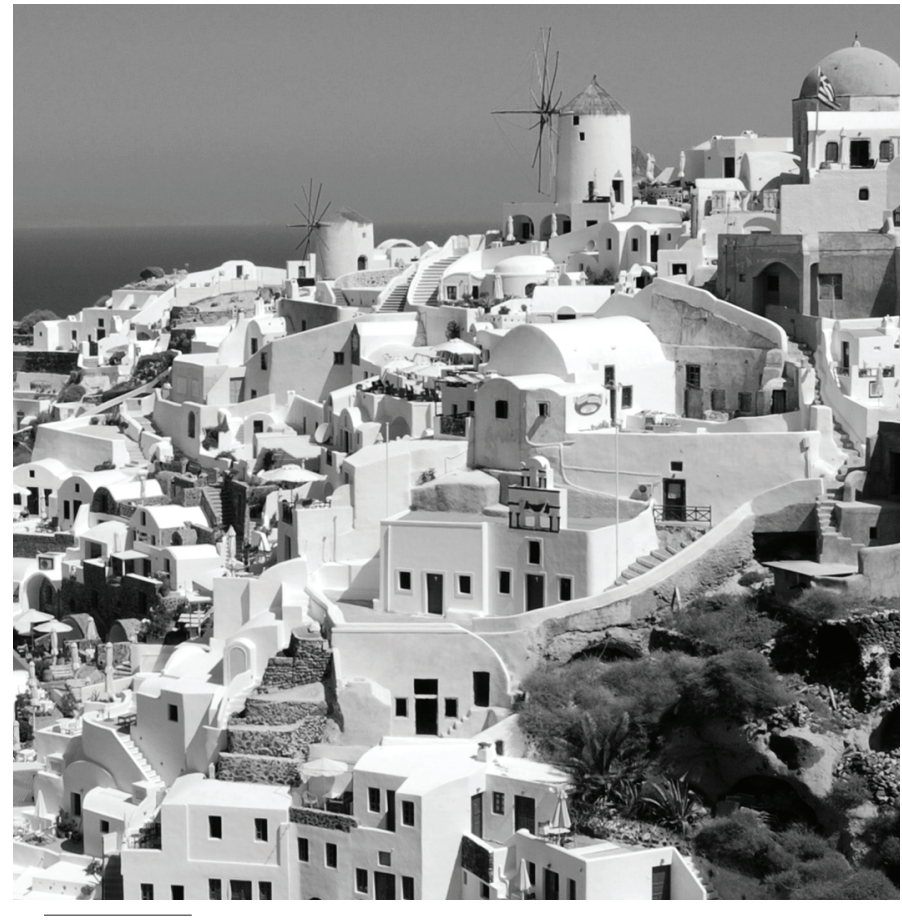

fig: 6.7 Santormi: Oia

Source: Harvey Barrison (2009) 


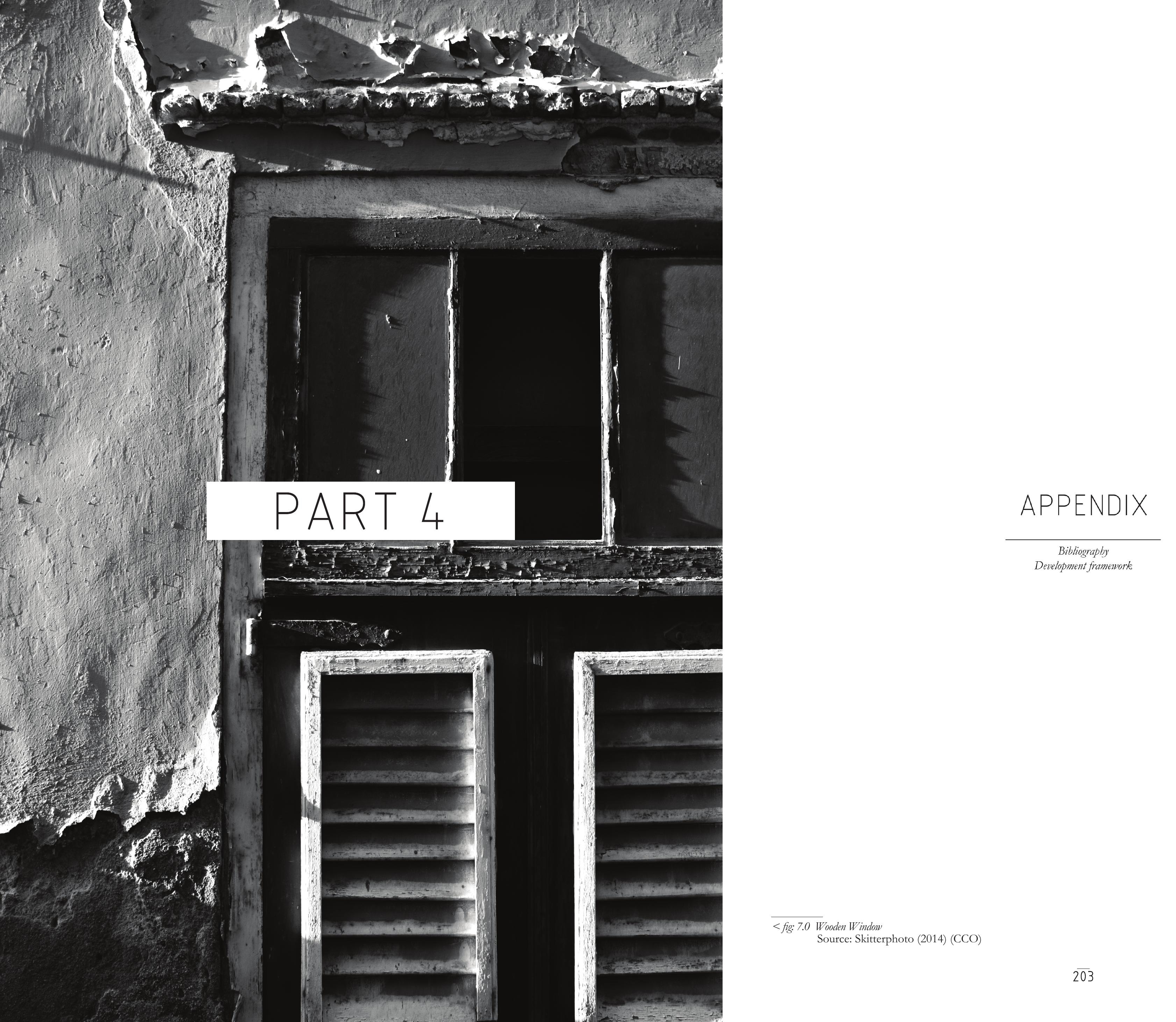


BIBLIOGRAPHY

Aalen, F. H. A. "The Cycladic House in South Evvoia, Greece." Vernacular Arcbitecture 13, no. 1 (1982): 5-19.

Alexander, Christopher. A New Theory of Urban Design. New York: Oxford University Press, 1987.

- The Oregon Experiment / Christopher Alexander ... [E Al.]. edited by Christopher Alexander New York: New York : Oxford University Press, 1975

Alexander, Christopher, Sara Ishikawa, and Murray Silverstein. A Pattern Language : Towns, Buildings Construction [in English]. New York: Oxford University Press, 1977.

Arnaoutoglou, C. "Sporades: Skyros." In Greek Traditional Architecture, edited by Dimitri Philippides. Athens: Melissa Publishing House, 1999.

Baudrillard, Jean. Simulacra and Simulation. Translated by Sheila Faria Glaser. Michigan: The University of Michigan Press, 1994.

Bouras, C. "General Introduction." Translated by David. Hardy. Chap. 1 In Greek Traditional Architecture, edited by Dimitri Philippides. Athens: Melissa Publishing House, 1999.

Breuegman, Robert. Sprawl: A Compact History. Chicago: University of Chicago Press, 2005

Bunker, Raymond. "Urban Consolidation and Australian Cities." Built Environment (1978-) 11, no. 2 (1985): $83-96$.

Bunker, Raymond, and Glen Searle. "Seeking Certainty: Recent Planning for Sydney and Melbourne." The Town Planning Review 78, no. 5 (2007): 619-42.
Consultants, CityScope. "Improving the Design, Quality and Affordability of Residential Intensification in New Zealand." Centre for Housing Research, Aotearoa New Zealand, 2011.

Davey, Peter. "Organic Growth." Architectural Review 208, no. 1241 (2000): 36-7

Deleuze, Gilles, and Rosalind Krauss. "Plato and the Simulacrum." October 27 (1983): 45-56.

Duany, Andres, and Institute Seaside. Views of Seaside Commentaries and Observations on a City of Ideas [in English]. New York; [Santa Rosa Beach, FL] Rizzoli : Distributed to the U.S. trade by Random House ; Seaside Institute, 2008.

Ellin, Nan. "Participatory Architecture on the Parisian Periphery: Lucien Kroll's Vignes Blanches." Journal of Architectural Education 53, no. 3 (2000): 178-83.

Ellis, Cliff. “The New Urbanism: Critiques and Rebuttals." Journal of Urban Design 7, no. 3 (2002): 261-91.

Falk, Nicholas. "Smarter Growth and Sustainable Suburbs." Built Environment (1978-) 32, no. 3 (2006): 328-41.

Ferreira, Renata. "Medium Density Housing Case Study: The Altair, Wellington." Wellington: Ministry for the Environment, 2012

Gibson, Campbell. "Urbanization in New Zealand: A Comparative Analysis." Demography 10, no. 1 (1973):

Group, Urban Design Advisory. "New Zealand Urban Desion Protocol," Wellington: Ministry for the Environment, 2005. 
Hall, Peter. Urban and Regional Planning Fourth Edition. Fourth ed. London: Routledge, 2002.

Kostof, Spiro. The City Assembled: The Elements of Urban Form through History. London: Thames \& Hudson Ltd., 1992.

- The City Shaped: Urban Patterns and Meanings through History. London: Thames and Hudson, 1991

Kovatsi, Athena. "The Church and the Urban Structure of the Aegean Island Towns." 1: ProQuest Dissertations Publishing, 1979

Krieger, Alex, William R. Lennertz, Gallery Gund Hall, University Harvard, and Design Graduate School of. Andres Duany and Elizabeth Plater-Zyberk: Town and Town-Making Principles [in English]. [Cambridge, Mass.]; New York: Harvard University Graduate School of Design ; Rizzoli, 1991.

Ltd., Boffa Miskell. "Medium-Density Housing Case Study Assessment Methodology." Wellington: Ministry for the Environment, 2012.

Mahar, Cheleen Ann-Catherine. "Creating New Zealand from Aotearoa." Pacific Coast Philology 49, no. 2 (2014): 176-82

Marmaras, Emmanuel V. "Cycladic Settlements of the Aegean Sea: A Blending of Local and Foreign Influences." Planning Perspectives 23, no. 4 (2008): 503-20.

Maudlin, Daniel. "Crossing Boundaries: Revisiting the Thresholds of Vernacular Architecture." Vernacular Architecture 41, no. 1 (2010): 10-14.
McDonald, C. "City of Melbourne." Lighting Strategy, (Melburne, 2003).

Michaelides, Constantine E. Hydra: A Greek Island Town Its Growth and Form. Chicago: The University of Chicago Press, 1967.

Mohney, David, and Keller Easterling. Seaside : Making a Town in America [in English]. 1991.

Moudon, Anne V. "Proof of Goodness: A Substantive Basis for New Urbanism [the Promise of New Urbanism]." Places 13, no. 2 (2000).

Moughtin, C. Urban Design:Methodand Techniques. Architectural Press, 1999.

New Urbanism: Peter Calthorpe Vs. Lars Lerup. Michigan Debates on Urbanism. Vol. II: University of Michigan, 2005.

Philippides, Dimitri, ed. Greek Traditional Architecture Eastern Aegean, Sporades, Ionian Islands. Vol. 1. Athens: Melissa Publishing House, 1999.

Rudofsky, Bernard. Architecture without Architects : A Short Introduction to Non-Pedigreed Arcbitecture / by Bernard Rudofsky. London: London : Academy Editions, 1964.

Sigalos, Lefteris. "Housing People in Medieval Greece." International Journal of Historical Archaeology 7, no. 3 (2003): 195-221.

Sternberg, Ernest. "An Integrative Theory of Urban Design." Journal of the American Planning Association 66, no. 3 (2000/09/30 2000): 265-78. 
Talen, Emily. "Connecting New Urbanism and American Planning: An Historical Interpretation." Urban Design International 11, no. 2 (2006): 83-98.

- New Urbanism \& American Planning: The Conflict of Cultures. Planning, History and the Environment Series. edited by Dennis Hardy New York: Routledge, 2005.

Tice, James. "Theme and Variations: A Typological Approach to Housing Design, Teaching, and Research." Journal of Arcbitectural Education (1984-) 46, no. 3 (1993): 162-75.

Vionis, Athanasios K. A Crusader, Ottoman, and Early Modern Aegean Archaeology. edited by C.C Kamerman Bakels, H. Leiden: Leiden University Press, 2012.

Walton, D., S. J. Murray, and J. A. Thomas. "Relationship between Population Density and the Perceived Quality of Neighbourhood." Social Indicators Research 89, no. 3 (2008): 405-20.

Ward, Stephen V., Robert Freestone, and Christopher Silver. "Centenary Paper: The 'New' Planning History: Reflections, Issues and Directions." The Town Planning Review 82, no. 3 (2011): 231-61.

Western, John. "Undoing the Colonial City?". Geographical Review 75, no. 3 (1985): 335-57.

Witten, Karen, Wokje Abrahamse, and Keriata Stuart. Growth Misconduct? : Avoiding Sprawl and Improving Urban Intensification in New Zealand [in English]. Auckland, N.Z.: Steele Roberts Aotearoa, 2011. 
IMAGE SOURCES

Barrison, H. Santorini - Oia. 2009, Digital Image. https:// upload.wikimedia.org/wikipedia/commons/0/0a/ Santorini_07_02_09_0808.jpg (accessed 18/11/2015)

Capper, P. Wellington Hillside. 2005, Digital Image. https://

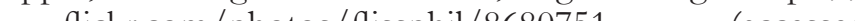
03/02/2016)

-... Ship and houses, Khandallah, Wellington, New Zealand. 2006, Digital Image. https://www.flickr.com/photos/ flissphil/88981272 (accessed 20/01/2016)

Gagnon, B. View of Imerovigli, example of Cycladic Arcbitecture. 2011, Digital Image. https://en.wikipedia.org/wiki/ Santorini\#/media/File:Imerovigli_02.jpg (accessed $12 / 11 / 2015)$

- - A Street in Mykonos. 2011, Digital Image. https:// upload.wikimedia.org/wikipedia/commons/f/ff/Street in_Mykonos.jpg (accessed 24/11/2015)

- -. Ancient Greek Theatre in Delos. 2011, Digital Image. https://en.wikipedia.org/wiki/Cyclades\#/media/ File:Ancient_Greek_theatre_in_Delos_01.jpg (accesse 26/01/2016)

- - . Houses in Mykonos. 2011, Digital Image. https:// en.wikipedia.org/wiki/Mykonos\#/media/File:Houses_in_ Mykonos.jpg (accessed 26/01/2016)

Horology at English Wikipedia. Apollonia on Sifnos. 2007, Digital Image. https://commons.wikimedia.org/wiki/ File:Apollonia_on_Sifnos.jpg (accessed 02/12/2015)

- - . Paros Church. 2007, Digital Image. https://commons. wikimedia.org/wiki/File:Paros-Church.jpg （accessed 2/02/2016)

Ministry for the Environment. Manukau, Auckland. Digita Image. http:/ /www.mfe.govt.nz/more/towns-and-cities/ medium-density-housing (accessed 12/02/2016)
Ortner, H. Hydra Town. 1993, Digital Image. https:// en.wikipedia.org/wiki/Hydra_\%28island\%2 $/$ /media/ File:Hydra_town_01.jpg (accessed 01/12/2015)

Ramos, D. Dancing in the Moonligbt. 2009, Digital Image. https://www.Alickr.com/photos/dylanramos/3812581100 (accessed 12/02/2016)

Roue 2. Photo of Ngaio, Wellington, New Zealand taken from the Ngaio bills. 2012, Digital Image. https://en.wikipedia.org/ wiki/File:Ngaio,_Wellington,_New_Zealand_from_the Ngaio_Hills.jpg

Skitterphoto. Wooden Window. 2014, Digital Image. https:/ / pixabay.com/en/window-old-wall-decayabandoned-384580/ (accessed 12/02/2016)

Spensley, S. Cbia Seeds. 2010, Digital Image. https://www flickr.com/photos/notahipster/4999199198

accessed $03 / 02 / 2016$ )

Staudt, W. Thira Santorini. 2007, Digital Image. Santorini_\%281204372067\%29.jpg (accessed 02/02/2016)

- - . A typical white and blue painted house of Oia. 2007, Digital Image. https://en.wikipedia.org/wiki/Oia,_Greece\#/ (35757085\%29.jpg (accessed 03/02/2016)

Szekely, P. Sunset in Oia, Santorini. 2012, Digital Image. https://commons.wikimedia.org/wiki/File:Oia,_Santorini_ HDR_sunset.jpg

User:Mountain. Cycladic Female Figurine. 2006, Digital Image. https://commons.wikimedia.org/wiki/File:Cycladic_ female_figurine_2.jpg (accessed 12/02/2016)

Utting, K. Crane Gears. 2006, Digital Image. https:// www.flickr.com/photos/tallkev/256810217_ (accessed 18/11/2015) 


\subsection{Introduction}

1.1 Actual Process [simulated for this project] The process that will be set up for the design aspect of the project is intended to allow an organic, aggregative, multi-authored outcome to develop over different Architectldesinner, rather than a singled by in a single stage as is common with current MDH typologies and models. This aggregative process allows for a more dynamic response to both site and forlitions over time as well as allowing for the complexity, and sometimes irrationality which gives a richr

The project as a whole is governed by an oversight committee; this role would be held by an architectural firm that is hired as consultants to the body corporate. outside designers, as well as the upkeep of the master drawing set for the development. In addition, the firm would also lead the development and upkeep of the behalf (and in collaboration with) the body corporate.

\subsection{Simulation Methodology}

To simulate the aggregative build-up of the development, the design simulation will encompass design input from third party designers, and inpu from the researcher. Input from outside designers simulates the different interpretation of the guidelines Meanwhile the input from the researcher allows for faster process, with the iterations able to propaga faster throughout the process. To try and limit the idiosyncratic nature of the single author stages, student designers will be approached in the role of client to choose siting, formal strategy and brie requirements such as programme, orientation and priorities of sun vs. view etc.

The research vill also fill the role of the oversight project and maintain editorial control over the process.

\subsection{Access/Public Space}

1.3 Land Division/Ownership The major element of this development that sets
it apart from other MDH projects is the treatment of ownership and site. Here the site is treated as something to be defined following the design of the dwelling rather than helping to form the design. In this way the design of individual dwellings can adapt to the stock in a much mor orgasic and dyng building This approach is consciously not master planned instead relying on an aggregative and organic buildup of the site. Ownership structure is based on unit title ownership, whereby the body corporate own the land and has collective responsibility for shared/ access areas and collective parking amenity. Land division follows bulling concept, a set area of land is the area that design inhabits.
Without the mediating and regulating backdrop of a traditional street, lot, and yard pattern the public interaction between dwellings becomes one of the main organising factors of his development. Social of a place and this development seeks to allow for informal meeting places, whether by the variation of the access network allowing places of pause or more formal courtyard areas shared by several adjacent dwellings. The following points give stucture to these goals.

2.1 Access Network

Create an efficient network of access to and around dwellings, as well as allowing for a means of social

2.1.1 Each dwelling is to continue/add to the communal pedestrian access infrastructure, The meror axis of the pedestin netr.

2.1.2 The major axis of the pedestrian network will fall generaly topography

2.1.3 Minor axis of pedestrian network will fal generally perpendicular to the site contours the development

1.4 Irregular path width is recommended to avoid spaces of pause where the path widens, even allowing for courtyards and public open space [see 2.2]

2.2 Public Open Space

Create formal and informal shared public space to increase the communal usage of the outdoor space and allowing for a richer sense of community.

2.2.1 Open space can be defined either as a stopping place in the access network, through to a shared courtyard, deck area, or inhabitab activity space.

2.2.2 Each dwelling will initiate/extend/complete a semi-public open space within easily accessible distance of the new dwelling.

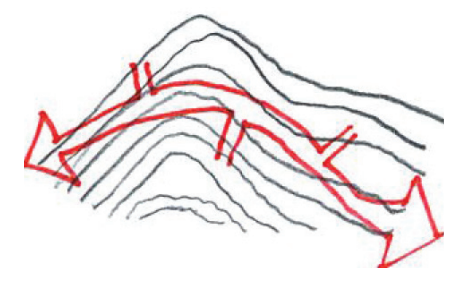

2.1.2 Major Axis

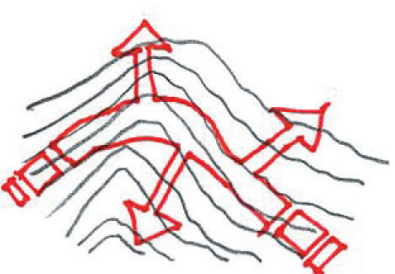

2.1.3 Minor Axis

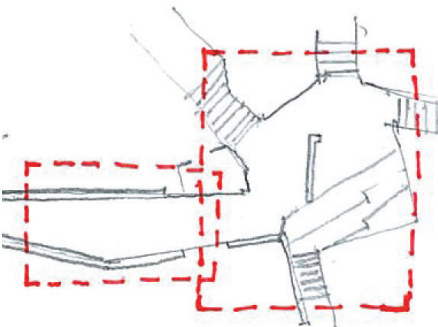

2.1.4 Irregular Path 


\subsection{Outdoor Private Space}

Create private or semi-private space to allow for a private amenity as well as creating a threshold between the public and private/built and open areas of the development

2.3.1 Each dwelling to provide between $10 \mathrm{~m}^{2}$ and $30 \mathrm{~m}^{2}$ of private outdoor space

2.3.2 Threshold outdoor space; this private space can take the form of threshold between public and private space, such as a courtyard or partially screened space

2.3.3 Balconies or roof gardens/space can also make up the private space quota

\subsection{Designing Dwellings}

Dwellings for this development are to be designed around a higher level of response to the topography
of the hillside as well as a higher density mode. The traditional model of building on hillsides in New Zealand has developed out of the way in which streets sit in the hillside and the resulting lot patterns that follow these streets. With the restrictions of the street pattern litted as well as pre-deffned lots, the connected following the natura lines of the hillside more closely.

\subsection{Building Footprint (single dwelling)}

Define the footprint area of the building [area of building in plan] within the maximum $120 \mathrm{~m}^{2}$. Building must be partially grounded on

3.1.1 Maximum building footprint area of $120 \mathrm{~m}^{2}$

3.1.2 Minimum width for building sections to be $4 \mathrm{~m}$ to allow for habitable internal areas

3.1.3 Buildings are to be grounded [defined here construction] for at least $70 \%$ of their footprin

1.4 Building envelope may encompass up to $10 \%$ larger floor area than building footprint to allow building design and articulation, does not interfere with development of future dwellings (see 4.3)
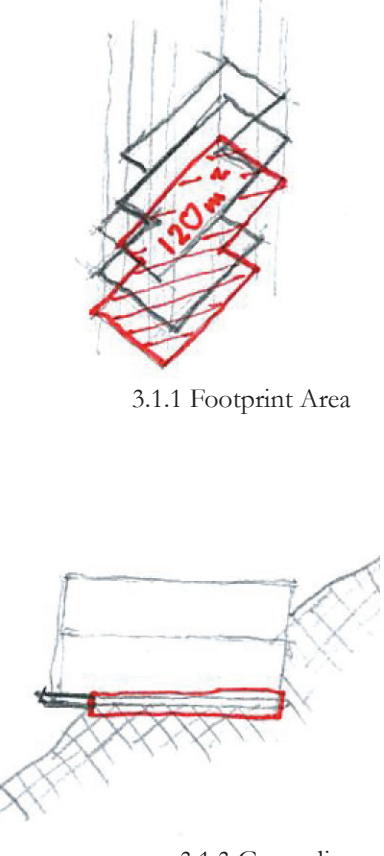

3.1.3 Grounding

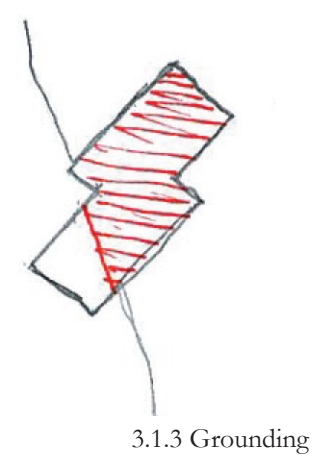

3.2 Building Footprint (multiple dwellings)

Multiple dwellings may be developed together, designers are encouraged to minimise impact of large

3.2.1 Up to four dwellings are permitted to be purchased and developed as a single unit. These must be separate dwellings but can be built as a single form.

3.2.2 Where multiple dwellings are developed together the total building footprint is $120 \mathrm{~m}^{2}$ for the first dwelling then $80 \mathrm{~m}^{2}$ for all subsequent dwelling

\subsection{Party/Common Wall}

Use party walls as origin point for, and connection to, act as origin/connection points for future dwellings

3.3.1 Dwellings must be based around a connection to an existing party wall as a grounding element to an existing party
of the built fabric

3.3.2 Exceptions may be made to this rule where no party wall areas can be found suitable to accommodate building. Decision at this stage sits with the planning committee

3.3.3 Dwellings to allow for (at least) one common wall for future dwellings

3.3.4 Party wall construction to be of heavy construction (defined here as concrete or masonry construction)

3.3.5 Party wall to allow for structural stability for up to four storey future building to attach to it.

3.3.5 Any retaining walls as part of the building structure should be treated as a possible party common wall allowance.

\subsection{Height Range}

Buildings are to conform to a height range to normalise the massing on site. This range allows for some articulation of topography and how that affects

3.4.1 New Dwellings/building forms are to be a minimum two storeys

3.4.2 Built forms are to be a maximum of four storeys, even where multiple dwellings are presentwinh hesame form $12 \mathrm{~m}$ at any given point

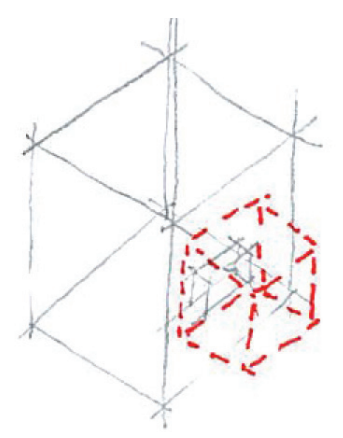

3.1.4 Building envelope

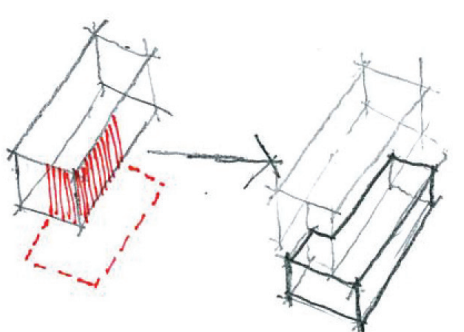

3.3.1 Party Wall

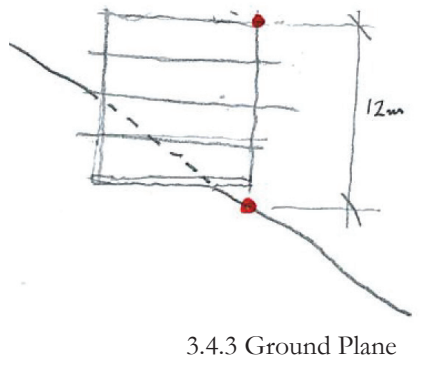

3.4.4 Exceptions may be made to maximum height where the topography of the site does not allow for the building to be grounded at the natural ground level provided the building makes 
3.5 View/Sunlight Access

Ensure new dwellings do not destroy or limit existing dwellings access to both sunlight/daylight access and retaining existing view shafts and sun shading of other dwellings, whether existing or future.

3.5.1 Each new dwelling may nominate up to two built in front of above the level of the sill height. Nominated view shafts may not be located on the bottom story of the dwelling.

3.5.2 Each new dwelling should receive at least 2 hours of direct sunlight between $9 \mathrm{am}$ and orientation makes this unfeasible in which case designers must demonstrate sufficient daylight availability to create a desirable living condition.

3.5.3 Each new dwelling may nominate up to two openings of up to a combined area of $10 \mathrm{~m}^{2}$
where no future dwelling may shade incoming sunlight.

3.5.4 Skylights may be used for sun/daylighting but should be treated as secondary lighting for the purposes of the above rules (3.5.2)

3.5.5 New dwellings should not shade an existing dwellings so that any of the above conditions cannot be met by the existing dwelling.

3.5.6 New dwellings adjacent to an existing opening should provide for a light court with minimum $3 \mathrm{~m}^{2}$ and set back from the opening at least $1 / 2$ of the height of the new wall to allow for

\subsection{Materiality}

Ensure a loose consistency of building type and construction method to create relaxed unifying elements to the arch

3.6.1 Light weight construction of timber and stee structure is encouraged.

3.6.2 Heavy concrete or masonry construction is required for common party walls.

3.6.3 Heavy concrete or masonry construction is recaining of the hillide is required.
3.6.4 Any retaining for buildings [not including public spaces] is to be included in the building structure. (no retaining walls set of trom the

3.6.5 Use of cladding materials should take into account the survinding bulldings and style so

\subsection{Roof Pitch/Treatment}

Ensure a visual consistency and unity of roof elements for larger planes, while still allowing for smaller feature elements.

3.7.1 Mono or double pitched roofs are to be used with a minimum slope of $4^{\circ}$ and a maximum slope of $15^{\circ}$ unless the roofed area is less than $10 \mathrm{~m}^{2}$

3.7.2 Flat roofs are permitted only as habitable deck areas or as a further articulated architectural element such as a green roof.

3.7.3 Eves or roof overhangs are not permitted where roof line intersects with party walls. This
allows for extension of new built elements past the existing roof line.
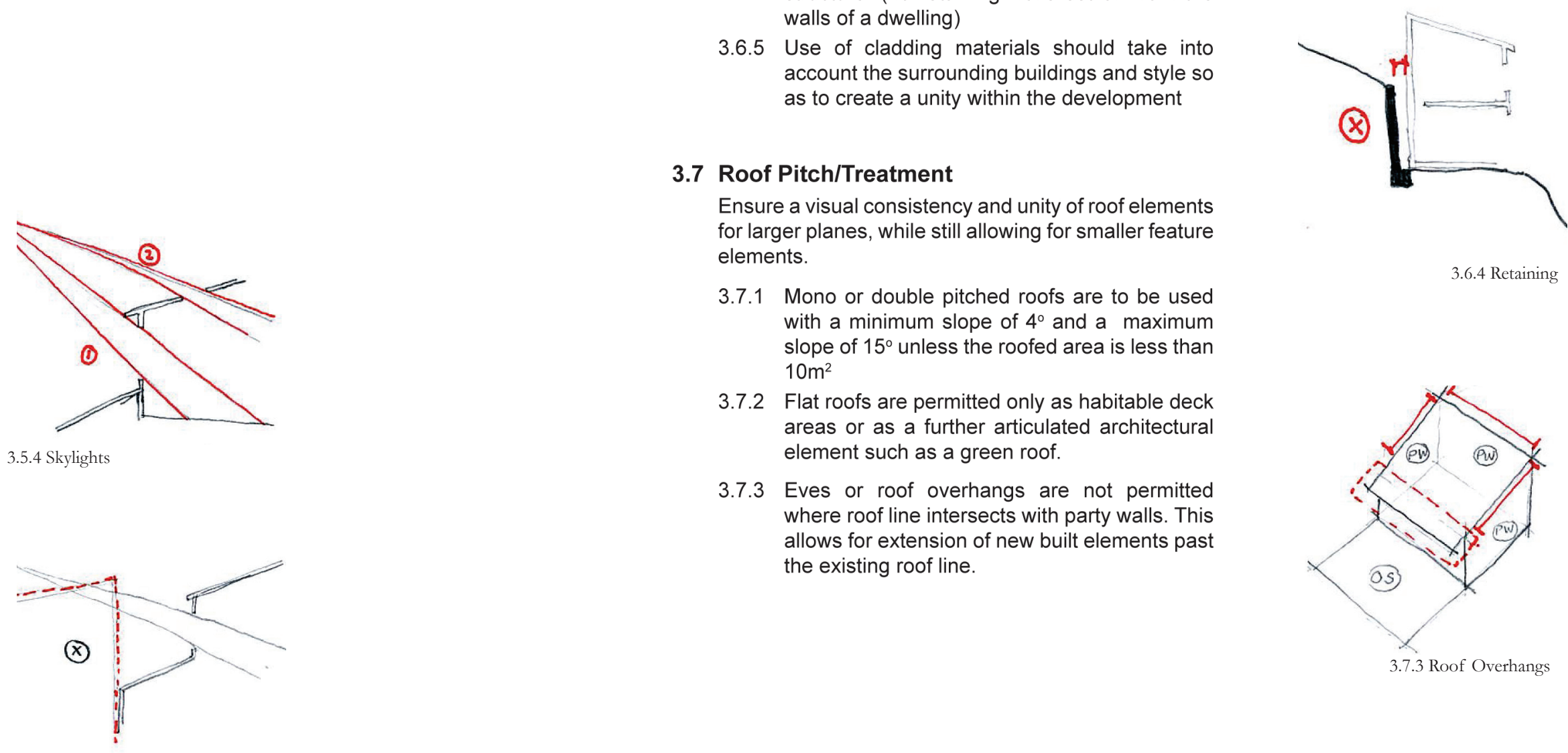

3.6.4 Retaining
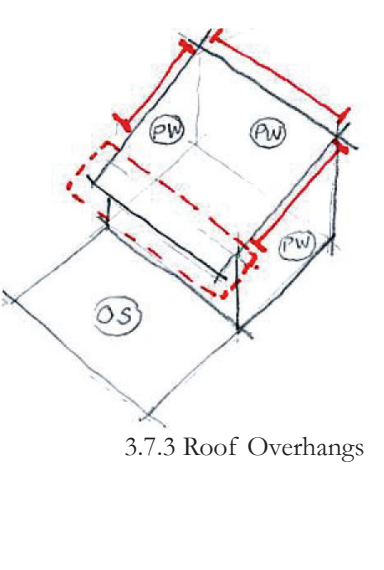
